$$
\begin{array}{r}
\text { Pontifícia Universidade C Católica } \\
\text { do Rio de Janeiro } \\
\end{array}
$$

Marcelo Musci Zaib Antonio

\title{
Uma Metodologia para Análise de Imagens Usando Segmentações Específicas Por Classe
}

Tese apresentada como requisito parcial para obtenção do grau de Doutor pelo Programa de Pós-graduação em Engenharia Elétrica do Departamento de Engenharia Elétrica da PUC-Rio.

Orientador: Prof. Raul Queiroz Feitosa

Co-orientador: Prof. Gilson Alexandre Ostwald Pedro da Costa

Rio de Janeiro 


$$
\begin{array}{r}
\text { Pontifícia Universidade Católica } \\
\text { do Rio de Janeiro }
\end{array}
$$

\section{Marcelo Musci Zaib Antonio}

\section{Uma Metodologia para Análise de Imagens Usando Segmentações Específicas Por Classe}

Tese apresentada como requisito parcial para obtenção do grau de Doutor pelo Programa de Pós-Graduação em Engenharia Elétrica do Departamento de Engenharia Elétrica do Centro Técnico Científico da PUC-Rio. Aprovada pela Comissão Examinadora abaixo assinada.

Prof. Raul Queiroz Feitosa Orientador Departamento de Engenharia Elétrica - PUC-Rio

Prof. Gilson Alexandre Ostwald Pedro da Costa Co-Orientador Departamento de Engenharia Elétrica - PUC-Rio

Profa. Cláudia Maria de Almeida INPE

Prof. Luciano Vieira Dutra INPE

Profa. Maria Luiza Fernandes Velloso UERJ

Prof. Guilherme Lucio Abelha Mota

UERJ

Prof. José Eugenio Leal Coordenador Setorial do Centro

Técnico Científico 
Todos os direitos reservados. É proibida a reprodução total ou parcial do trabalho sem autorização do autor, do orientador e da universidade.

\section{Marcelo Musci Zaib Antonio}

Graduou-se em Engenharia Elétrica com ênfase em Eletrônica na Universidade do Estado do Rio de Janeiro em 1993. Obteve o título de Mestre em Engenharia Computação com ênfase em Geomática pela Universidade do Estado do Rio de Janeiro em 2008.

Ficha Catalográfica

Antonio, Marcelo Musci Zaib

Uma metodologia para análise de imagens usando segmentações específicas por classe / Marcelo Musci Zaib Antonio; orientador: Raul Queiroz Feitosa; co-orientador: Gilson Alexandre Ostwald Pedro da Costa. - 2013.

169 f. ; $30 \mathrm{~cm}$

Tese (doutorado) - Pontifícia Universidade Católica do Rio de Janeiro, Departamento de Engenharia Elétrica, 2013.

Inclui bibliografia

1. Engenharia elétrica - Teses. 2. Processamento de imagens. 3. Sensoriamento remoto. 4. Segmentação. I. Feitosa, Raul Queiroz. II. Costa, Gilson Alexandre Ostwald Pedro da. III. Pontifícia Universidade Católica do Rio de Janeiro. Departamento de Engenharia Elétrica. IV. Título. 
À memória de minha mãe. 


\section{Agradecimentos}

Acima de tudo, agradeço a Deus pela dádiva da vida e por, em muitos momentos aflitivos, proporcionar-me a sua paz e a serenidade para enfrentar os obstáculos que me atravessavam e superar os desafios.

Aos meus orientadores, Prof. Raul Queiroz Feitosa e Prof. Gilson A. O. P. Costa, pela dedicação, contribuições e também pela cobrança.

Às minhas mães Eli e Eny (in memoriam), pela dedicação, amor e carinho.

À Prof. a Maria Luiza Fernandes Velloso, pelos valorosos conselhos ao longo da minha jornada acadêmica.

Aos meus colegas do Laboratório de Visão Computacional (LVC) da PUC-Rio.

Aos professores que participaram da Comissão Examinadora.

Aos funcionários do Departamento de Engenharia Elétrica da PUC-Rio.

A todas as pessoas que, direta ou indiretamente, contribuíram para que este trabalho pudesse ser concluído. 


\section{Resumo}

Musci, Marcelo Zaib Antonio; Feitosa, Raul Queiroz (Orientador); Costa, Gilson Alexandre Ostwald Pedro da (Co-orientador). Uma metodologia para análise de imagens usando segmentações específicas por classe. Rio de Janeiro, 2013. 169p. Tese de Doutorado - Departamento de Engenharia Elétrica, Pontifícia Universidade Católica do Rio de Janeiro.

A técnica de análise de imagens conhecida pelo acrônimo de GEOBIA (do inglês Geographic Object Based Image Analysis) torna possível a exploração de uma série de novos recursos no processo de classificação de imagens de sensoriamento remoto, em comparação com as alternativas tradicionais baseadas em pixel. Esta possibilidade resulta da introdução de uma etapa de segmentação no processo de análise. Os novos recursos referem-se às propriedades espectrais, texturais, morfológicas e topológicas computadas para os diferentes segmentos de imagem. A abordagem de segmentação habitual encontrada na maioria dos trabalhos de GEOBIA depende de uma hierarquia de segmentações, cada nível de hierarquia associado a um número de classes de objetos caracterizados por tamanhos similares, ou seja, detectáveis em uma determinada escala. A prática usual, porém, não considera segmentações específicas para cada uma das classes de interesse no problema de interpretação, agrupando objetos de mesma escala em um procedimento de segmentação única, ou seja, usando o mesmo algoritmo e parâmetros. A tese investigada neste trabalho baseia-se na suposição de que, se segmentações não são especializadas para cada classe de objeto, então muitos atributos a eles relacionados não podem ser devidamente explorados no processo de classificação. A metodologia proposta baseia-se em uma regra específica para resolver eventuais conflitos espaciais entre as diferentes segmentações. Os resultados experimentais obtidos com base nos experimentos realizados apresentaram um desempenho melhor que o de costume, isto é, produziu melhores resultados de classificação, na maior parte dos problemas de interpretação investigados.

\section{Palavras-chave}

Sensoriamento remoto; processamento de imagens; segmentação. 


\section{Abstract}

Musci, Marcelo Zaib Antonio; Feitosa, Raul Queiroz (Advisor); Costa, Gilson Alexandre Ostwald Pedro da (Co-Advisor). An image analysis methodology using per class specific segmentations. Rio de Janeiro, 2013. 169p. D.Sc. Thesis - Departamento de Engenharia Elétrica, Pontifícia Universidade Católica do Rio de Janeiro.

Geographic Object-Based Image Analysis (GEOBIA) makes it possible to exploit a number of new features in the remote sensing image classification process in comparison to the traditional pixel-based alternatives. Such possibility arises from the introduction of a segmentation step in the analysis process. The new features refer to aggregated spectral pixel values, textural, morphological and topological properties computed for the different image segments. The usual segmentation approach found in most GEOBIA works relies on a hierarchy of segmentations, each hierarchy level associated to a number of classes of objects characterized by similar sizes, i.e., which are detectable at a particular scale. The usual practice, therefore, does not consider specific, independent segmentations for each class of interest in the interpretation problem, grouping objects at the same scale through a single segmentation procedure, for instance, using the same algorithm and parameters. The thesis investigated in this work lied on the assumption that if segmentations are not specialized for each object class, then many object features cannot be properly exploited in the classification process. The proposed approach relies on a specific rule to solve eventual spatial conflicts among different segmentations. The experimental results have showed that the proposed approach performed better, i.e., produced better classification results, than the usual one in most of the investigated interpretation problems.

\section{Keywords}

Remote sensing; image processing; segmentation. 


\section{Sumário}

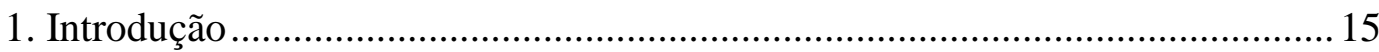

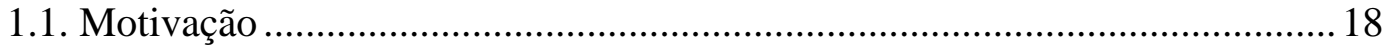

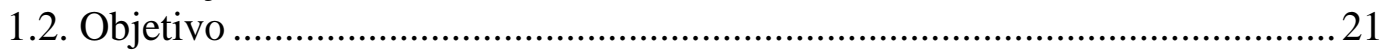

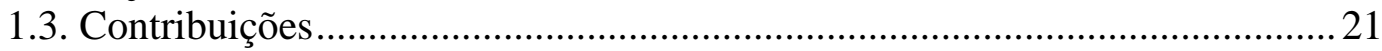

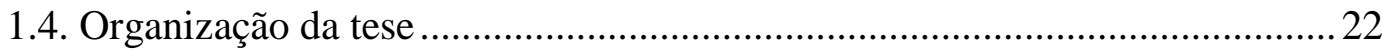

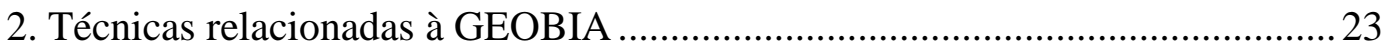

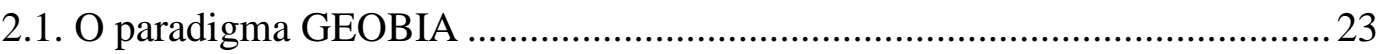

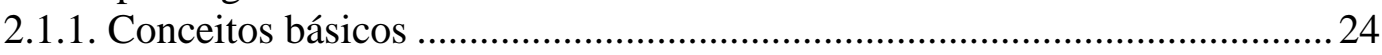

2.1.1.1. Objetos de imagem e segmentos .......................................................... 25

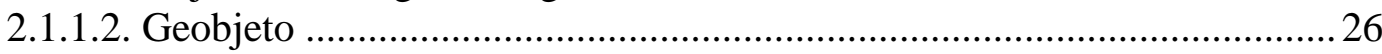

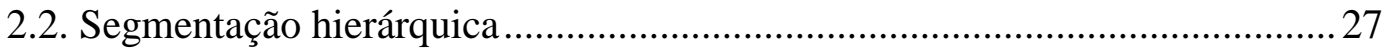

2.3. Trabalhos que fizeram uso das técnicas descritas ......................................... 30

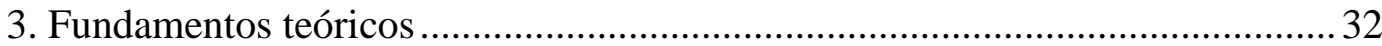

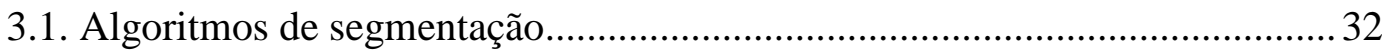

3.2. Otimização dos parâmetros da segmentação .................................................. 38

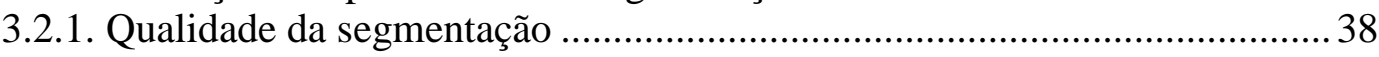

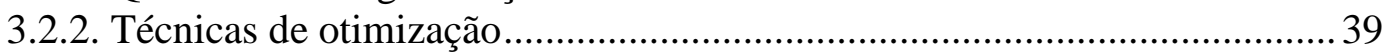

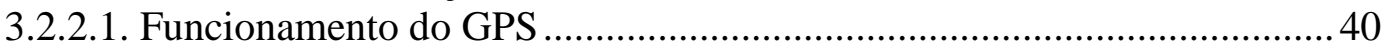

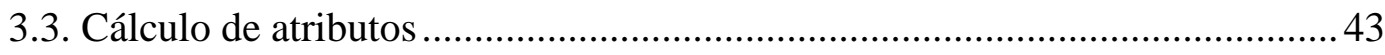

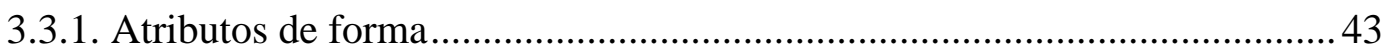

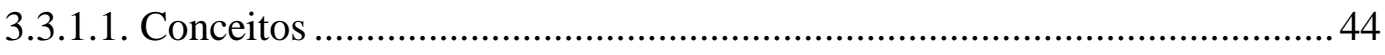

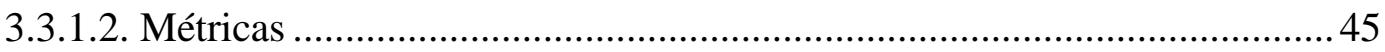

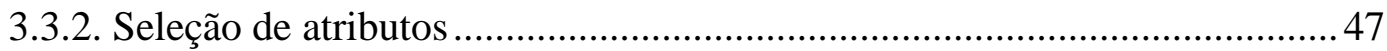

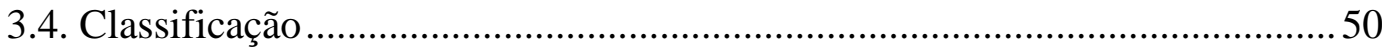

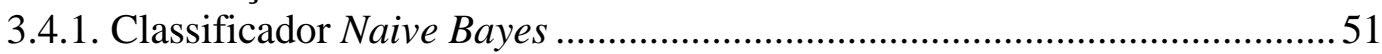

3.4.2. Classificador de Máxima Verossimilhança .............................................. 53

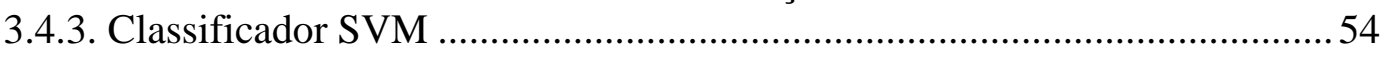

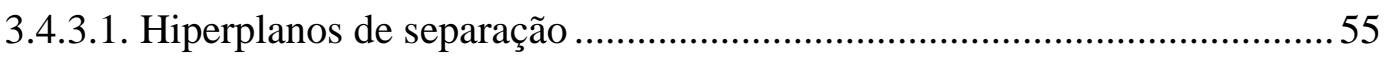

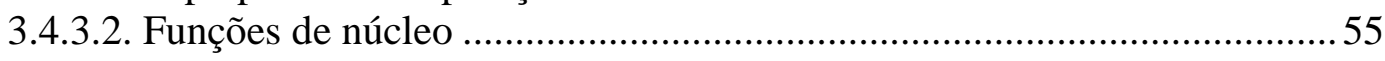

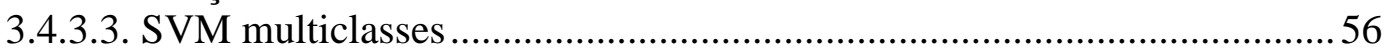

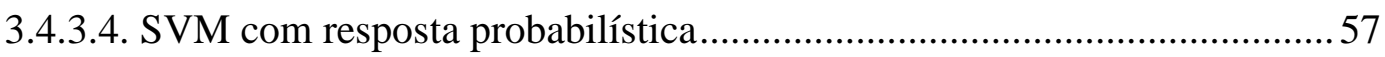

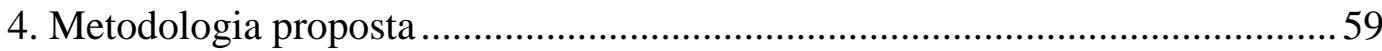

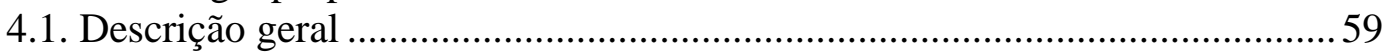

4.2. Etapas da metodologia de segmentação específica ......................................63

4.2.1. Etapa 1 - Ajuste dos parâmetros de segmentação ......................................66

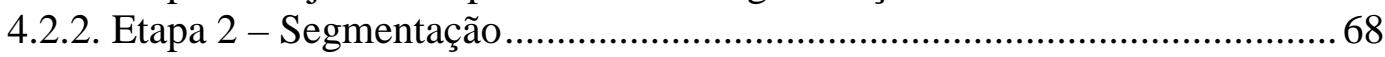

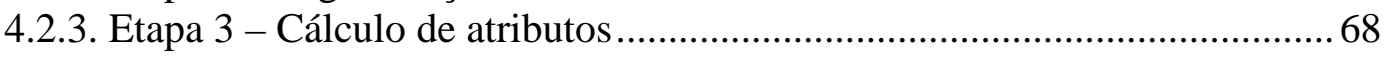

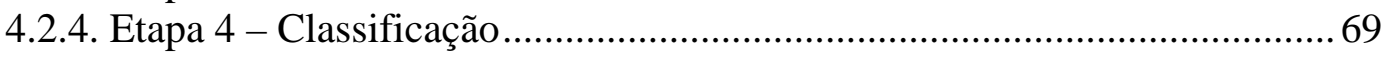

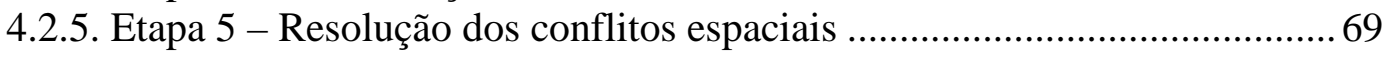

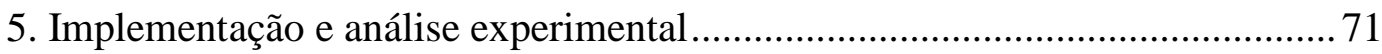

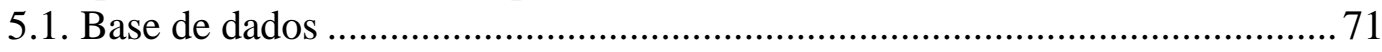




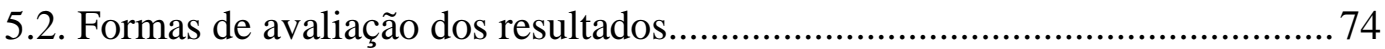

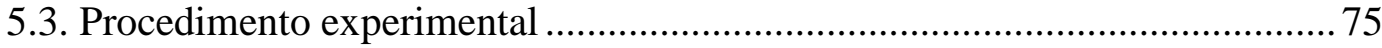

5.3.1. Etapa 1 - Ajuste dos parâmetros de segmentação...................................... 77

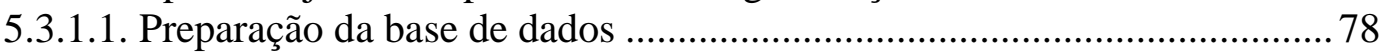

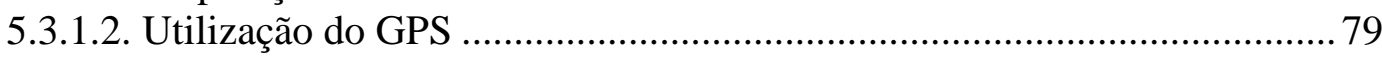

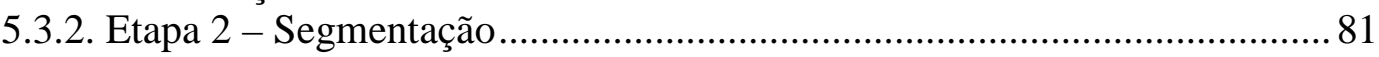

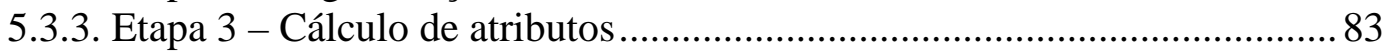

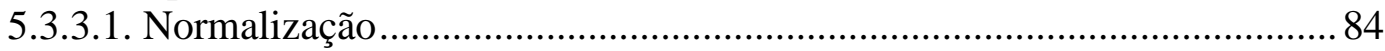

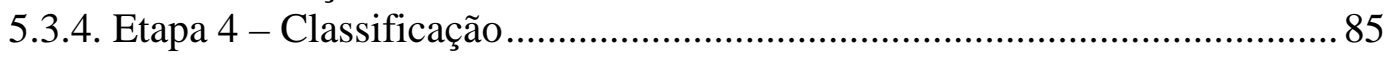

5.3.5. Etapa 5 - Resolução dos conflitos espaciais ............................................... 86

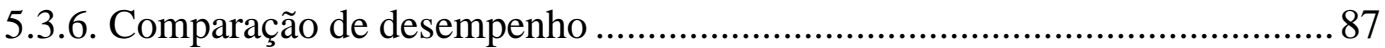

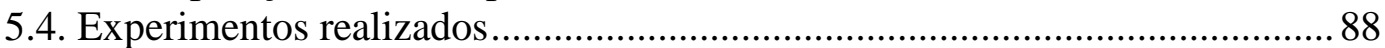

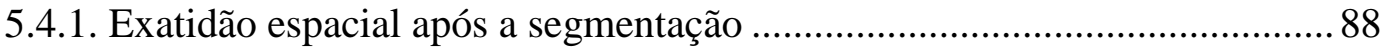

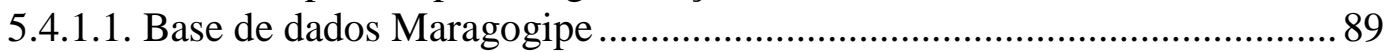

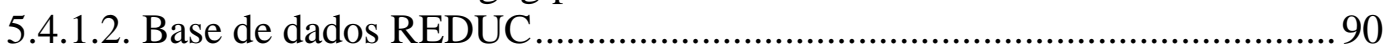

5.4.1.3. Base de dados Congonhas ................................................................ 92

5.4.2. Exatidão temática e espacial após a classificação ........................................ 93

5.4.2.1. Base de dados Maragogipe ...................................................................... 93

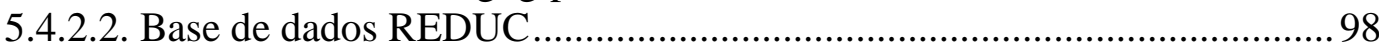

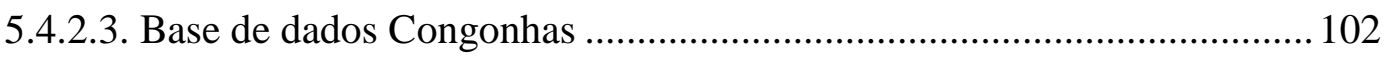

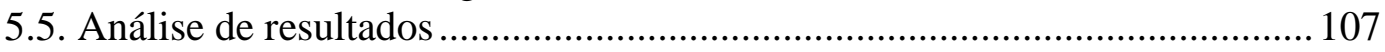

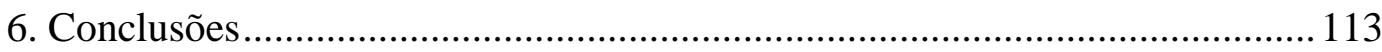

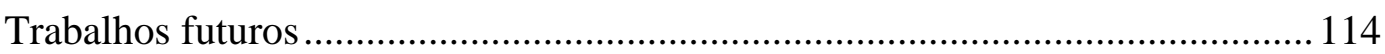

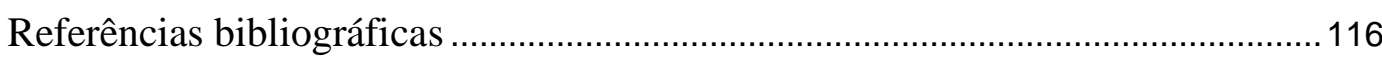

Apêndice A: Resultados dos Experimentos.................................................... 126

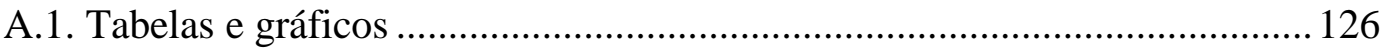

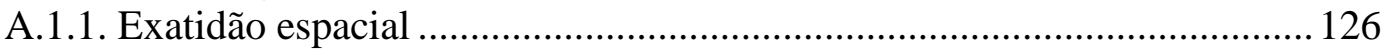

A.1.1.1. Base de dados de Maragogipe ........................................................... 126

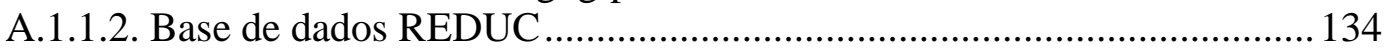

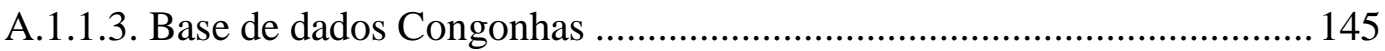

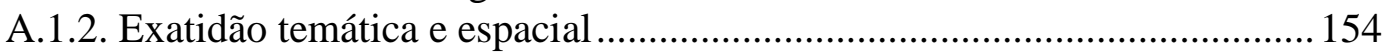

A.1.2.1. Base de dados de Maragogipe .......................................................... 154

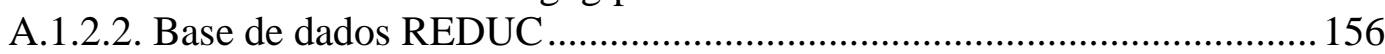

A.1.2.3. Base de dados Congonhas ............................................................... 158

Apêndice B: Elementos de Imagens Digitais 160_Toc372127088

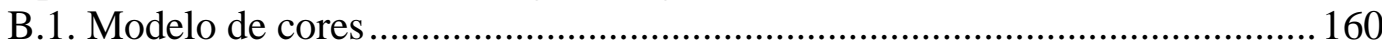

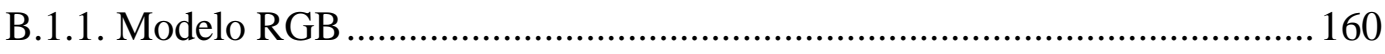

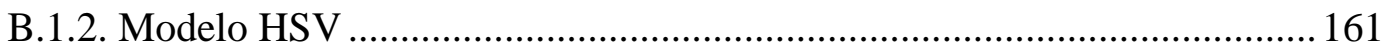

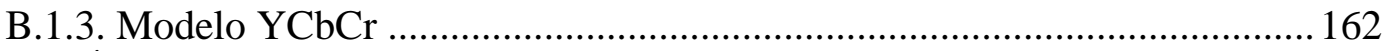

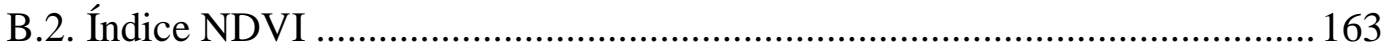

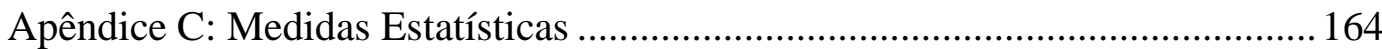

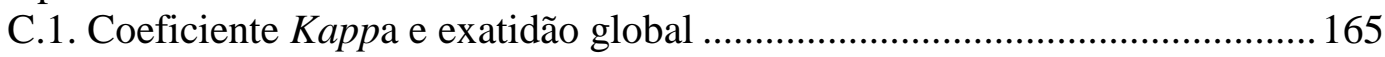

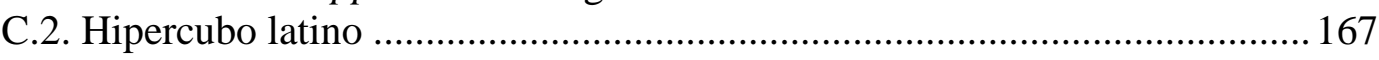




\section{Lista de Figuras}

Figura 1 - Segmentação Hierárquica Multiescala (adaptado de Lang et al., 2006).

Figura 2 - Ilustrações dos conceitos de supersegmentação e subsegmentação (adaptado de Fourie, 2011). 26

Figura 3 - Conceito de objeto de imagem (a) e objeto de imagem significativo (b) no domínio da imagem, em comparação com o contexto geográfico de geobjeto (c).

Figura 4 - Procedimentos bottom-up e top-down em segmentação hierárquica. .. 29

Figura 5 - Métrica RBSB 39

Figura 6 - Fluxograma do algoritmo GPS (adaptado de Mathworks, 2011). ....... 41

Figura 7 - Malha ao redor do ponto $x_{k}$ com padrão Base Positiva 2N, para $\mathrm{N}=2$.

Figura 8 - Cálculo do perímetro para um círculo e um quadrado de 10x10 pixels de borda em cinza, (adaptado de Ferreira, 2011)....................................... 44

Figura 9 - Elipse ajustada a um objeto, (adaptada de Ferreira, 2011). ................ 45

Figura 10 - Estimação de densidade de núcleo .53

Figura 11 - Hiperplano de separação, em (a) hiperplano com margem pequena e em (b) hiperplano com margem máxima. 55

Figura 12 - Estratégia da classificação não linearmente separável em uma classificação linearmente separável, através de um mapeamento do espaço de atributos para um espaço de maior dimensão.

Figura 13 - Exemplifica SVM multiclasse, (a) técnica de decomposição oneagainst-all para três classes, (b) técnica de decomposição one-against-one para três classes.

Figura 14 - Histograma das probabilidades condicionais das classes $(+1$ : positiva; -1 : negativa $), \mathrm{P}(\mathrm{y}= \pm 1 \mid \mathrm{x})$.. .58

Figura 15 - Exemplo de segmentação específica. 61

Figura 16 - Uso de pertinências para resolução de conflitos espaciais. 62

Figura 17 - Abordagem de segmentação específica. 65 
Figura 18 - Avaliação dos parâmetros de segmentação.

Figura 19 - Uso de recortes da imagem para o processo de busca de parâmetros ótimos de segmentação com o GPS.

Figura 20 - Esquema de segmentação específica................................................ 68

Figura 21 - Resolução de conflitos espaciais................................................... 70

Figura 22 - Imagem do município de Maragogipe - Img1 (a), referência

- Ref1 (b)

Figura 23 - Imagem da REDUC - Img2 (a), referência - Ref2 (b)...................... 73

Figura 24 - Imagem de Congonhas - Img3 (a), referência - Ref3 (b)................. 74

Figura 25 - Etapas de segmentação e classificação (a), detalhes mostrando o uso dos diferentes segmentadores e classificadores utilizados (b)..................... 76

Figura 26 - Esquema de busca dos parâmetros ótimos de segmentação para a abordagem hierárquica top-down (a) e bottom-up(b). 78

Figura 27 - Divisão do conjunto de dados em partições para a metodologia de segmentação específica (a) e hierárquica (b).

Figura 28 - Fluxograma da abordagem de testes utilizada no processo de segmentação.

Figura 29 - Segmentos válidos (A e B) e não válido (C) para o objeto de referência $\mathrm{O}_{1}$ 85

Figura 30 - Exemplo do esquema de validação cruzada dos dados, considerando três classes de interesse na imagem 86

Figura 31 - Resolução de conflitos espaciais.

Figura 32 - Valores médios de Kappa e Exatidão Global, combinados dos classificadores SVM, NB e MLE, para as segmentações baseadas nos algoritmos SCR, MS e XMRS, para a base de dados de Maragogipe.

Figura 33 - Média combinada das métricas RBSB para os classificadores SVM, NB e MLE, referentes às classes de objetos após a etapa de classificação, para a base de dados de Maragogipe. 98

Figura 34 - Valores médios de Kappa e Exatidão Global, combinados dos classificadores SVM, NB e MLE, para as segmentações baseadas nos algoritmos SCR, MS e XMRS, para a base de dados REDUC. 
Figura 35 - Média combinada das métricas RBSB para os classificadores SVM, NB e MLE, referente às classes de objetos após a etapa de classificação, para a base de dados REDUC

Figura 36 - Valores médios de Kappa e Exatidão Global, combinados dos classificadores SVM, NB e MLE, para as segmentações baseadas nos algoritmos SCR, MS e XMRS, para a base de dados de Congonhas.

Figura 37 - Média combinada das métricas RBSB para os classificadores SVM, NB e MLE, referente às classes de objetos após a etapa de classificação, para a base de dados de Congonhas.

Figura 38 - Comparação das abordagens TD e Específica, na escolha de segmentos representativos dos objetos de referência (em azul), para o cálculo da métrica RBSB.

Figura 39 - Apresentação visual dos erros de classificação.

Figura 40 - Exemplo de fusões de segmentos na etapa de classificação, delineando melhor os objetos de referência (em azul).

Figura 41 - Exemplo de fusões de segmentos na etapa de classificação, delineando melhor os objetos de referência (em azul).

Figura 42 - Exemplo de desempenho superior, em termos de exatidão espacial, após a etapa de classificação. 


\section{Lista de Tabelas}

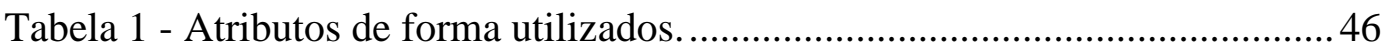

Tabela 2 - Principais diferenças entre segmentação específica e hierárquica. ..... 63

Tabela 3 - Segmentadores e classificadores utilizados....................................... 77

Tabela 4 - Parâmetros de Segmentação determinados pelo GPS para cada

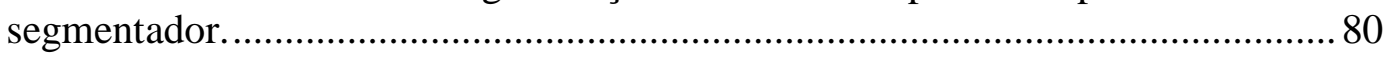

Tabela 5 - Sequencia de procedimentos para a etapa de segmentação................. 83

Tabela 6 - Número de segmentos de referência por classes para a base de dados de Maragogipe.

Tabela 7 - Resultados comparativos das classes de interesse, em termos de RBSB, entre as abordagens de segmentação específica (Esp), hierárquica topdown (TD) e hierárquica bottom-up (BU) para a base de dados de Maragogipe. . 90

Tabela 8 - Número de segmentos de referência por classes para a base de dados REDUC

Tabela 9 - Resultados comparativos das classes de interesse, em termos de RBSB, entre as abordagens de segmentação específica (Esp), hierárquica topdown (TD) e hierárquica bottom-up (BU) para a base de dados REDUC

Tabela 10 - Número de segmentos de referência por classes para a base de dados Congonhas.

Tabela 11 - Resultados comparativos das classes de interesse, em termos de RBSB, entre as abordagens de segmentação específica (Esp), hierárquica topdown (TD) e hierárquica bottom-up (BU) para a base de dados Congonhas.

Tabela 12 - Atributos selecionados para a classificação temática, para a base de dados Maragogipe.

Tabela 13 - Exatidão temática para a base de dados de Maragogipe. 95

Tabela 14 - Resultados do teste de hipótese para as medidas de exatidão temática da metodologia de segmentação específica versus a abordagem de segmentação hierárquica para a base de dados de Maragogipe

Tabela 15 - Exatidão espacial (RBSB) após a classificação para a base de dados de Maragogipe. 
Tabela 16 - Resultados do teste de hipótese para medidas de acurácia espacial (RBSB) após a classificação para a base de dados de Maragogipe. Campos sombreados indicam casos em que a hipótese nula não pode ser rejeitada..... 97

Tabela 17 - Atributos selecionados para a classificação temática, para a base de dados REDUC.

Tabela 18 - Exatidão temática para a base de dados REDUC

Tabela 19 - Resultados do teste de hipótese para as medidas de exatidão da metodologia de segmentação específica versus a abordagem de segmentação hierárquica.

Tabela 20 - Exatidão espacial (RBSB) após a classificação para a base de dados REDUC.

Tabela 21 - Resultados do teste de hipótese para as métricas RBSB. Campos sombreados indicam casos em que a hipótese nula não pode ser rejeitada.

Tabela 22 - Atributos selecionados para a classificação temática, para a base de dados Congonhas.

Tabela 23 - Exatidão temática para a base de dados Congonhas

Tabela 24 - Resultados do teste de hipótese para as medidas de exatidão temática da metodologia de segmentação específica versus a abordagem de segmentação hierárquica para a base de dados Congonhas. Campos sombreados indicam casos em que a hipótese nula não pode ser rejeitada

Tabela 25 - Exatidão espacial (RBSB) após a classificação para a base de dados de Congonhas.

Tabela 26 - Resultados do teste de hipótese para medidas de exatidão espacial (RBSB) após a classificação para a base de dados de Congonhas. Campos sombreados indicam casos em que a hipótese nula não pode ser rejeitada. 


\section{Introdução}

A partir do final da década de 1990, tornaram-se disponíveis comercialmente imagens de satélite de altíssima resolução espacial, frequentemente denotadas pela sigla VHR (do inglês very high resolution), com pixels de dimensão menor que $1 \mathrm{~m}$ (Lu e Weng, 2007). Técnicas tradicionais de classificação pixel-a-pixel demonstraram-se ineficientes para a interpretação de imagens com tal resolução, sobretudo devido à grande variabilidade dos atributos espectrais dentro de uma mesma classe. Essa limitação fez crescer a partir de então a análise de imagens por regiões, operando exclusivamente com atributos meramente estatísticos, culminando recentemente, com o interesse pela técnica de análise de imagens baseada em objeto, conhecida pelos acrônimos OBIA (do inglês Object Based Image Analysis) ou GEOBIA (do inglês Geographic Object Based Image Analysis) (Yothi et al., 2008; Hay e Castilla, 2008). As virtudes de GEOBIA foram comprovadas ao longo da última década em inúmeras aplicações, como indica, por exemplo, o extenso levantamento bibliografico conduzido por Blaschke (2010). Tal sucesso decorre, sobretudo, de se considerarem nesta abordagem atributos estruturais, de forma e textura, além de atributos espectrais, e, ao mesmo tempo, da capacidade de emular a habilidade humana de delinear e identificar objetos de interesse nas imagens.

Diversos métodos de classificação automática têm sido desenvolvidos, e uma grande revolução no processamento e análise de dados de sensoriamento remoto vem ocorrendo (Hay e Castilla, 2008), principalmente devido às elevadas resoluções espaciais, impondo novos desafios e metodologias de processamento. As imagens de alta resolução originárias de sensores remotos apresentam detalhes de cenas muito heterogêneas e com grande variabilidade de classes, principalmente em áreas urbanas. Métodos tradicionais de classificação automática resultam em confusão entre classes de características espectrais semelhantes, como por exemplo, solo exposto com telhado cerâmico, vegetação arbórea com vegetação rasteira e telhas de cimento amianto com asfalto (Pinho, 2005). Sendo assim uma grande vantagem da análise baseada em objetos é a 
utilização de vários tipos de atributos (tamanho, forma, textura, cor e relações topológicas), que permitem tornar mais eficiente o processo de análise da imagem. A utilização do conceito de objeto é peça chave neste tipo de análise de imagens, pois parte-se do princípio de que a informação semântica necessária para a interpretação de uma imagem não está presente no pixel, e sim em objetos da imagem e nas relações existentes entre eles (Definiens, 2003). Estes objetos são os segmentos, os quais são gerados a partir de um procedimento de segmentação. Segmentação é um conceito que existe desde as décadas de 1970 e 1980, e o conceito de OBIA/GEOBIA promoveu a aglutinação de conhecimentos e ferramentas preexistentes do paradigma de orientação a objeto, como representação do conhecimento, o reconhecimento de que o objeto é a instanciação de uma classe e que possui propriedades tais como herança, generalização, polimorfismo, encapsulamento, dentre outras.

Uma vantagem de se trabalhar com segmentos ao invés de pixels é que o número de elementos que servem de base para a classificação é reduzido sobremaneira, aumentando a eficiência da classificação tanto para métodos automáticos como para a classificação realizada visualmente por foto intérpretes. Para Meinel e Neubert (2004), segmentar uma imagem significa agrupar pixels vizinhos em regiões baseado em critérios de similaridade. Pekkarinen (2002) descreve tal processo como a divisão de uma imagem em regiões espacialmente contínuas, disjuntas e homogêneas. Moigne e Tilton (1995) definem segmentação como o processo onde pixels individuais são agrupados em partições de acordo com alguma propriedade intrínseca da imagem, tal como intensidade dos níveis de cinza, contraste ou textura.

Segundo Benz et al. (2004), segmentos são uma aproximação dos objetos do mundo real. A exatidão da classificação depende, portanto, de que os segmentos gerados representem o mais fielmente possível objetos significativos da imagem. De acordo com Baatz e Schäpe (2000), a melhor segmentação é a que proporciona informação espacial ótima para um processamento posterior. Para Soh e Tsatsoulis (1999), a obtenção de resultados satisfatórios na etapa de classificação é diretamente dependente da existência de algoritmos eficientes na etapa de segmentação.

A qualidade da segmentação está intimamente relacionada com o algoritmo utilizado e com o adequado ajuste dos seus parâmetros. Antunes (2003) 
destaca que o processo de ajuste dos parâmetros de segmentação é essencialmente empírico e, em geral, ajustável aos diferentes tipos de imagem, com limiares definidos face à complexidade dos alvos investigados.

Grande parte da pesquisa em análise e interpretação de imagens da última década adota metodologias que segmentam a imagem em diferentes escalas espaciais que correspondem às dimensões dos objetos de imagem de interesse. Conforme Brunnet e Blaschke (2003), a análise de imagem é tipicamente conduzida através de vários níveis e detalhes, do mais grosseiro para o mais fino, e vice-versa; várias vezes até que o resultado desejado seja alcançado. Baseandose nesta percepção, ambos os autores discutem o que chamam de segmentação hierárquica. Trata-se em essência de segmentar a imagem em um número de escalas diferentes, de tal forma que cada segmento de uma escala menor esteja inteiramente contido em um segmento de escala maior.

Baatz e Schäpe (2000) apresentaram uma abordagem de segmentação multiescala para imagens de alta resolução, em que o tamanho médio dos segmentos pode ser ajustado de forma a se adequar à escala espacial das estruturas que se pretende analisar. Esta tem sido a abordagem dominante dentro da comunidade de GEOBIA na última década (Blaschke et al., 2008).

O processo da segmentação multiescala é baseado no agrupamento de objetos de uma determinada escala em outros objetos maiores. Essa aglomeração é realizada respeitando os mesmos critérios do procedimento de segmentação inicial, porém mudando o valor de um parâmetro, não acidentalmente chamado “escala”, que define o tamanho médio dos segmentos. Os segmentos assim gerados obedecem a uma relação hierárquica. De forma geral, cada segmento está contido em um, assim chamado, superobjeto em um nível superior, e pode ainda conter inúmeros objetos de um nível abaixo do seu, os chamados subobjetos. Dentro de tal estrutura hierárquica, é possível definir relações topológicas dos objetos com seus super e subobjetos, que podem compor a descrição semântica da cena.

Na segmentação hierárquica, como já se mencionou, a fronteira de um superobjeto é coerente com as fronteiras dos subobjetos; em outras palavras, nenhum objeto extrapola os limites espaciais definidos por seu superobjeto. A Figura 1 ilustra esse conceito. 


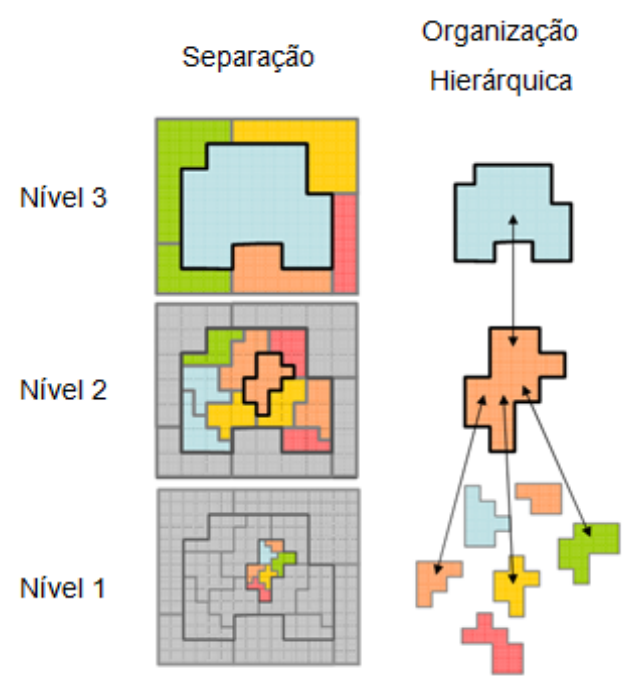

Figura 1 - Segmentação Hierárquica Multiescala (adaptado de Lang et al., 2006).

Cada classe de objetos pode assim ser descrita através das suas características espectrais, espaciais, estruturais e topológicas (Carleer et al., 2004; Haralick e Shapiro, 1985). Esta abordagem permite que especialistas utilizem seu conhecimento no desenvolvimento de modelos semânticos mais representativos dos objetos cujas instâncias se esperam identificar nas imagens.

\section{1}

\section{Motivação}

Um dos mais importantes desafios que enfrenta a comunidade de sensoriamento remoto é o desenvolvimento de técnicas eficazes de análise de imagens geradas pela última geração de sensores de altíssima resolução espacial. A disponibilidade de imagens obtidas por estes sensores viabiliza um novo e amplo conjunto de aplicações, que requerem elevada exatidão espacial e elevado nível de detalhamento temático.

Devido à alta resolução espacial das imagens, a informação morfométrica da cena também pode ser considerada no processo de classificação. Nesse contexto, o paradigma baseado em objeto na análise e interpretação automática de imagens tem despertado grande interesse nos anos recentes. Neste paradigma, a qualidade da segmentação é determinante no desempenho da interpretação como um todo. 
Grandes esforços têm sido investidos na investigação de estratégias para avaliação da qualidade da segmentação (p.ex., Espíndola et. al, 2006; Scofield et al., 2007; Neubert e Herold, 2008; Marpu et al., 2010). Merecem também menção os trabalhos de Uba e Dutra (2009) e Korting (2012) que procuraram otimizar a segmentação com a utilização de processamento pós-classificação. O desafio aqui advém do fato de que a segmentação é um problema mal condicionado (Hay and Castilla, 2008). Isso significa, por um lado, que pequenas alterações na imagem, no algoritmo ou nos valores de seus parâmetros, podem redundar em alterações substanciais no resultado da segmentação. Por outro lado, a segmentação admite múltiplas soluções. Constitui ainda um desafio determinar no espaço dos possíveis resultados da segmentação, aquele que melhor se coaduna com as classes de objetos que se pretende encontrar na imagem. Em vista disso, algumas abordagens para a avaliação da qualidade da segmentação baseiam-se na comparação entre o resultado da segmentação e um conjunto de segmentos de referências delineados manualmente por um especialista humano (p.ex., Costa et al., 2008).

Surge dai a questão quanto à confiança ou exatidão de tais referências. Com efeito, a interpretação de uma mesma imagem produzida por diferentes analistas geralmente diverge em algum grau, não apenas em termos temáticos, mas também espaciais. Esta questão tem sido assunto de investigação e novas abordagens têm sido propostas nos anos recentes (p.ex., Schöpfer et al., 2008; Albrecht, 2010; Albrecht et al., 2010; Lang et al., 2010; Tiede et al., 2010).

O presente trabalho foi motivado basicamente por três dificuldades inerentes à segmentação hierárquica que se baseia nos conceitos propostos por Baatz e Schäpe (2000) para uma abordagem por crescimento de região. Em primeiro lugar, a variante conhecida como top-down, que parte dos segmentos maiores, tende a produzir fronteiras pouco exatas. A razão é que transcorrem muitas iterações até que a restrição quanto ao tamanho dos segmentos passe a interferir no processo de crescimento de região. As bordas dos segmentos resultantes são pouco fieis às arestas presentes na imagem. Ao mesmo tempo, as etapas de segmentação nos níveis de menor escala estão comprometidas com as fronteiras dos superobjetos aos quais estão confinados, de tal forma que os desvios gerados no primeiro nível acabam se propagando para os níveis de menor escala. 
Para contornar esta dificuldade alguns optam pela abordagem bottom-up, que parte de segmentos pequenos, que vão sendo sucessivamente agregados para formar segmentos dos níveis de escala mais elevada. Os segmentos resultantes desta supersegmentação inicial guardam em geral pouca semelhança morfológica com os alvos de interesse na imagem. Por conseguinte, atributos de forma perdem poder de discriminação, o que pode por a perder uma das vantagens importantes de se trabalhar com segmentos ao invés de pixel, como se preconiza em GEOBIA.

A terceira e mais importante dificuldade não é particular da segmentação hierárquica, mas decorre, em certo sentido, da definição de segmentação que prevê segmentos “disjuntos” (p.ex., Pekkarinen, 2002). Ainda no âmbito da segmentação hierárquica, isso significa que se espera que uma única segmentação delineie adequadamente todos os diferentes tipos de alvos de tamanhos próximos. A prática frequentemente não corresponde a tal expectativa, e acaba se adotando algum compromisso na segmentação dos diversos tipos de alvos, que em geral está ainda distante do almejado.

A hipótese que inspira o presente trabalho é a de que uma melhor exatidão espacial referente à delimitação de objetos de classes diferentes poderá ser alcançada com segmentações distintas, cada uma otimizada para um tipo particular de alvo, e que a maior exatidão na delimitação de objetos proporcionará maior acurácia na classificação.

Claramente, tal ideia despreza a condição de consistência entre as fronteiras dos segmentos, conforme prevê a técnica de segmentação hierárquica, e é estranha à definição de que segmentos devem ser “disjuntos”. Haverá, ao contrário, subdivisões conflitantes da imagem, fazendo-se necessário decidir qual delas adotar em cada região da imagem.

Seguindo esta reflexão, o presente trabalho apresenta uma estratégia de análise baseada em objetos que envolve segmentações específicas para cada tipo de alvo, podendo ser inserida dentro do contexto de GEOBIA. Uma extensiva análise experimental demonstra a validade da hipótese inicial em que se baseia esta estratégia e demonstra seus benefícios em relação à segmentação hierárquica, tanto em termos de exatidão temática quanto espacial. 


\section{2}

\section{Objetivo}

O objetivo geral do presente trabalho é propor uma metodologia para interpretação automática de imagens segundo o paradigma baseado em objetos que envolvem segmentações específicas para cada classe de objeto.

São objetivos específicos desta tese:

- Construir um protótipo que permita validar a metodologia proposta.

- Apresentar um mecanismo para solução dos conflitos espaciais.

- Avaliar os ganhos de qualidade da segmentação.

- Avaliar o impacto do novo esquema de segmentação sobre a exatidão temática e espacial da análise.

\section{3}

\section{Contribuições}

Duas são as principais contribuições deste trabalho. Em primeiro lugar, propõe-se uma metodologia para análise de imagem baseada em objeto que difere em aspectos fundamentais do que se vem praticando na última década desde que GEOBIA passou ser a abordagem dominante para interpretação de imagens de altíssima resolução.

Há que se reconhecer, contudo, que, isoladamente, os passos que compõem a metodologia proposta foram trazidos de trabalhos anteriores. Em particular, cabe mencionar que a possibilidade de se trabalhar com segmentos não disjuntos e portanto, individualizados para cada classe, já estava presente no software AINDA (Liedtke et al., 1997) e está disponível na plataforma InterIMAGE (InterIMAGE, 2013), inspirado no software GeoAIDA (GEOAIDA, 2001), há alguns anos.

Da mesma forma, os métodos supervisionados de ajuste de parâmetros de segmentação já vêm sendo utilizados há anos (i.e., Tian e Chen, 2007; Costa et al., 2008; Lübker e Schaab, 2009; Ferreira, 2011). 
O autor desconhece, no entanto, trabalhos anteriores em que estas ideias tenham sido combinadas numa metodologia como a que ora se propõe.

Em segundo lugar, demonstra-se neste trabalho pela primeira vez o potencial desta metodologia sobre a segmentação hierárquica, que, conforme já mencionado, constitui o atual estado da arte em OBIA.

\section{4}

\section{Organização da tese}

Este trabalho está estruturado em seis capítulos, da seguinte forma:

O Capítulo 2 apresenta as técnicas atualmente utilizadas em segmentação segundo o paradigma baseado em objeto e suas limitações, bem como o contexto em que se insere esta Tese.

O Capítulo 3 apresenta os aspectos teóricos sobre os principais temas e conceitos relacionados ao âmbito deste trabalho.

No Capítulo 4, é apresentada a metodologia proposta e suas etapas de desenvolvimento.

No Capítulo 5, são apresentados, avaliados e discutidos os experimentos envolvendo segmentação e classificação de imagens.

O Capítulo 6 apresenta as conclusões e propostas de trabalhos futuros. 


\section{Técnicas relacionadas à GEOBIA}

A metodologia proposta tem como objetivo ser utilizada no ambiente de GEOBIA, portanto, este capítulo tem o objetivo de prover informações sobre o estado da arte em interpretação de imagens de acordo com o paradigma GEOBIA.

As seções seguintes estão divididas em três partes. A Seção 2.1 apresenta uma breve descrição de GEOBIA e alguns conceitos, a Seção 2.2 descreve a técnica atual de segmentação hierárquica, e a Seção 2.3 ilustra alguns trabalhos relacionados.

\section{1}

\section{O paradigma GEOBIA}

O acrônimo GEOBIA significa análise baseada em objeto de imagens de sensoriamento remoto (SR). Mais especificamente,

GEOBIA é um subcampo da Ciência da Informação Geográfica (Geographic Information Science - GIScience) dedicada ao desenvolvimento de métodos automatizados para dividir imagens provenientes de sensores remotos em objetos significativos, e avaliar as propriedades desses objetos por intermédio de suas escalas espaciais, espectrais e temporais, de modo a gerar nova informação geográfica em formato adequado para aplicações em Sistemas de Informação Geográfica (GIS) (Hay e Castilla, 2008).

Segundo Hay e Castilla (2008), GEOBIA incorpora conhecimentos e métodos de uma vasta gama de disciplinas envolvidas na geração e uso da informação geográfica. Na verdade, é esta singular ênfase e dependência em SR e informação geográfica - e os desafios que a acompanham - que distingue GEOBIA da análise de imagem baseada em objetos (OBIA) utilizada em 
disciplinas relacionadas, tais como visão computacional e análise de imagens biomédicas.

Dois grandes acontecimentos vieram para questionar o paradigma baseado na classificação de pixels e por regiões, baseada em atributos meramente estatísticos: o advento dos satélites civis de alta resolução espacial e a estreia em 2000 do software eCognition. A disponibilidade deste primeiro software comercial permitiu o acesso em todo o mundo a ferramentas que existiam anteriormente apenas em laboratórios de pesquisa. GEOBIA surgiu como uma alternativa ao paradigma tradicional baseado não somente em pixels e regiões com base em atributos exclusivamente estatisticos, e é baseada na ideia de que mudando as unidades básicas na análise de imagens, de pixels para segmentos, pode-se emular melhor a interpretação visual humana, fazendo melhor uso da informação espacial implícita dentro de imagens de SR (Lang e Blaschke, 2006).

GEOBIA assume que é possível identificar objetos em imagens de SR relacionados a entidades reais da paisagem. Um primeiro passo neste tipo de análise é a segmentação, a divisão da imagem em um conjunto de regiões espacialmente contínuas, disjuntas e homogêneas, que são mais uniformes do que quando comparadas com regiões adjacentes (Pekkarinen, 2002). Estas regiões (também conhecidas como segmentos) são posteriormente relacionadas com os objetos geográficos (como florestas e lagos) através do processo de classificação.

\subsection{1}

\section{Conceitos básicos}

Castilla e Hay (2008) chamam atenção para a considerável confusão na literatura produzida ao longo da última década sobre GEOBIA quanto à definição de certos conceitos que dizem respeito à própria identidade desta área de investigação. Esta seção apresenta alguns desses conceitos baseando-se em Castilla e Hay, (2008). 


\subsubsection{1}

\section{Objetos de imagem e segmentos}

Um dos mais importantes é o conceito de objeto de imagem.

Em (Benz et al., 2004), objetos de imagem são definidos como "regiões contíguas em uma imagem".

O termo objeto de imagem precisa ser explicitamente relacionado com a saída de algum processo digital. Desde que a segmentação de imagens é a técnica habitual utilizada para obter as unidades iniciais dentro de GEOBIA, uma abordagem seria igualar os segmentos, gerados pelo processo de segmentação da imagem, com os objetos de imagem. De fato, como a abordagem se baseia no paradigma de orientação a objeto, isto qualifica um segmento como objeto de imagem, em função do tratamento que é dado a ele.

Informalmente, se um determinado segmento corresponde a um padrão distinto e unitário, então ele pode ser considerado como um objeto de imagem. Disso decorre a importância da segmentação dentro do paradigma GEOBIA de interpretação de imagens.

Se um algoritmo gera muito mais segmentos do que seria a segmentação hipotética ideal, diz-se que ocorreu uma supersegmentação (over-segmentation). Se um algoritmo gera muito poucos segmentos, diz-se que ocorreu uma subsegmentação (under-segmentation). A Figura 2 ilustra com base em uma imagem abstrata, de cima para baixo a segmentação ideal, a supersegmentação e a subsegmentação. Segmentos de cores diferentes correspondem aos objetos de interesse para o analista.

Este esquema simples é, contudo, insuficiente para se avaliar a qualidade da segmentação com o detalhamento que requerem as aplicações reais de análise de imagens de SR. Critérios que avaliem mais objetivamente a qualidade da segmentação fazem-se necessários. Medidas da qualidade da segmentação fazemse necessárias (Espíndola et. al, 2006; Weidner, 2008; Zhang et al., 2008). 


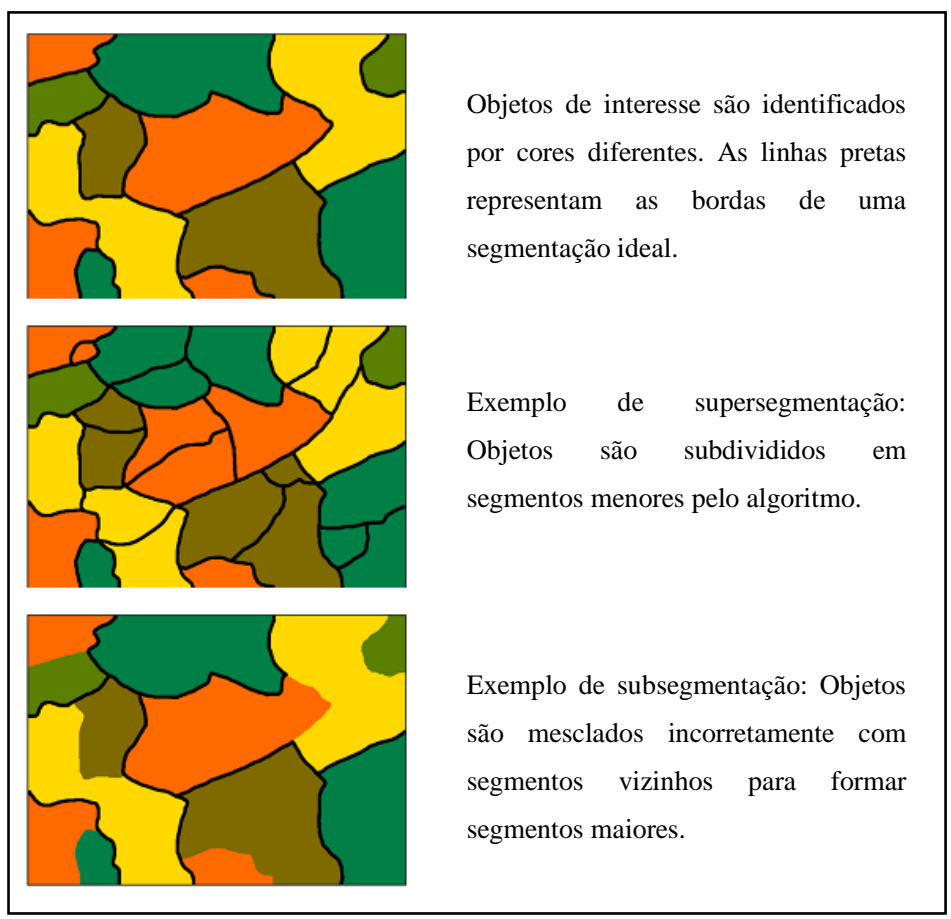

Figura 2 - llustrações dos conceitos de supersegmentação e subsegmentação (adaptado de Fourie, 2011).

\subsubsection{2}

\section{Geobjeto}

Em GEOBIA temos de lidar com dois domínios: a imagem e o contexto geográfico, que devem ser relacionados. Outro conceito importante é o de objeto geográfico, ou geobjeto. Trata-se de uma entidade física de tamanho significativo (de forma a permitir sua representação em um mapa) sobre ou perto da superfície da Terra, como uma cidade, uma floresta, um lago, uma montanha, um campo agrícola, uma área de vegetação e assim por diante (Smith e Mark, 1998).

Se a imagem é dividida em regiões coerentes, existem razões para acreditar que seus homólogos na paisagem também podem ser semanticamente coerentes. Em outras palavras, os objetos de imagem têm o potencial para corresponder na paisagem a alguma classe de objetos geográficos (geobjetos). Quando um objeto de imagem constitui representação adequada de uma instância de algum tipo de geobjeto, então se diz tratar-se de um objeto de imagem significativo, isto é, da representação de um geobjeto. 
No entanto, na prática, os segmentos raramente se qualificam como objetos de imagem significativos. Portanto, "objeto de imagem significativo" deve ser considerado um termo diferente do que apenas "objeto de imagem", o primeiro descrevendo uma unidade semântica e o último uma unidade perceptiva (vide Hay and Castilla, 2008).

A Figura 3 ilustra a diferença entre "objeto de imagem” e “objeto de imagem significativo" dentro do domínio da imagem, onde um objeto de imagem significativo (b) pode ser formado por vários objetos de imagem (a) de modo a representar dentro do contexto geográfico um geobjeto (c).

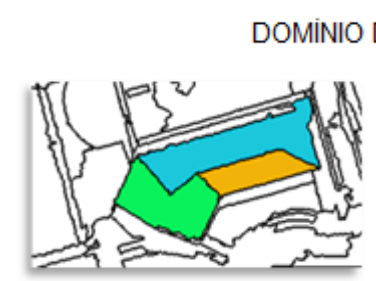

(a)

Objetos de imagem

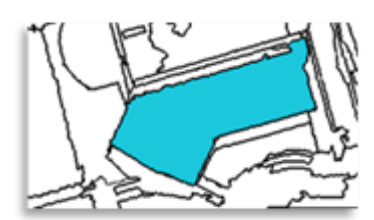

(b) CONTEXTO GEOGRÁFICO

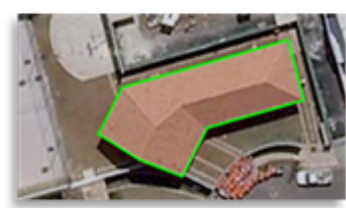

(c)

Objeto geográfico (geobjeto)

Figura 3 - Conceito de objeto de imagem (a) e objeto de imagem significativo (b) no domínio da imagem, em comparação com o contexto geográfico de geobjeto (c).

\section{2}

\section{Segmentação hierárquica}

A segmentação de imagens tem sido alvo de extensa pesquisa nas áreas de processamento digital de imagens e visão computacional. O processo de segmentação é um passo crítico e muito importante em GEOBIA e deve ser cuidadosamente efetuado de forma a garantir resultados eficientes (Blaschke e Strobl, 2001). De uma maneira geral, a eficiência dos algoritmos de segmentação está vinculada à extração automática de todos os objetos de imagem significativos. Neste sentido, há métodos que são adaptados a aplicações particulares, sendo que não existem algoritmos de segmentação universalmente adequados a todos os tipos de imagens (Beauchemin e Thomson, 1997). Em seus trabalhos, Pal e Pal (1993), Haralick e Shapiro (1985), Fu e Mui (1981) e Deb (2008) apresentam uma extensa revisão das principais classes de algoritmos de segmentação descritos na literatura. 
Técnicas de segmentação baseadas em similaridade levam em consideração coerência interna das regiões, analisando propriedades similares entre os pixels. Recaem neste grupo os métodos de segmentação por crescimento de regiões (region growing), limiarização, divisor de águas (watershed), divisão e fusão de regiões (split-and-merge) e agrupamento (clustering). Em meio à ampla variedade de métodos de segmentação, Tilton e Lawrence (2000) sustentam que os métodos de crescimento de regiões são dos mais conhecidos e mais amplamente utilizados para segmentação de imagens de SR.

Algumas das rotinas computacionais para segmentação de imagens de SR implementam métodos de crescimento de regiões, merecendo especial menção o SPRING (Bins et al., 1996; Câmara et al., 1996) e o Definiens (Baatz e Schape, 2000).

O algoritmo de segmentação por agrupamento de média móvel ou meanshift (Fukunaga e Hostetler, 1975) tem sido explorado na literatura recente como um método de segmentação de imagens promissor (Aytekin et al., 2009; Banerjee et al., 2012; Dongping et al., 2012; Büschenfeld e Ostermann 2012; Senaras et al, 2013).

Imagens de alta resolução espacial possuem natureza multiescala, incluindo detalhes e informações acerca dos elementos de dimensões distintas. Uma imagem pode ser representada em escalas diferentes simultaneamente, dependendo das dimensões dos geobjetos. A estratégia conhecida como segmentação hierárquica consegue lidar, dentro de certos limites, com a heterogeneidade espacial, ao separar e ordenar os componentes da imagem de acordo com a escala (tamanho) de seus objetos. Segundo Lang (2008), representações com a utilização dessa estratégia em escalas aninhadas nem sempre levam a resultados satisfatórios e não existe uma solução única entre as diferentes abordagens para resolver esta questão.

Duas abordagens muito utilizadas dentro do princípio da segmentação hierárquica para a geração dos objetos de imagem significativos são: Bottom-up (de baixo para cima), o processo começa por um nível mais detalhado de objetos de imagem que são agregados em objetos maiores à medida que se passa a níveis hierárquicos de maior escala; e Top-down (de cima para baixo), onde o processo inicia com objetos de imagem maiores que são subdivididos até se alcançar o nível de escala mais detalhado. 
A Figura 4 ilustra ambas as abordagens de segmentação hierárquica em imagens formadas a partir de parâmetros de segmentação diferentes. Na abordagem bottom-up, o nível superior é obtido pela fusão dos objetos similares do nível imediatamente inferior. Desse modo, no nível 1 os objetos de imagem são menores e em maior quantidade, sendo portanto o nível que oferece melhor detalhamento. No nível 3, devido às fusões dos objetos ocorridas nos níveis 1 e 2 , os objetos de imagem são maiores e em menor quantidade, sendo o nível mais grosseiro.

O procedimento top-down garante que os objetos de imagem gerados abaixo de um determinado nível respeitem os limites do nível superior, subdividindo objetos de imagem ou simplesmente fazendo-os coincidirem com as unidades superiores, mas jamais os agrupando.

Ambas as abordagens possuem vantagens e desvantagens, sendo em certo sentido complementares.

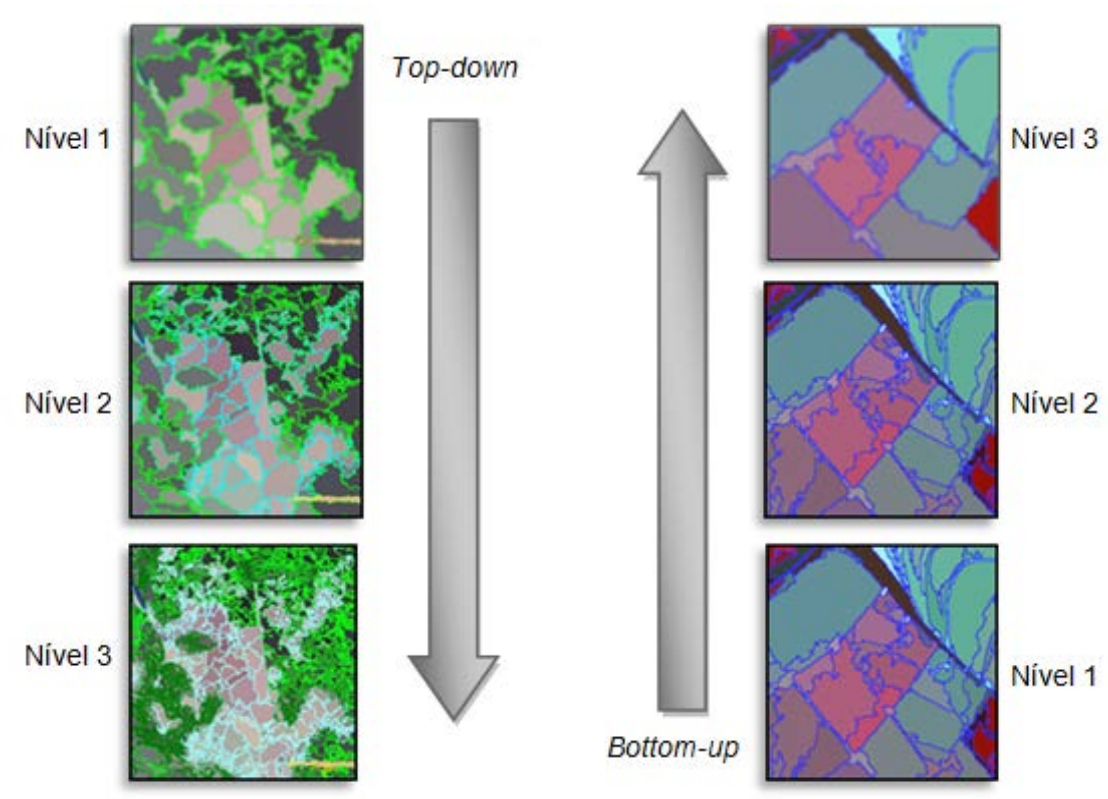

Figura 4 - Procedimentos bottom-up e top-down em segmentação hierárquica.

De acordo com Hay et al. (2003), para descrever como objetos de imagem se relacionam dentro e entre domínios de escala, precisamos de técnicas para definir automaticamente os dados de sensoriamento remoto e a capacidade para vinculá-los dentro de estruturas hierárquicas. As principais questões a serem esclarecidas para se alcançar este objetivo são: Quais são as escalas “ideais” para 
avaliar as variações de tamanho, forma, e cor dos objetos inseridos na imagem? Em que escalas devem ser estabelecidas as hierarquias?

Alguns algoritmos de segmentação possuem parâmetros diretamente relacionados à escala. Seus valores são definidos na maioria dos casos práticos de forma empírica pelos usuários, não havendo garantia de que se encontrem, de fato, os valores ótimos. Os parâmetros influenciam diretamente a qualidade da segmentação, e seus valores ótimos podem variar bastante para problemas diferentes, considerando os diferentes sensores, suas diferentes resoluções espectrais e espaciais, e considerando também as diferentes características das regiões imageadas (área urbana, vegetação etc).

O algoritmo do SPRING requer que sejam definidos limiares de área e de similaridade. Por sua vez, o algoritmo do Definiens requer que sejam definidos quatro parâmetros. Para os usuários desses algoritmos, um grande desafio consiste em selecionar os parâmetros que derivem nos melhores resultados da segmentação.

Para a escolha desses parâmetros, apenas recentemente se desenvolveram programas e extensões para programas que realizam a escolha de forma objetiva e mais automatizada (Feitosa et al., 2009; Drăguţ et al., 2010; Novack et al., 2011; Kux et al., 2010);

Após a etapa de segmentação, utilizam-se classificadores para categorizar todos os segmentos de uma imagem digital em uma das várias classes de objetos representadas na imagem.

\section{3}

\section{Trabalhos que fizeram uso das técnicas descritas}

Recentemente, vários autores têm utilizado a abordagem de segmentação hierárquica multiescala para análise e interpretação de imagens provenientes de sensores remotos.

Antunes e Cortese (2007) desenvolveram um estudo de forma a avaliar a discriminação de ocupações irregulares ou aglomerados subnormais com a utilização de imagem QuickBird segmentada em diferentes níveis hierárquicos. Rocha (2007) apresentou uma metodologia de classificação de imagens de alta resolução espacial QuickBird para identificar e avaliar o crescimento de áreas de 
ocupação irregular. Novack e Kux (2009) fizeram uso de árvores de decisão e redes hierárquicas para definição automática de atributos e limiares na classificação de cobertura do solo urbano a partir de imagens de alta resolução. Alguns autores utilizaram otimização automática de parâmetros de segmentação, dos quais podemos citar os trabalhos de Novack et al. (2011), em imagens QuickBird e WorldView-2 (WV-2), para classificação urbana de cobertura da terra em uma abordagem orientada a objeto; Lübker e Schaab (2009) para classificação de áreas agrícolas e florestais em imagens QuickBird; Tian e Chen (2007) na identificação de alvos urbanos em imagens Ikonos. Pinho et al. (2012) utilizaram segmentação multiescala na classificação de cobertura urbana em imagens de alta resolução. 


\section{3}

\section{Fundamentos teóricos}

Este capítulo apresenta os fundamentos teóricos necessários à compreensão do modelo proposto. Na Seção 3.1, são apresentados os algoritmos de segmentação utilizados. A Seção 3.2 apresenta as técnicas de otimização dos parâmetros dos segmentadores. Na Seção 3.3, são definidos os atributos de forma e como são selecionados para a etapa de classificação. Finalmente, a Seção 3.4 apresenta os classificadores utilizados.

\section{1}

\section{Algoritmos de segmentação}

Conforme mencionado anteriormente, existem diversas classes de algoritmos de segmentação, e o algoritmo de crescimento de regiões (region growing) proposto por Baatz e Schäpe (2000), implementado nos softwares Definiens e InterImage, e é hoje provavelmente o mais usado em aplicações de sensoriamento remoto por OBIA

O processo de crescimento de regiões implementado por esse algoritmo segue uma decisão heurística. Começando por uma região A qualquer, e um outra região $B$, vizinha a $A$, as regiões $A$ e $B$ serão agrupadas (fundidas) de acordo com um determinado critério de tolerância, baseado em uma medida de heterogeneidade.

O algoritmo proposto por Baatz and Schäpe (2000) utiliza três componentes em sua formulação de heterogeneidade no processo de crescimento de regiões: uma componente espectral, associada aos valores dos pixels que compõem as regiões e ponderada por pesos arbitrários definidos para cada banda espectral da imagem; uma componente morfológica, definida por dois atributos de forma (suavidade e compacidade), ponderados por pesos complementares; e um parâmetro de escala. O parâmetro de escala é a medida para a variação máxima em heterogeneidade decorrente da fusão de duas regiões. Internamente, esse valor é elevado ao quadrado e serve como limiar para a fusão de regiões. 
O critério geral de heterogeneidade é composto pelos parâmetros, denominados heterogeneidade de cor e de forma. O processo procura a minimização da heterogeneidade global, levando em conta a dimensão do segmento.

A soma ponderada de cor e forma gera o critério $f$ :

$$
f=\left(1-w_{\text {forma }}\right) \cdot h_{\text {cor }}+w_{\text {forma }} \cdot h_{\text {forma }}
$$

em que,

$w_{\text {forma }}$ - peso da forma variando de 0 a1;

$h_{\text {cor }}$ - componente espectral;

$h_{\text {forma }}$ - componente morfológica.

A componente espectral constitui-se de uma soma ponderada dos desvios padrões de cada banda para uma determinada região. O peso de cada banda é estabelecido pelo usuário e varia entre 0 e 1. Segundo Hofmann (2001), os valores de níveis de cinza das bandas multiespectrais possuem uma correlação significativa e ao utilizar o mesmo peso para cada banda é encontrado um resultado bastante razoável.

A componente espectral é dada por:

$$
h_{c o r}=\sum_{c} w_{c}\left(n_{u n i a ̃ o} \cdot \sigma_{c}^{u n i a ̃ o}-\left(n_{o b j 1} \cdot \sigma_{c}^{o b j 1}+n_{o b j 2} \cdot \sigma_{c}^{o b j 2}\right)\right),
$$

em que,

$w_{C}$ - peso atribuído a cada banda multiespectral;

$n_{\text {união }}$ - número de pixels do possível segmento a ser formado;

$\sigma_{c}^{\text {união }}$ - desvio padrão do possível segmento a ser formado;

$n_{o b j 1}$ - número de pixels do segmento 1 ;

$\sigma_{c}^{o b j 1}$ - desvio padrão do segmento 1 para cada banda c;

$n_{o b j 2}$ - número de pixels do segmento 2;

$\sigma_{c}^{o b j 2}$ - desvio padrão do segmento 2 para cada banda c.

A forma é um atributo morfológico que leva em consideração os critérios de compacidade e suavidade, com intervalo variando de 0 a 1. 


$$
h_{\text {forma }}=w_{\text {comp }} \cdot h_{\text {comp }}+\left(1-w_{\text {comp }}\right) h_{\text {suav }}
$$

onde,

$h_{\text {comp }}$ - heterogeneidade para compacidade;

$h_{\text {suav }}$ - heterogeneidade para a suavidade.

$w_{\text {comp }}$ - peso atribuído a compacidade variando de 0 a 1 ;

O segmentador utilizado nesse trabalho é o segmentador multiresolução estendido (eXtended MultiResolution Segmentation - XMRS) (XMRS, 2012), proposto no trabalho de Ferreira (2011), que modificou o algoritmo de Baatz and Schäpe, de modo que possam ser utilizados outros atributos de forma além da suavidade e compacidade.

A componente morfológica $h_{\text {forma }}$ é definida pelo desvio relativo da forma do objeto em relação a formas geométricas bem definidas. O algoritmo original considera dois atributos de forma: compacidade e suavidade. $\mathrm{O}$ algoritmo multicritério estende o número de atributos de forma para o cálculo da componente morfológica.

A formulação da componente morfológica $h_{f o r m a}$ é então generalizada, na qual, não apenas dois, mas vários atributos de forma podem ser utilizados. Na equação $4, s$ e $w_{s}$ são, respectivamente, o índice e o peso do atributo de forma; $a_{s}$ é o valor do atributo de forma, e $n$ o número de pixels de cada objeto.

$$
h_{\text {forma }}=\sum_{s} w_{s}\left(n_{\text {união3 }} \cdot a_{s}^{\text {união }}-\left(n_{o b j 1} \cdot a_{s}^{o b j 1}+n_{o b j 2} \cdot a_{s}^{o b j 2}\right)\right) .
$$

Os pesos dos atributos de forma $w_{s}$ e dos atributos de cor são normalizados, de forma que: $\sum_{s} w_{s}=1$ e $\sum_{c} w_{c}=1$.

Os atributos de forma utilizados nesse trabalho foram: suavidade, compacidade, retangularidade, isometria, excentricidade, fator de estrutura e fator de forma circular, cujas definições são apresentadas mais adiante, na Seção 3.3.1.

O segmentador multicritério possibilita a utilização simultânea de mais de um atributo de forma no processo de segmentação. Porém, por simplicidade, neste trabalho apenas dois, dentre os listados na Tabela 1, serão utilizados simultaneamente no processo de segmentação das imagens. Com o uso de apenas 
dois atributos de forma, seus pesos na equação 4 serão complementares, ou seja, $w_{s}$ e $\left(1-w_{s}\right)$.

Na prática, os parâmetros de entrada desse algoritmo são:

$p_{e}$ - parâmetro de escala;

$w_{\text {forma }}$ - peso da forma em relação à cor;

$w_{c}$ - peso das bandas espectrais (nesse trabalho deixados iguais a 1);

$w_{s}$ - pesos dos atributos de forma utilizados.

O outro algoritmo baseado em crescimento de regiões usado nesse trabalho é o algoritmo implementado no software SPRING, desenvolvido pelo Instituto Nacional de Pesquisas Espaciais (Câmara et al., 1996), de agora em diante denominado SCR (SPRING - Crescimento de Regiões).

Este algoritmo funciona da seguinte maneira: dados os segmentos iniciais correspondentes aos pixels da imagem, a decisão de agrupamento é definida a partir do cálculo da distância euclidiana (módulo da diferença das médias das intensidades dos pixels nas diferentes bandas espectrais) de dois segmentos adjacentes; a decisão de agrupar é aceita se a distância euclidiana for menor que o limiar de similaridade definido pelo usuário, dando preferência para o agrupamento dos vizinhos com menor distância euclidiana.

Seja $L_{s}$ o limiar de similaridade; $M_{i}$ o valor de média da região $R_{i}$; $\operatorname{dist}\left(R_{i}, R_{j}\right)=\left\|M_{i}-M_{j}\right\|$ a distância Euclidiana entre as regiões $R_{i}$ e $R_{j}$; e $N\left(R_{i}\right)$ o conjunto de regiões vizinhas da região $R_{i}$, duas regiões vizinhas $R_{i}$ e $R_{j}$ serão agrupadas se satisfizerem as seguintes condições:

1. Condição de Similaridade: $\operatorname{dist}\left(R_{i}, R_{j}\right) \leq L_{s}$

2. Condição de Vizinhança 1:

$$
R_{j} \in N\left(R_{i}\right) \text { and } \operatorname{dist}\left(R_{j}, R_{i}\right) \leq \operatorname{dist}\left(R_{k}, R_{i}\right), R_{k} \in N\left(R_{i}\right)
$$

3. Condição de Vizinhança 2:

$$
R_{i} \in N\left(R_{j}\right) \text { and } \operatorname{dist}\left(R_{i}, R_{j}\right) \leq \operatorname{dist}\left(R_{k}, R_{j}\right), R_{k} \in N\left(R_{j}\right)
$$

Ou seja, segundo a condição (1), a distância Euclidiana entre as regiões $R_{i}$ e $R_{j}$ deverá ser menor que o limiar de similaridade $L_{s}$. As condições (2) e (3) garantem que, dados os conjuntos $N\left(R_{i}\right)$ e $N\left(R_{j}\right)$ de regiões vizinhas, as regiões $R_{i}$ e 
$R_{j}$ são mutuamente as mais similares destes conjuntos. Regiões menores que o limiar de área são agrupadas na região vizinha mais similar.

Os resultados deste processo de segmentação são sensíveis à escolha dos limiares de área e de similaridade. Baixos limiares tendem a produzir resultados com grande número de regiões fragmentadas, gerando supersegmentações. Em contra partida, altos valores forçam a união de regiões distintas, gerando subsegmentações.

Os parâmetros de entrada do algoritmo são:

$L_{s}$ - limiar de similaridade: limiar de decisão para agrupamento;

$L_{a}$ - limiar de área mínima: se o segmento for menor que a área mínima, ele será mesclado ao vizinho mais similar.

Finalmente o último algoritmo utilizado é o média móvel ou mean shift (Fukunaga e Hostetler, 1975), que é um poderoso e versátil algoritmo iterativo não paramétrico que pode ser usado para muitas finalidades. $\mathrm{O}$ algoritmo estima a moda (regiões densas) de distribuições multivariadas no espaço de atributos de forma iterativa. Os agrupamentos descobertos são obtidos a partir dos centros dessas modas. O algoritmo se tornou popular em 1995 com o trabalho de Cheng (1995), que focou no agrupamento de dados e localização de modas de uma função de probabilidade. Comaniciu e Meer (1999) realizaram um estudo aprofundado do mean shift e o aplicaram na área de visão computacional, mais especificamente em segmentação e suavização de imagens.

A equação 5 define o vetor mean shift, da forma apresentada por Fukunaga e Hostetler, e mostra que a estimativa do gradiente de densidade normalizado $\widehat{\nabla} f(x) / \hat{f}(x)$ pode ser calculada através do deslocamento amostral pela média em um kernel uniforme centrado em $x$. O vetor mean shift representa a diferença entre uma média local, calculada em uma janela com raio $h$ no espaço $d$-dimensional, e o centro desta janela.

$$
\vec{M}_{h}(x)=\frac{h^{2}}{(d+2)} \frac{\widehat{\nabla} f(x)}{\hat{f}(x)}
$$

O vetor mean shift aponta sempre na direção do maior incremento na densidade, ou seja, descobre o caminho que leva a um máximo local de densidade 
(moda da densidade). A cada iteração do algoritmo, as amostragens são sucessivamente deslocadas em direção ao máximo local mais adequado.

As imagens geralmente são representadas na forma de matrizes, onde cada posição é ocupada por vetores (os pixels), com dimensão $p$, onde $p=1$ para imagens em níveis de cinza, e $\mathrm{p} \geq 2$ para imagens multiespectrais. A posição de cada píxel na matriz de imagem está contida no domínio espacial (localização do pixel) e o valor de intensidade faz parte do domínio da imagem (atributos espectrais). De acordo com essa definição, cada elemento da matriz de posicionamento da imagem contém um atributo no espaço com domínio de dimensão $d=p+2$. Deste modo, um kernel multivariado pode ser definido como o produto de dois kernels radialmente simétricos em um espaço euclidiano, calculado com um parâmetro de cada domínio através da equação 6, expressa nesta forma por Comaniciu e Meer (1999).

$$
K_{h_{s}, h_{r}}(\mathbf{x})=\frac{c}{h_{s}^{2} h_{r}^{p}} k\left(\left\|\frac{\mathbf{x}^{s}}{h_{s}}\right\|^{2}\right) k\left(\left\|\frac{\mathbf{x}^{r}}{h_{r}}\right\|^{2}\right)
$$

onde:

$\mathbf{x}^{S}$ - Corresponde ao domínio espacial, posição do píxel na imagem;

$\mathbf{x}^{r}$ - Corresponde ao domínio da imagem, nível de cinza do píxel;

$k(x)$ - Elementos da função calculados em ambos os domínios;

$h_{s}, h_{r}$ - Parâmetros das bandas de cada domínio do kernel empregado;

$C$ - Constante de normalização entre as bandas.

O algoritmo clássico do mean shift procede da seguinte maneira:

1. É fixada uma janela centrada em cada ponto do conjunto de dados;

2. O centro de massa (média dos pontos) é calculado para cada janela;

3. O deslocamento para a média é calculado;

4. O centro da janela é deslocado para a média calculada no passo anterior;

5. O processo é repetido até que ocorra a convergência.

Os parâmetros de entrada do algoritmo são:

$h_{s}$ - largura de banda espacial;

$h_{r}$ - largura de banda de cor;

$A_{\text {min }}$ - área mínima de segmentação. 


\section{2}

\section{Otimização dos parâmetros da segmentação}

O desempenho da segmentação não apenas depende do algoritmo utilizado para realizar a tarefa. Outro fator tão importante quanto à escolha do algoritmo é a escolha dos parâmetros de entrada adequados do algoritmo.

Antes do desenvolvimento de ferramentas automáticas de otimização, a escolha se dava por tentativa e erro, seguido de análise visual da imagem. Isso tornava o processo de escolha dos parâmetros de segmentação uma etapa extremamente subjetiva, demorada e difícil, ainda mais para algoritmos que requerem muitos parâmetros de entrada.

Zhang (1996) e Zhang et al. (2008) sugerem que a utilização de métodos empíricos de discrepância são mais adequados do que os métodos analíticos para a avaliação da qualidade dos algoritmos de segmentação. E dentre os métodos empíricos, os métodos de discrepância se mostraram melhores para avaliar objetivamente a qualidade da segmentação. Embora os métodos de discrepância sejam mais complexos que os de qualidade, considerando-se o fato de que uma segmentação de referência precisa ser produzida, os métodos de discrepância se mostraram mais efetivos.

As métricas de discrepância são utilizadas para avaliar a diferença entre a segmentação de referência e a saída do algoritmo de segmentação.

Em (Zhang et al., 2008), critérios típicos de discrepância incluem o:

- número de pixels segmentados incorretamente, ou métricas baseadas na área;

- posição física dos pixels incorretamente segmentados ou métricas baseadas em bordas;

- número de segmentos na imagem; e

- atributos dos objetos segmentados.

\subsection{1}

\section{Qualidade da segmentação}

As ferramentas para calibração automática dos parâmetros de algoritmos de segmentação normalmente necessitam de uma função que verifique a qualidade 
das segmentações que serão geradas, para que se possam escolher objetivamente quais parâmetros resultaram em melhores produtos.

Seguindo esta linha, algumas métricas de discrepância foram propostas e Ferreira (2011) concluiu em seu trabalho, após diversos testes comparativos com algumas métricas de discrepância, que a métrica Reference Bounded Segments Booster - RBSB (Feitosa et al., 2006) mostra boa correlação com a percepção humana de qualidade de segmentação.

A métrica RBSB é formalmente definida como:

$$
F_{R B S B}=\frac{1}{n} \sum_{i=1}^{n} \frac{\#\left(S_{i}-O(P)_{i}\right)+\#\left(O(P)_{i}-S_{i}\right)}{\# S_{i}}
$$

sendo $S$ um conjunto de $n$ segmentos de referência, e $P$ é um vetor que representa os parâmetros do algoritmo de segmentação; $S_{i}$ e $O(P)_{i}$ são conjuntos de pixels; o primeiro pertencente ao i-ésimo segmento em $S$, e o segundo, ao resultado da segmentação, através de $P$, com maior interseção com $S_{i}$. Tem-se $F_{\mathrm{RBSB}}=0$ para um ajuste perfeito entre referência e segmentação, e $F_{\mathrm{RBSB}}>0$, caso contrário. A Figura 5 ilustra a métrica RBSB.

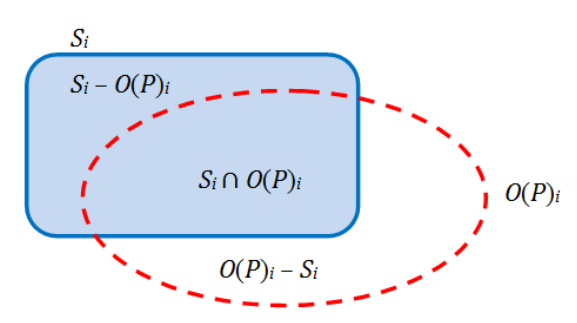

Figura 5 - Métrica RBSB.

\section{2 .2}

\section{Técnicas de otimização}

Após aferir a qualidade do resultado, é necessário que exista alguma técnica de otimização que faça a inferência de quais parâmetros de entrada poderiam gerar melhores resultados.

Técnicas de otimização objetivam encontrar a melhor solução dentre aquelas pertencentes a um conjunto de soluções para a resolução de um problema. 
Devem ser utilizadas quando não existe uma solução simples e diretamente calculável para o problema. Isso geralmente ocorre quando a estrutura do problema é complexa, ou existem milhões de possíveis soluções. Nesses casos, é possível que não exista nenhum procedimento direto de solução, de forma que essas técnicas podem ser utilizadas na busca pela melhor solução para o problema.

A tarefa de ajustar os parâmetros de um algoritmo de segmentação consiste em encontrar os valores que levem o algoritmo a produzir um resultado ótimo, medido a partir de um critério de qualidade apropriado. Em termos matemáticos, dados um conjunto de segmentos $S$, uma função de discrepância $F$ e

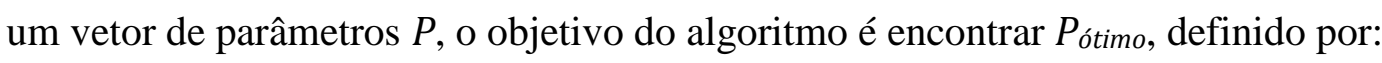

$$
P_{\text {ótimo }}=\arg _{P}(\min [F(S, P)]) \text {, }
$$

A maioria das abordagens de obtenção de parâmetros ótimos de segmentação é baseada em técnicas estocásticas. Feitosa et al. (2006) propuseram o uso de algoritmos genéticos (AG) para o ajuste dos parâmetros de segmentação. Métodos que não utilizam derivadas da função objetivo têm estado em foco nos últimos anos para otimização de funções para as quais não existe formulação analítica (Conn et al., 2009). Dentre esses métodos de otimização se encontram os métodos de busca direta Generalized Pattern Search (GPS), proposto por Torczon (1997) e o Mesh Adaptive Direct Search (MADS), proposto por Audet e Dennis Jr. (2006). Happ et al. (2012) sugerem a utilização do GPS como um método eficaz para a sintonização automática de parâmetros de segmentação como alternativas aos algoritmos genéticos, principalmente no que se refere ao elevado custo computacional envolvido.

\subsubsection{1}

\section{Funcionamento do GPS}

GPS é um método de procura direta para determinar o valor ótimo de uma determinada função não linear por meio da comparação de valores em um conjunto finito de pontos em cada iteração. Este tipo de método, além de não usar derivadas da função objetivo também não as tenta aproximar. 
Algoritmos GPS calculam uma sequência de soluções que se aproximam de forma iterativa do ótimo global. A cada iteração, o algoritmo seleciona um conjunto de pontos ao redor da solução atual em busca de uma solução para a qual o valor da função objetivo seja menor do que o da solução corrente.

O fluxograma mostrado na Figura 6 ilustra o funcionamento do GPS.

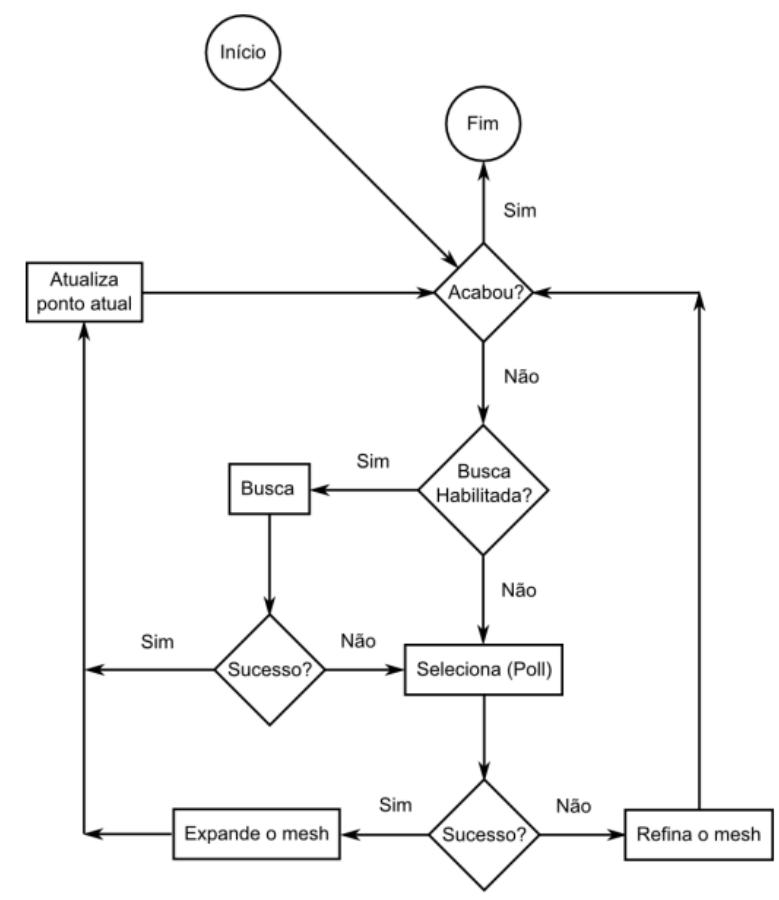

Figura 6 - Fluxograma do algoritmo GPS (adaptado de Mathworks, 2011).

Ao iniciar, o algoritmo calcula o valor da função objetivo para um ponto inicial $x_{0} \in \mathbb{R}^{n}$ fornecido, que passa a ser o ponto corrente $x_{k}$, sendo $k=0,1, \ldots$ o número de iterações. Após isso, o algoritmo realiza uma busca procurando por pontos que melhorem o valor da função objetivo. A busca visa minimizar a possibilidade de que o GPS pare em um mínimo local. Essa busca é opcional e não possui implicações na convergência do método. Qualquer método de otimização pode ser utilizado nessa etapa, como outro padrão de busca direta ou um algoritmo genético. Se nessa busca é encontrado um ponto melhor, então esse ponto passa a ser o ponto corrente, nenhuma seleção é realizada, e o algoritmo vai para a próxima iteração. Se um ponto melhor não é encontrado, então a seleção é realizada. 
Na seleção, o algoritmo calcula um conjunto de pontos ao redor do ponto corrente. Esses pontos são calculados a partir de um padrão, isto é, um conjunto de vetores $v p_{i} \in \mathbb{R}^{n}$ onde $1 \leq i \leq \mathrm{N}$.

Existem vários padrões de vetores possíveis. Nesse trabalho, foi utilizado um padrão de busca a partir de uma Base Positiva 2N. Um padrão é um conjunto composto por $2 \mathrm{~N}$ vetores (em que $\mathrm{N}$ representa o número de variáveis a serem otimizadas) que são utilizadas a cada iteração com a finalidade de determinar novos pontos para a busca do ponto ótimo.

Então a partir do ponto inicial e do padrão de busca, define-se o conjunto de pontos denominado malha (mesh), que será utilizado para encontrar novos pontos. Uma malha é um conjunto de vetores formado pelo produto de cada elemento dos vetores $v p_{i}$ por um escalar $\Delta_{\mathrm{k}} \in \mathbb{R}$, denominado de tamanho da malha. Este produto é somado ao ponto corrente, gerando os pontos para a seleção:

$$
\beta_{i}=x_{k}+\left(\Delta_{k} v p_{i}\right)
$$

Para um exemplo do padrão Base Positiva $2 \mathrm{~N}$, com $\mathrm{N}=2$, a malha ao redor do ponto $x_{k}$ ficaria como mostrado na Figura 7 .

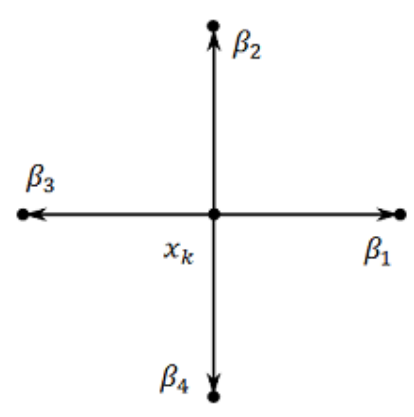

Figura 7 - Malha ao redor do ponto $x_{k}$ com padrão Base Positiva $2 \mathrm{~N}$, para $\mathrm{N}=2$.

A seguir, avalia-se o valor da função objetivo em cada um desses novos pontos da malha e faz-se a comparação com o valor da função objetivo no ponto atual. Se, para um determinado ponto da malha $\beta_{i}$, o valor da função objetivo avaliado for inferior ao valor da função objetivo no ponto atual $x_{k}$, este será o novo ponto atual $x_{k}=\beta_{i}$, e o tamanho da malha é expandido $\Delta_{k+1}=\lambda \Delta_{k}$, sendo 
$\lambda \geq 1$. Caso contrário, a seleção é considerada malsucedida, o ponto corrente fica inalterado $x_{k+1}=x_{k}$, e o tamanho da malha é contraído $\Delta_{k+1}=\theta \Delta_{k}$, sendo $0<\theta<1$.

Ao final da iteração, o algoritmo verifica se o tamanho da malha é menor do que o limiar definido $\Delta_{k}<\varepsilon$. Neste caso, o algoritmo é terminado, e o ponto atual passa a ser a solução aproximada do problema. Caso contrário, uma nova iteração é iniciada (Ferreira, 2011).

\section{3}

\section{Cálculo de atributos}

O cálculo de atributos visa à caracterização de medidas associadas com o objeto que se deseja extrair da imagem, de tal forma que essas medidas sejam similares para objetos similares e diferentes para objetos distintos.

Essa etapa consiste, portanto, em medir em cada segmento os atributos discriminatórios para as classes de objetos de imagem significativos, de forma que cada segmento seja descrito por um vetor cujos elementos contêm o valor de um determinado atributo.

\subsection{1}

\section{Atributos de forma}

Não existe na literatura uma definição universal de forma suficientemente genérica para descrever a forma de qualquer objeto. De maneira geral, a forma de um objeto é descrita por comparação a outro ou através de propriedades do seu contorno, sendo geralmente caracterizada por intermédio de atributos que quantificam o afastamento da forma do objeto em relação a um modelo teórico ou que denotam alguma propriedade característica de seu contorno.

Esses atributos são chamados atributos de forma e são, em última análise, de primordial importância para a discriminação de objetos que possuem a mesma aparência espectral. 


\subsubsection{1}

\section{Conceitos}

Para a compreensão dos atributos de forma utilizados nesse trabalho, torna-se necessária a definição de alguns conceitos. O primeiro refere-se ao cálculo do perímetro de um objeto. Segundo Russ (1998), existem várias maneiras de se calcular o perímetro de um objeto, sendo o cálculo do perímetro utilizado neste trabalho correspondente ao número de pixels de borda do objeto, utilizando a vizinhança 4, como mostrado na Figura 8.

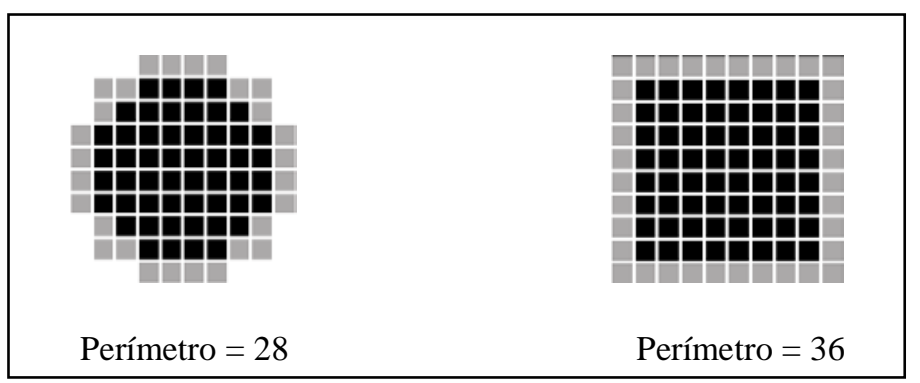

Figura 8 - Cálculo do perímetro para um círculo e um quadrado de 10×10 - pixels de borda em cinza, (adaptado de Ferreira, 2011).

Para o cálculo das dimensões dos objetos, foi utilizado o método conhecido como Ajuste de Elipse. O ajuste é baseado nas estatísticas da distribuição espacial dos pixels que pertencem ao objeto. Para o cálculo dessas estatísticas, usa-se a matriz de covariância:

$$
\begin{gathered}
S=\left[\begin{array}{cc}
\operatorname{Var}(X) & \operatorname{Cov}(X, Y) \\
\operatorname{Cov}(X, Y) & \operatorname{Var}(Y)
\end{array}\right], \\
\operatorname{Var}(X)=\frac{1}{n} \sum_{x}(\bar{x}-x)^{2}, \\
\operatorname{Var}(Y)=\frac{1}{n} \sum_{y}(\bar{y}-y)^{2}, \\
\operatorname{Cov}(X, Y)=\frac{1}{n} \sum_{x} \sum_{y}(\bar{x}-x)(\bar{y}-y),
\end{gathered}
$$

em que $X$ é o vetor com todas as coordenadas $x$ dos pixels do objeto, $Y$ é o vetor com todas as coordenadas $y$ dos pixels do objeto, $n$ é o número de pixels do objeto. 
Os dois eixos da elipse ajustada correspondem aos autovalores da matriz de covariância:

$$
\begin{gathered}
2 a=\sqrt{8\left(\operatorname{Var}(X)+\operatorname{Var}(Y)+\sqrt{(\operatorname{Var}(X)-\operatorname{Var}(Y))^{2}+4 \operatorname{Cov}(X, Y)^{2}}\right)}, \\
2 b=\sqrt{8\left(\operatorname{Var}(X)+\operatorname{Var}(Y)-\sqrt{\left.(\operatorname{Var}(X)-\operatorname{Var}(Y))^{2}+4 \operatorname{Cov}(X, Y)^{2}\right)}\right.},
\end{gathered}
$$

A partir dos eixos da elipse ajustada, mostrada na Figura 9, é possível obter as medidas utilizadas no cálculo dos atributos.

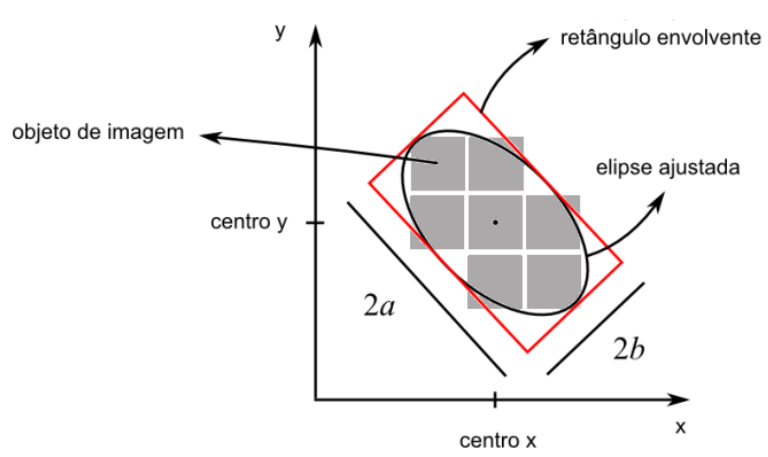

Figura 9 - Elipse ajustada a um objeto, (adaptada de Ferreira, 2011).

\subsubsection{2}

\section{Métricas}

A Tabela 1 apresenta algumas métricas referentes a atributos geométricos de segmentos, que foram utilizadas nesse trabalho, extraídas de (Russ, 1998), (Baatz e Shäpe, 2000) e o software de Visão Computacional Halcon (Halcon, 2011). Todos os atributos são adimensionais e são definidos de modo a alcançarem seu valor mínimo teórico quando a forma do segmento coincide perfeitamente com uma forma de referência (p.ex., círculo, retângulo etc.). Em vista disso, a definição de alguns dos atributos apresentados nesta seção pode diferir da definição que se encontra em outras publicações da área. 
Tabela 1 - Atributos de forma utilizados.

\begin{tabular}{|c|c|c|}
\hline Atributo & Definição & Descrição \\
\hline Suavidade & $S u a v=\frac{l}{2 a+2 b}$ & $\begin{array}{l}\text { Mede o quanto o objeto se afasta de sua } \\
\text { envoltória convexa. A suavidade é mínima } \\
\text { para um retângulo perfeito e cresce com a } \\
\text { presença de concavidades. }\end{array}$ \\
\hline Compacidade & $\operatorname{Comp}=\frac{l}{\sqrt{A}}$ & $\begin{array}{l}\text { Representa o desvio em relação a um } \\
\text { quadrado. A compacidade é mínima para } \\
\text { um quadrado e é sensível a irregularidades } \\
\text { de contorno. }\end{array}$ \\
\hline Retangularidade & $\operatorname{Ret}=\frac{a \cdot b}{A}$ & $\begin{array}{l}\text { Corresponde à dissimilaridade em relação } \\
\text { a uma forma retangular. A retangularidade } \\
\text { é igual a } 1 \text { (um) para um retângulo perfeito } \\
\text { e aumenta com a presença de reentrâncias. } \\
\text { É sensível à presença de ramificações finas } \\
\text { e longas. }\end{array}$ \\
\hline Isometria & $I s o=\frac{a}{b}$ & $\begin{array}{l}\text { Representa o desvio em relação a uma } \\
\text { forma isométrica. A isometria é igual a } 1 \\
\text { (um) para um objeto isométrico e aumenta } \\
\text { à medida que ele se alonga. }\end{array}$ \\
\hline Excentricidade & $E x c=\sqrt{1-\left(\frac{b}{a}\right)^{2}}$ & $\begin{array}{l}\text { Trata-se de um atributo que visa capturar o } \\
\text { quanto a forma do objeto difere da de um } \\
\text { círculo. A excentricidade é igual a } 0 \text { (zero) } \\
\text { para um círculo perfeito e tende a } 1 \text { (um) } \\
\text { quando o alongamento tende a infinito. }\end{array}$ \\
\hline $\begin{array}{l}\text { Fator de } \\
\text { estrutura }\end{array}$ & $F E=\frac{\pi \cdot a^{2}}{A}-1$ & $\begin{array}{l}\text { Representa o desvio em relação a um } \\
\text { círculo com raio igual ao semieixo } \\
\text { principal da elipse ajustada. É mínimo para } \\
\text { um círculo e aumenta à medida que o } \\
\text { semieixo principal aumenta em relação à } \\
\text { área. }\end{array}$ \\
\hline $\begin{array}{l}\text { Fator de forma } \\
\text { circular }\end{array}$ & $F F C=\frac{p^{2}}{4 \cdot \pi \cdot A}$ & $\begin{array}{l}\text { Este atributo mede o desvio em relação a } \\
\text { um círculo. É mínimo para um círculo } \\
\text { perfeito e aumenta à medida que o } \\
\text { comprimento da borda do segmento } \\
\text { aumenta em relação à sua área. }\end{array}$ \\
\hline
\end{tabular}


em que:

$a$ e $b$ semieixos maior e menor da elipse que compreende o objeto;

$l=4(a+b)$ (comprimento da borda do objeto);

$A=4 a \cdot b$ (área do retângulo envolvente da elipse ajustada);

$p=$ perímetro do objeto.

\subsection{2}

\section{Seleção de atributos}

As medições que podem ser realizadas para determinação das características dos objetos de imagem geralmente se compõem de atributos espectrais, atributos de textura, ou atributos de forma, como área, perímetro, excentricidade, entre muitos outros. De acordo com as classes de objetos a serem reconhecidas, diferentes conjuntos de atributos podem ser utilizados. A escolha desses conjuntos, e seus respectivos parâmetros, é uma tarefa que encontra certa dificuldade na solução de um problema específico.

Geralmente, as abordagens de seleção de atributos podem ser divididas em dois tipos: "wrapper" avaliam os atributos usando estimativas de precisão providas por algoritmos de aprendizado pré-determinados, enquanto abordagens do tipo "filtro" avaliam os atributos de acordo com a heurística baseada em características gerais dos dados.

A escolha do método de seleção de atributos é geralmente dependente do problema. Segundo Kuang (2009), quando o tamanho da amostra é pequeno, os métodos filtros produzem um melhor desempenho relativamente à sua capacidade de fornecer estimativas mais estáveis.

O algoritmo Correlation-based Feature Selection (CFS), proposto por (Hall, 1999), é um método de seleção de atributos do tipo filtro que obteve bom desempenho em experimentos com imagens naturais, eliminado bem mais da metade dos atributos. Na maioria dos casos, a precisão da classificação usando um conjunto reduzido selecionado por esse algoritmo obteve resultados iguais ou superiores à utilização do conjunto completo de atributos. 
Alguns trabalhos baseados no CFS para redução da dimensionalidade dos dados em atributos provenientes de imagens de sensoriamento remoto incluem Novack e Kux (2009), Pal e Foody (2010), Piedra-Fernández et. al (2010) e Silva et al. (2013).

A técnica de seleção de atributos CFS parte da hipótese de que um bom subconjunto de atributos é aquele que contém atributos com alta correlação com a classe, mas com uma baixa correlação entre si. Dessa forma, o CFS avalia o subconjunto de atributos considerando a capacidade preditiva individual de cada um em conjunto com o grau de redundância entre eles. Subconjuntos de atributos que são muito correlacionados com a classe ao mesmo tempo em que possuem uma baixa correlação entre si são preferidos para a seleção.

De acordo com (Hall, 1999), o CFS utiliza uma estratégia de busca heurística baseada no algoritmo "subida da encosta” (hill-climbing), que constrói uma árvore de busca com todos os atributos e suas possíveis combinações. Em cada passo, o algoritmo seleciona os atributos que possuem a maior correlação com a classe e o subconjunto de atributos. A expressão de dependência é:

$$
H=\frac{k \bar{r}_{k c}}{\sqrt{k+k(k-1) \bar{r}_{k k}}}
$$

em que $k$ é o número de atributos no subconjunto, $\bar{r}_{k c}=\bar{r}\left(X_{k}, C\right)$ é o coeficiente de correlação médio entre os $k$ atributos de um subconjunto $X_{k}$ e a classe C, e $\bar{r}_{k k}=\bar{r}\left(X_{k}, X_{k}\right)$ é o coeficiente de correlação médio entre os diferentes atributos. O numerador representa a eficiência da discriminação, e o denominador mede a redundância dos atributos.

A equação 15 é utilizada como uma medida heurística do "mérito" de subconjuntos de atributos em sistemas de classificação supervisionada. O problema restante é desenvolver maneiras adequadas para se medir a correlação atributo-classe e a intercorrelação atributo-atributo. De modo a ter uma base comum para o cálculo das correlações na equação 15, é desejável dispor de um modo uniforme para o tratamento de diferentes tipos de atributos. A discretização utilizando o método de diferenciação de Fayyad e Irani (1993) é aplicada como um passo de pré-processamento para converter atributos contínuos para um valor nominal. 
Para medir a correlação entre dois atributos ou entre um atributo e uma classe, adota-se em geral a medida de correlação denominada incerteza simétrica (Symmetrical Uncertainty - SU) (Press et al., 1988). Sendo uma variável discreta $X$ com $N$ valores possíveis $\left\{x_{i}, i=1, \ldots, N\right\}$, sua entropia é definida pela equação:

$$
\mathrm{H}(\mathrm{X})=-\sum_{i=1}^{N} P\left(x_{i}\right) \log _{2}\left(P\left(x_{i}\right)\right)
$$

A entropia de X após observar os valores de outra variável Y, é definida como:

$$
\mathrm{H}(\mathrm{X}, \mathrm{Y})=-\sum_{j=1}^{N} P\left(y_{j}\right) \sum_{i=1}^{N} P\left(x \mid y_{i}\right) \log _{2}\left(P\left(x_{i} \mid y\right)\right),
$$

em que $P\left(x_{i}\right)$ é a probabilidade para todos os valores de $\mathrm{X}$, e $P\left(x_{i} \mid y\right)$ é a probabilidade posterior de $\mathrm{X}$ dados os valores de $\mathrm{Y}$. A quantidade pela qual a entropia de $\mathrm{X}$ diminui reflete o ganho de informação acerca de $\mathrm{X}$ dado $\mathrm{Y}$. O Ganho de Informação GI(X|Y) será:

$$
\mathrm{GI}(\mathrm{X} \mid \mathrm{Y})=\mathrm{H}(\mathrm{X})+\mathrm{H}(\mathrm{Y})-\mathrm{H}(\mathrm{X}, \mathrm{Y})
$$

em que $H(X), H(X, Y)$ e $G I(X \mid Y)$ representam, respectivamente, a entropia do atributo $\mathrm{X}$, a entropia condicional de $\mathrm{X}$ dado $\mathrm{Y}$, e o ganho de informação, que é uma medida simétrica, a qual reflete a informação adicional acerca de $\mathrm{X}$ dado $\mathrm{Y}$.

De acordo com a equação acima, o atributo $\mathrm{Y}$ é considerado mais correlacionado ao atributo $X$ do que a um atributo $Z$, se $G I(X \mid Y)>G I(Z \mid Y)$. A simetria significa que a quantidade de informação ganha com um atributo Y após observar $\mathrm{X}$ é igual à quantidade de informação ganha com o atributo $\mathrm{X}$ após observar Y.

Hall et al. (1999) propôs para o cálculo simultâneo da contribuição do atributo e a correlação a seguinte expressão:

$$
\mathrm{SU}(\mathrm{X}, \mathrm{Y})=2\left[\frac{\mathrm{GI}(\mathrm{X} \mid \mathrm{Y})}{\mathrm{H}(\mathrm{X})+\mathrm{H}(\mathrm{Y})}\right]
$$


Seu valor varia de 0 (se não existir nenhuma correlação entre os dois atributos) a 1 (caso os atributos sejam linearmente dependentes).

O algoritmo CFS faz uma ordenação de todos os subconjuntos de atributos no espaço de busca de todas as possíveis combinações. Porém, a enumeração exaustiva de todos os possíveis subconjuntos de atributos é proibitiva na maioria dos casos, por isso alguns critérios devem ser definidos, como os pontos de partida e parada do algoritmo. A implementação do CFS permite ao usuário escolher entre três estratégias de busca heurística: a "seleção para frente" (sequencial forward selection - SFS), a “eliminação para trás” (selection backward elimination - SBE), e "melhor escolha" (best-first search - BFS). Para evitar que o algoritmo explore todo o espaço de busca dos atributos, é imposto um critério de parada. A busca irá terminar, se um determinado número predefinido de subconjuntos de atributos completamente expandidos não mostrar nenhuma melhora em relação ao melhor subconjunto atual.

\section{4}

\section{Classificação}

A etapa final da análise de imagem por regiões ou orientada a objeto é a classificação ou rotulação dos segmentos dentro das classes de interesse.

Para executar esse tipo de classificação, pode-se utilizar qualquer algoritmo classificador capaz de realizar uma classificação multivariada. Em face da complexidade, na maioria dos casos, das múltiplas variáveis e do número de classes, utilizam-se os classificadores supervisionados.

Os classificadores supervisionados necessitam de amostras de treinamento que devem ser amostradas de forma criteriosa, dependendo das necessidades do estudo. Com a finalidade de facilitar a aquisição, pode-se optar por métodos de amostragem sistematizada e estratificada ao longo das imagens e direcionando as amostras dentro das classes de interesse. 


\subsection{1}

\section{Classificador Naive Bayes}

O classificador Naive Bayes fornece uma abordagem simples e com semânticas claras para a representação, uso e aprendizado do conhecimento probabilístico e é indicado para o contexto de indução supervisionada, em que a meta de desempenho consiste na predição das instâncias de teste e o conhecimento sobre quais instâncias de treinamento possuem informações sobre as classes (John e Langley, 1995). O classificador Naive Bayes é uma técnica simples e possui a vantagem de requerer apenas uma pequena quantidade de dados de treinamento para estimar os parâmetros necessários para a classificação.

De acordo com Buntine (1994), o classificador Naive Bayes emprega uma versão simplificada da fórmula de Bayes intitulada "Naive" (ingênua) por assumir duas importantes suposições:

i) todos os atributos preditivos são apenas dependentes da classe a que pertencem, e

ii) não possuem relação alguma de dependência entre si.

O classificador Naive Bayes procura inferir as probabilidades de uma instância pertencer a cada uma das classes do conjunto de treinamento. A probabilidade de uma instância pertencer a determinada classe, dada a observação dos atributos, é conhecida como probabilidade a posteriori. O Teorema de Bayes calcula esse tipo de probabilidade como enunciado na equação abaixo:

$$
P(C=c \mid X=x)=\frac{P(C=c) P(X=x \mid C=c)}{P(X=x)},
$$

em que $C$ é uma variável aleatória que denota a classe de uma instância e $X$ um vetor de variáveis aleatórias representando os valores observados dos atributos, $c$ é um rótulo de uma determinada classe, e $x$, um vetor de valores de atributo. A classe mais provável será aquela com maior valor para $P(C=c \mid X=x)$, ou seja, a probabilidade da classe $c$ dada a instância $x$. De acordo com a equação 20, $X=x$ corresponde ao evento $X_{1}=x_{1} \wedge X_{2}=x_{2} \wedge \ldots X_{k}=x_{k}$ e $P(C=c)$ representa a probabilidade a priori de $c$, ou seja, a probabilidade de obtenção da classe $c$ sem levar em conta os dados de treinamento. 
A partir da amostra de treinamento fornecida ao Classificador, é simples calcular a probabilidade a priori de cada classe $P(C=c)$. O denominador do lado direito da equação 20 envolve apenas os valores observados para cada atributo, sendo que, em uma operação de classificação na qual esses valores são fixos, tal probabilidade se torna uma constante normalizadora. O cálculo de $P(X=x \mid C=$ c) torna-se simples a partir da hipótese da independência dos atributos:

$$
P(X=x \mid C=c)=\prod_{i}^{k} P\left(X_{i}=x_{i} \mid C=c\right)
$$

A suposição de independência dos atributos não parece afetar grandemente as probabilidades posteriores, especialmente nas regiões próximas aos limites de decisão, portanto, deixando a tarefa de classificação inalterada (Domingos e Pazzani, 1996).

Para o cálculo de $P\left(X_{i}=x_{i} \mid C=c\right)$ para cada atributo é preciso conhecer a distribuição de probabilidade de cada um deles. Uma suposição comum frequentemente usada é que, para cada classe, os valores dos atributos numéricos são normalmente distribuídos. Porém, podem ser utilizadas várias outras formas diferentes de distribuição, incluindo lognormal, gama, funções de densidade de Poisson e métodos de estimação não paramétricos dentre eles, a estimação de densidade de núcleo (do inglês kernel density estimation - KDE) (John e Langley, 1995), que foi o método utilizado neste trabalho.

A função usada para a estimação de densidade de núcleo é expressa pela fórmula:

$$
P(X=x \mid C=c)=\frac{1}{n h} \sum_{i=1}^{n} \frac{K\left(x-x_{i}\right)}{h},
$$

em que $K(\bullet)$ é o núcleo, uma função simétrica, mas não necessariamente positiva, cuja integral é unitária, e $h>0$ é um parâmetro chamado de largura de banda (bandwidth). O valor de $n$ corresponde ao número de instâncias de treinamento pertencentes à classe $c, x_{i}$ é o atributo de cada exemplo de treinamento.

Neste trabalho foi utilizado o classificador Naive Bayes implementado pelo Matlab (Mathworks, 2012), que utiliza o núcleo Gaussiano e $h \approx$ 1,06 $\hat{\sigma} n^{-1 / 5}$ (aproximação de distribuição normal) como parâmetro de largura de banda, em que $\hat{\sigma}$ é o desvio padrão dos atributos. 
No cálculo de $P(X=x \mid C=c)$ para um atributo contínuo, o classificador Naive Bayes irá executar $n$ estimações da função de densidade de probabilidade Gaussiana (vide Figura 10).

O método KDE permita que o classificador tenha um bom desempenho em domínios que violam a suposição de normalidade dos atributos.

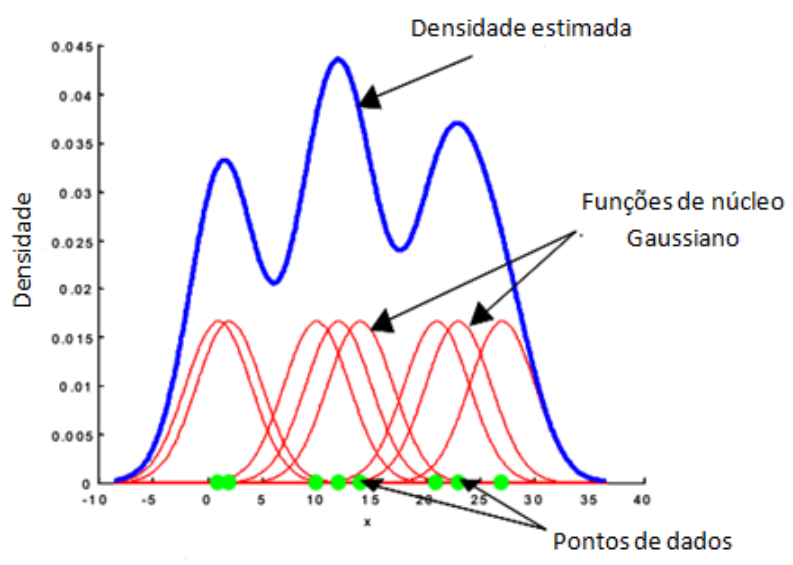

Figura 10 - Estimação de densidade de núcleo.

\subsection{2}

\section{Classificador de Máxima Verossimilhança}

O classificador probabilístico baseado na estimativa de máxima verossimilhança (do inglês Maximum Likelihood Estimation - MLE) é um método bastante popular de classificação de imagens de sensoriamento remoto, que descobre a classe de um pixel desconhecido baseado em funções de densidade de probabilidade (probability density functions - pdf) das classes de interesse. Propriedades estatísticas dos conjuntos de dados de treinamento são normalmente utilizadas para estimar as $p d f s$ das classes. Cada pixel desconhecido é atribuído à classe com a maior probabilidade próxima à localização do pixel. Se existirem $m$ classes predefinidas, a classe da probabilidade a posteriori é expressa como:

$$
P(k \mid x)=\frac{P(k) P(k \mid x)}{\sum_{i=1}^{m} P(i) P(k \mid i)},
$$


em que $P(k)$ é a probabilidade a priori da classe $k$ e $P(k \mid x)$ é a $p d f$ de $x$ na classe $k$. Para distribuições normais, a função de probabilidade, $P(x \mid k)$, é dada por:

$$
L_{k}(x)=\frac{1}{(2 \pi)^{\frac{m}{2}}\left|\sum_{k}\right|^{\frac{1}{2}}} \exp \left(-\frac{1}{2}\left(x-\mu_{k}\right)^{T} \sum_{k}^{-1}\left(x-\mu_{k}\right)\right)
$$

em que $x=\left(x_{1}, x_{2}, \ldots, x_{n}\right)^{T}$ corresponde ao vetor de pixels com $n$ atributos espectrais; $L_{k}(x)$ significa a função de pertinência de probabilidade de $x$ pertencer à classe $k ; \mu_{k}=\left(\mu_{1}, \mu_{2}, \ldots, \mu_{m}\right)^{T}$ é um vetor correspondente às médias das $k$ classes, e $\sum_{k}$ é a matriz de variância-covariância da classe $k$.

O classificador MLE tem sido utilizado principalmente em abordagens baseadas em pixels. Para contornar essa limitação, neste trabalho foram utilizados grupos de pixels que formam os segmentos da imagem, em que os atributos dos segmentos são então usados para estimar os parâmetros do classificador. Semelhante abordagem foi utilizada em (Lee e Warner, 2004).

\subsection{3}

\section{Classificador SVM}

Uma alternativa aos classificadores descritos anteriormente é a utilização de classificadores não-paramétricos. Recentemente, particular atenção tem sido dedicada pela comunidade científica às técnicas baseadas em máquinas de vetores de suporte (Support Vector Machines - SVM) (Boser et al., 1992; Cortes e Vapnik, 1995), para fins de reconhecimento de padrões em imagens de alta dimensionalidade em sensores remotos. Estudos desenvolvidos por alguns autores, como Melgani e Bruzzone (2004), Foody e Mathur (2008) e Huang et al. (2002), afirmam que SVM binários, aplicados em problemas multiclasse, tem frequentemente proporcionado uma exatidão na classificação melhor que outras técnicas de reconhecimento de padrões largamente utilizadas.

Uma das grandes vantagens do uso de SVM é seu alto poder de generalização, pois a complexidade da hipótese não depende do número de atributos, mas sim da margem com que eles separam os dados (Joachims, 1998), proporcionando com isso a construção de um sistema de classificação mais robusto. 


\subsubsection{1}

\section{Hiperplanos de separação}

O SVM consiste em uma técnica de classificação não estatística para reconhecer padrões por ele identificados nos exemplos de treinamento, em que a classificação é conhecida. Baseia-se na montagem de um hiperplano ideal de separação entre as classes, focalizando as amostras à margem das classes de modo a maximizar a distância entre elas (Foody e Mathur, 2008). O hiperplano com margem máxima é chamado de hiperplano ótimo, que será o objeto de busca durante o treinamento do classificador. A Figura 11(a) mostra um dos possíveis hiperplanos de separação com margem pequena, e 12(b) mostra o hiperplano de separação ótimo com a margem maximizada.

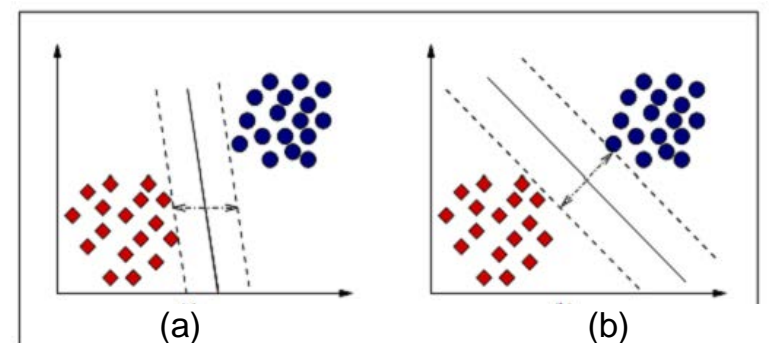

(a)

(b)

Figura 11 - Hiperplano de separação, em (a) hiperplano com margem pequena e em (b) hiperplano com margem máxima.

$\operatorname{Seja}\left(x_{1}, y_{1}\right), \ldots,\left(x_{i}, y_{i}\right),(\mathrm{x} 1, \mathrm{y} 1)$, tal que $x \in \mathbb{R}^{n}$ e $y \in\{-1,1\}, i=$ $1, \ldots, N$, em que $N$ é o número de instâncias do treinamento, $x$ é o vetor de entrada e $y$ é a classificação desejada. O objetivo é estimar uma função $F: \mathbb{R}^{n} \rightarrow$ $\{-1$ ou 1$\}$, usando os exemplos de treinamento e aplicá-la nos exemplos de teste, não utilizados anteriormente, com o objetivo de que sejam classificados corretamente.

\subsubsection{2}

\section{Funções de núcleo}

A finalidade das funções de núcleo (kernel) são a de projetar os vetores de atributos de entrada em um espaço de atributos de alta dimensão de forma a classificar problemas que se encontram em espaços não linearmente separáveis. A 
Figura 12 mostra o processo de transformação de um domínio não linearmente separável, em um problema linearmente separável através do aumento da dimensão, onde é feito um mapeamento por uma função de núcleo $\phi(x)$.

Existem vários tipos de núcleos que podem ser usados, porém os mais conhecidos são polinomial, função de base radial (Radial Basis Function RBF) e sigmoidal.

Neste trabalho foi utilizado o núcleo não linear RBF, pois segundo Brown et al. (2000), é o mais adequado na discriminação de classes em que o hiperplano não apresenta linearidade. Alguns parâmetros do classificador são definidos pelo usuário, dentre eles podem ser citados a penalidade e o sigma. A penalidade é um parâmetro utilizado durante a classificação de dados não separáveis. Altos valores deste parâmetro implicam em menores índices de erro durante o treinamento, porém, podem ocasionar perda de generalidade do modelo. Já o sigma é um parâmetro da função RBF, responsável em modelar a flexibilidade do hiperplano de separação fornecida pelo SVM.

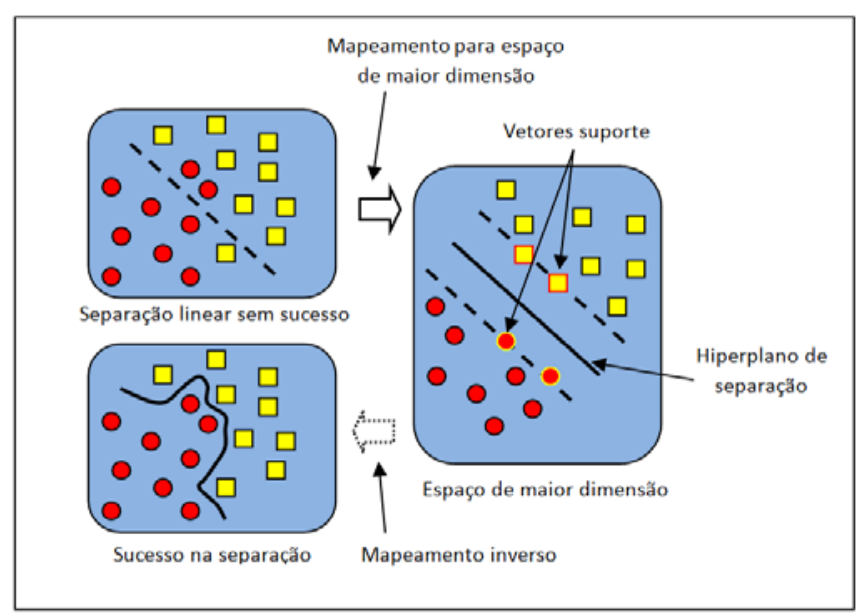

Figura 12 - Estratégia da classificação não linearmente separável em uma classificação linearmente separável, através de um mapeamento do espaço de atributos para um espaço de maior dimensão.

\subsubsection{3}

\section{SVM multiclasses}

O SVM foi projetado para separar os dados linearmente em duas classes, porém o reconhecimento de mais do que duas classes é possível utilizando a estratégia de decomposição do problema multiclasses em subproblemas binários. 
As técnicas mais conhecidas são a "um contra todos" (one-against-all) e "um contra um” (one-against-one):

Para um número $\mathrm{M}$ de classes temos:

- Técnica one-against-all: consiste em separar uma classe A e agrupar as 1-M classes restantes em uma classe B. A partir da separação encontraremos o hiperplano que separa a classe A da classe B. O processo é realizado $M$ vezes para cada uma das classes, ao final teremos $C$ hiperplanos de separação;

- Técnica one-against-one: consiste em separar duas classes A e B dentre todas as classes e encontrar um hiperplano que separe esse par de classes. Para cada par de classes, tem-se um hiperplano de separação, logo teremos M hiperplanos que separam as classes.

A Figura 13 ilustra as duas técnicas de decomposição descritas para três classes (Allwein et al., 2000).

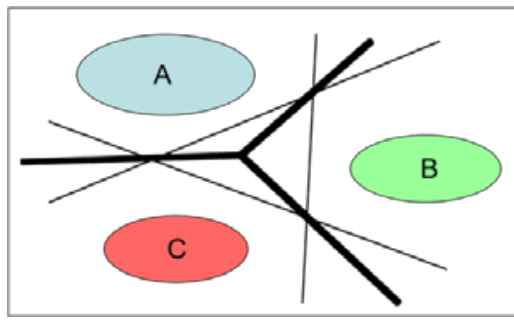

(a)

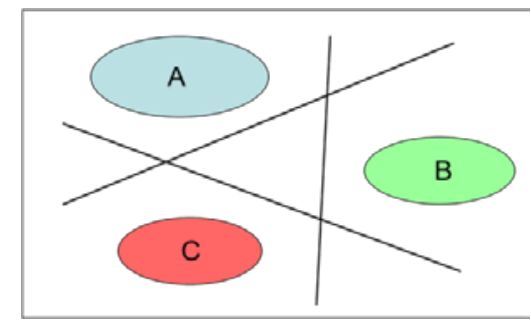

(b)

Figura 13 - Exemplifica SVM multiclasse, (a) técnica de decomposição one-against-all para três classes, (b) técnica de decomposição one-against-one para três classes.

\subsubsection{4}

\section{SVM com resposta probabilística}

A função de decisão $F(x)$ do SVM possui uma resposta de valor numérico não calibrado (vide Figura 14) pertencente ao conjunto dos números reais. Na predição dos resultados, a resposta do SVM a essa função é:

- Se $F(x)$ possui valor negativo, implica que o ponto $x$ pertence à classe negativa $(-1)$;

- Se $F(x)$ possui valor positivo, implica que o ponto $x$ pertence à classe positiva $(+1)$. 


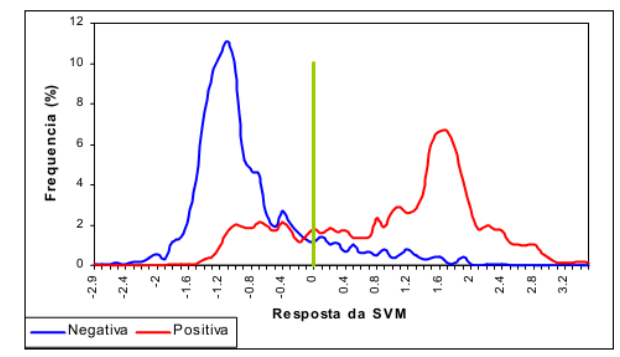

Figura 14 - Histograma das probabilidades condicionais das classes (+1: positiva; -1 : negativa), $P(y= \pm 1 \mid x)$. A linha vertical em verde é o ponto onde a função de decisão $F(x)$ é igual a 0 . Os dados foram extraídos de um problema de previsão de risco no mercado financeiro (adaptado de Semolini, 2002).

Muitas vezes, o interesse não está em apenas classificar cada amostra dos dados em uma das duas classes, e sim em obter a probabilidade condicional da amostra pertencer a uma determinada classe, dado o seu vetor de variáveis de entrada, $P(y= \pm 1 \mid x)$. Sendo a resposta do SVM um valor não calibrado, faz-se necessário desenvolver métodos para calibrar a resposta do SVM para assim permitir interpretá-lo com o uma probabilidade condicional.

O método de maior utilização, e também o utilizado neste trabalho, é o desenvolvido por Platt (2000), que para mapear a resposta do SVM em probabilidade, faz um treinamento de uma função sigmoide, não alterando em nada o mecanismo do SVM.

Platt emprega um modelo paramétrico que ajusta a probabilidade condicional $P(y=+1 \mid F(x))$ utilizando os parâmetros que geram a melhor probabilidade.

Através da regra de Bayes para o cálculo da probabilidade a posteriori e da premissa de que as funções de densidade condicionais das duas classes são funções exponenciais, Platt sugere que a resposta do SVM seja proporcional a:

$$
p\left(x_{i}\right)=P\left(y=1 \mid F\left(x_{i}\right)\right)=\frac{1}{1+\exp \left(A F\left(x_{i}\right)+B\right)},
$$

em que os parâmetros $A$ e $B$ são ajustados utilizando-se os dados de treinamento.

Para predição, utiliza-se a função de decisão do SVM e depois a equação 25 para obter a probabilidade de a amostra pertencer à classe positiva. A probabilidade de a amostra pertencer à classe negativa é o complementar da primeira. 


\section{Metodologia proposta}

Este capítulo apresenta a metodologia proposta no trabalho de interpretação de imagens automáticas com a utilização de segmentações específicas por classe.

A Seção 4.1 apresenta uma descrição geral da metodologia proposta, e a Seção 4.2, descreve as diversas etapas envolvidas.

\section{1 \\ Descrição geral}

A abordagem GEOBIA envolve a divisão da imagem de entrada em objetos de imagem significativos, como se mencionou na Seção 2. A maioria dos objetos de imagem significativos resulta da agregação, através de um processo de associação, entre os objetos de imagem iniciais (segmentos), com base nos atributos espectrais e morfológicos dos segmentos e em suas relações, uma vez que segmentos não são em geral os objetos de imagem significativos, e a forma dos segmentos, via de regra, não corresponde à forma dos objetos de imagem significativos, o que compromete a classificação.

Se a etapa de segmentação produzisse sempre e de maneira eficiente os objetos de imagem significativos, o processo de classificação seria mais simples, uma vez que se tornaria desnecessário proceder à fusão de segmentos para gerar os geobjetos.

Em (Ferreira, 2011), demonstrou-se que a utilização de atributos de forma na composição do critério de homogeneidade/heterogeneidade do algoritmo de segmentação como o proposto por Baatz e Schäpe (2000), pode, efetivamente, melhorar a exatidão da segmentação.

A recomendação implícita do trabalho de Ferreira e coautores é que os valores dos parâmetros de segmentação sejam ajustados individualmente para cada uma das classes de objetos. 
Os benefícios são de duas naturezas. Em primeiro lugar, diminui-se a supersegmentação dos objetos de imagem significativos, e os segmentos serão mais próximos dos objetos de imagem significativos. Consequentemente, os segmentos de uma dada classe tendem a ter a forma dos correspondentes objetos de imagem significativos e, portanto, serem mais claramente discriminados através de atributos de forma, o que contribui para aumentar a exatidão temática.

Em segundo lugar, as fronteiras dos segmentos são mais coerentes com as bordas dos objetos de imagem, uma vez que os parâmetros são ajustados para uma classe particular de objetos, os segmentos resultantes correspondentes a esta classe tendem a ter suas fronteiras delineadas de modo mais exato, o que contribui para aumentar a exatidão espacial da análise.

Cabe ressaltar aqui, que esta metodologia é claramente distinta da técnica conhecida como segmentação hierárquica multiescala, que não admite a coexistência de diferentes segmentações em um mesmo nível hierárquico.

Como uma alternativa à segmentação hierárquica multiescala, considera-se nesta tese uma metodologia que prevê uma segmentação específica para cada classe de objetos, para as quais os valores dos parâmetros de segmentação são otimizados especificamente. A metodologia proposta prevê que as segmentações das diferentes classes de objetos que compõem a imagem não respeitem as restrições de fronteira, como ocorre na segmentação hierárquica. A Figura 15 ilustra a metodologia proposta. A Figura 15 em (a) mostra a imagem de entrada e em (b) as classes de objetos. Na Figura 15 em (c) e (d), veem-se os resultados de duas segmentações específicas, cujos parâmetros foram ajustados para cada uma das classes de interesse (A e B). Os resultados mostram que cada segmentação específica conseguiu produzir segmentos que delinearam melhor os objetos das classes de interesse. 


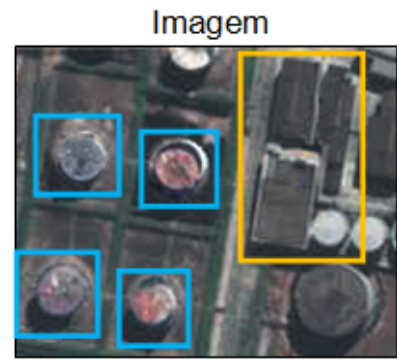

(a)

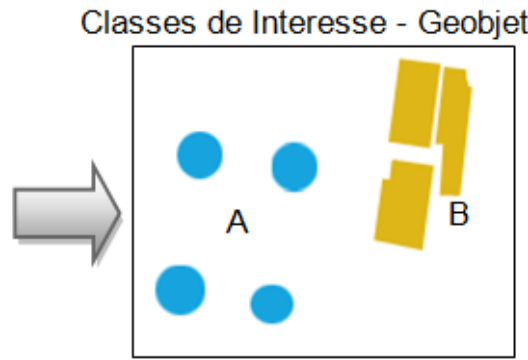

(b)

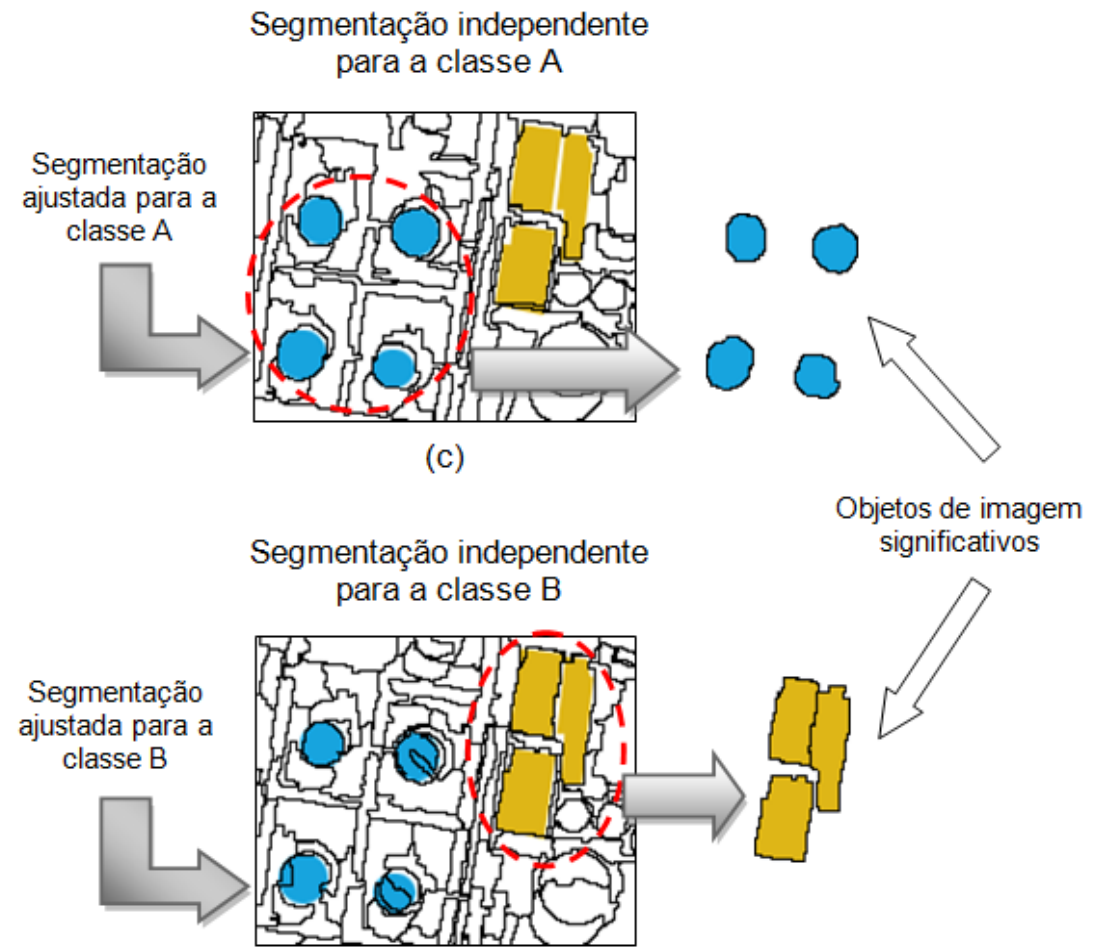

(d)

Figura 15 - Exemplo de segmentação específica. Em (a), imagem com duas classes de objetos (A e B), mostradas em (b), de mesma escala (tamanhos) e formas diferentes. Em (c) e (d), segmentações específicas com ajuste de parâmetros otimizados para as classes A e B, respectivamente.

A metodologia proposta prevê igualmente classificações específicas. Utilizou-se um classificador distinto, de mesma arquitetura, para cada classe, que atribui um grau de pertinência ou uma probabilidade de que cada segmento pertença à classe para a qual o segmentador e o classificador foram ajustados. Haverá, portanto, para cada classe de objeto uma segmentação específica, e a cada um de seus segmentos, uma atribuição de probabilidade ou pertinência à classe correspondente àquela segmentação. Assim, se for $N$ o número de classes de objetos, cada pixel terá associado $N$ rótulos, cada um identificando o segmento 
particular a que pertence em cada uma das $N$ segmentações, e $N$ valores de pertinência/probabilidade, cada um relativo a uma das classes do problema.

A principal dificuldade desta metodologia decorre de que as fronteiras entre segmentos são diferentes em cada uma das segmentações, gerando os chamados "conflitos espaciais”, que devem ser tratados em uma etapa posterior à classificação.

Uma maneira simples de resolver esses conflitos, e a forma adotada neste trabalho, inspirada na solução implementada nos aplicativos AIDA/GeoAIDA, é por intermédio dos valores de pertinência/probabilidade gerados pelos classificadores associados a cada segmento classificado. Havendo conflito, a classe com a maior pertinência prevalece. Ao serem resolvidos os conflitos, cada pixel da imagem reterá apenas o rótulo do segmento correspondente à classe com maior pertinência.

É importante notar que este método de resolução dos conflitos espaciais pressupõe que os valores de pertinência gerados pelos classificadores sejam comparáveis. A Figura 16 ilustra o procedimento.

Considere-se, por exemplo, um problema envolvendo apenas duas classes, denotadas por A e B. Sejam $A_{i}$ e $B_{j}$ o i-ésimo segmento da segmentação ajustada para a classe A e o j-ésimo segmento da segmentação ajustadas a classe $B$, respectivamente. Sejam ainda $\mathrm{A}_{\mu_{i}}$ e $\mathrm{B}_{\mu_{j}}$ as pertinências de $\mathrm{A}_{i}$ e $\mathrm{B}_{j}$ respectivamente, às classes $\mathrm{A}$ e $\mathrm{B}$. Na intersecção de $\mathrm{A}_{i}$ e $\mathrm{B}_{j}$, há um conflito. Como $\mathrm{A}_{\mu_{i}}<\mathrm{B}_{\mu_{j}}$, $\mathrm{B}_{i}$ mantém a área de conflito, que é retirada de $\mathrm{A}_{j}$. As regiões de $\mathrm{A}_{i}$ e $\mathrm{B}_{j}$ fora da intersecção serão associadas a uma ou outra classe dependendo da aplicação do mesmo procedimento.
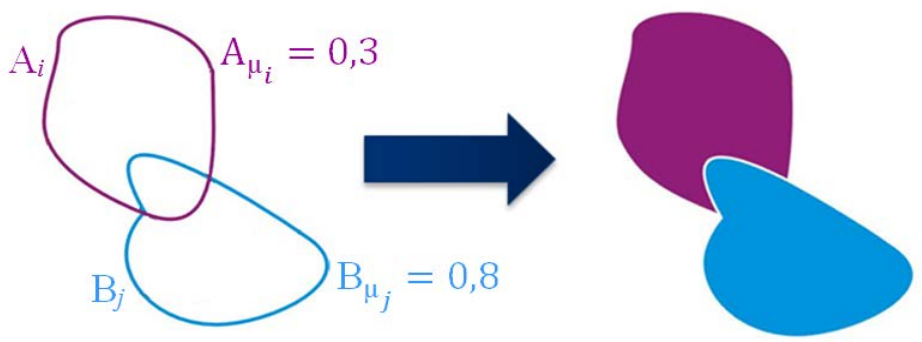

Figura 16 - Uso de pertinências para resolução de conflitos espaciais. 
Essa metodologia de segmentações específicas permite a possibilidade de se usar um algoritmo distinto de segmentação para cada classe de objeto, e com isso, aumentam-se as chances de um melhor delineamento dos objetos de imagem significativos.

Espera-se que esta metodologia implique em um aumento de exatidão em relação à que se baseia na segmentação hierárquica, tanto do ponto de vista temático quanto espacial.

Na Tabela 2, são apresentadas as principais diferenças entre as abordagens expostas.

Tabela 2 - Principais diferenças entre segmentação específica e hierárquica.

\begin{tabular}{|c|c|c|}
\hline & Específica & Hierárquica \\
\hline Objetos de mesma escala & $\begin{array}{l}\text { Segmentações específicas para } \\
\text { cada classe }\end{array}$ & $\begin{array}{l}\text { Uma única segmentação para } \\
\text { todas as classes }\end{array}$ \\
\hline Parâmetros de segmentação & $\begin{array}{l}\text { Otimizados para cada classe } \\
\text { de interesse }\end{array}$ & $\begin{array}{l}\text { Otimizados para o conjunto de } \\
\text { segmentos correspondentes a } \\
\text { um mesmo nível de } \\
\text { segmentação }\end{array}$ \\
\hline Conflitos espaciais & Existem & Não existem \\
\hline
\end{tabular}

\section{2}

\section{Etapas da metodologia de segmentação específica}

O esquema geral da metodologia proposta é apresentado na Figura 17. Para maior entendimento da metodologia, a descrição que se segue está dividida em cinco etapas, Ajuste dos Parâmetros de Segmentação, Segmentação, Cálculo de Atributos, Classificação e, por fim, Resolução de Conflitos Espaciais.

A primeira etapa consiste no ajuste de parâmetros dos segmentadores para cada classe de objetos de imagem significativos presentes na imagem. Em seguida, na segunda etapa, são geradas segmentações específicas para cada uma dessas classes. 
A terceira etapa consiste em extrair de cada segmento os atributos, espectrais ou morfológicos, que melhor discriminam as classes do problema. De posse desses atributos, a próxima etapa compreende a classificação dos segmentos. Finalmente, os conflitos espaciais entre segmentos, originários de todas as segmentações, são resolvidos usando os valores de pertinências às diferentes classes. As três etapas intermediárias são típicas do GEOBIA, a diferença é que elas são realizadas tantas vezes quantas forem as classes do problema. 


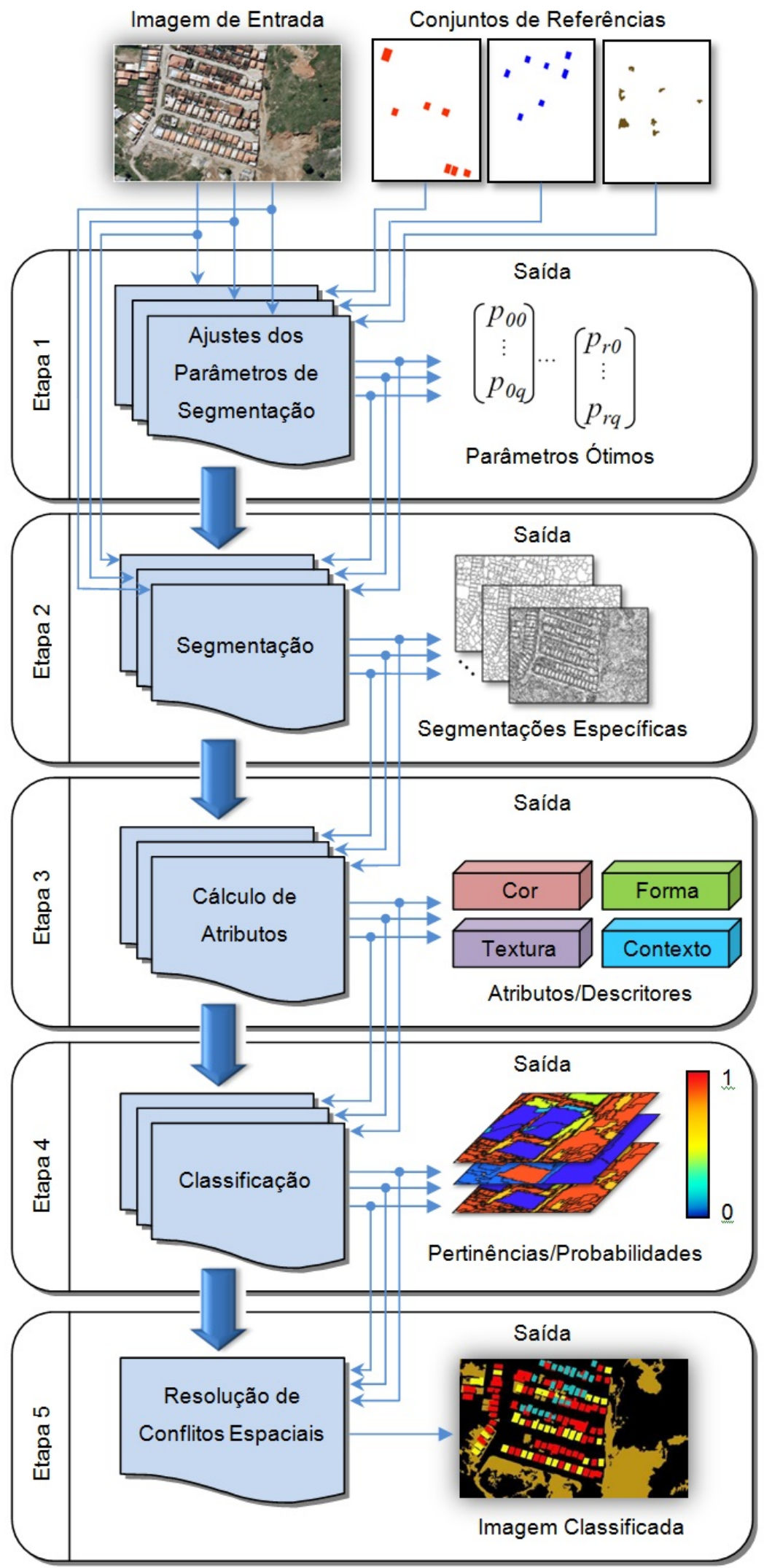

Figura 17 - Abordagem de segmentação específica. 


\subsection{1}

\section{Etapa 1 - Ajuste dos parâmetros de segmentação}

O que se procura nessa etapa é o conjunto de valores de parâmetros de segmentação que produza o resultado mais consistente com a referência produzida por um especialista. A relação entre os valores dos parâmetros de segmentação, com respeito a uma dada classe de objetos, e a qualidade da segmentação resultante não pode ser formulada analiticamente. Por isso, métodos baseados em cálculo numérico não podem ser aplicados no processo de busca dos valores ótimos. Métodos estocásticos de otimização constituem, neste caso, uma alternativa viável.

No processo de busca ótima, foi utilizado o método de busca direta GPS descrito na Seção 3.2.2.1. No GPS, cada ponto de busca é formado por um vetor que contém valores dos parâmetros do algoritmo de segmentação. A função de avaliação de cada ponto foi realizada pela métrica RBSB (Seção 3.2.2.2), que compara a segmentação produzida pelo algoritmo de segmentação e a segmentação de referência.

A Figura 18 ilustra o funcionamento do processo de busca ótima, em que cada ponto inicial (vetor de parâmetros de segmentação) é gerado randomicamente, respeitando o intervalo de valores permitidos para cada parâmetro, conforme definido pelo usuário.

O processo de otimização termina quando o limiar do tamanho do mesh é atingido. Nesse ponto, os valores do ponto corrente são definidos como os parâmetros finais (otimizados) do método de segmentação.

A metodologia prevê que para cada classe de interesse presente na imagem, teremos um conjunto de segmentos de referência associado, e igualmente uma segmentação específica, contemplando os objetos presentes nessas classes.

Para reduzir o custo computacional da procura pelos parâmetros ótimos de segmentação, o algoritmo GPS foi utilizado em um mosaico formado com recortes da imagem; dessa forma, também é possível verificar se os parâmetros otimizados para o mosaico podem ser extrapolados para a imagem (vide Figura 19). 


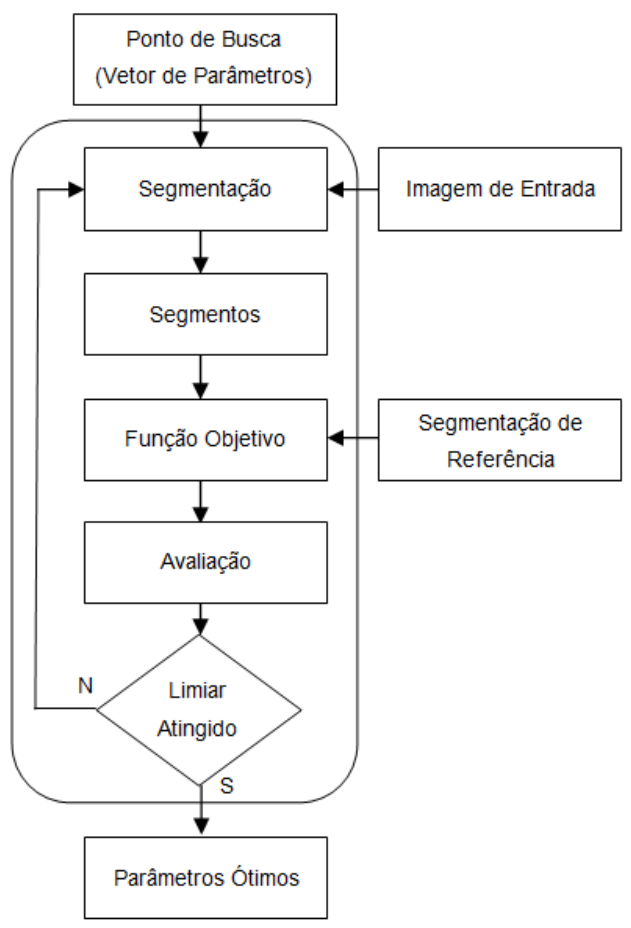

Figura 18 - Avaliação dos parâmetros de segmentação.

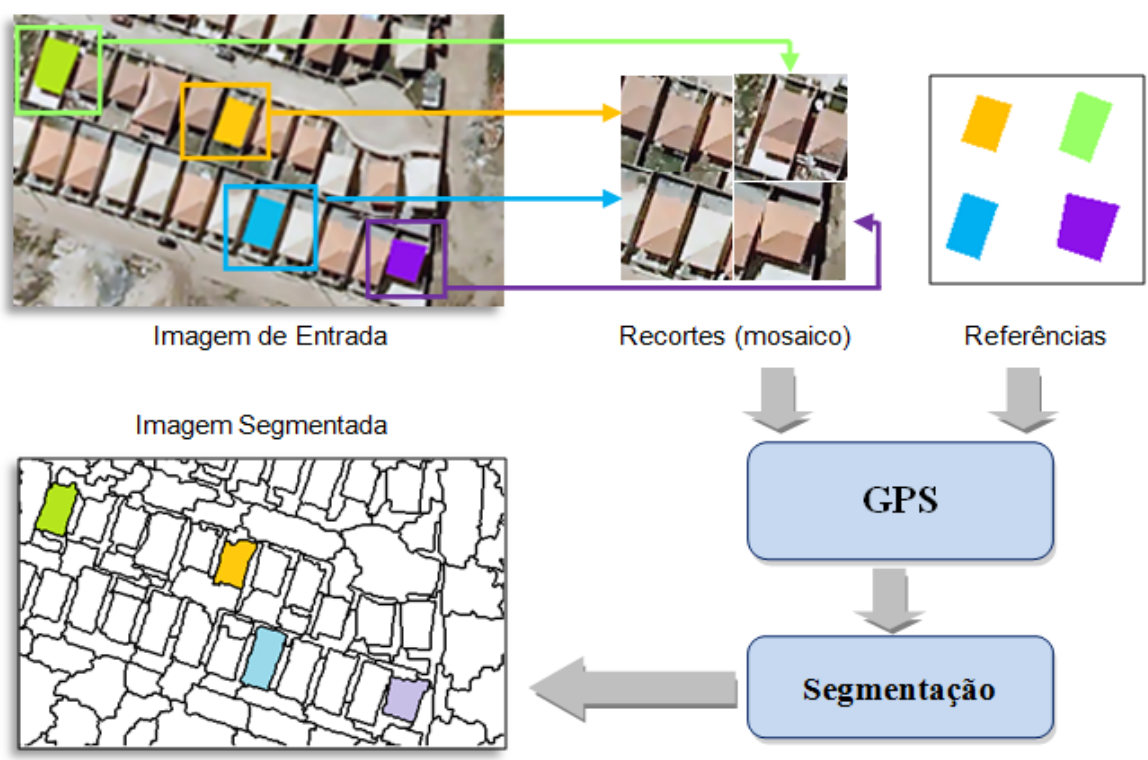

Figura 19 - Uso de recortes da imagem para o processo de busca de parâmetros ótimos de segmentação com o GPS. 


\subsection{2}

\section{Etapa 2 - Segmentação}

Essa etapa compreende segmentações específicas para cada classe de objetos de interesse na imagem, com a utilização dos parâmetros ótimos dos segmentadores obtidos pelo GPS, na etapa anterior. Os parâmetros do algoritmo de segmentação devem ser devidamente sintonizados com as classes desses objetos. A Figura 20 ilustra esse procedimento.

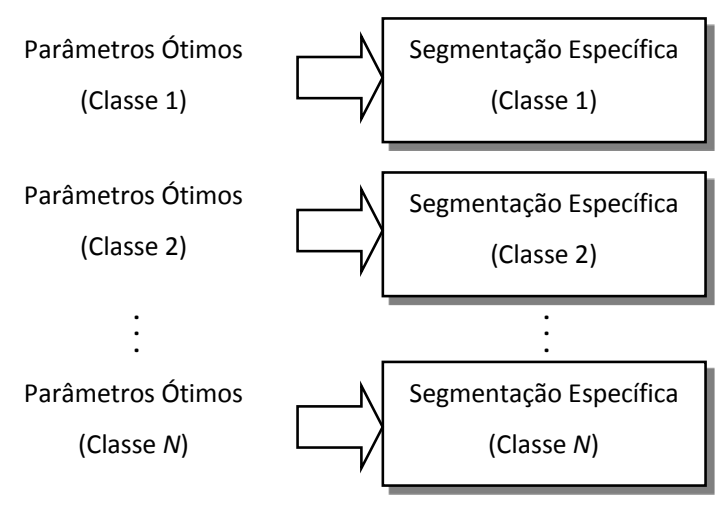

Figura 20 - Esquema de segmentação específica.

\subsection{3}

\section{Etapa 3 - Cálculo de atributos}

Essa etapa é responsável pela mensuração dos atributos dos objetos de imagem, extraindo informações úteis, de modo a evidenciar as diferenças e similaridades. Para isso, além das propriedades espectrais, podem ser utilizados numerosos atributos (descritores), associados à forma, textura, relações contextuais e semânticas, entre outros.

De acordo com as classes de objetos a serem reconhecidas, diferentes conjuntos de atributos podem ser utilizados. A escolha desses conjuntos é uma tarefa que encontra certa dificuldade na solução de um problema específico, pois se escolhido os atributos a se extrair incorretamente, por exemplo, por serem redundantes e fornecerem poucas informações para diferenciar os segmentos entre si, certamente o algoritmo classificador, por melhor desempenho que tiver, não conseguirá definir as classes corretamente. 
Técnicas de seleção de atributos visam eliminar da base de treinamento atributos que não contribuem ou mesmo prejudicam o desempenho das estratégias de classificação (Liu e Motoda, 2008).

Neste trabalho foi utilizado, para redução da dimensionalidade do conjunto de atributos, o algoritmo de seleção CFS (Correlation-based Feature Selection, vide Seção 3.3). Segundo (Hall, 1999), que efetuou experimentos com imagens naturais, o algoritmo CFS obteve um bom desempenho nos experimentos por ele realizados. Na maioria dos casos, a precisão da classificação usando um conjunto reduzido selecionado por esse algoritmo obteve resultados iguais ou superiores à utilização do conjunto completo de atributos.

\subsection{4}

\section{Etapa 4 - Classificação}

Nesta etapa, tem-se um classificador para cada classe de interesse e, por conseguinte, para cada segmentação. Os classificadores são treinados para identificar os segmentos de uma determinada classe, atribuindo uma probabilidade a cada segmento. No treinamento dos classificadores, os objetos de imagem devem ter as características mais representativas de suas respectivas classes.

Em princípio, qualquer tipo de arquitetura de classificação pode ser utilizada nesta abordagem, a única restrição é que os classificadores gerem em suas saídas pertinências ou probabilidades referentes aos objetos classificados.

\subsection{5}

\section{Etapa 5 - Resolução dos conflitos espaciais}

De posse de todas as probabilidades dos segmentos oriundos das diversas segmentações realizadas, a construção do mapa temático final é feita atribuindo simplesmente a cada pixel a classe correspondente à maior probabilidade.

Outra forma de visualizar o resultado dos conflitos espaciais é através das matrizes de classificação de cada classificador, cujos pixels possuem a mesma pertinência dos objetos. A matriz de imagem resultante é então formada pela aplicação da equação 28 (ver Figura 31): 


$$
\omega_{k}=\operatorname{argmax}_{\omega_{j}}\left(p_{i, \omega_{j}}\right),
$$

em que,

$\omega_{k}=$ rótulo do pixel $i$ na imagem classificada;

$p_{i, \omega_{j}}=$ probabilidade da classe $\omega_{j}$ para o pixel $i$ da imagem;

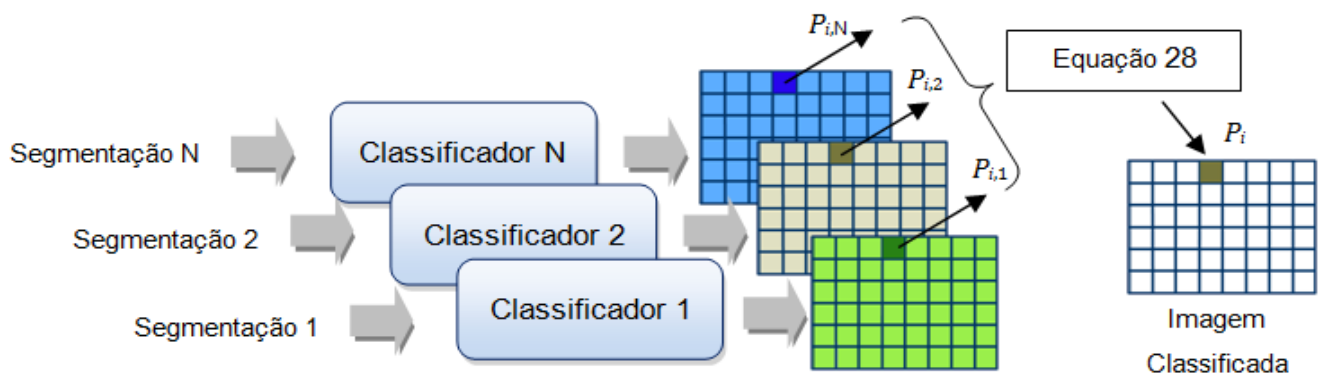

Figura 21 - Resolução de conflitos espaciais. 


\section{5}

\section{Implementação e análise experimental}

Este capítulo apresenta a avaliação experimental da metodologia proposta neste trabalho quanto à segmentação e classificação de imagens em comparação com o método de segmentação hierárquica. A Seção 5.1 apresenta a base de dados utilizada. Na Seção 5.2, são definidas as formas de avaliação dos resultados. A Seção 5.3 traz detalhes a respeito dos procedimentos metodológicos adotados na avaliação experimental e a organização dos experimentos realizados. A Seção 5.4 apresenta os experimentos realizados, agrupados pelas imagens da base de dados. Finalmente, a Seção 5.5 faz uma análise dos resultados obtidos.

\section{1}

\section{Base de dados}

Os experimentos para avaliação do método proposto foram realizados com a utilização de três imagens de sensoriamento remoto. A primeira imagem (Img1), mostrada na Figura 22(a), se refere a um recorte de uma região do município de Maragogipe no estado da Bahia, Brasil. A imagem foi capturada em novembro de 2010, através de um levantamento aerofotogramétrico com resolução de 0,6 m, bandas vermelho, verde e azul, possuindo dimensão de $1500 \times 768$ pixels (coordenadas Norte/Leste -38.937777/-12.710833 Sul/Oeste -38.935833/12.711944, projeção UTM-SAD69). A imagem de referência (Ref1) é mostrada na Figura 22(b), contendo as classes Barcos, Telhados e Vegetação. 


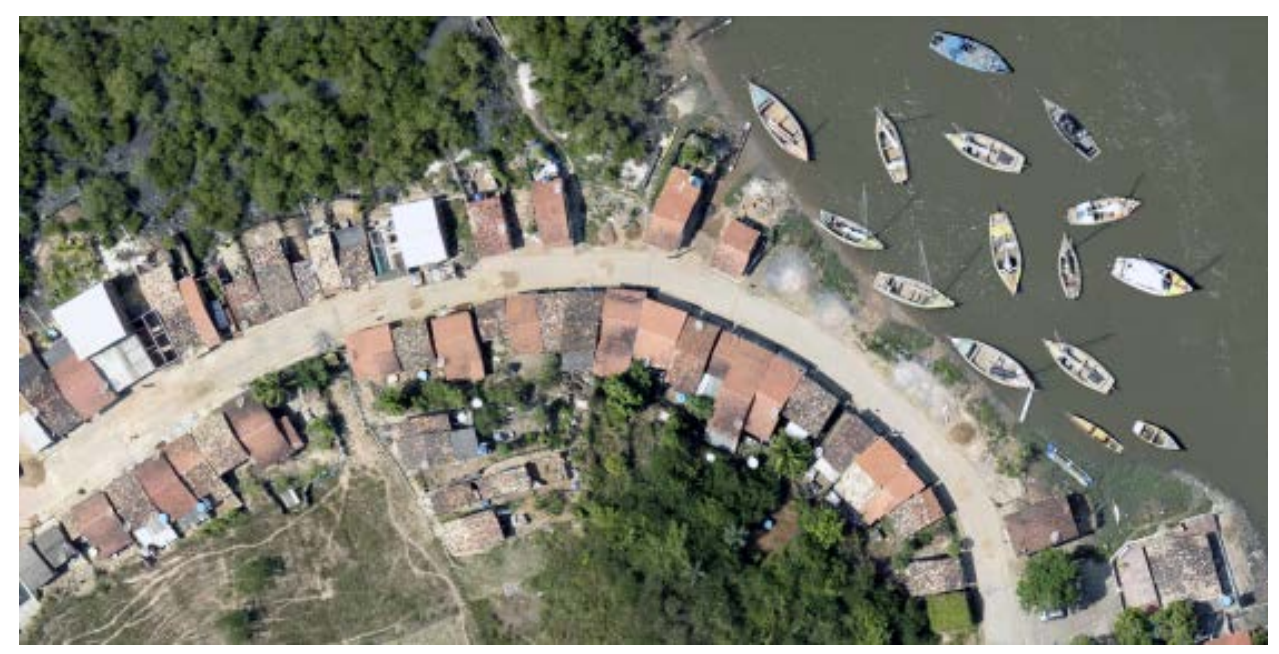

(a)

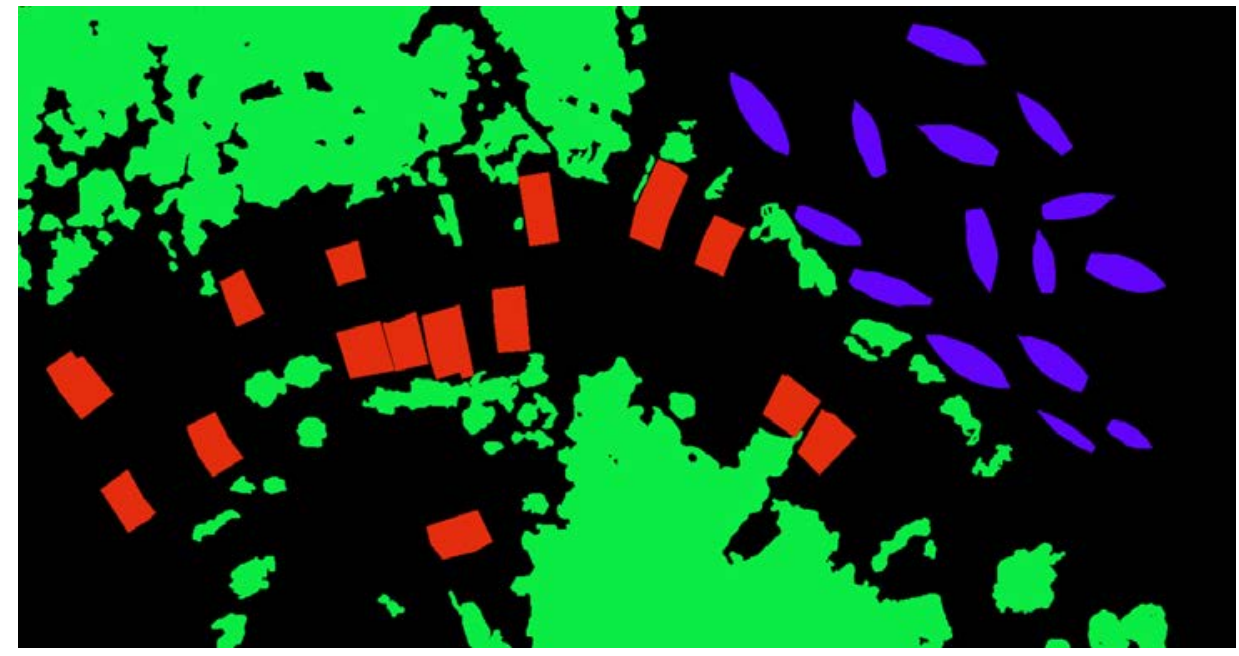

(b)

\section{Telhados $\square$ Barcos $\square$ Vegetação}

Figura 22 - Imagem do município de Maragogipe - Img1 (a), referência - Ref1 (b).

A segunda imagem selecionada (Img2), mostrada na Figura 23(a), se refere a um recorte da Refinaria de Duque de Caxias (REDUC), localizada no município de Duque de Caxias, no estado do Rio de Janeiro, Brasil. A imagem foi capturada em 7 de janeiro de 2012 pelo sensor WorldView-2, com resolução de 0,5m após a fusão com a banda pancromática, bandas vermelho, verde, azul e infravermelho próximo, possuindo dimensão de 4668×2397 pixels (coordenadas Norte/Leste -22.715420/-43.284727 Sul/Oeste -22.725583/-43.262229, projeção UTM-WGS84). A imagem de referência (Ref2) é mostrada na Figura 23(b), contendo as classes Tanque1, Tanque2, Predios1, Predios2 e Solo. 


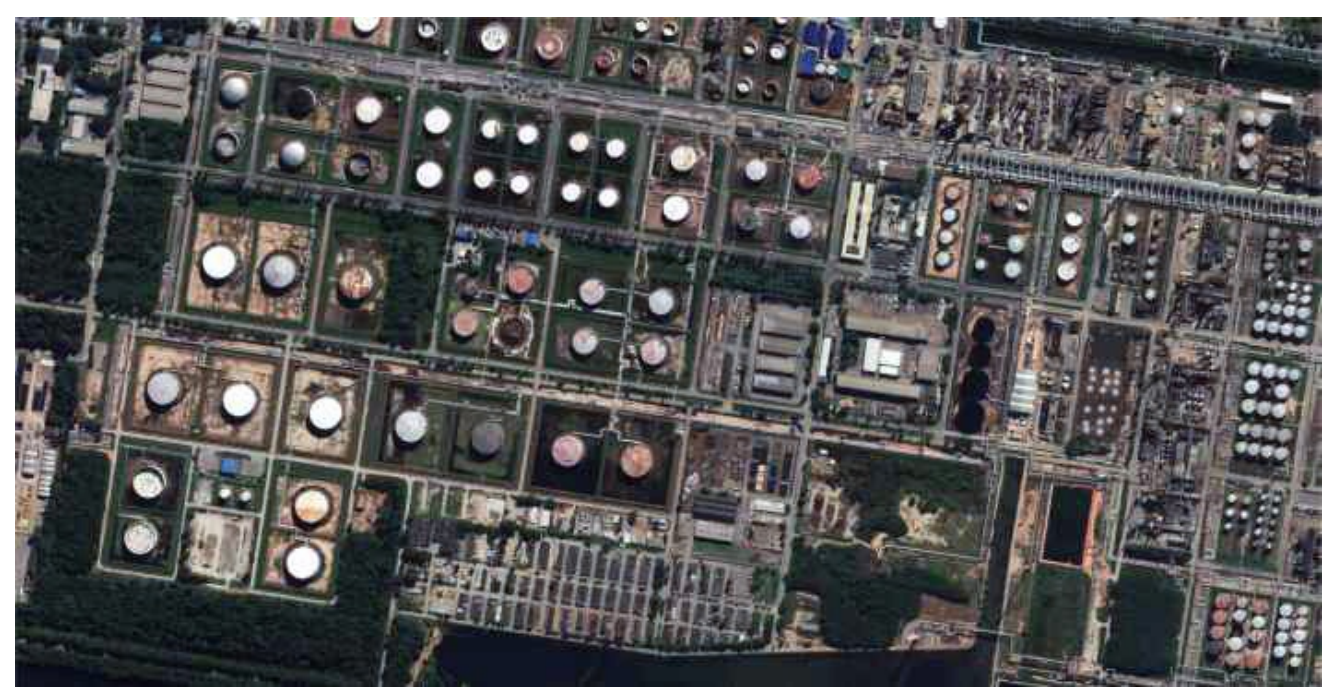

(a)

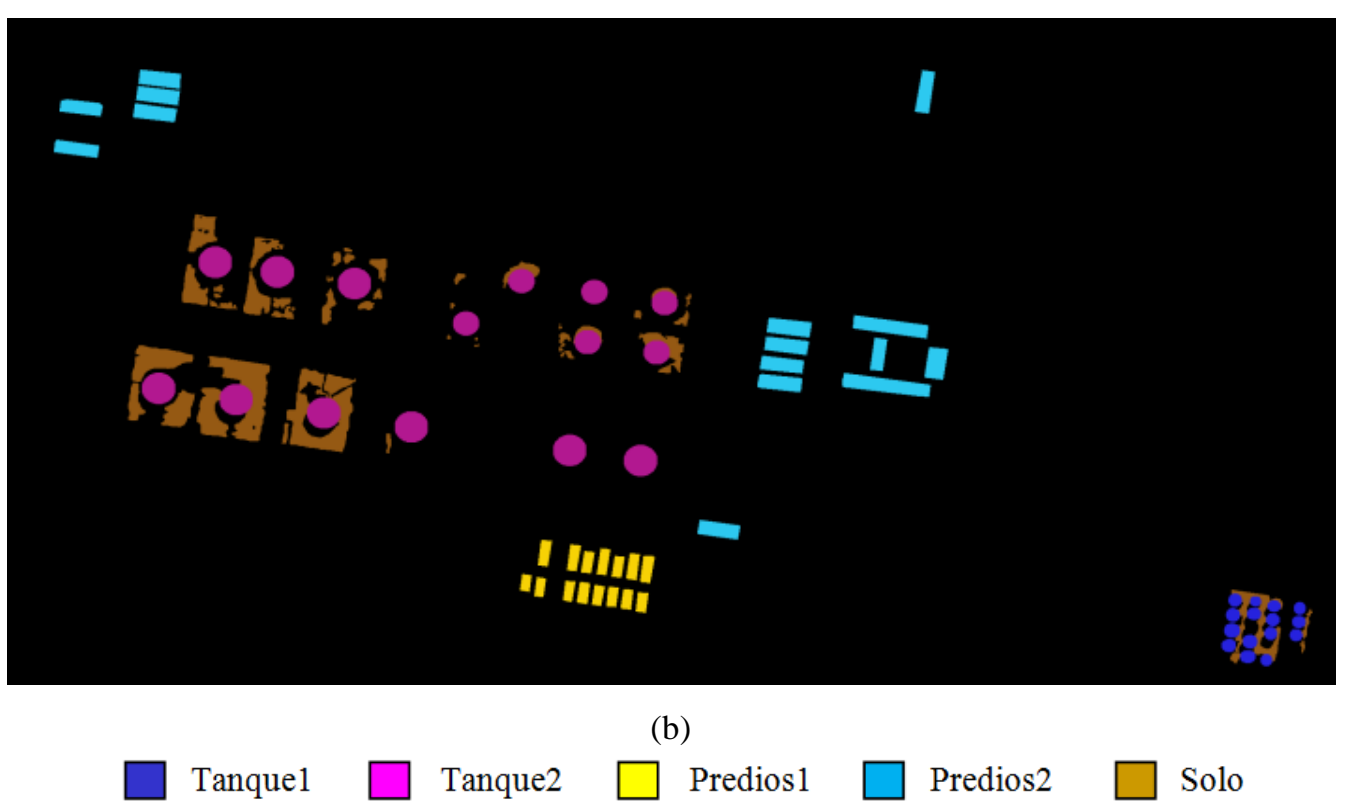

Figura 23 - Imagem da REDUC - Img2 (a), referência - Ref2 (b).

A terceira imagem selecionada (Img3), Figura 24(a), refere-se a um recorte de uma área próxima ao Aeroporto de Congonhas, localizada no centro da Cidade de São Paulo, no Estado de São Paulo, Brasil. A imagem foi capturada em 29 de fevereiro de 2012 pelo sensor WorldView-2, com resolução de 0,5m, após a fusão com a banda pancromática, bandas vermelho, verde, azul, possuindo dimensão de $1829 \times 1444$ pixels (coordenadas Norte/Leste -23.623850/-46.666310 Sul/Oeste 23.630420/-46657007, projeção UTM-WGS84). A imagem de referência (Ref3) é mostrada na Figura 24(b), contendo as classes Aviões, Telhados e Solo. 


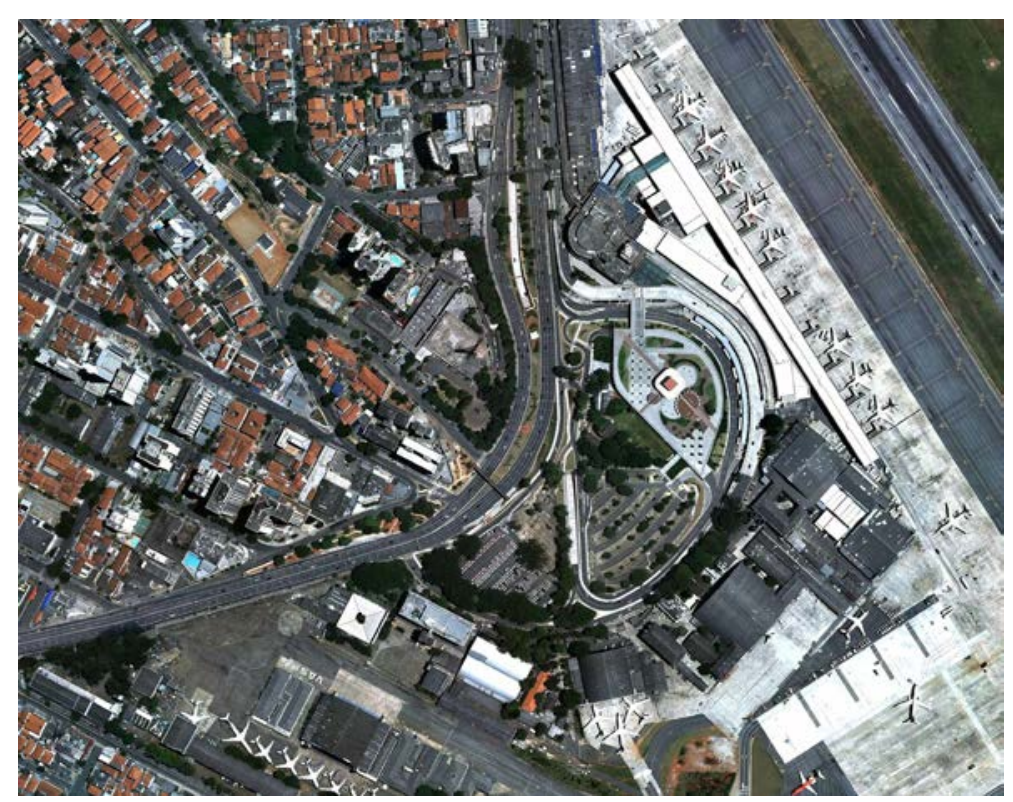

(a)

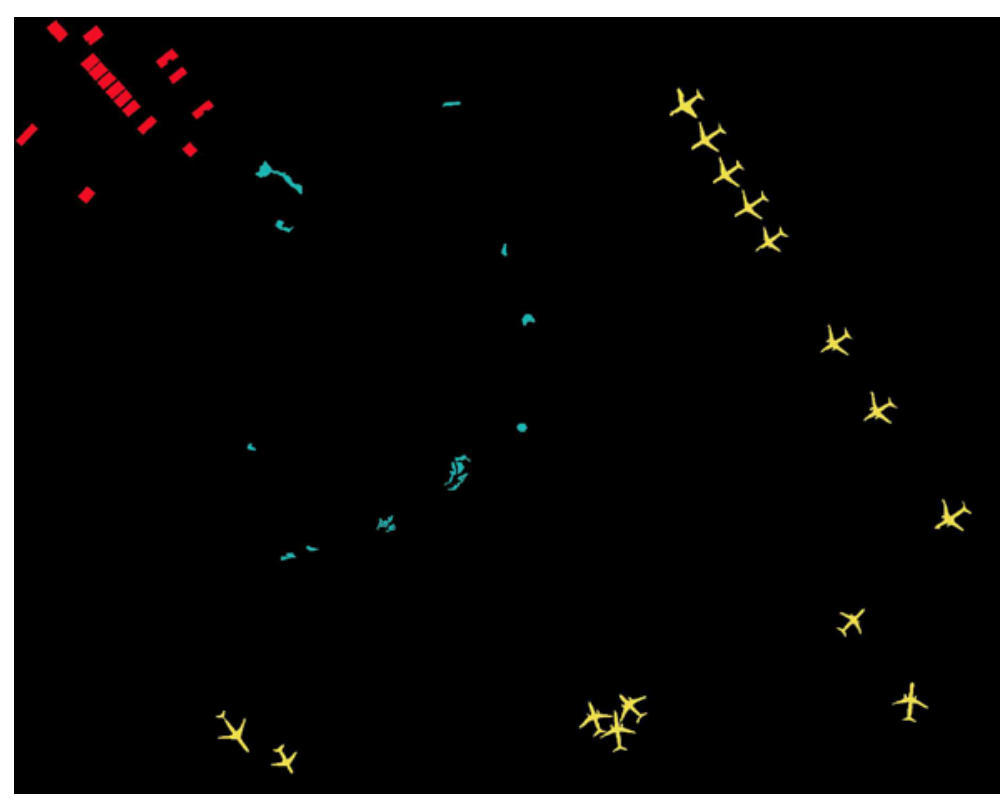

(b)

Telhados

Aviões

Solo

Figura 24 - Imagem de Congonhas - Img3 (a), referência - Ref3 (b).

\section{2}

\section{Formas de avaliação dos resultados}

A avaliação que se segue tem duas abordagens. A primeira refere-se à exatidão espacial, por intermédio da medida de discrepância RBSB apresentada na Seção 3.2.1. 
A segunda forma de avaliação diz respeito à exatidão temática e é baseada na análise dos elementos derivados da matriz de confusão da classificação. A maioria dos métodos quantitativos utiliza a matriz de confusão derivada dos conjuntos de dados de classificação e referência como ponto inicial das medidas de exatidão. A matriz de confusão permite o cálculo de medidas específicas, tais como a exatidão global e coeficiente Kappa (vide Apêndice C). A exatidão global é uma das medidas mais simples, sendo calculada pela soma do total dos pixels corretamente classificados dividida pelo número total de pixels da matriz de confusão. O coeficiente Kappa, introduzido por Cohen (1960), é uma medida largamente utilizada da exatidão em vários estudos de classificação de imagens de sensoriamento remoto (Congalton, 1991; Congalton and Green, 2008, Foody, 2009). Este coeficiente mede o grau de concordância além do que seria esperado tão somente pelo acaso. Esta medida de concordância tem como valor máximo 1, que representa total concordância e os valores próximos e até abaixo de 0 , que indicam pouca concordância, ou concordância gerada pelo acaso.

Nesse trabalho, as medidas de exatidão foram obtidas de forma a apresentar os resultados da classificação em pixels e objetos.

Para os resultados em pixels, os elementos da matriz de confusão resultante da classificação, são os próprios pixels das amostras que foram correta e incorretamente classificadas. Na análise da acurácia por objeto, o que se analisa na matriz de confusão são os segmentos relacionados às classes dos objetos classificados, sendo que, para um segmento ser considerado como uma instância de uma classe é necessário que ele tenha no mínimo 10\% da área (em pixels) do objeto correspondente.

\section{3}

\section{Procedimento experimental}

Os experimentos realizados em cada imagem da base de dados foram desenvolvidos ao longo das cinco etapas discutidas na Seção 4.2, que são: ajuste dos parâmetros de segmentação, segmentação, extração de atributos, classificação e resolução de conflitos espaciais, sendo posteriormente agrupados os resultados das etapas de segmentação e classificação em uma análise comparativa das abordagens de segmentação específica e hierárquica top-down e bottom-up. 
A Figura 25(a) mostra como é feita a comparação entre as etapas de segmentação e classificação, em que pode ser observado que as diferentes abordagens foram comparadas (para ambas as etapas) com a utilização de métricas distintas, ou seja, uso da métrica RBSB para medir a acurácia da segmentação e o coeficiente Kappa e a exatidão global para a análise temática.

Neste estudo, três algoritmos de segmentação de imagens e três classificadores diferentes foram utilizados, de modo a se comparar a generalidade da metodologia proposta.

Os segmentadores utilizados foram definidos na Seção 3.1, e os classificadores na Seção 3.4, ambos mostrados na Tabela 3.

Na Figura 25(b), é apresentada a configuração utilizada para a realização dos experimentos, mostrados de forma detalhada a utilização dos segmentadores e classificadores em cada uma das abordagens. Deve ser observado que em cada experimento somente uma combinação segmentador-classificador foi utilizada de cada vez, ou seja, para um dado experimento somente um algoritmo de segmentação e um modelo de classificador são utilizados simultaneamente para todas as classes presentes na imagem.

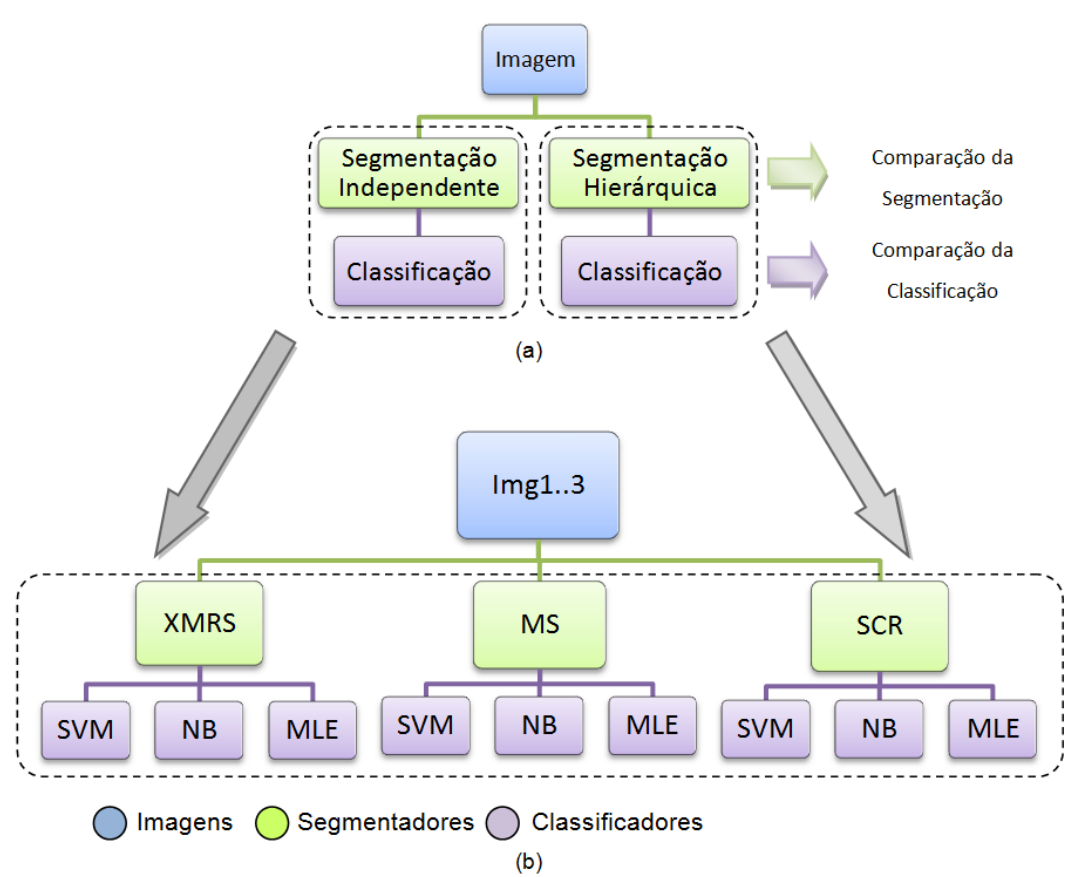

Figura 25 - Etapas de segmentação e classificação (a), detalhes mostrando o uso dos diferentes segmentadores e classificadores utilizados (b). 
Tabela 3 - Segmentadores e classificadores utilizados.

\begin{tabular}{ll|l}
\hline \multicolumn{2}{c|}{ Segmentadores } & \multicolumn{1}{c}{ Classificadores } \\
\hline - Multiresolução Estendido (XMRS) & $\bullet \quad$ Máquinas de Vetor de Suporte (SVM) \\
- Mean Shift (MS) & $\bullet \quad$ Naive Bayes (NB) \\
- Spring-Crescimento de Regiões (SCR) & $\bullet \quad$ Máxima Verossimilhança (MLE) \\
\hline
\end{tabular}

\subsection{1}

\section{Etapa 1 - Ajuste dos parâmetros de segmentação}

Para cada classe de objetos de interesse, presentes nas imagens da base de dados, foram delineados conjuntos de referência como entrada para o método de busca direta GPS, para a determinação automática dos valores ótimos dos parâmetros de segmentação. Esse procedimento foi realizado tanto para a metodologia de segmentação especifica quanto para a abordagem hierárquica topdown e bottom-up.

Para a metodologia de segmentação específica não existem restrições de fronteiras entre as diversas segmentações realizadas para cada classe, por isso, os parâmetros ótimos de segmentação foram obtidos de forma independente com a utilização das respectivas referências das classes, de acordo com os procedimentos mostrados na Seção 4.2.1. O procedimento para a abordagem hierárquica, que deve obedecer as restrições de fronteira entre os diferentes níveis de segmentações, foi realizado conforme mostrado na Figura 26, em que para cada nível de segmentação, correspondentes as diferentes escalas, são encontrados os respectivos parâmetros ótimos do algoritmo de segmentação. Para a abordagem top-down, Figura 26(a), foram primeiramente encontrados os parâmetros referentes aos objetos de maior escala (nível 1) e posteriormente os parâmetros das escalas subsequentes. A abordagem bottom-up, Figura 26(b), segue o caminho inverso, em que o nível 1 corresponde as referências dos objetos de menor escala, seguindo até o nível de escalas superiores (maiores). 


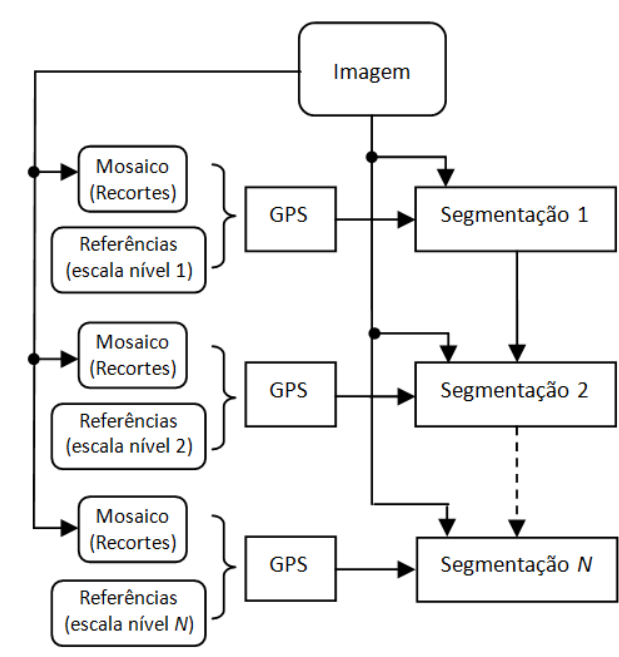

(a)

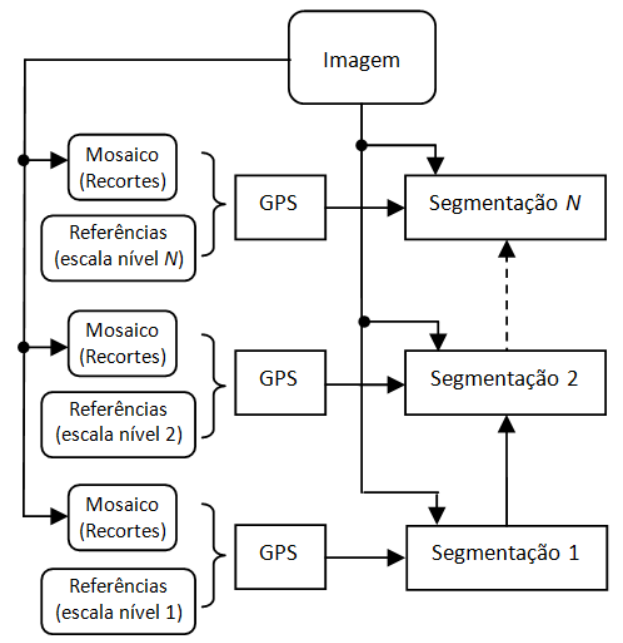

(b)

Figura 26 - Esquema de busca dos parâmetros ótimos de segmentação para a abordagem hierárquica top-down (a) e bottom-up(b).

\subsubsection{1}

\section{Preparação da base de dados}

Os conjuntos de referência, delineados para cada classe de objetos presentes nas imagens utilizadas nos experimentos, Img1, Img2 e Img3, mostradas nas Figuras 22(a), 23(a) e 24(a), foram particionados em três conjuntos de treinamento e três conjuntos de teste para cada classe de objetos pertencentes às imagens. Os objetos pertinentes a cada conjunto foram selecionados de forma aleatória, tendo-se por base na sua seleção às referências de cada imagem (Ref1, Ref2 e Ref3), mostradas nas Figuras 22(b), 23(b) e 24(b). Para cada partição, foram utilizadas 2/3 das referências para treinamento e 1/3 para teste.

Os conjuntos de treinamento foram utilizados para obtenção dos parâmetros ótimos para os segmentadores, com o uso do GPS, e os respectivos conjuntos de teste foram utilizados para aferir a acurácia espacial das segmentações efetuadas na etapa seguinte de segmentação.

Assim, cada classe de objeto de imagem de cada uma das imagens da base de dados terá três partições de dados formadas pelos três conjuntos de treinamento e três conjuntos de teste conforme ilustrado na Figura 27(a). 


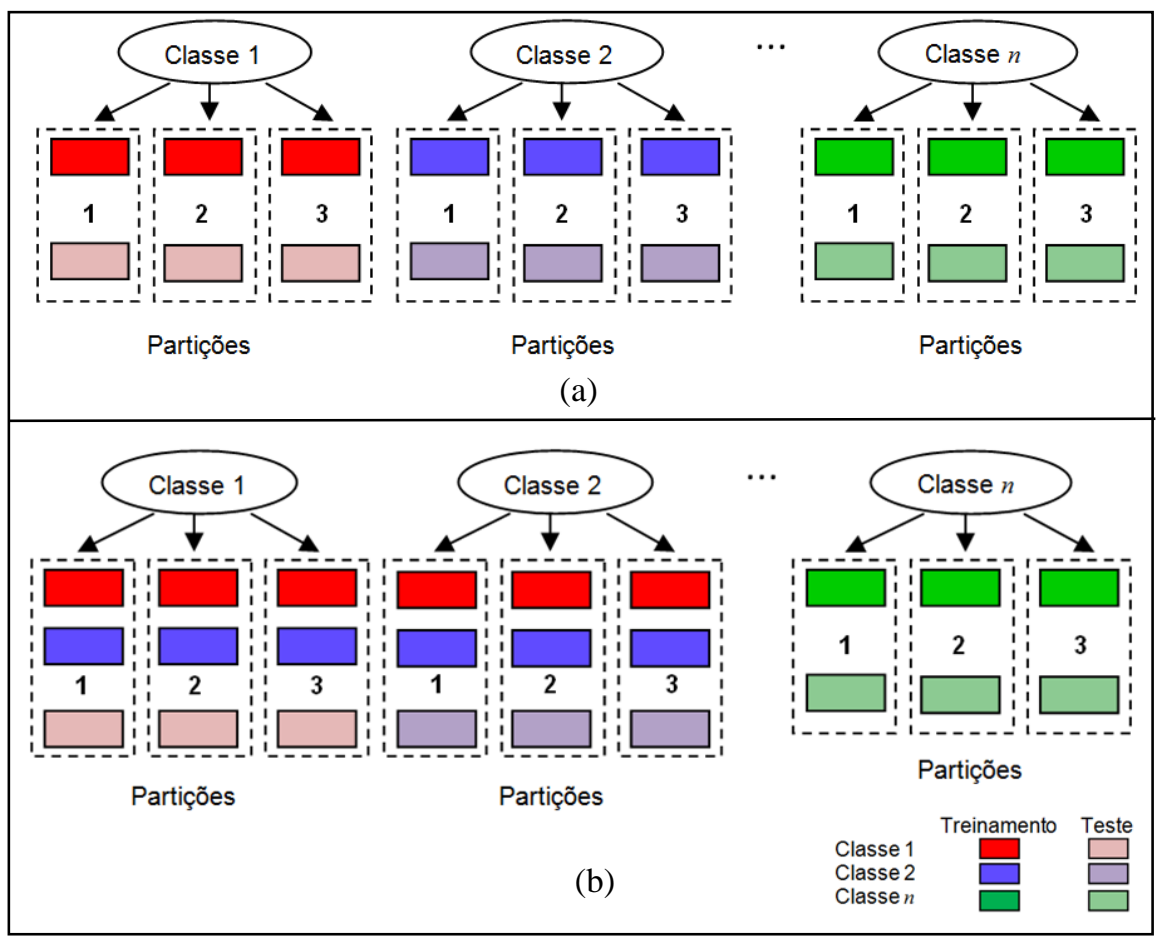

Figura 27 - Divisão do conjunto de dados em partições para a metodologia de segmentação específica (a) e hierárquica (b).

De acordo com o paradigma de segmentação hierárquica (vide Seção 2.2), classes de objetos de imagem de mesma escala devem estar em um mesmo nível de segmentação, por isso os parâmetros ótimos de segmentação devem ser ajustados simultaneamente para essas classes. Assim, os conjuntos de treinamento, que foram utilizados para o ajuste de parâmetros com o GPS para essas classes, foram formados a partir da fusão dos conjuntos de treinamento de todas as classes de mesma escala, respeitando-se as partições definidas anteriormente. A Figura 27(b) ilustra o que foi descrito para duas classes de objetos de mesma escala (classes 1 e 2), que possuem dessa forma o mesmo conjunto de treinamento, porém conjuntos de teste distintos.

\subsubsection{2}

\section{Utilização do GPS}

A Tabela 4 mostra os parâmetros dos segmentadores que foram determinados pelo GPS.

A escolha do par de atributos morfológicos utilizados no processo de segmentação, para o segmentador multiresolução estendido (XMRS), foi realizada 
de forma automática. O atributo suavidade foi combinado com todos os outros atributos apresentados na Tabela 1. Para cada par de atributos, foram obtidos pelo GPS os parâmetros de segmentação correspondentes. O par de atributos utilizados em cada uma das abordagens foi aquele que obteve o menor índice RBSB para a segmentação (vide Anexo A). Os parâmetros pesos das bandas $\left(w_{c}\right)$ (vide Seção 3.1) foram fixados em 1 em todos os experimentos realizados.

Tabela 4 - Parâmetros de Segmentação determinados pelo GPS para cada segmentador.

\begin{tabular}{c|ll}
\hline Segmentador & \multicolumn{1}{c}{ Parâmetros } \\
\hline Multiresolução Estendido & $\bullet$ & parâmetro de escala $\left(p_{e}\right)$ \\
(XRMS) & $\bullet$ & peso da forma $\left(w_{f o r m a}\right)$ \\
& $\bullet$ & peso do atributo de forma $\left(w_{s}\right)$ \\
\hline Mean shift & $\bullet$ & largura de banda espacial $\left(h_{s}\right)$ \\
(MS) & $\bullet$ & largura de banda de cor $\left(h_{r}\right)$ \\
& $\bullet$ & área mínima de segmentação $\left(A_{\text {min }}\right)$ \\
\hline $\begin{array}{c}\text { Spring-crescimento de regiões } \\
\text { (SCR) }\end{array}$ & $\bullet$ & limiar de similaridade $\left(L_{s}\right)$ \\
\hline
\end{tabular}

Neste trabalho, o GPS foi configurado da seguinte maneira:

- Método de busca: MADS Base Positiva 2N

- Método de seleção: Base Positiva 2N

- Expansão do tamanho do mesh: 2

- Contração do tamanho do mesh: 0,5

- Limiar do tamanho do mesh: $10^{-3}$

- Padrão de busca: hipercubo latino (Latin Hypercube Search - LHS) (vide Apêndice C)

Esta configuração foi escolhida com base no trabalho realizado por Happ et al. (2012), que comparou alguns métodos de otimização para obtenção de parâmetros de segmentação em imagens de sensoriamento remoto. 


\section{3 .2}

\section{Etapa 2 - Segmentação}

Após a obtenção dos parâmetros ótimos dos segmentadores dados pelo GPS, a segmentação das imagens foi realizada em duas fases, a primeira consistiu de segmentações específicas para cada classe de objetos de imagem significativos contido nas imagens. A segunda foi realizada de acordo com o paradigma de segmentação hierárquica (vide Seção 2.2), onde as classes de objetos de imagem significativos de mesma escala (tamanhos parecidos) foram segmentados utilizando os mesmos parâmetros. O processo de segmentação hierárquica foi realizado nos experimentos para as duas variantes da abordagem de segmentação hierárquica (top-down e bottom-up).

Para a abordagem top-down o primeiro nível de segmentação corresponde aos objetos de maior escala (tamanho), a partir dessa segmentação os segmentos obtidos são enviados novamente ao algoritmo de segmentação, com a utilização de novos parâmetros de modo a se encontrar os objetos de nível inferior (menor escala), com isso preservando as fronteiras entre as diversas segmentações. Esse ambiente foi implementado dentro do software Matlab (Mathworks, 2012).

A abordagem bottom-up começa a partir de uma segmentação inicial, correspondente aos objetos de menor escala (tamanho), os segmentos resultantes foram novamente enviados ao algoritmo de segmentação, com parâmetros ajustados para a obtenção de objetos de maior escala. Esses segmentos formam as “sementes” iniciais utilizadas na nova segmentação, que irá mescla-los de acordo com os parâmetros de cada algoritmo de segmentação utilizado. Pode-se observar que, as fronteiras entre os segmentos entre os diferentes níveis de segmentação também foram respeitadas.

O fluxograma apresentado na Figura 28 ilustra de forma geral como foi feita a comparação da segmentação entre as diferentes abordagens. Portanto, para cada classe de objetos de imagem significativos e para cada algoritmo de segmentação, foram feitos três tipos de segmentações: específica; hierárquica topdown; e hierárquica bottom-up.

Finalmente, os resultados de todas as segmentações foram avaliados pela métrica RBSB, tendo como referência os objetos utilizados nos conjuntos de teste. 
Isso permite uma avaliação da eficiência e da generalidade da segmentação para cada classe de objetos de referência.

A Tabela 5 mostra a sequência dos procedimentos realizados.

O segmentador mean shift utilizado foi obtido da Orfeu Toolbox (OTB) (Inglada e Christophe, 2009), que consiste de um conjunto de algoritmos adaptados para imagens de sensoriamento remoto. O segmentador multiresolução estendido foi obtido em (XMRS, 2012), e o segmentador crescimento de regiões do SPRING, em sua versão 1.27, foi obtido do software InterImage (InterImage, 2012).

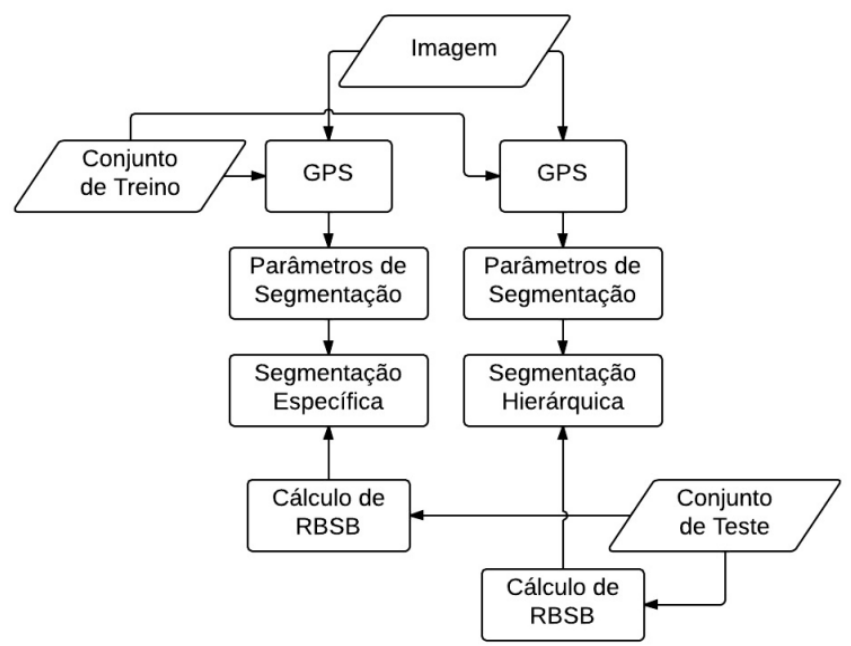

Figura 28 - Fluxograma da abordagem de testes utilizada no processo de segmentação. 
Tabela 5 - Sequencia de procedimentos para a etapa de segmentação.

\begin{tabular}{|c|c|c|}
\hline Passo & Procedimento & Detalhes \\
\hline 1. & Dada uma imagem I; & $\mathrm{I}=\{\operatorname{Img} 1, \operatorname{Img} 2, \operatorname{Img} 3\}$ \\
\hline 2. & $\begin{array}{l}\text { Para uma determinada classe C de I, selecionar N de } \\
\text { M objetos dessa classe; }\end{array}$ & $\mathrm{N}=$ conjunto de treinamento \\
\hline 3. & $\begin{array}{l}\text { Estimar os valores ótimos dos parâmetros dos } \\
\text { segmentadores com esses } \mathrm{N} \text { objetos; }\end{array}$ & $\begin{array}{l}\text { Segmentadores }=\{\text { XMRS, MS, } \\
\text { SCR }\}\end{array}$ \\
\hline 4. & $\begin{array}{l}\text { Medir o RBSB para cada classe presente em I; Para } \\
\text { a classe C, medir o RBSB separadamente para os } \mathrm{N} \\
\text { objetos usados no treinamento e os M-N objetos não } \\
\text { usados no treinamento; }\end{array}$ & $\mathrm{M}-\mathrm{N}=$ conjunto de teste \\
\hline 5. & $\begin{array}{l}\text { Repetir os passos de } 1 \text { a } 4 \text { trocando os objetos de } \\
\text { treinamento; }\end{array}$ & Validação cruzada com 3 rodadas \\
\hline 6. & $\begin{array}{l}\text { Repetir os passos } 1 \text { a } 5 \text { para cada uma das classes de } \\
\text { I; }\end{array}$ & \\
\hline 7. & $\begin{array}{l}\text { Repetir os passos de } 1 \text { a } 6 \text { selecionando-se outra } \\
\text { imagem; }\end{array}$ & \\
\hline 8. & $\begin{array}{l}\text { Realizar os passos de } 1 \text { a } 7 \text { para cada tipo de } \\
\text { segmentação; }\end{array}$ & $\begin{array}{l}\text { Tipo de segmentação = } \\
\text { \{específica, top-down, bottom- } \\
\text { up\} }\end{array}$ \\
\hline 9. & $\begin{array}{l}\text { Comparar os resultados obtidos em termos de } \\
\text { RBSB. }\end{array}$ & \\
\hline
\end{tabular}

\section{3 .3}

\section{Etapa 3 - Cálculo de atributos}

Após a realização de testes empíricos, na qual foram selecionadas várias amostras para diferentes classes e analisada a eficiência discriminatória de cada um dos modelos de cores RGB, HSV e YCbCr, o modelo de cor escolhido para este trabalho, que obteve o melhor resultado para a base de dados utilizada, foi o modelo YCbCr (vide Apêndice B).

Foram os seguintes os atributos escolhidos para descreverem os segmentos (vide Tabela 1): atributos espectrais: Componentes do modelo de cor YCbCr;

- atributos morfológicos: suavidade, compacidade, retangularidade, isometria, excentricidade, fator de estrutura, fator de forma circular e área. 
Para a base de dados Maragogipe, o atributo espectral índice NDVI (vide Apêndice B) também foi utilizado na seleção dos melhores atributos.

Os atributos espectrais e morfológicos de cada classe de objetos, para cada abordagem de segmentação, foram submetidos à técnica de seleção de atributos CFS (Seção 3.3), onde foram escolhidos os três atributos com maior poder discriminatório de cada classe e para cada abordagem.

A implementação do CFS utilizada neste trabalho é a oferecida pelo software Weka (Hall et al., 2009). O algoritmo foi configurado para que a busca no espaço de atributos fosse realizada com no máximo 30 níveis de backtracking. Ou seja, se durante a busca fossem encontrados 30 subconjuntos seguidos sem que houvesse uma melhora na métrica do CFS, a busca era terminada. A estratégia de busca heurística utilizada foi a best-first search - BFS.

Para cada subconjunto de atributos encontrado pelo CFS, foram utilizados os três melhores atributos discriminatórios para cada classe de objetos.

\subsubsection{1}

\section{Normalização}

Devido à diversidade de atributos, foi utilizada uma técnica de normalização que tem como propósito minimizar os problemas provenientes do uso de unidades distintas entre variáveis. Desta forma, os atributos foram escalonados para um intervalo específico [ $\left.\min ^{\prime}, \max ^{\prime}\right]$. A normalização adotada neste trabalho foi a indicada pela equação:

$$
y^{\prime}=\frac{\left(\max ^{\prime}-\min ^{\prime}\right)(y-\max (\mathrm{Y}))}{\max (\mathrm{Y})-\min (\mathrm{Y})}+\max ^{\prime},
$$

em que Y é conjunto dos valores encontrados para um atributo, $y$ é o valor encontrado deste atributo para um determinado caso, $y^{\prime}$ é o valor normalizado de $y, \min (\mathrm{Y})$ e $\max (\mathrm{Y})$ são, respectivamente, os valores mínimo e máximo de Y e min' e max' são os valores mínimo e máximo desejados, que no presente trabalho foram escolhidos, respectivamente, como -1 e +1 . 


\subsection{4}

\section{Etapa 4 - Classificação}

Para o treinamento e teste dos classificadores, foram utilizadas como referências na escolha dos segmentos, para cada classe de objetos, as partições de treinamento e teste da etapa de segmentação.

No processo de segmentação, pode ocorrer a fragmentação de objetos de imagem, gerando assim mais de um segmento correspondente a um único objeto de referência. Assim, somente os segmentos que possuíam no mínimo 40\% de sua área dentro dos objetos dos conjuntos de referência foram considerados válidos no processo de classificação. A Figura 29 mostra três exemplos de segmentos (A, B, C) que representam o objeto de referência $\mathrm{O}_{1}$, no qual A e B são considerados válidos e C não.

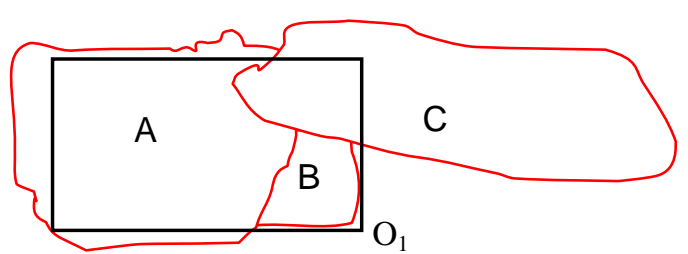

Figura 29 - Segmentos válidos (A e B) e não válido (C) para o objeto de referência $\mathrm{O}_{1}$.

A escolha do segmento representativo para cada objeto do conjunto de treinamento recaiu no segmento que possuía a maior área. Assim, de acordo com a Figura 29, se o objeto de referência $\mathrm{O}_{1}$ pertencer ao conjunto de treinamento, o segmento A seria escolhido como objeto de treinamento.

Todo o processo de classificação foi realizado de acordo com o modelo descrito na Seção 5.1, sendo utilizado um classificador para cada classe de objeto em todas as abordagens consideradas - específica, hierárquica top-down e hierárquica bottom-up.

Como para cada classe de objetos de uma imagem, ter-se-ão três segmentações distintas, uma para cada partição dos dados, conforme descrito na Seção 5.4.1.1. Para avaliar a capacidade de generalização do modelo a partir desse conjunto de dados, aplicou-se na etapa de classificação uma validação cruzada.

A Figura 30 ilustra o procedimento realizado. Os conjuntos de dados foram particionados em $3^{n}$ subconjuntos, em que $n$ é igual ao número de classes 
de interesse. Após a classificação, computaram-se a exatidão temática (índice Kappa e global) e espacial (RBSB). Ao final, as médias dessas medidas foram calculadas.

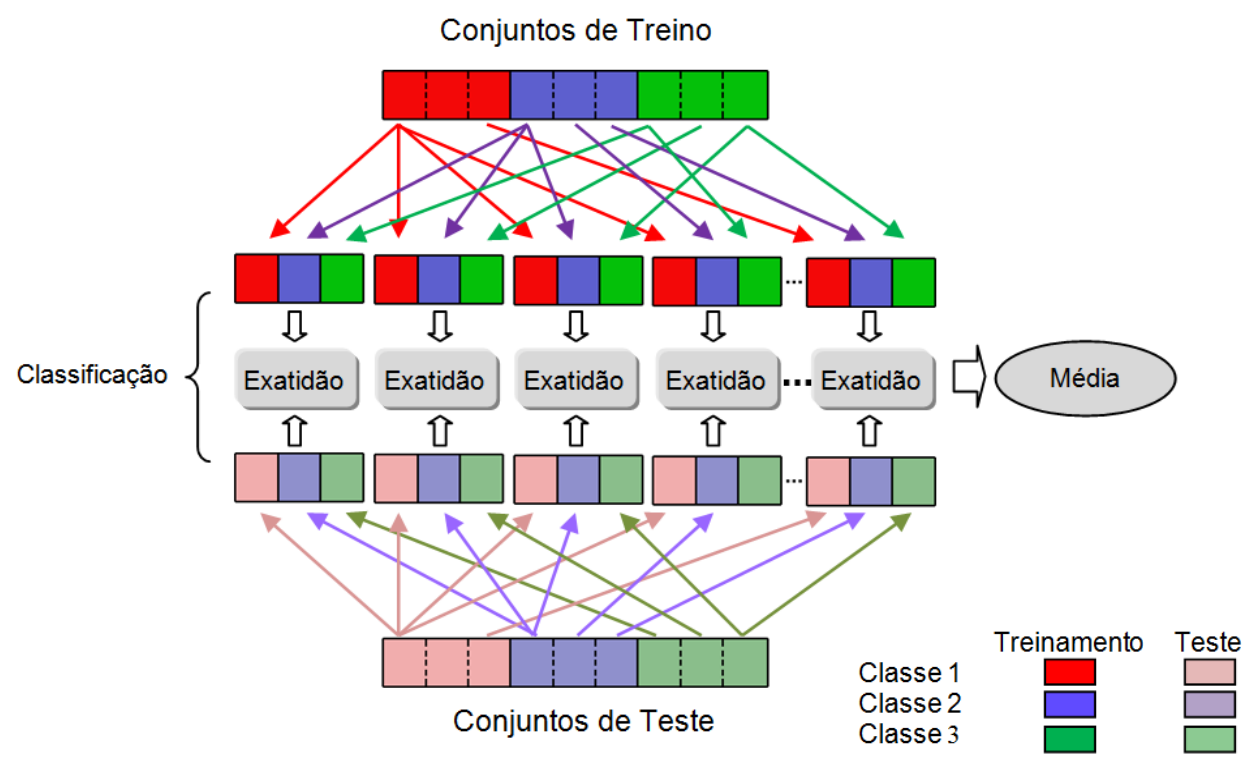

Figura 30 - Exemplo do esquema de validação cruzada dos dados, considerando três classes de interesse na imagem.

Os classificadores Naive Bayes e Máxima Verossimilhança foram implementados através do software Matlab (Mathworks, 2012), para o classificador SVM, foi utilizada a versão 3.16 para Matlab da biblioteca LIBSVM (Chang e Lin, 2001) em sua configuração one-against-all com saídas probabilísticas (vide Seção 3.4).

\subsection{5}

\section{Etapa 5 - Resolução dos conflitos espaciais}

De posse de todas as probabilidades dos segmentos oriundos das diversas segmentações realizadas, a construção do mapa temático final é feita atribuindo simplesmente a cada pixel a classe correspondente à maior probabilidade.

Outra forma de visualizar o resultado dos conflitos espaciais é através das matrizes de classificação de cada classificador, cujos pixels possuem a mesma pertinência dos objetos. A matriz de imagem resultante é então formada pela aplicação da equação 28 (ver Figura 31): 


$$
\omega_{k}=\operatorname{argmax}_{\omega_{j}}\left(p_{i, \omega_{j}}\right),
$$

em que,

$$
\begin{aligned}
& \omega_{k}=\text { rótulo do pixel } i \text { na imagem classificada; } \\
& p_{i, \omega_{j}}=\text { probabilidade da classe } \omega_{j} \text { para o pixel } i \text { da imagem; }
\end{aligned}
$$

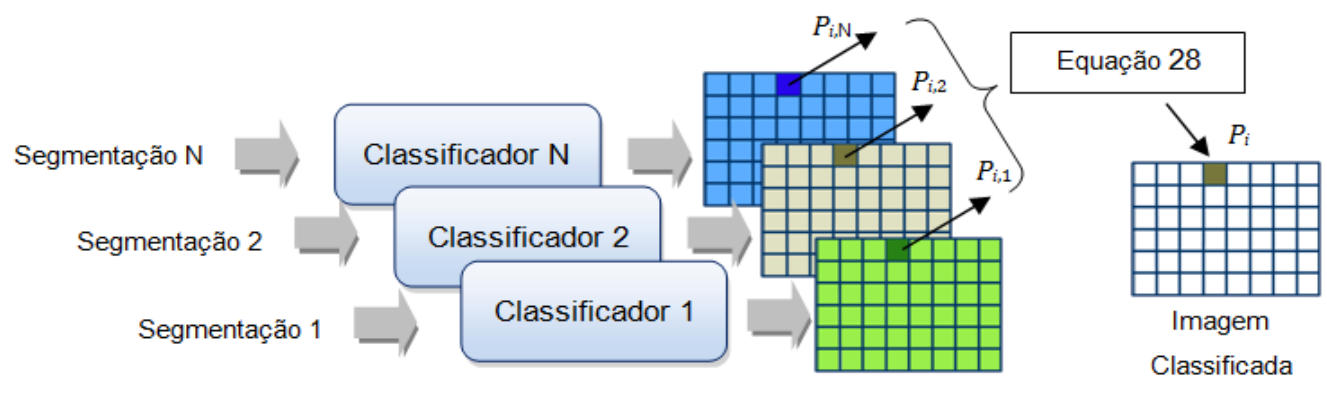

Figura 31 - Resolução de conflitos espaciais.

\subsection{6}

\section{Comparação de desempenho}

Os resultados da etapa de classificação foram tabulados separadamente para cada abordagem de segmentação. Para melhor avaliar as discrepâncias entre as classificações realizadas, aplicou-se um teste de hipótese com o objetivo de verificar se as exatidões obtidas a partir da metodologia proposta são significantemente melhores do que a abordagem hierárquica.

Nos resultados da classificação, cada valor de exatidão foi calculado como uma média de um procedimento de validação cruzada com $3^{n}$ partições. Para aplicar a análise do teste $t$-Student (vide equação 29), será considerado cada um dos resultados individuais em cada uma das partições.

A hipótese testada (vide equação 30) foi que a metodologia proposta apresenta exatidão igual ou inferior às abordagens alternativas, dentro de uma significância estatística de 95\%. Para cada uma das partições a que se refere a Figura 31, mediu-se a exatidão temática e espacial para a metodologia de segmentação específica, identificadas por $\mathrm{V}_{\mathrm{i}}$, versus a abordagem de segmentação hierárquica (top-down - TD e bottom-up - BU), identificadas por $\mathrm{V}_{\mathrm{h}}$, em que $\mathrm{h}$ pode ser TD ou BU.

Calculou-se também para cada caso: 
$\mathrm{Ci}$ = valor mínimo que $\mathrm{V}_{\mathrm{i}}$ excede $\mathrm{V}_{\mathrm{h}}$ (para exatidão temática, ou valor mínimo que $V_{h}$ excede $V_{i}$ (para exatidão espacial), com probabilidade igual ou inferior a 95\%;

p-valor $=$ probabilidade de que a exatidão do método proposto seja igual ou pior do que os métodos hierárquicos.

$$
\begin{aligned}
& \mathrm{t}=\frac{\bar{d}}{s_{\mathrm{d}} / \sqrt{\mathrm{k}}}, \\
& \text { H0: } d \leq 0, \\
& \text { H1: } d>0,
\end{aligned}
$$

em que:

$\mathrm{d}=\mathrm{V}_{\mathrm{i}}-\mathrm{V}_{\mathrm{h}}$ para exatidão temática e $\mathrm{d}=\mathrm{V}_{\mathrm{h}}-\mathrm{V}_{\mathrm{i}}$ para exatidão espacial;

$\bar{d}=$ média da diferença da amostra;

$s_{d}=$ desvio padrão da diferença da amostra;

$\mathrm{k}=3^{n}$, tamanho da amostra - sendo $n$ o número de classes;

Intervalo de confiança $=95 \%$.

\section{4}

\section{Experimentos realizados}

Na sequência deste capítulo, são apresentados os resultados de uma série de experimentos realizados nas imagens apresentadas na Seção 5.1, de acordo com o procedimento experimental descrito na Seção 5.3.

\section{4 .1}

\section{Exatidão espacial após a segmentação}

O objetivo deste experimento foi verificar a hipótese inicial enunciada no capítulo introdutório, ou seja, que a segmentação específica redunda em segmentos que delineiam mais propriamente as instâncias dos geobjetos.

O Apêndice A contém todas as imagens de referência para os conjuntos de treinamento e de teste, para cada classe de interesse de toda a base de dados, 
contemplando ambas as abordagens de segmentação, e todos os parâmetros obtidos pelo GPS.

\subsubsection{1}

\section{Base de dados Maragogipe}

A imagem apresentada na Figura 22(a) representa uma área rural, onde as classes de interesse são: Barcos, Telhados e Vegetação, mostradas na Tabela 6, em que são apresentadas informações adicionais de cada classe.

Tabela 6 - Número de segmentos de referência por classes para a base de dados de Maragogipe.

\begin{tabular}{ccc}
\hline Classe & Número de Segmentos de Referência & Área Média (pixels) \\
\hline Barcos & 15 & 2281 \\
Telhados & 15 & 2969 \\
Vegetação & 55 & 5205 \\
\hline
\end{tabular}

Os segmentos de referência da classe Barcos e da classe Telhados possuem tamanhos/áreas semelhantes, por isso foram combinados em uma única segmentação contemplando ambas as classes para a abordagem de segmentação hierárquica.

A imagem foi segmentada em dois diferentes níveis para cada procedimento hierárquico (top-down e bottom-up), que permitiram extrair os objetos da imagem em duas escalas diferentes.

A Tabela 7 mostra os resultados comparativos, com os valores de RBSB obtidos pelo conjunto de teste, de ambas as abordagens consideradas, enfatizando em negrito os melhores resultados.

Os resultados mostram que, para as classes Barcos e Telhados, a metodologia de segmentação específica (Esp) foi melhor na maioria dos casos. A classe Vegetação não possui forma típica o que pode explicar que, em alguns casos, o melhor valor foi obtido para segmentação hierárquica. Os baixos desempenhos da abordagem hierárquica BU com o segmentador SCR, para as classes Barcos e Telhados, estão provavelmente relacionados com fusões dos 
objetos de imagem da classe Vegetação, do nível imediatamente inferior, os quais devem ter extrapolado as fronteiras das classes dos objetos de imagem de nível superior.

Tabela 7 - Resultados comparativos das classes de interesse, em termos de RBSB, entre as abordagens de segmentação específica (Esp), hierárquica top-down (TD) e hierárquica bottom-up (BU) para a base de dados de Maragogipe.

\begin{tabular}{|c|c|c|c|c|c|c|c|c|c|c|}
\hline \multirow{4}{*}{ Segmentador } & \multicolumn{9}{|c|}{ Classes } & \multirow{4}{*}{ Partição } \\
\hline & \multicolumn{3}{|c|}{ Barcos } & \multicolumn{3}{|c|}{ Telhados } & \multicolumn{3}{|c|}{ Vegetação } & \\
\hline & \multicolumn{9}{|c|}{ Abordagem } & \\
\hline & Esp & TD & $\mathrm{BU}$ & Esp & TD & BU & Esp & TD & BU & \\
\hline \multirow{3}{*}{ XMRS } & 0,24 & 0,32 & 0,30 & 0,31 & 0,45 & 0,41 & 0,68 & 0,69 & 0,68 & 1 \\
\hline & 0,16 & 0,49 & 0,26 & 0,33 & 0,36 & 0,47 & 0,80 & 0,71 & 0,80 & 2 \\
\hline & 0,18 & 0,22 & 0,30 & 0,33 & 0,69 & 0,49 & 0,72 & 0,87 & 0,72 & 3 \\
\hline \multirow{3}{*}{ MS } & 0,30 & 0,49 & 0,55 & 0,44 & 0,45 & 0,54 & 0,78 & 1,08 & 0,78 & 1 \\
\hline & 0,31 & 0,57 & 0,50 & 0,49 & 0,59 & 0,54 & 0,78 & 1,17 & 0,78 & 2 \\
\hline & 0,48 & 0,53 & 0,54 & 0,45 & 0,48 & 0,78 & 1,22 & 1,52 & 1,22 & 3 \\
\hline \multirow{3}{*}{ SCR } & 0,57 & 0,60 & 72,25 & 0,39 & 0,76 & 139,74 & 3,12 & 0,70 & 3,12 & 1 \\
\hline & 0,54 & 0,51 & 78,40 & 0,45 & 0,55 & 141,64 & 3,71 & 0,80 & 3,71 & 2 \\
\hline & 0,45 & 0,48 & 85,45 & 0,48 & 0,52 & 139,74 & 2,70 & 0,87 & 2,70 & 3 \\
\hline
\end{tabular}

\subsubsection{2}

\section{Base de dados REDUC}

Na Figura 23(a), é apresentada uma imagem representativa de uma área industrial, onde as classes de interesse são: Tanque1, Tanque2, Predios1, Predios2 e Solo, mostradas na Tabela 8.

Tabela 8 - Número de segmentos de referência por classes para a base de dados REDUC.

\section{Classe Número de Segmentos de Referência Área Média (pixels)}

\begin{tabular}{ccc}
\hline Tanque1 & 15 & 381 \\
Tanque2 & 15 & 1886 \\
Predios1 & 15 & 501 \\
Predios2 & 15 & 1737 \\
Solo & 45 & 882 \\
\hline
\end{tabular}


De acordo com a imagem de referência Ref2 e a Tabela 8, os segmentos de referência das classes Tanque 1 e Predios1 possuem tamanhos/áreas semelhantes, e por isso, para a abordagem de segmentação hierárquica foram combinados em uma única segmentação contemplando ambas as classes. De forma semelhante, também foram combinados em uma única segmentação os objetos das classes Tanque2 e Predios2. Assim, para a abordagem hierárquica (top-down e bottom-up), consideraran-se três níveis de segmentação: Tanque1/Predios1, Tanque2/Predios2 e Solo.

A Tabela 9 mostra os resultados comparativos, com os valores de RBSB obtidos pelo conjunto de teste, de ambas as abordagens consideradas, enfatizando em negrito os melhores resultados.

Tabela 9 - Resultados comparativos das classes de interesse, em termos de RBSB, entre as abordagens de segmentação específica (Esp), hierárquica top-down (TD) e hierárquica bottom-up (BU) para a base de dados REDUC.

\begin{tabular}{|c|c|c|c|c|c|c|c|c|c|c|c|c|c|c|c|c|}
\hline \multirow{4}{*}{ 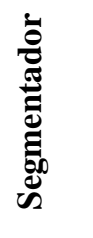 } & \multicolumn{15}{|c|}{ Classes } & \multirow{4}{*}{ لِ } \\
\hline & \multicolumn{3}{|c|}{ Tanque1 } & \multicolumn{3}{|c|}{ Tanque2 } & \multicolumn{3}{|c|}{ Predios1 } & \multicolumn{3}{|c|}{ Predios2 } & \multicolumn{3}{|c|}{ Solo } & \\
\hline & \multicolumn{15}{|c|}{ Abordagem } & \\
\hline & Esp & TD & BU & Esp & TD & BU & Esp & TD & BU & Esp & TD & BU & Esp & TD & BU & \\
\hline \multirow{3}{*}{ XMRS } & 0,23 & 0,41 & 0,49 & 0,23 & 0,27 & 0,24 & 0,24 & 0,24 & 0,28 & 0,39 & 0,47 & 0,45 & 0,78 & 0,69 & 0,78 & 1 \\
\hline & 0,24 & 0,27 & 0,36 & 0,14 & 0,25 & 0,28 & 0,26 & 0,27 & 0,26 & 0,32 & 0,40 & 0,38 & 0,94 & 0,78 & 0,94 & 2 \\
\hline & 0,23 & 0,33 & 0,40 & 0,17 & 0,17 & 0,25 & 0,26 & 0,27 & 0,27 & 0,30 & 0,42 & 0,34 & 0,83 & 0,84 & 0,83 & 3 \\
\hline \multirow{3}{*}{ MS } & 0,40 & 1,94 & 0,40 & 0,34 & 0,40 & 0,35 & 0,28 & 0,62 & 0,37 & 0,41 & 0,47 & 1,63 & 1,52 & 1,51 & 1,52 & 1 \\
\hline & 0,38 & 0,94 & 0,44 & 0,22 & 0,42 & 0,36 & 0,30 & 0,56 & 0,32 & 0,43 & 0,43 & 1,51 & 1,47 & 1,12 & 1,47 & 2 \\
\hline & 0,30 & 1,53 & 0,53 & 0,14 & 0,40 & 0,39 & 0,27 & 0,74 & 0,31 & 0,42 & 0,46 & 1,24 & 1,74 & 1,35 & 1,74 & 3 \\
\hline \multirow{3}{*}{ SCR } & 0,35 & 0,38 & 0,41 & 0,24 & 0,28 & 0,29 & 0,29 & 0,32 & 0,96 & 1,13 & 1,00 & 8,03 & 8,98 & 7,28 & 8,98 & 1 \\
\hline & 0,44 & 0,44 & 0,51 & 0,15 & 0,29 & 0,33 & 0,32 & 0,57 & 1,32 & 0,92 & 1,33 & 6,55 & 6,50 & 5,26 & 6,50 & 2 \\
\hline & 0,47 & 0,48 & 0,47 & 0,26 & 0,35 & 0,29 & 0,27 & 0,39 & 1,36 & 3,18 & 3,28 & 7,85 & 9,81 & 5,15 & 9,81 & 3 \\
\hline
\end{tabular}

Os resultados mostraram que, para as classes que possuem formas bem definidas, como as classes Tanque1, Tanque2, Prédios1 e Prédios2, a metodologia proposta obteve o melhor desempenho, com exceção de apenas um exemplo. A classe Solo foi à única que não obteve bom desempenho. 


\subsubsection{3}

\section{Base de dados Congonhas}

A imagem apresentada na Figura 24(a) representa uma área urbana, onde as classes de interesse são: Aviões, Telhados e Solo. Na Tabela 10, são apresentadas informações adicionais de cada classe.

Tabela 10 - Número de segmentos de referência por classes para a base de dados Congonhas.

\begin{tabular}{ccc}
\hline Classe & Número de Segmentos de Referência & Área Média (pixels) \\
\hline Aviões & 15 & 800 \\
Telhados & 15 & 600 \\
Solo & 15 & 268 \\
\hline
\end{tabular}

Os segmentos de referência da classe Aviões e da classe Telhados possuem áreas semelhantes, e por isso, foram combinados em uma única segmentação contemplando ambas as classes para a abordagem de segmentação hierárquica.

A Tabela 11 mostra os resultados comparativos, com a métrica RBSB, para o conjunto de teste, entre as abordagens investigadas, enfatizando em negrito os melhores resultados. 
Tabela 11 - Resultados comparativos das classes de interesse, em termos de RBSB, entre as abordagens de segmentação específica (Esp), hierárquica top-down (TD) e hierárquica bottom-up (BU) para a base de dados Congonhas.

\begin{tabular}{|c|c|c|c|c|c|c|c|c|c|c|}
\hline \multirow{4}{*}{ Segmentador } & \multicolumn{9}{|c|}{ Classes } & \multirow{4}{*}{ Partição } \\
\hline & \multicolumn{3}{|c|}{ Aviões } & \multicolumn{3}{|c|}{ Telhados } & \multicolumn{3}{|c|}{ Solo } & \\
\hline & \multicolumn{9}{|c|}{ Abordagem } & \\
\hline & Esp & TD & $\mathrm{BU}$ & Esp & TD & $\mathrm{BU}$ & Esp & TD & $\mathrm{BU}$ & \\
\hline \multirow{3}{*}{ XMRS } & 0,55 & 0,55 & 0,57 & 0,11 & 0,41 & 0,49 & 0,50 & 0,53 & 0,50 & 1 \\
\hline & 0,43 & 0,57 & 0,47 & 0,11 & 0,23 & 0,24 & 1,03 & 0,61 & 1,03 & 2 \\
\hline & 0,53 & 0,67 & 0,53 & 0,17 & 0,43 & 0,22 & 0,54 & 0,56 & 0,54 & 3 \\
\hline \multirow{3}{*}{ MS } & 0,42 & 3,24 & 3,25 & 0,24 & 0,41 & 0,56 & 0,56 & 0,80 & 0,56 & 1 \\
\hline & 0,43 & 4,32 & 3,19 & 0,20 & 0,27 & 0,49 & 0,43 & 1,11 & 0,43 & 2 \\
\hline & 0,38 & 3,25 & 3,37 & 0,26 & 0,33 & 0,53 & 0,67 & 1,01 & 0,67 & 3 \\
\hline \multirow{3}{*}{ SCR } & 1,96 & 3,02 & 3,03 & 0,36 & 0,68 & 0,65 & 2,41 & 2,82 & 2,41 & 1 \\
\hline & 3,01 & 3,12 & 3,28 & 0,36 & 0,61 & 0,67 & 3,26 & 3,23 & 3,26 & 2 \\
\hline & 3,23 & 3,91 & 6,50 & 0,34 & 0,76 & 0,73 & 3,67 & 3,12 & 3,67 & 3 \\
\hline
\end{tabular}

\subsection{2}

\section{Exatidão temática e espacial após a classificação}

O objetivo deste experimento foi aferir a exatidão temática e espacial das instâncias dos geobjetos após a classificação, verificando a hipótese de que segmentações específicas por classe conseguem delinear melhor os objetos das imagens e, por conseguinte, melhorar o desempenho do processo de classificação.

O Apêndice A contém gráficos, detalhados por classe, da exatidão temática e espacial de todos os experimentos.

\subsubsection{1}

\section{Base de dados Maragogipe}

A Tabela 12 mostra os atributos selecionados, por classe que foram usados como entrada dos classificadores. 
Tabela 12 - Atributos selecionados para a classificação temática, para a base de dados Maragogipe

\begin{tabular}{c|l|l|l|l}
\hline \multirow{2}{*}{ Segmentador } & \multicolumn{1}{|c|}{ Classe } & \multicolumn{1}{c|}{ Esp } & \multicolumn{1}{c}{ TD } & \multicolumn{1}{c}{ BU } \\
\hline \multirow{4}{*}{ XMRS } & Barcos & Cb, Cr, Suav & Cb, Cr, Suav & Cb, Cr, Suav \\
\cline { 2 - 5 } & Telhados & Cb, Cr, Comp & Cb, Cr, Comp & Cb, Cr, Comp \\
\cline { 2 - 5 } & Vegetação & Cb, Cr, NDVI & Cb, Cr, NDVI & Cb, Cr, NDVI \\
\hline \multirow{4}{*}{ MS } & Barcos & Cb, Cr, Suav & Cb, Cr, Suav & Cb, Cr, Suav \\
\cline { 2 - 5 } & Telhados & Cb, Cr, Suav & Cb, Cr, Comp & Cb, Cr, Iso \\
\cline { 2 - 5 } & Vegetação & Cb, Cr, NDVI & Cb, Cr, NDVI & Cb, Cr, NDVI \\
\hline \multirow{3}{*}{ SCR } & Barcos & Cb, Cr, Suav & Y, Cr, FE & Cb, Cr, Suav \\
\cline { 2 - 5 } & Telhados & Cb, Cr, Comp & Cb, Cr, Comp & Y, Cb, Cr \\
\cline { 2 - 5 } & Vegetação & Cb, Cr, NDVI & Cb, Cr, NDVI & Cb, Cr, NDVI \\
\hline
\end{tabular}

Nas Tabelas 13 e 15, são mostrados os resultados da classificação com as diferentes abordagens, respectivamente para exatidão temática e espacial. Os valores realçados indicam os melhores resultados. É significativo que os melhores resultados de exatidão temática (Tabela 13) tenham sido em todos os casos os produzidos pela metodologia proposta neste trabalho.

É igualmente significativo que, em termos de exatidão espacial (Tabela 15) a metodologia de segmentação específica produziu os melhores resultados para as classes Barcos e Telhados, sem exceção. Para a classe Vegetação, dadas suas características particulares de cor altamente homogênea e forma irregular, houve alguns casos em que a exatidão espacial foi melhor para o método hierárquico. Contudo, na média, sem exceção, os melhores resultados de exatidão espacial foram obtidos pelo método de segmentação específica.

As Tabelas 14 e 16 mostram os resultados do teste de hipótese para exatidão temática e espacial, respectivamente. As células sombreadas correspondem aos casos em que a hipótese nula não pode ser rejeitada. Os resultados da Tabela 14, indicam que a hipótese nula foi rejeitada em todos os experimentos com a base de dados de Maragogipe, ou seja, em termos de exatidão temática o método da segmentação específica foi inequivocamente superior aos métodos de segmentação hierárquica. Semelhantemente, a Tabela 16 mostra que a hipótese nula relativamente aos valores médios de todas as classes foi rejeitada sempre. Em outras palavras, também do ponto de vista da exatidão espacial, o método da segmentação específica foi melhor do que os métodos que utilizam segmentação hierárquica. 
O gráfico da Figura 32 apresenta os valores médios de exatidão resultantes da classificação, e o gráfico da Figura 33, a média das métricas RBSB das classes de objetos após a etapa de classificação. Em ambos os gráficos, as médias foram calculadas tendo por base os valores obtidos dos classificadores SVM, NB e MLE.

Os gráficos mostram que, em todos os casos, os valores médios de exatidão temática e espacial apresentaram melhores resultados para a metodologia de segmentação específica.

Tabela 13 - Exatidão temática para a base de dados de Maragogipe.

\begin{tabular}{|c|c|c|c|c|c|c|c|c|c|c|c|c|c|}
\hline \multirow{3}{*}{ 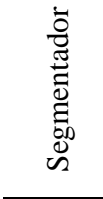 } & \multirow{3}{*}{ 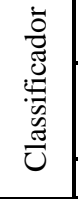 } & \multicolumn{4}{|c|}{ Esp } & \multicolumn{4}{|c|}{ TD } & \multicolumn{4}{|c|}{ BU } \\
\hline & & \multicolumn{2}{|c|}{ Карра } & \multicolumn{2}{|c|}{$\begin{array}{c}\text { Exatidão } \\
\text { Global }\end{array}$} & \multicolumn{2}{|c|}{ Kappa } & \multicolumn{2}{|c|}{$\begin{array}{c}\text { Exatidão } \\
\text { Global }\end{array}$} & \multicolumn{2}{|c|}{ Карра } & \multicolumn{2}{|c|}{$\begin{array}{c}\text { Exatidão } \\
\text { Global }\end{array}$} \\
\hline & & Pixel & Objeto & Pixel & Objeto & Pixel & Objeto & Pixel & Objeto & Pixel & Objeto & Pixel & Objeto \\
\hline \multirow{3}{*}{ XMRS } & SVM & 0,76 & 0,76 & 0,82 & 0,82 & 0,73 & 0,72 & 0,78 & 0,76 & 0,72 & 0,73 & 0,77 & 0,78 \\
\hline & \begin{tabular}{|l|l|} 
NB \\
\end{tabular} & 0,77 & 0,79 & 0,83 & 0,85 & 0,70 & 0,72 & 0,76 & 0,76 & 0,71 & 0,73 & 0,77 & 0,77 \\
\hline & MLE & 0,77 & 0,76 & 0,84 & 0,84 & 0,73 & 0,73 & 0,79 & 0,77 & 0,72 & 0,68 & 0,78 & 0,77 \\
\hline \multirow{3}{*}{ MS } & SVM & $\mathbf{0 , 6 8}$ & 0,75 & $\mathbf{0 , 7 5}$ & $\mathbf{0 , 8 0}$ & 0,61 & 0,69 & 0,70 & 0,78 & 0,42 & 0,58 & 0,49 & 0,63 \\
\hline & NB & 0,68 & 0,79 & 0,76 & 0,82 & 0,63 & 0,77 & 0,71 & 0,80 & 0,55 & 0,71 & 0,61 & 0,78 \\
\hline & MLE & 0,70 & $\mathbf{0 , 8 0}$ & $\mathbf{0 , 8 0}$ & 0,85 & 0,61 & 0,68 & 0,68 & 0,74 & 0,51 & 0,64 & 0,56 & 0,71 \\
\hline \multirow{3}{*}{ SCR } & SVM & 0,72 & 0,64 & 0,79 & 0,69 & 0,63 & 0,50 & 0,72 & 0,57 & 0,61 & 0,48 & 0,73 & 0,51 \\
\hline & NB & 0,74 & 0,67 & $\mathbf{0 , 8 0}$ & 0,72 & 0,65 & 0,52 & 0,74 & 0,58 & 0,61 & 0,47 & 0,72 & 0,51 \\
\hline & MLE & 0,73 & 0,65 & 0,78 & 0,71 & 0,63 & 0,51 & 0,73 & 0,57 & 0,64 & 0,47 & 0,74 & 0,51 \\
\hline
\end{tabular}


Tabela 14 - Resultados do teste de hipótese para as medidas de exatidão temática da metodologia de segmentação específica versus a abordagem de segmentação hierárquica para a base de dados de Maragogipe.

\begin{tabular}{|c|c|c|c|c|c|c|c|c|c|}
\hline \multirow{3}{*}{ 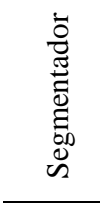 } & \multirow{3}{*}{ 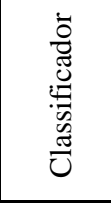 } & \multicolumn{4}{|c|}{ TD } & \multicolumn{4}{|c|}{ BU } \\
\hline & & \multicolumn{2}{|c|}{ Карра } & \multicolumn{2}{|c|}{ Exatidão Global } & \multicolumn{2}{|c|}{ Kappa } & \multicolumn{2}{|c|}{ Exatidão Global } \\
\hline & & Pixel & Objeto & Pixel & Objeto & Pixel & Objeto & Pixel & $\begin{array}{l}\text { Objeto } \\
\end{array}$ \\
\hline \multirow{6}{*}{ XMRS } & $\mathrm{Ci}$ & 0,02 & 0,03 & 0,03 & 0,05 & 0,03 & 0,02 & 0,04 & 0,02 \\
\hline & SVM & $<0,001$ & $<0,001$ & $<0,001$ & $<0,001$ & $<0,001$ & $<0,001$ & $<0,001$ & $<0,001$ \\
\hline & $\mathrm{Ci}$ & 0,05 & 0,05 & 0,05 & 0,08 & 0,05 & 0,04 & 0,05 & 0,05 \\
\hline & $\mathrm{p}$ & $<0,001$ & $<0,001$ & $<0,001$ & $<0,001$ & $<0,001$ & $<0,001$ & $<0,001$ & $<0,001$ \\
\hline & $\mathrm{Ci}$ & 0,01 & 0,01 & 0,04 & 0,05 & 0,03 & 0,03 & 0,05 & 0,04 \\
\hline & $\mathrm{p}$ & $<0,001$ & $<0,001$ & $<0,001$ & $<0,001$ & $<0,001$ & $<0,001$ & $<0,001$ & $<0,001$ \\
\hline \multirow{6}{*}{ MS } & $\mathrm{Ci}$ & 0,03 & 0,03 & 0,02 & 0,01 & 0,21 & 0,11 & 0,22 & 0,11 \\
\hline & $p$ & $<0,001$ & $<0,001$ & $<0,001$ & $<0,001$ & $<0,001$ & $<0,001$ & $<0,001$ & $<0,001$ \\
\hline & $\mathrm{Ci}$ & 0,03 & 0,00 & 0,04 & 0,02 & 0,09 & 0,04 & 0,11 & 0,03 \\
\hline & $\mathrm{p}$ & $<0,001$ & 0,02 & $<0,001$ & $<0,001$ & $<0,001$ & $<0,001$ & $<0,001$ & $<0,001$ \\
\hline & $\mathrm{Ci}$ & 0,03 & 0,08 & 0,07 & 0,09 & 0,14 & 0,12 & 0,21 & 0,11 \\
\hline & MILE $p$ & $<0,001$ & $<0,001$ & $<0,001$ & $<0,001$ & $<0,001$ & $<0,001$ & $<0,001$ & $<0,001$ \\
\hline \multirow{6}{*}{ SCR } & $\mathrm{Ci}$ & 0,07 & 0,13 & 0,05 & 0,12 & 0,07 & 0,13 & 0,04 & 0,16 \\
\hline & $\mathrm{p}$ & $<0,001$ & $<0,001$ & $<0,001$ & $<0,001$ & $<0,001$ & $<0,001$ & $<0,001$ & $<0,001$ \\
\hline & \begin{tabular}{l|l}
$\mathrm{NB}$ & $\mathrm{Ci}$ \\
\end{tabular} & 0,06 & 0,14 & 0,05 & 0,13 & 0,08 & 0,19 & 0,07 & 0,19 \\
\hline & & $<0,001$ & $<0,001$ & $<0,001$ & $<0,001$ & $<0,001$ & $<0,001$ & $<0,001$ & $<0,001$ \\
\hline & MLF $\mathrm{Ci}$ & 0,08 & 0,13 & 0,05 & 0,13 & 0,06 & 0,16 & 0,03 & 0,18 \\
\hline & & $<0,001$ & $<0,001$ & $<0,001$ & $<0,001$ & $<0,001$ & $<0,001$ & $<0,001$ & $<0,001$ \\
\hline
\end{tabular}

Tabela 15 - Exatidão espacial (RBSB) após a classificação para a base de dados de Maragogipe.

\begin{tabular}{|c|c|c|c|c|c|c|c|c|c|c|c|c|c|}
\hline \multirow[b]{2}{*}{ 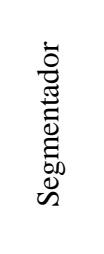 } & \multirow{2}{*}{ 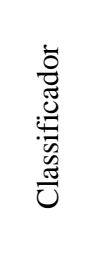 } & \multicolumn{4}{|c|}{ Esp } & \multicolumn{4}{|c|}{ TD } & \multicolumn{4}{|c|}{ BU } \\
\hline & & 总 & 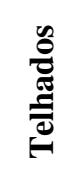 & 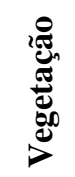 & 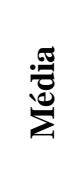 & 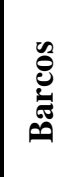 & 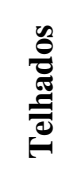 & 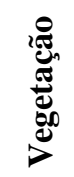 & 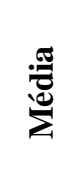 & 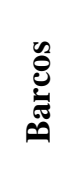 & 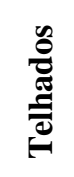 & 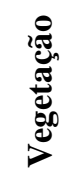 & 寽 \\
\hline \multirow{3}{*}{ XMRS } & SVM & 0,30 & 0,20 & 0,40 & 0,30 & 0,47 & 0,27 & 0,41 & 0,38 & 0,42 & 0,41 & 0,40 & 0,41 \\
\hline & NB & 0,29 & 0,21 & 0,39 & 0,29 & 0,57 & 0,31 & 0,39 & 0,42 & 0,43 & 0,39 & 0,39 & 0,41 \\
\hline & MLE & $\mathbf{0 , 3 0}$ & 0,24 & 0,39 & $\mathbf{0 , 3 1}$ & 0,40 & 0,37 & $\mathbf{0 , 3 8}$ & 0,38 & 0,36 & 0,46 & 0,39 & 0,41 \\
\hline \multirow{3}{*}{ MS } & SVM & 0,50 & 0,45 & 0,49 & 0,48 & 0,64 & 0,51 & 0,56 & 0,57 & 0,64 & 0,83 & 0,51 & 0,66 \\
\hline & NB & 0,81 & 0,43 & 0,41 & 0,55 & 0,80 & 0,46 & 0,56 & 0,61 & 0,93 & 0,76 & 0,39 & 0,69 \\
\hline & MLE & 0,42 & 0,30 & 0,48 & 0,40 & 0,55 & 0,49 & 0,62 & 0,55 & 0,64 & 0,72 & 0,49 & 0,61 \\
\hline \multirow{3}{*}{ SCR } & SVM & 0,43 & 0,46 & $\mathbf{0 , 5 7}$ & 0,48 & 0,62 & 0,60 & 0,59 & 0,60 & 0,51 & 1,01 & 0,59 & 0,70 \\
\hline & NB & 0,55 & 0,47 & 0,47 & 0,51 & \begin{tabular}{|l|l|}
0,67 \\
\end{tabular} & 0,67 & 0,38 & 0,57 & 0,65 & 1,01 & 0,49 & 0,72 \\
\hline & MLE & 0,42 & 0,49 & 0,48 & 0,46 & 0,54 & 0,60 & 0,39 & 0,51 & 0,55 & 1,01 & 0,48 & 0,68 \\
\hline
\end{tabular}


Tabela 16 - Resultados do teste de hipótese para medidas de acurácia espacial (RBSB) após a classificação para a base de dados de Maragogipe. Campos sombreados indicam casos em que a hipótese nula não pode ser rejeitada.

\begin{tabular}{|c|c|c|c|c|c|c|c|c|c|c|}
\hline \multirow{2}{*}{ 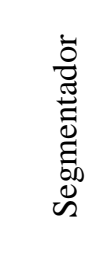 } & \multirow{2}{*}{\multicolumn{2}{|c|}{ 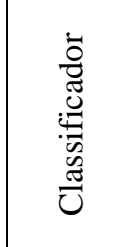 }} & \multicolumn{4}{|c|}{ TD } & \multicolumn{4}{|c|}{ BU } \\
\hline & & & 总 & 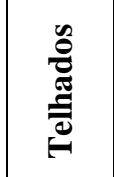 & 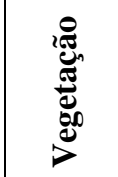 & 忢 & 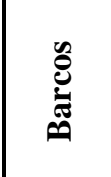 & 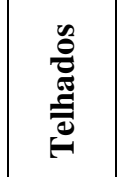 & 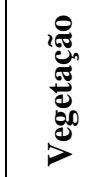 & 䄊 \\
\hline \multirow{6}{*}{ XMRS } & \multirow{2}{*}{$\mathrm{SVM}$} & $\mathrm{Ci}$ & 0,14 & 0,03 & $<-0,001$ & 0,07 & 0,09 & 0,15 & $-0,01$ & 0,09 \\
\hline & & $\mathrm{p}$ & $<0,001$ & $<0,001$ & 0,12 & $<0,001$ & $<0,001$ & $<0,001$ & 0,71 & $<0,001$ \\
\hline & \multirow{2}{*}{ NB } & $\mathrm{Ci}$ & 0,23 & 0,05 & $<0,001$ & 0,11 & 0,11 & 0,13 & $<0,001$ & 0,09 \\
\hline & & $\mathrm{p}$ & $<0,001$ & $<0,001$ & 0,07 & $<0,001$ & $<0,001$ & $<0,001$ & 0,02 & $<0,001$ \\
\hline & \multirow{2}{*}{ MLE } & $\mathrm{Ci}$ & 0,07 & 0,08 & $-0,02$ & 0,06 & 0,04 & \begin{tabular}{|c|}
0,17 \\
\end{tabular} & $-0,01$ & 0,08 \\
\hline & & $\mathrm{p}$ & $<0,001$ & $<0,001$ & 0,97 & $<0,001$ & $<0,001$ & $<0,001$ & 0,69 & $<0,001$ \\
\hline \multirow{6}{*}{ MS } & \multirow{2}{*}{ SVM } & $\mathrm{Ci}$ & 0,09 & 0,03 & 0,04 & \begin{tabular}{|c|}
0,08 \\
\end{tabular} & 0,07 & \begin{tabular}{|c|}
0,34 \\
\end{tabular} & 0,08 & 0,19 \\
\hline & & $\mathrm{p}$ & $<0,001$ & $<0,001$ & $<0,001$ & $<0,001$ & $<0,001$ & 0 & $<0,001$ & 0 \\
\hline & \multirow{2}{*}{ NB } & $\mathrm{Ci}$ & 0,01 & 0,03 & 0,13 & 0,04 & 0,11 & 0,33 & $-0,02$ & 0,13 \\
\hline & & $\mathrm{p}$ & 0,02 & $<0,001$ & $<0,001$ & $<0,001$ & $<0,001$ & 0 & 1,0 & 0 \\
\hline & \multirow{2}{*}{ MLE } & $\mathrm{Ci}$ & 0,09 & 0,15 & 0,09 & 0,13 & 0,20 & 0,36 & $-0,01$ & 0,19 \\
\hline & & $\mathrm{p}$ & $<0,001$ & $<0,001$ & $<0,001$ & $<0,001$ & 0 & $<0,001$ & 0,30 & 0 \\
\hline \multirow{6}{*}{ SCR } & \multirow{2}{*}{ SVM } & $\mathrm{Ci}$ & 0,16 & 0,09 & 0,14 & 0,15 & 0,04 & 0,51 & 0,14 & 0,24 \\
\hline & & $\mathrm{p}$ & $<0,001$ & $<0,001$ & $<0,001$ & $<0,001$ & $<0,001$ & $<0,001$ & $<0,001$ & $1<0,001$ \\
\hline & \multirow{2}{*}{ NB } & $\mathrm{Ci}$ & 0,10 & 0,13 & 0,02 & 0,09 & 0,06 & 0,50 & 0,22 & 0,28 \\
\hline & & $\mathrm{p}$ & $<0,001$ & $<0,001$ & $<0,001$ & $<0,001$ & $<0,001$ & $<0,001$ & $<0,001$ & $1<0,001$ \\
\hline & \multirow{2}{*}{ MLE } & $\mathrm{Ci}$ & 0,08 & 0,02 & 0,01 & 0,05 & 0,11 & 0,47 & 0,19 & 0,27 \\
\hline & & & $<0,001$ & 0,02 & 0,03 & $<0,001$ & $<0,001$ & $<0,001$ & $<0,001$ & $\mid<0,001$ \\
\hline
\end{tabular}

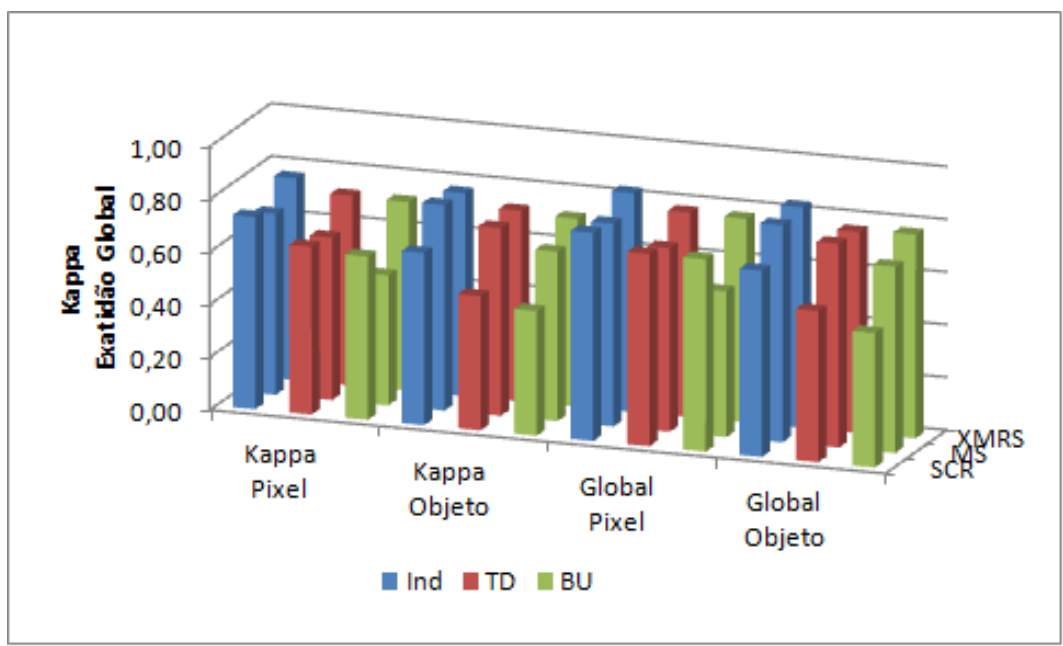

Figura 32 - Valores médios de Kappa e Exatidão Global, combinados dos classificadores SVM, NB e MLE, para as segmentações baseadas nos algoritmos SCR, MS e XMRS, para a base de dados de Maragogipe. 


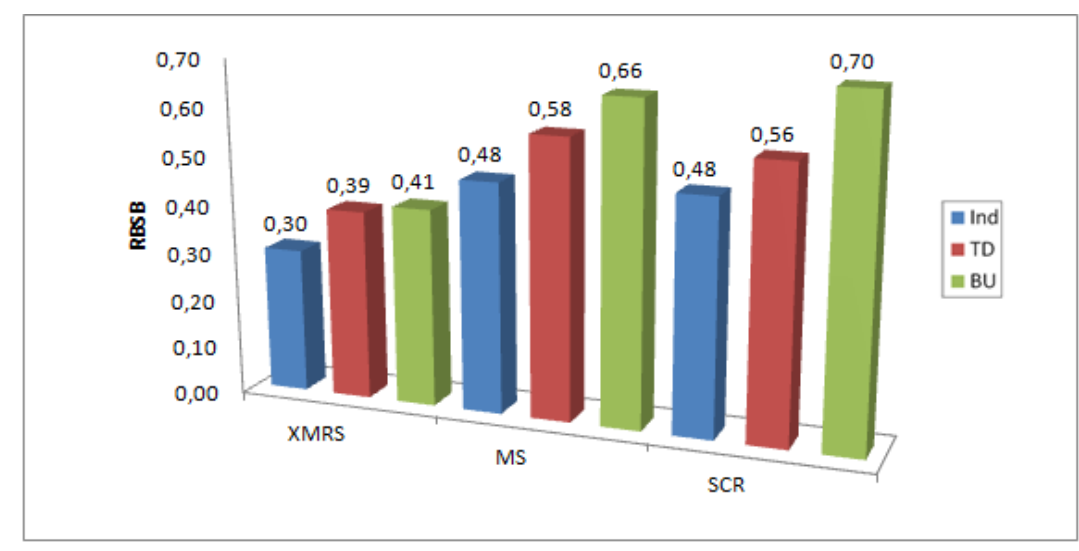

Figura 33 - Média combinada das métricas RBSB para os classificadores SVM, NB e MLE, referentes às classes de objetos após a etapa de classificação, para a base de dados de Maragogipe.

\subsubsection{2}

\section{Base de dados REDUC}

Os atributos selecionados para cada classe que foram usados como entrada dos classificadores, são apresentados na Tabela 17.

Tabela 17 - Atributos selecionados para a classificação temática, para a base de dados REDUC.

\begin{tabular}{c|l|l|l|l}
\hline \multirow{2}{*}{ Segmentador } & \multirow{2}{*}{ Classe } & \multicolumn{1}{|c|}{ Esp } & \multicolumn{1}{c|}{ TD } & \multicolumn{1}{c}{ BU } \\
\hline \multirow{4}{*}{ XMRS } & Tanque1 & Cb, Cr, Comp & Cb, Cr, Comp & Cb, Cr, Comp \\
\cline { 2 - 5 } & Tanque2 & Cb, Cr, Exc & Cb, Cr, Exc & Cb, Cr, Comp \\
\cline { 2 - 5 } & Predios1 & Cb, Cr, Comp & Cb, Cr, Comp & Cb, Cr, Comp \\
\cline { 2 - 5 } & Predios2 & Cb, Cr, Iso & Cb, Cr, Iso & Cb, Cr, Comp \\
\cline { 2 - 5 } & Solo & Y, Cb, Cr & Y, Cb, Cr & Y, Cb, Cr \\
\hline \multirow{5}{*}{ MS } & Tanque1 & Cb, Cr, Comp & Y, Cr, Comp & Cb, Cr, Suav \\
\cline { 2 - 5 } & Tanque2 & Cb, Cr, Exc & Cb, Cr, Exc & Cb, Cr, Exc \\
\cline { 2 - 5 } & Predios1 & Cb, Cr, Comp & Cb, Cr, Comp & Cb, Cr, Comp \\
\cline { 2 - 5 } & Predios2 & Cb, Cr, Comp & Cb, Cr, Comp & Cb, Cr, Comp \\
\cline { 2 - 5 } & Solo & Y, Cb, Cr & Y, Cb, Cr & Y, Cb, Cr \\
\hline \multirow{5}{*}{ SCR } & Tanque1 & Cb, Cr, Suav & Cb, Cr, Suav & Cb, Cr, Suav \\
\cline { 2 - 5 } & Tanque2 & Cb, Cr, Comp & Cb, Cr, Suav & Cb, Cr, Comp \\
\cline { 2 - 5 } & Predios1 & Cb, Cr, Iso & Cb, Cr, Comp & Cb, Cr, Suav \\
\cline { 2 - 5 } & Predios2 & Cb, Cr, Iso & Cb, Cr, Iso & Cb, Cr, Iso \\
\cline { 2 - 5 } & Solo & Y, Cb, Cr & Y, Cb, Cr & Y, Cb, Cr \\
\hline
\end{tabular}

Nas Tabelas 18 e 20, são mostrados os resultados da classificação com as diferentes abordagens, respectivamente para exatidão temática e espacial. Os valores realçados indicam os melhores resultados. Estes resultados são 
consistentes com os apresentados nas Tabelas 14 e 16 para a base de dados de Maragogipe, e deles se extraem as mesmas conclusões. Novamente, para a base de dados REDUC, os melhores resultados de exatidão temática (Tabela 18) foram em todos os casos os produzidos pela metodologia baseada em segmentações específicas.

Em termos de exatidão espacial (Tabela 20), o método das segmentações específicas por classe produziu os melhores resultados para todas as classes com algumas exceções para a classe Solo, que à semelhança da classe Vegetação da base de dados de Maragogipe, tem objetos com formas irregulares. Ainda assim, na média, sem exceção, os melhores resultados de exatidão espacial foram obtidos pela metodologia de segmentação específica.

As Tabelas 19 e 21 mostram os resultados do teste de hipótese para exatidão temática e espacial, respectivamente. As células sombreadas correspondem aos casos em que a hipótese nula não pode ser rejeitada. De modo semelhante ao que se pode verificar nos experimentos para Maragogipe, a Tabela 19 mostra que a hipótese nula foi também rejeitada em todos os experimentos com a base de dados REDUC. Portanto, em termos de exatidão temática, o método da segmentação específica foi inequivocamente superior aos métodos de segmentação hierárquica. Semelhantemente, a Tabela 21 mostra que a hipótese nula relativamente aos valores médios de todas as classes foi rejeitada sempre. Em outras palavras, também do ponto de vista da exatidão espacial, o método de segmentação específica foi melhor do que os métodos que utilizam segmentação hierárquica.

O gráfico da Figura 34 apresenta os valores médios de exatidão resultantes da classificação, e o gráfico da Figura 35, a média das métricas RBSB das classes de objetos após a etapa de classificação. Em ambos os gráficos as médias foram calculadas tendo por base os valores obtidos dos classificadores SVM, NB e MLE.

De forma semelhante aos experimentos para Maragogipe, os gráficos das Figuras 34 e 35 mostram que, em todos os casos, os valores médios de exatidão temática e espacial apresentaram melhores resultados para a metodologia de segmentação específica. 
Tabela 18 - Exatidão temática para a base de dados REDUC.

\begin{tabular}{|c|c|c|c|c|c|c|c|c|c|c|c|c|c|}
\hline \multirow{3}{*}{ 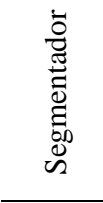 } & \multirow{3}{*}{ 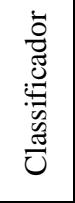 } & \multicolumn{4}{|c|}{ Esp } & \multicolumn{4}{|c|}{ TD } & \multicolumn{4}{|c|}{ BU } \\
\hline & & \multicolumn{2}{|c|}{ Карра } & \multicolumn{2}{|c|}{$\begin{array}{c}\text { Exatidão } \\
\text { Global }\end{array}$} & \multicolumn{2}{|c|}{ Карра } & \multicolumn{2}{|c|}{$\begin{array}{c}\text { Exatidão } \\
\text { Global }\end{array}$} & \multicolumn{2}{|c|}{ Карра } & \multicolumn{2}{|c|}{$\begin{array}{c}\text { Exatidão } \\
\text { Global }\end{array}$} \\
\hline & & Pixel & Objeto & Pixel & Objeto & \begin{tabular}{|l|} 
Pixel \\
\end{tabular} & Objeto & $\begin{array}{l}\text { Pixel } \\
\end{array}$ & Objeto & Pixel & Objeto & Pixel & Objeto \\
\hline \multirow{3}{*}{ XMRS } & SVM & 0,61 & \begin{tabular}{|l|l|}
0,60 \\
\end{tabular} & 0,64 & 0,64 & 0,53 & 0,50 & 0,55 & 0,51 & \begin{tabular}{|l|}
0,52 \\
\end{tabular} & 0,48 & 0,55 & \begin{tabular}{|l|l|}
0,50 \\
\end{tabular} \\
\hline & \begin{tabular}{|l|} 
NB \\
\end{tabular} & 0,66 & 0,65 & 0,69 & 0,68 & 0,61 & 0,58 & 0,63 & 0,60 & 0,58 & 0,60 & 0,60 & 0,61 \\
\hline & MLE & 0,69 & 0,68 & 0,71 & 0,69 & 0,63 & 0,56 & 0,65 & 0,58 & 0,60 & 0,54 & 0,63 & 0,57 \\
\hline \multirow{3}{*}{ MS } & SVM & 0,51 & 0,42 & 0,54 & 0,45 & 0,44 & 0,39 & 0,46 & 0,41 & 0,30 & 0,14 & 0,32 & 0,17 \\
\hline & NB & 0,52 & 0,47 & 0,54 & 0,49 & 0,38 & 0,39 & 0,40 & 0,44 & 0,35 & 0,20 & 0,37 & 0,29 \\
\hline & MLE & $\mathbf{0 , 5 5}$ & 0,49 & 0,58 & 0,55 & 0,52 & 0,47 & 0,55 & 0,50 & 0,48 & 0,33 & 0,50 & 0,35 \\
\hline \multirow{3}{*}{ SCR } & SVM & 0,59 & 0,38 & 0,61 & 0,39 & 0,52 & 0,36 & 0,55 & 0,38 & 0,48 & 0,32 & 0,50 & 0,35 \\
\hline & NB & $\mathbf{0 , 6 1}$ & 0,42 & 0,63 & 0,43 & 0,52 & 0,41 & 0,55 & 0,42 & 0,50 & 0,36 & 0,52 & 0,39 \\
\hline & MLE & 0,64 & 0,40 & 0,66 & $\mathbf{0 , 4 6}$ & 0,59 & 0,38 & 0,61 & 0,40 & 0,51 & 0,34 & 0,53 & 0,39 \\
\hline
\end{tabular}

Tabela 19 - Resultados do teste de hipótese para as medidas de exatidão da metodologia de segmentação específica versus a abordagem de segmentação hierárquica.

\begin{tabular}{|c|c|c|c|c|c|c|c|c|c|c|}
\hline \multirow{3}{*}{ 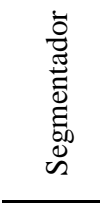 } & \multirow{3}{*}{\multicolumn{2}{|c|}{ 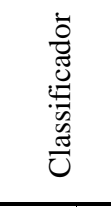 }} & \multicolumn{4}{|c|}{ TD } & \multicolumn{4}{|c|}{ BU } \\
\hline & & & \multicolumn{2}{|c|}{ Карра } & \multicolumn{2}{|c|}{ Exatidão Global } & \multicolumn{2}{|c|}{ Карра } & \multicolumn{2}{|c|}{ Exatidão Global } \\
\hline & & & Pixel & Objeto & Pixel & Objeto & Pixel & Objeto & Pixel & Objeto \\
\hline \multirow{6}{*}{ XMRS } & & $\mathrm{Ci}$ & 0,07 & 0,10 & 0,08 & 0,12 & 0,08 & 0,12 & 0,08 & 0,13 \\
\hline & & $p$ & $<0,001$ & $<0,001$ & $<0,001$ & $<0,001$ & $<0,001$ & $<0,001$ & $<0,001$ & $<0,001$ \\
\hline & & $\mathrm{Ci}$ & 0,04 & 0,07 & 0,05 & 0,07 & 0,08 & 0,05 & 0,08 & 0,06 \\
\hline & $\mathrm{NB}$ & $\mathrm{p}$ & $<0,001$ & $<0,001$ & $<0,001$ & $<0,001$ & $<0,001$ & $<0,001$ & $<0,001$ & $<0,001$ \\
\hline & & $\mathrm{Ci}$ & 0,05 & 0,11 & 0,06 & 0,11 & 0,08 & 0,12 & 0,07 & 0,12 \\
\hline & & $\mathrm{p}$ & $<0,001$ & $<0,001$ & $<0,001$ & $<0,001$ & $<0,001$ & $<0,001$ & $<0,001$ & $<0,001$ \\
\hline \multirow{6}{*}{ MS } & & $\mathrm{Ci}$ & 0,06 & 0,02 & 0,06 & 0,02 & 0,20 & 0,27 & 0,21 & 0,27 \\
\hline & & $\mathrm{p}$ & $<0,001$ & $<0,001$ & $<0,001$ & $<0,001$ & $<0,001$ & $<0,001$ & $<0,001$ & $<0,001$ \\
\hline & & $\mathrm{Ci}$ & 0,13 & 0,08 & 0,13 & 0,03 & 0,16 & 0,26 & 0,16 & 0,19 \\
\hline & $\mathrm{NB}$ & $\mathrm{p}$ & $<0,001$ & $<0,001$ & $<0,001$ & $<0,001$ & $<0,001$ & $<0,001$ & $<0,001$ & $<0,001$ \\
\hline & & $\mathrm{Ci}$ & 0,02 & 0,01 & 0,02 & 0,04 & 0,06 & 0,15 & 0,07 & 0,19 \\
\hline & & $\mathrm{p}$ & $<0,001$ & $<0,001$ & $<0,001$ & $<0,001$ & $<0,001$ & $<0,001$ & $<0,001$ & $<0,001$ \\
\hline \multirow{6}{*}{ SCR } & & $\mathrm{Ci}$ & 0,05 & 0,01 & 0,05 & 0,01 & 0,10 & 0,04 & 0,09 & 0,04 \\
\hline & & $\mathrm{p}$ & $<0,001$ & $<0,001$ & $<0,001$ & $<0,001$ & $<0,001$ & $<0,001$ & $<0,001$ & $<0,001$ \\
\hline & NB & $\mathrm{Ci}$ & 0,09 & $4,8 \mathrm{E}-03$ & 0,08 & $1,1 \mathrm{E}-03$ & 0,10 & 0,05 & 0,10 & 0,04 \\
\hline & TVD & $\mathrm{p}$ & $<0,001$ & $<0,001$ & $<0,001$ & $<0,001$ & $<0,001$ & $<0,001$ & $<0,001$ & $<0,001$ \\
\hline & & $\mathrm{Ci}$ & 0,04 & 0,01 & 0,04 & 0,06 & 0,12 & 0,05 & 0,12 & 0,07 \\
\hline & & $\mathrm{p}$ & $<0,001$ & $<0,001$ & $<0,001$ & $<0,001$ & $<0,001$ & $<0,001$ & $<0,001$ & $<0,001$ \\
\hline
\end{tabular}


Tabela 20 - Exatidão espacial (RBSB) após a classificação para a base de dados REDUC.

\begin{tabular}{|c|c|c|c|c|c|c|c|c|c|c|c|c|c|c|c|c|c|c|c|}
\hline \multirow{2}{*}{ 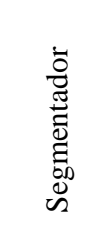 } & \multirow{2}{*}{ 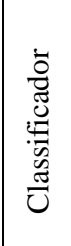 } & \multicolumn{6}{|c|}{ Esp } & \multicolumn{6}{|c|}{ TD } & \multicolumn{6}{|c|}{ BU } \\
\hline & & 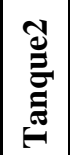 & 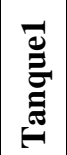 & 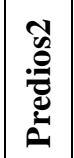 & 竞 & 훙 & 吾 & 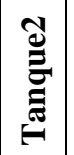 & 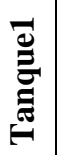 & 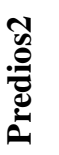 & 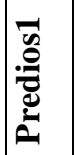 & 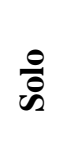 & 范 & 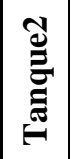 & 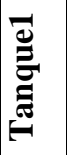 & لَّ & 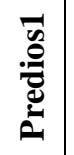 & 훙 & 宽 \\
\hline \multirow{3}{*}{ XMRS } & \multirow{2}{*}{\multicolumn{7}{|c|}{\begin{tabular}{|lllllll} 
SVM & $\mathbf{0 , 4 2}$ & $\mathbf{0 , 4 7}$ & $\mathbf{0 , 3}$ & $\mathbf{0 , 3 2}$ & 0,77 & $\mathbf{0 , 4 7}$
\end{tabular}}} & \multicolumn{6}{|c|}{\begin{tabular}{l|l|l|l|l|l|}
$, 5,51$ & 0,66 & 0,54 & 0,33 & 0,56
\end{tabular}} & \multicolumn{6}{|c|}{\begin{tabular}{|l|l|l|l|l|l|l|l|}
0,63 & 0,34 & 0,79 & 0,55 \\
\end{tabular}} \\
\hline & NB & 0,22 & & 033 & & & 0,41 & 0,37 & 0,50 & 0,47 & & & 0,48 & 0,39 & & & & & 0,53 \\
\hline & MLE & 0,27 & & & & & & 0,34 & 0,60 & 0,4 & & & 0,54 & 0,45 & & 0,3 & & 0,6 & 0,5 \\
\hline \multirow{3}{*}{ MS } & SVM & & & & & & 0,52 & 0,63 & 0,68 & 0,81 & & & & 0,78 & 0,70 & 0,59 & & 0,80 & 0,74 \\
\hline & NB & 0,36 & $\mathbf{0}$ & 0,57 & & 0,8 & & 0,68 & 0,57 & 0,80 & 0,31 & & & & 0,90 & 0,57 & 0 & 0,81 & 0,74 \\
\hline & MLE & 0,3 & & & & & & 0,60 & 0,70 & 0,62 & 0,53 & & 0,65 & 0,50 & 0,82 & 0,54 & & & 0,65 \\
\hline \multirow{3}{*}{ SCR } & SVM & 0,27 & & 0,6 & & & 0,48 & 0,65 & 0,66 & 0,66 & 0,20 & 0,83 & 0,60 & 0,66 & 0,67 & 0,76 & 0,35 & 0,84 & 0,65 \\
\hline & NB & 0,26 & & & & & 0,42 & 0,57 & 0,56 & 0,78 & & 0,8 & & 0,57 & 0,60 & & 0,34 & 0,81 & 0,62 \\
\hline & TIF F & & & & & & & & & & & & & & & & & & \\
\hline
\end{tabular}

Tabela 21 - Resultados do teste de hipótese para as métricas RBSB. Campos sombreados indicam casos em que a hipótese nula não pode ser rejeitada.

\begin{tabular}{|c|c|c|c|c|c|c|c|c|c|c|c|c|c|}
\hline \multirow{2}{*}{ 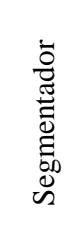 } & \multirow{2}{*}{ 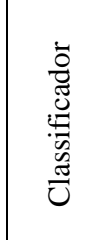 } & \multicolumn{6}{|c|}{ TD } & \multicolumn{6}{|c|}{ BU } \\
\hline & & 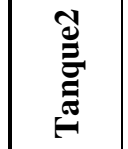 & 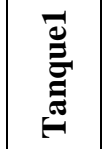 & 议 & 串总 & 웅 & 祃 & 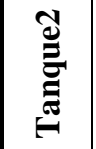 & 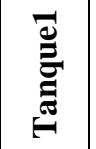 & ָָ & 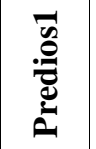 & 을 & 殏 \\
\hline \multirow{6}{*}{ XMRS } & $\mathrm{Ci}$ & 0,07 & 0,17 & 0,16 & $\begin{array}{ll}0,01- \\
-\end{array}$ & $-0,03$ & 0,08 & 0,18 & 0,09 & 0,05 & 0,01 & 0,01 & 0,08 \\
\hline & & $<0,001$ & $<0,001$ & $<0,001$ & $<0,001$ & 0,98 & $<0,001$ & $<0,001$ & $<0,001$ & $<0,001$ & $<0,001$ & $<0,001$ & $<0,001$ \\
\hline & \begin{tabular}{|l|l|}
$\mathrm{NB}$ & $\mathrm{Ci}$ \\
\end{tabular} & 0,14 & 0,06 & 0,10 & $0,05-$ & $-0,03$ & 0,07 & 0,16 & 0,04 & 0,29 & 0,09 & 0 & 0,12 \\
\hline & 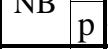 & $<0,001$ & $<0,001$ & $<0,001$ & $<0,001$ & 0,97 & $<0,001$ & $<0,001$ & $<0,001$ & $<0,001$ & $<0,001$ & 0,18 & $<0,001$ \\
\hline & $\mathrm{Ci}$ & 0,06 & 0,10 & 0,16 & $0,31-$ & $-0,02$ & 0,14 & 0,17 & 0,18 & 0,10 & 0,35 & 0,02 & 0,18 \\
\hline & & $<0,001$ & $<0,001$ & $<0,001$ & $<0,001$ & 0,98 & $<0,001$ & $<0,001$ & $<0,001$ & $<0,001$ & $<0,001$ & $<0,001$ & $<0,001$ \\
\hline \multirow{6}{*}{ MS } & $\mathrm{Ci}$ & 0,12 & 0,08 & 0,26 & 0,10 & 0,12 & 0,14 & 0,26 & 0,09 & 0,15 & 0,56 & $-0,02$ & 0,22 \\
\hline & $\mathrm{p}$ & $<0,001$ & $<0,001$ & $<0,001$ & $<0,001<$ & $<0,001$ & $<0,001$ & $<0,001$ & $<0,001$ & $<0,001$ & $<0,001$ & 0,93 & $<0,001$ \\
\hline & $\mathrm{Ci}$ & 0,30 & 0,05 & 0,21 & \begin{tabular}{l|l}
0,05 \\
\end{tabular} & 0,07 & 0,14 & 0,31 & 0,37 & 0,01 & 0,42 & $-0,01$ & 0,23 \\
\hline & $\mathrm{p}$ & $<0,001$ & $<0,001$ & $<0,001$ & $<0,001<$ & $<0,001$ & $<0,001$ & $<0,001$ & $<0,001$ & $<0,001$ & $<0,001$ & 0,51 & $<0,001$ \\
\hline & & 0,18 & 0,10 & 0,11 & 0,08 & 0,13 & 0,13 & 0,08 & 0,22 & 0,02 & 0,26 & $<-0,001$ & 0,13 \\
\hline & $\mathrm{p}$ & $<0,001$ & $<0,001$ & $<0,001$ & $<0,001<$ & $<0,001$ & $<0,001$ & $<0,001$ & $<0,001$ & $<0,001$ & $<0,001$ & 0,37 & $<0,001$ \\
\hline \multirow{6}{*}{ SCR } & $\mathrm{Ci}$ & 0,36 & 0,14 & 0,01 & $0,03-$ & $-0,01$ & 0,11 & 0,36 & 0,15 & 0,10 & 0,17 & $<-0,001$ & 0,16 \\
\hline & $p$ & $<0,001$ & $<0,001$ & $<0,001$ & $<0,001$ & 0,81 & $<0,001$ & $<0,001$ & $<0,001$ & $<0,001$ & $<0,001$ & 0,21 & $<0,001$ \\
\hline & & 0,28 & 0,04 & 0,02 & $0,03-$ & $-0,01$ & 0,16 & 0,29 & \begin{tabular}{|l|}
0,08 \\
\end{tabular} & \begin{tabular}{|l|}
0,02 \\
\end{tabular} & 0,17 & $-0,01$ & 0,19 \\
\hline & $\mathrm{pB}$ & $<0,001$ & $<0,001$ & $<0,001$ & $<0,001$ & 0,98 & $<0,001$ & $<0,001$ & $<0,001$ & $<0,001$ & $<0,001$ & 0,92 & $<0,001$ \\
\hline & MLE Ci & 0,05 & $-0,03$ & $-0,01$ & \begin{tabular}{|l|l}
0,14 & -
\end{tabular} & $-0,03$ & 0,03 & 0,25 & \begin{tabular}{|l|}
$-0,02$ \\
\end{tabular} & \begin{tabular}{|l|}
0,11 \\
\end{tabular} & 0,11 & $-0,01$ & 0,09 \\
\hline & & $<0,001$ & 0,77 & 0,52 & $<0,001$ & 0,98 & $<0,001$ & $<0,001$ & $<0,001$ & $<0,001$ & $<0,001$ & 0,86 & $<0,001$ \\
\hline
\end{tabular}




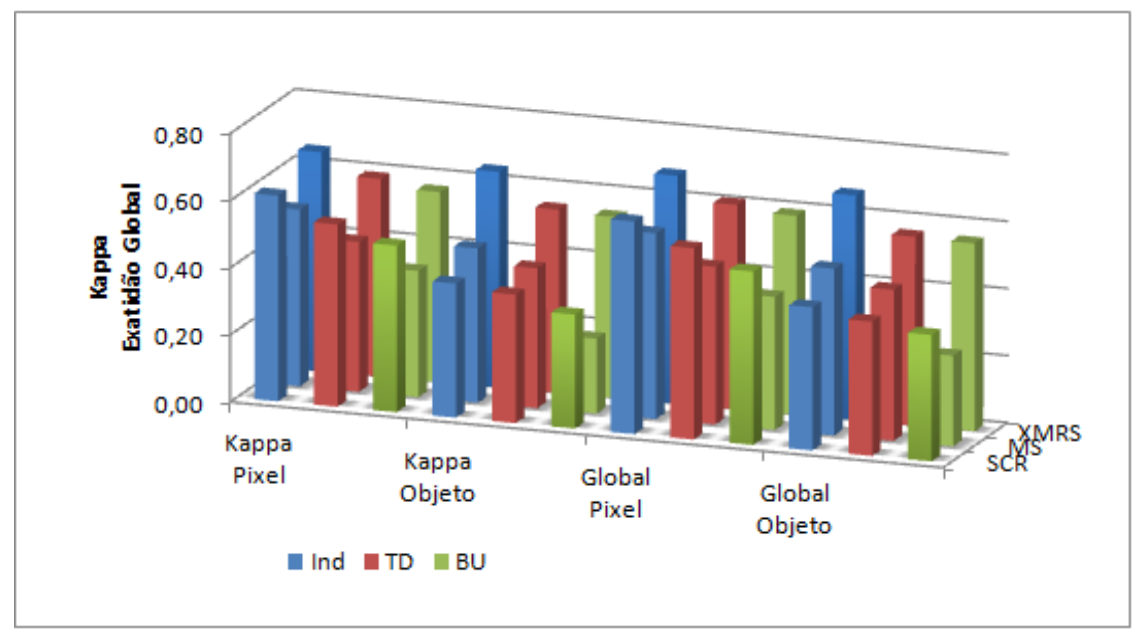

Figura 34 - Valores médios de Kappa e Exatidão Global, combinados dos classificadores SVM, NB e MLE, para as segmentações baseadas nos algoritmos SCR, MS e XMRS, para a base de dados REDUC.

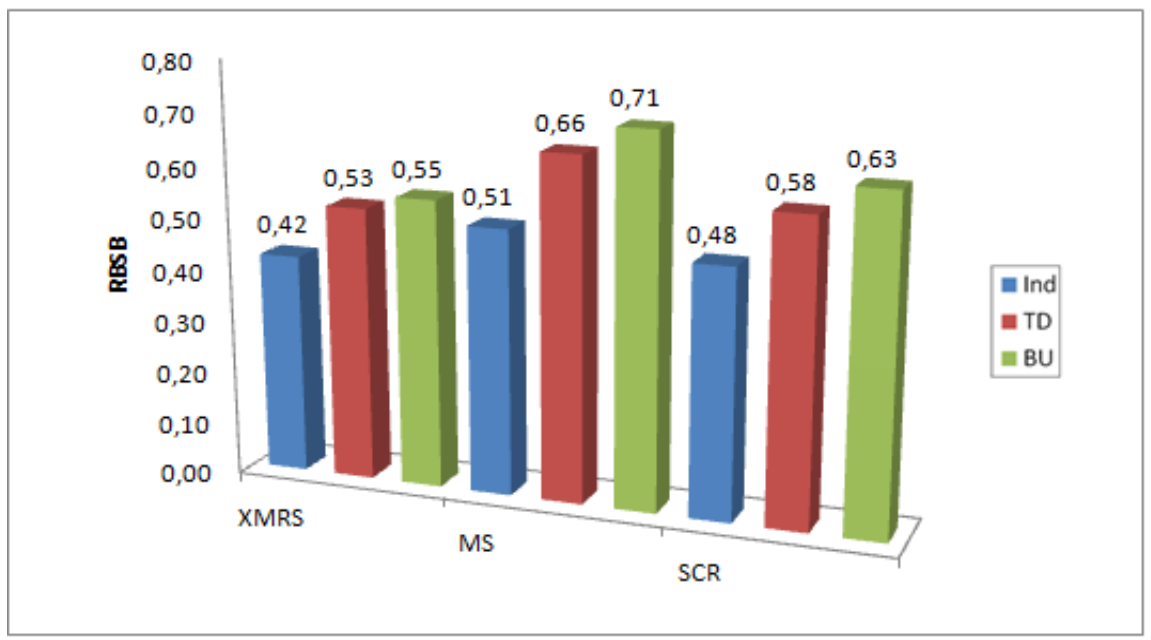

Figura 35 - Média combinada das métricas RBSB para os classificadores SVM, NB e MLE, referente às classes de objetos após a etapa de classificação, para a base de dados REDUC.

\subsubsection{3}

\section{Base de dados Congonhas}

A Tabela 22 apresenta os atributos selecionados, por classe que foram usados como entrada dos classificadores para essa base de dados. 
Tabela 22 - Atributos selecionados para a classificação temática, para a base de dados Congonhas.

\begin{tabular}{c|l|l|l|l}
\hline \multirow{2}{*}{ Segmentador } & \multirow{2}{*}{ Classe } & \multicolumn{1}{c|}{ Esp } & \multicolumn{1}{c}{ TD } & \multicolumn{1}{c}{ BU } \\
\hline \multirow{3}{*}{ XMRS } & Aviões & Cb, Cr, Suav & Cb, Cr, Suav & Y, Cb, Cr \\
\cline { 2 - 5 } & Telhados & Cb, Cr, Comp & Cb, Cr, Comp & Cb, Cr, Comp \\
\cline { 2 - 5 } & Solo & Y, Cb, Cr & Y, Cb, Cr & Y, Cb, Cr \\
\hline \multirow{3}{*}{ MS } & Aviões & Cb, Cr, Suav & Cb, Cr, Suav & Cb, Cr, Suav \\
\cline { 2 - 5 } & Telhados & Cb, Cr, Comp & Cb, Cr, Comp & Cb, Cr, Comp \\
\cline { 2 - 5 } & Solo & Y, Cb, Cr & Y, Cb, Cr & Y, Cb, Cr \\
\hline \multirow{3}{*}{ SCR } & Aviões & Cb, Cr, Suav & Cb, Cr, Suav & Y, Cb, Cr \\
\cline { 2 - 5 } & Telhados & Cb, Cr, Suav & Cb, Cr, Suav & Y, Cb, Cr \\
\cline { 2 - 5 } & Solo & Y, Cb, Cr & Y, Cb, Cr & Y, Cb, Cr \\
\hline
\end{tabular}

Nas Tabelas 23 e 25, são mostrados os resultados da classificação com as diferentes abordagens, respectivamente para exatidão temática e espacial. Os valores realçados indicam os melhores resultados. Confirmam-se aqui as conclusões extraídas dos experimentos correspondentes realizados sobre as bases de dados Maragogipe e REDUC. Tanto em termos de exatidão temática quanto espacial, o método baseado em segmentações específicas supera os métodos alternativos analisados neste trabalho.

As Tabelas 24 e 26 mostram os resultados do teste de hipótese para as médias das medidas de exatidão temática e espacial, respectivamente. As células sombreadas correspondem aos casos em que a hipótese nula não pode ser rejeitada. De modo semelhante ao que se pode verificar nos experimentos para Maragogipe e REDUC, a Tabela 24 mostra que a hipótese nula foi rejeitada em quase todos os experimentos, as exceções são alguns experimentos com o segmentador SCR. Podemos afirmar, com base na maioria dos experimentos, que em termos de exatidão temática, o método da segmentação específica foi superior aos métodos de segmentação hierárquica. A Tabela 21 mostra que a hipótese nula relativamente aos valores médios de todas as classes foi quase sempre rejeitada, também com exceção de alguns experimentos com o segmentador SCR. Em outras palavras, também do ponto de vista da exatidão espacial, o método de segmentação específica foi na maioria das vezes superior aos métodos que utilizam segmentação hierárquica.

Os gráficos mostrados nas Figuras 36 e 37 apresentam os valores médios de exatidão resultantes da classificação e a média das métricas RBSB das classes 
de objetos após a etapa de classificação, respectivamente. Para ambos os gráficos as médias foram calculadas tendo por base os valores obtidos dos classificadores SVM, NB e MLE. Igualmente aos experimentos para Maragogipe e REDUC, os gráficos mostram que, em todos os casos, os valores médios de exatidão temática e espacial apresentaram resultados superiores para a metodologia de segmentação específica.

Tabela 23 - Exatidão temática para a base de dados Congonhas.

\begin{tabular}{|c|c|c|c|c|c|c|c|c|c|c|c|c|c|}
\hline \multirow{3}{*}{ 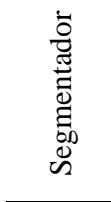 } & \multirow{3}{*}{ 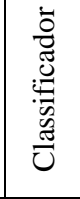 } & \multicolumn{4}{|c|}{ Esp } & \multicolumn{4}{|c|}{ TD } & \multicolumn{4}{|c|}{ BU } \\
\hline & & \multicolumn{2}{|c|}{ Карра } & \multicolumn{2}{|c|}{$\begin{array}{c}\text { Exatidão } \\
\text { Global }\end{array}$} & \multicolumn{2}{|c|}{ Карра } & \multicolumn{2}{|c|}{$\begin{array}{c}\text { Exatidão } \\
\text { Global }\end{array}$} & \multicolumn{2}{|c|}{ Карра } & \multicolumn{2}{|c|}{$\begin{array}{c}\text { Exatidão } \\
\text { Global }\end{array}$} \\
\hline & & Pixel & Objeto & Pixel & Objeto & Pixel & Objeto & Pixel & Objeto & Pixel & Objeto & Pixel & Objeto \\
\hline \multirow{3}{*}{ XMRS } & SVM & 0,59 & 0,60 & 0,62 & 0,63 & 0,40 & 0,43 & 0,45 & 0,45 & 0,39 & 0,40 & 0,56 & 0,58 \\
\hline & NB & 0,59 & 0,63 & 0,64 & 0,72 & 0,52 & 0,60 & 0,54 & 0,63 & 0,50 & 0,54 & 0,53 & 0,56 \\
\hline & MLE & 0,58 & 0,62 & 0,68 & 0,72 & 0,48 & 0,49 & 0,61 & 0,68 & 0,54 & 0,57 & 0,58 & 0,61 \\
\hline \multirow{3}{*}{ MS } & SVM & 0,62 & 0,62 & 0,65 & 0,66 & 0,53 & 0,49 & 0,57 & 0,62 & 0,51 & 0,57 & 0,59 & 0,59 \\
\hline & NB & 0,60 & 0,60 & 0,62 & 0,62 & 0,48 & 0,47 & 0,53 & 0,58 & 0,48 & 0,48 & 0,59 & 0,50 \\
\hline & MLE & 0,63 & 0,64 & 0,69 & 0,70 & 0,58 & 0,58 & 0,61 & 0,65 & 0,57 & 0,59 & 0,64 & 0,63 \\
\hline \multirow{3}{*}{ SCR } & SVM & 0,42 & 0,43 & 0,50 & 0,52 & 0,42 & 0,43 & 0,46 & 0,46 & 0,06 & 0,00 & 0,10 & 0,07 \\
\hline & NB & 0,42 & 0,42 & 0,46 & 0,46 & 0,38 & 0,39 & 0,43 & 0,43 & 0,04 & 0,00 & 0,06 & 0,04 \\
\hline & MLE & 0,41 & 0,42 & 0,48 & 0,48 & 0,41 & 0,42 & 0,46 & 0,46 & 0,01 & 0,00 & 0,02 & 0,03 \\
\hline
\end{tabular}


Tabela 24 - Resultados do teste de hipótese para as medidas de exatidão temática da metodologia de segmentação específica versus a abordagem de segmentação hierárquica para a base de dados Congonhas. Campos sombreados indicam casos em que a hipótese nula não pode ser rejeitada.

\begin{tabular}{|c|c|c|c|c|c|c|c|c|c|c|}
\hline \multirow{3}{*}{ 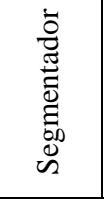 } & \multirow{3}{*}{\multicolumn{2}{|c|}{ 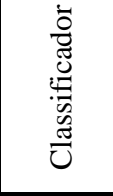 }} & \multicolumn{4}{|c|}{ TD } & \multicolumn{4}{|c|}{ BU } \\
\hline & & & \multicolumn{2}{|c|}{ Kappa } & \multicolumn{2}{|c|}{ Exatidão Global } & \multicolumn{2}{|c|}{ Kappa } & \multicolumn{2}{|c|}{ Exatidão Global } \\
\hline & & & Pixel & Objeto & Pixel & Objeto & Pixel & Objeto & Pixel & Objeto \\
\hline \multirow{6}{*}{ XMRS } & \multirow{2}{*}{ SVM } & $\mathrm{Ci}$ & 0,17 & 0,13 & 0,15 & 0,14 & 0,17 & 0,17 & 0,03 & 0,12 \\
\hline & & $\mathrm{p}$ & $<0,001$ & $<0,001$ & $<0,001$ & $<0,001$ & $<0,001$ & $<0,001$ & $<0,001$ & $<0,001$ \\
\hline & \multirow{2}{*}{ NB } & $\mathrm{Ci}$ & 0,04 & 0,01 & 0,07 & 0,06 & 0,06 & 0,06 & 0,08 & 0,12 \\
\hline & & $\mathrm{p}$ & $<0,001$ & $<0,001$ & $<0,001$ & $<0,001$ & $<0,001$ & $<0,001$ & $<0,001$ & $<0,001$ \\
\hline & \multirow{2}{*}{ MLE } & $\mathrm{Ci}$ & 0,07 & 0,11 & 0,05 & 0,12 & 0,01 & 0,01 & 0,07 & 0,07 \\
\hline & & $\mathrm{p}$ & $<0,001$ & $<0,001$ & $<0,001$ & $<0,001$ & $<0,001$ & $<0,001$ & $<0,001$ & $<0,001$ \\
\hline \multirow{6}{*}{ MS } & \multirow{2}{*}{ SVM } & $\mathrm{Ci}$ & 0,07 & $\begin{array}{l}0,09 \\
\end{array}$ & 0,06 & 0,12 & 0,09 & \begin{tabular}{|l}
0,03 \\
\end{tabular} & 0,03 & 0,05 \\
\hline & & $\mathrm{p}$ & $<0,001$ & $<0,001$ & $<0,001$ & $<0,001$ & $<0,001$ & $<0,001$ & $<0,001$ & $<0,001$ \\
\hline & \multirow{2}{*}{ NB } & $\mathrm{Ci}$ & 0,09 & 0,10 & 0,07 & 0,10 & 0,10 & 0,10 & 0,01 & 0,10 \\
\hline & & $\mathrm{p}$ & $<0,001$ & $<0,001$ & $<0,001$ & $<0,001$ & $<0,001$ & $<0,001$ & $<0,001$ & $<0,001$ \\
\hline & \multirow{2}{*}{ MLE } & $\mathrm{Ci}$ & 0,03 & \begin{tabular}{|r|}
0,02 \\
\end{tabular} & 0,05 & \begin{tabular}{|l}
0,06 \\
\end{tabular} & 0,04 & \begin{tabular}{|l|}
0,02 \\
\end{tabular} & 0,02 & 0,03 \\
\hline & & $\mathrm{p}$ & $<0,001$ & $<0,001$ & $<0,001$ & $<0,001$ & $<0,001$ & $<0,001$ & $<0,001$ & $<0,001$ \\
\hline \multirow{6}{*}{ SCR } & \multirow{2}{*}{ SVM } & $\mathrm{Ci}$ & $-0,01$ & $-0,01$ & 0,03 & 0,03 & 0,32 & 0,10 & 0,37 & 0,29 \\
\hline & & $\mathrm{p}$ & 0,18 & 0,20 & $<0,001$ & $<0,001$ & $<0,001$ & $<0,001$ & $<0,001$ & $<0,001$ \\
\hline & \multirow{2}{*}{ NB } & $\mathrm{Ci}$ & \begin{tabular}{|l}
0,01 \\
\end{tabular} & 0,02 & $\begin{array}{l}0,01 \\
\end{array}$ & \begin{tabular}{|l|}
0,03 \\
\end{tabular} & 0,35 & 0,12 & 0,37 & 0,28 \\
\hline & & $\mathrm{p}$ & $<0,001$ & $<0,001$ & 0,02 & $<0,001$ & $<0,001$ & $<0,001$ & $<0,001$ & $<0,001$ \\
\hline & \multirow{2}{*}{ MLE } & $\mathrm{Ci}$ & $-0,03$ & $-0,05$ & $-0,02$ & $-0,04$ & 0,40 & 0,10 & 0,43 & 0,28 \\
\hline & & $\mathrm{p}$ & 0,40 & 0,86 & 0,22 & 0,90 & $<0,001$ & $<0,001$ & $<0,001$ & $<0,001$ \\
\hline
\end{tabular}

Tabela 25 - Exatidão espacial (RBSB) após a classificação para a base de dados de Congonhas.

\begin{tabular}{|c|c|c|c|c|c|c|c|c|c|c|c|c|c|}
\hline \multirow{2}{*}{ 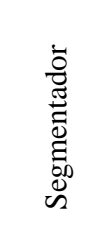 } & \multirow{2}{*}{ 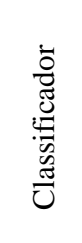 } & \multicolumn{4}{|c|}{ Esp } & \multicolumn{4}{|c|}{ TD } & \multicolumn{4}{|c|}{ BU } \\
\hline & & 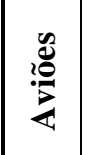 & 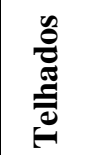 & के & 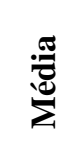 & 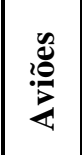 & 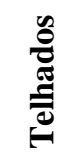 & ڤั & 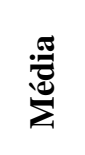 & 远 & 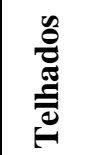 & 응 & 兟 \\
\hline \multirow{3}{*}{ XMRS } & SVM & \begin{tabular}{|c|}
0,47 \\
\end{tabular} & 0,17 & 0,79 & 0,50 & 0,53 & 0,43 & 0,80 & 0,58 & 0,54 & 0,40 & 0,81 & 0,55 \\
\hline & NB & 0,50 & 0,20 & 0,78 & 0,48 & 0,54 & 0,37 & 0,72 & 0,54 & 0,54 & 0,41 & 0,80 & 0,58 \\
\hline & MLE & 0,47 & 0,14 & 0,75 & 0,44 & 0,51 & 0,25 & 0,70 & 0,49 & 0,67 & 0,31 & 0,77 & 0,59 \\
\hline \multirow{3}{*}{ MS } & SVM & 0,37 & \begin{tabular}{|l|}
0,20 \\
\end{tabular} & 0,75 & 0,44 & 0,51 & 0,29 & 0,86 & 0,55 & 0,48 & 0,31 & 0,76 & 0,52 \\
\hline & NB & \begin{tabular}{|l|}
0,44 \\
\end{tabular} & 0,21 & 0,76 & 0,46 & 0,57 & 0,34 & 0,89 & 0,60 & $\mid 0,57$ & \begin{tabular}{|l|l|}
0,34 \\
\end{tabular} & 0,78 & 0,57 \\
\hline & MLE & 0,39 & \begin{tabular}{|l|}
0,17 \\
\end{tabular} & 0,70 & 0,42 & 0,49 & 0,24 & 0,81 & 0,52 & 0,50 & 0,26 & 0,72 & 0,51 \\
\hline \multirow{3}{*}{ SCR } & SVM & 0,65 & 0,25 & 0,96 & 0,65 & 0,66 & 0,38 & 0,96 & 0,66 & 0,84 & \begin{tabular}{|l|}
0,98 \\
\end{tabular} & 0,97 & 0,95 \\
\hline & NB & 0,64 & \begin{tabular}{|l|}
0,38 \\
\end{tabular} & 0,96 & 0,67 & 0,75 & 0,34 & 0,97 & 0,69 & 0,82 & \begin{tabular}{|l|}
0,98 \\
\end{tabular} & 0,95 & 0,97 \\
\hline & MLE & 0,70 & 0,27 & 0,95 & 0,65 & 0,63 & 0,38 & 0,96 & 0,67 & 1,00 & 1,01 & 0,93 & 0,98 \\
\hline
\end{tabular}


Tabela 26 - Resultados do teste de hipótese para medidas de exatidão espacial (RBSB) após a classificação para a base de dados de Congonhas. Campos sombreados indicam casos em que a hipótese nula não pode ser rejeitada.

\begin{tabular}{|c|c|c|c|c|c|c|c|c|c|c|}
\hline \multirow{2}{*}{ 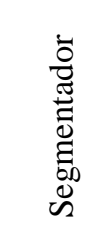 } & \multirow{2}{*}{\multicolumn{2}{|c|}{ 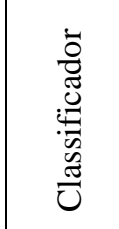 }} & \multicolumn{4}{|c|}{ TD } & \multicolumn{4}{|c|}{ BU } \\
\hline & & & 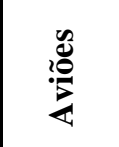 & 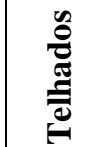 & 음 & : & 选 & 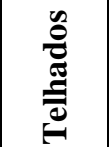 & 응 & 荧 \\
\hline \multirow{6}{*}{ XMRS } & \multirow{2}{*}{ SVM } & & 0,04 & 0,19 & $-0,03$ & 0,06 & 0,06 & 0,15 & 0,01 & 0,03 \\
\hline & & $\mathrm{p}$ & $<0,001$ & $<0,001$ & 0,37 & $<0,001$ & $<0,001$ & $<0,001$ & $<0,001$ & $<0,001$ \\
\hline & \multirow{2}{*}{ NB } & $\mathrm{Ci}$ & 0,03 & 0,11 & $-0,06$ & 0,04 & 0,03 & 0,14 & 0,02 & 0 \\
\hline & & $p$ & $<0,001$ & $<0,001$ & 0,82 & $<0,001$ & $<0,001$ & $<0,001$ & $<0,001$ & $<0,0$ \\
\hline & \multirow{2}{*}{ MLE } & $\mathrm{Ci}$ & 0,02 & 0,06 & $-0,05$ & 0,03 & \begin{tabular}{|l|}
0,14 \\
\end{tabular} & 0,10 & \begin{tabular}{|l|}
0,03 \\
\end{tabular} & 0,11 \\
\hline & & $\mathrm{p}$ & $<0,001$ & $<0,001$ & 0,80 & $<0,001$ & $<0,001$ & $<0,001$ & $<0,001$ & $<0,0$ \\
\hline \multirow{6}{*}{ MS } & \multirow{2}{*}{ SVM } & $\mathrm{Ci}$ & 0,11 & 0,06 & 0,04 & 0,08 & \begin{tabular}{|l|}
0,08 \\
\end{tabular} & \begin{tabular}{|l|}
0,08 \\
\end{tabular} & \begin{tabular}{|c|}
$-0,02$ \\
\end{tabular} & 0,06 \\
\hline & & $\mathrm{p}$ & $<0,001$ & $<0,001$ & $<0,001$ & $<0,001$ & $<0,001$ & $<0,001$ & 0,30 & $<0,001$ \\
\hline & \multirow{2}{*}{ NB } & $\mathrm{Ci}$ & 0,10 & 0,08 & 0,07 & 0,11 & \begin{tabular}{|l|}
0,10 \\
\end{tabular} & 0,07 & 0,02 & 0,09 \\
\hline & & $p$ & $<0,001$ & $<0,001$ & $<0,001$ & $<0,001$ & $<0,001$ & $<0,001$ & $<0,001$ & $<0,001$ \\
\hline & \multirow{2}{*}{ MLE } & $\mathrm{Ci}$ & 0,07 & 0,05 & 0,05 & $\begin{array}{c}0,07 \\
\end{array}$ & 0,10 & \begin{tabular}{|l|}
0,04 \\
\end{tabular} & \begin{tabular}{|l|}
0,03 \\
\end{tabular} & 0,08 \\
\hline & & $\mathrm{p}$ & $<0,001$ & $<0,001$ & $<0,001$ & $<0,001$ & $<0,001$ & $<0,001$ & $<0,001$ & $<0,001$ \\
\hline \multirow{6}{*}{ SCR } & \multirow{2}{*}{ SVM } & $\mathrm{Ci}$ & $<-0,001$ & 0,09 & $-0,01$ & $-0,01$ & 0,15 & 0,67 & \begin{tabular}{|l|}
$-0,01$ \\
\end{tabular} & 0,27 \\
\hline & & $\mathrm{p}$ & $<0,001$ & $<0,001$ & 0,32 & 0,26 & $<0,001$ & $<0,001$ & 0,13 & $<0,001$ \\
\hline & \multirow{2}{*}{ NB } & $\mathrm{Ci}$ & 0,07 & $-0,11$ & 0,00 & 0,00 & 0,15 & \begin{tabular}{|c|}
0,57 \\
\end{tabular} & $-0,02$ & 0,28 \\
\hline & & $\mathrm{p}$ & $<0,001$ & 0,81 & 0,07 & 0,07 & $<0,001$ & $<0,001$ & 0,91 & $<0,001$ \\
\hline & \multirow{2}{*}{ MLE } & & $-0,12$ & 0,05 & $<-0,001$ & $<-0,001$ & 0,27 & 0,66 & $-0,05$ & 0,30 \\
\hline & & & 0,997 & $<0,001$ & 0,17 & $<0,001$ & $<0,001$ & $<0,001$ & \begin{tabular}{|l|}
0,997 \\
\end{tabular} & $<0,001$ \\
\hline
\end{tabular}

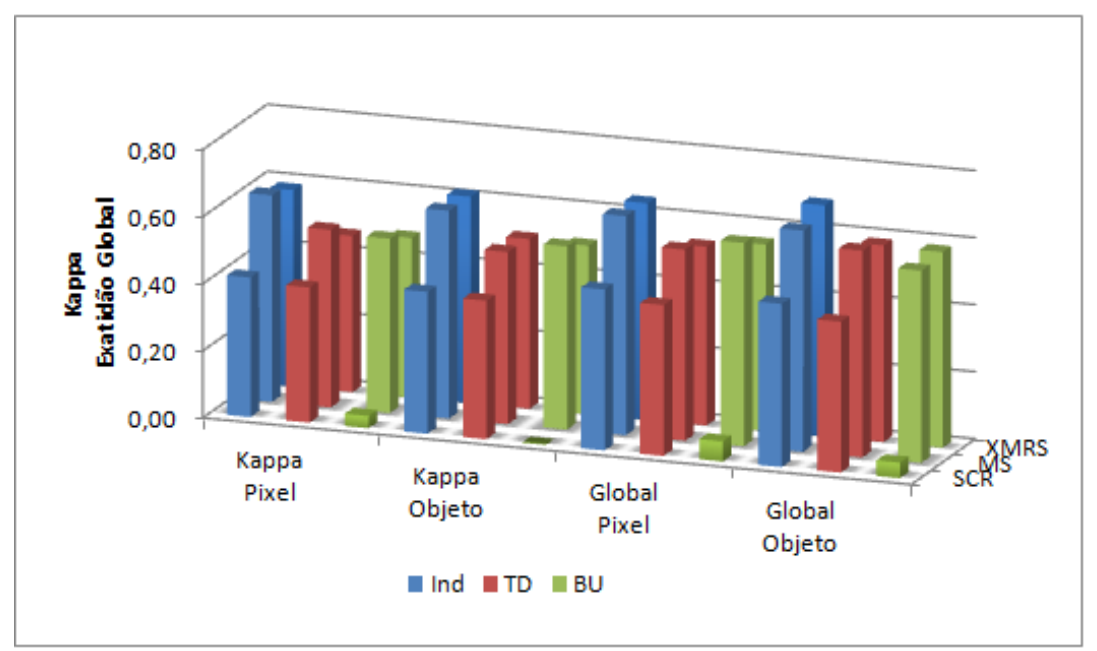

Figura 36 - Valores médios de Kappa e Exatidão Global, combinados dos classificadores SVM, NB e MLE, para as segmentações baseadas nos algoritmos SCR, MS e XMRS, para a base de dados de Congonhas. 


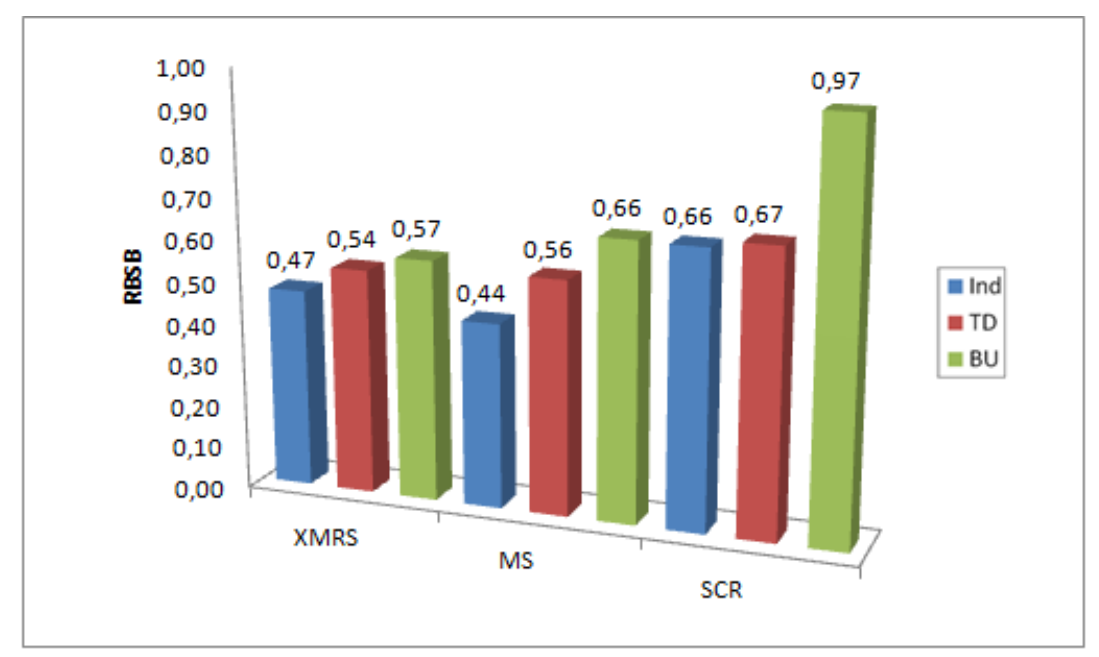

Figura 37 - Média combinada das métricas RBSB para os classificadores SVM, NB e MLE, referente às classes de objetos após a etapa de classificação, para a base de dados de Congonhas.

\section{5}

\section{Análise de resultados}

Os resultados dos experimentos indicaram a clara superioridade da metodologia de segmentação específica sobre a abordagem da segmentação hierárquica (em termos de exatidão espacial) para a maioria das classes de objetos que possuem características morfológicas bem definidas (classes Telhados, Barcos, Prédios, Tanques e Aviões), conforme pode se constatar nas Tabelas 7, 9 e 11. As exceções, além de alguns empates, foram apenas duas ocorridas quando se utilizou o segmentador SCR, cujo algoritmo não inclui atributos de forma.

Cabe ressaltar que, mesmo nos casos em que o número de segmentos de referência utilizados no conjunto de treinamento para o ajuste dos parâmetros da segmentação hierárquica continha o dobro de amostras do que o conjunto de treinamento utilizado para a segmentação específica (vide Apêndice A), os valores de exatidão espacial (métrica RBSB) não foram superiores aos da segmentação específica (salvo as exceções mencionadas).

A segmentação específica para uma classe de objetos gera resultados potencialmente ótimos para essa classe em detrimento das demais classes de objetos presentes na imagem. Isso pôde ser observado em todas as tabelas para a segmentação específica de uma classe em particular (vide Apêndice A). O mesmo 
não ocorreu quando se ajustou a segmentação para contemplar mais de uma classe de objetos de mesma escala (segmentação hierárquica).

Pôde ser observado que, para as classes que não possuem formas e escalas bem definidas, como as classes Vegetação e Solo, a metodologia de segmentação específica nem sempre superou a segmentação hierárquica. De acordo com as Tabelas 7, 9 e 11, a exatidão espacial (em termos de RBSB) da abordagem TD, superou a metodologia específica em algumas situações.

A Figura 38 ilustra dois exemplos de segmentações, com o uso do segmentador SCR em duas imagens da base de dados (Maragogipe e REDUC), onde os objetos de referência (em azul) foram sobrepostos. Pode ser observado, em ambos os exemplos, que a supersegmentação da abordagem hierárquica topdown levou à seleção de segmentos mais representativos do segmento de referência para o cálculo da métrica RBSB, lembrando que para o cálculo da métrica RBSB é usado o segmento com a maior área de intersecção com o objeto de referência. 


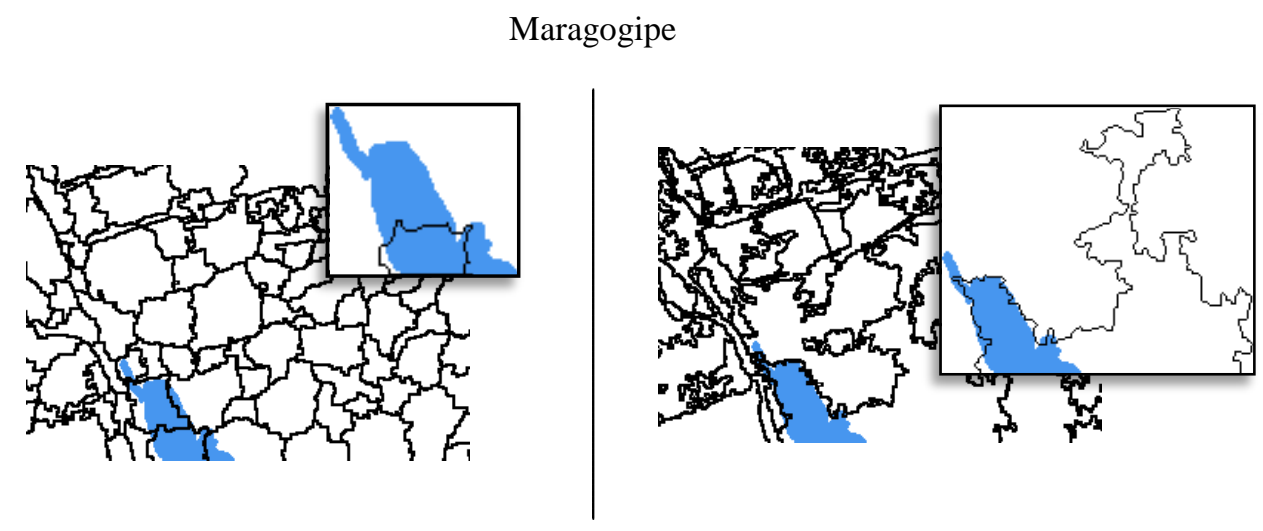

(a)

(b)

REDUC

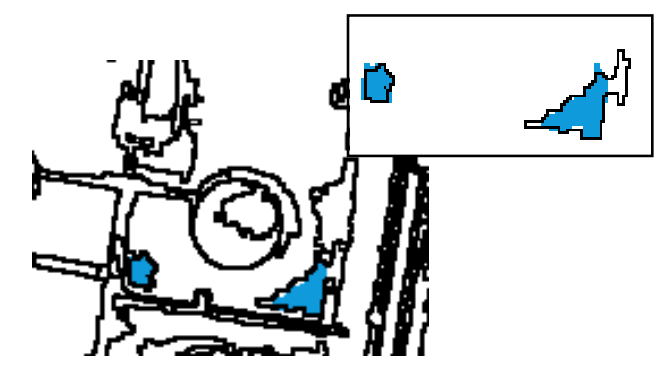

(c)

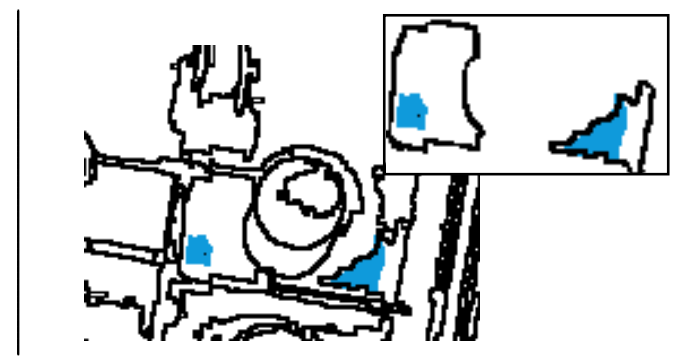

(d)

Figura 38 - Comparação das abordagens TD e Específica, na escolha de segmentos representativos dos objetos de referência (em azul), para o cálculo da métrica RBSB. Em (a) e (c), foi utilizada a abordagem de segmentação TD, e em (b) e (d), a metodologia Específica. As imagens sobrepostas (quadrado menor) indicam o segmento utilizado. As segmentações foram realizadas com a utilização do segmentador SCR sobre a base de dados de Maragogipe, para a classe Vegetação ((a) e (b)), e a base de dados REDUC, para a classe Solo ((c) e (d)).

Os resultados obtidos na classificação indicaram que a metodologia baseada em segmentações específicas apresentou desempenho superior, em termos de exatidão global e coeficiente Kappa, àqueles obtidos a partir da segmentação hierárquica (vide Tabelas 13, 18 e 23). Tal conclusão foi corroborada pelos resultados dos testes de hipóteses aplicados a esses indicadores de desempenho (vide Tabelas 14, 19 e 24).

Os testes de hipóteses somente não puderam rejeitar a hipótese nula em algumas situações entre a metodologia de segmentação específica e a hierárquica top-down, com a utilização do segmentador SCR na base de dados Congonhas. 
Para todos os casos em que o teste de hipótese não pôde rejeitar a hipótese nula, foram realizados novos testes trocando a hipótese nula, dada pela equação 30, para:

$$
\mathrm{HO}: d \geq 0
$$

que pressupõe a exatidão da abordagem de segmentação hierárquica igual ou superior a metodologia proposta nessa tese. Para o mesmo intervalo de confiança de 95\%, usado nos testes anteriores, a hipótese nula dada pela equação 32 não pôde ser igualmente rejeitada. Isso indica que os experimentos realizados nesses casos não indicaram nem a superioridade nem a inferioridade da metodologia de segmentação específica.

Em outras palavras, nos experimentos em que a hipótese nula não pôde ser rejeitada, ou os resultados das medidas de exatidão da metodologia de segmentação específica foram superiores às demais, ou nada se pode afirmar.

Para análise da classificação, em termos da exatidão espacial (métrica RBSB), além dos resultados quantitativos presentes nas tabelas, são mostrados alguns dos erros de discrepância entre as regiões classificadas e os objetos de referência. Para isso são introduzidos alguns conceitos de classificação.

Se a área correspondente ao objeto de referência coincide com a região classificada, tem-se um verdadeiro positivo (VP); no entanto se o classificador não considerou a região do objeto, conta-se como falso negativo (FN). Por outro lado, se os pixels não pertencentes ao objeto de referência estiverem presentes na classificação, serão definidos como falso positivo (FP). A Figura 39 apresenta graficamente os termos envolvidos na visualização dos erros de classificação.

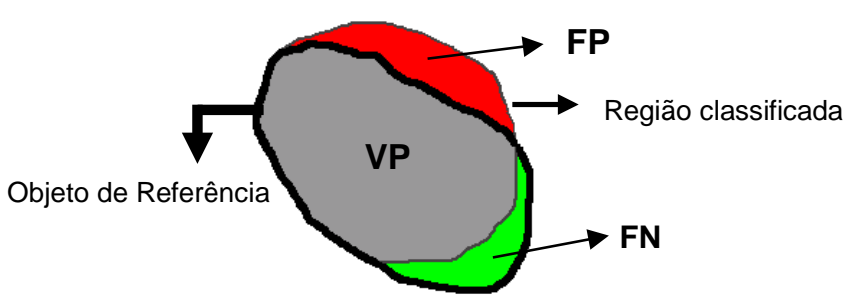

Figura 39 - Apresentação visual dos erros de classificação.

Os resultados mostrados nas Tabelas 15, 20 e 25 (medidas de discrepância RBSB), indicam que a melhor exatidão espacial se alcançou pela segmentação 
específica relativamente à abordagem hierárquica, sendo esses resultados confirmados pelos respectivos testes de hipóteses (vide Tabelas 16, 21 e 26). As exceções são as classes Vegetação e Solo, além de alguns resultados baseados no segmentador SCR, porém, como mencionado anteriormente, a reformulação da hipótese nula (vide equação 32) para esses casos, também não confirmou a superioridade da abordagem hierárquica.

Em alguns resultados, após a classificação, a exatidão espacial dos objetos de imagem classificados apresentou um resultado superior àquelas obtidas na etapa de segmentação. Isso constitui duas situações possíveis:

$1^{\circ}$ Fusões de segmentos classificados, delineando melhor os objetos de referência, conforme mostrado nas Figuras 40 e 41;

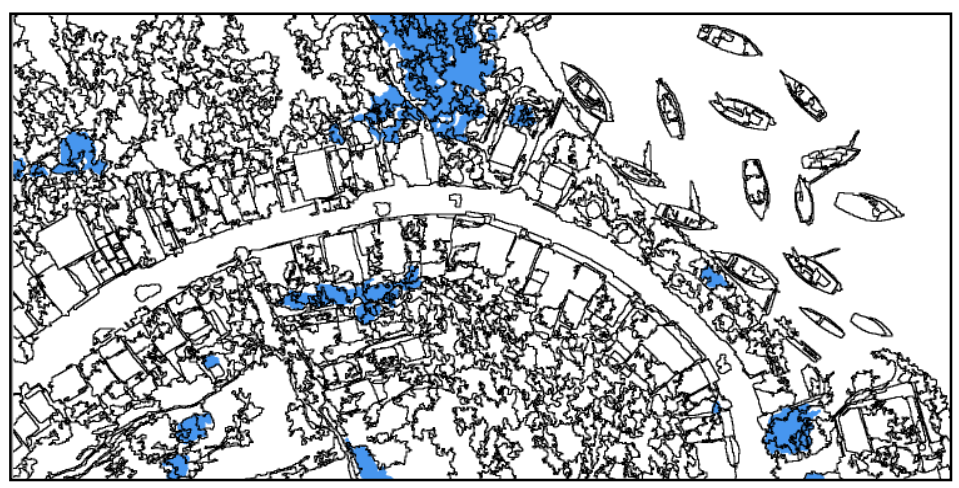

(a) - Segmentação (RBSB = 3,12)

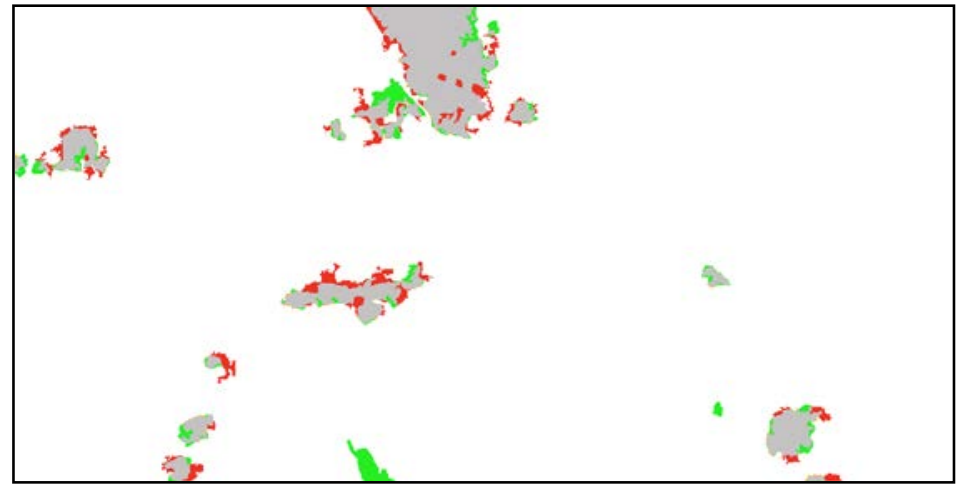

(b) - Classificação (RBSB = 0,65)

Figura 40 - Exemplo de fusões de segmentos na etapa de classificação, delineando melhor os objetos de referência (em azul). Para a base de dados de Maragogipe, tem-se: em (a) uso do segmentador SCR, otimizado para a classe Vegetação, e em (b), classificação da imagem em (a), com o classificador SVM, mostrando os erros de discrepância. 


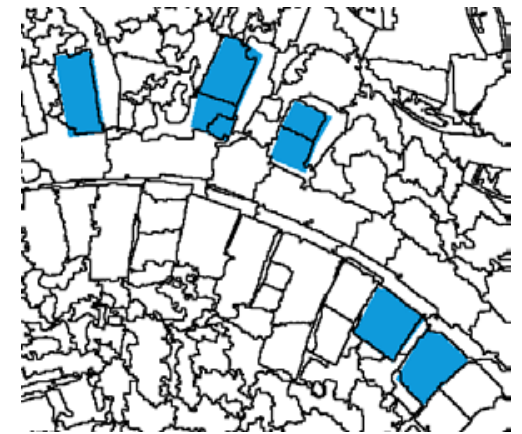

(a) - Segmentação (RBSB = 0,31)

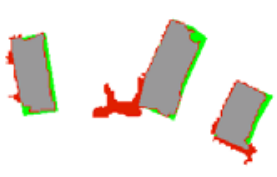

(b) - Classificação (RBSB = 0,21)

Figura 41 - Exemplo de fusões de segmentos na etapa de classificação, delineando melhor os objetos de referência (em azul). Para a base de dados de Maragogipe, tem-se: em (a), uso do segmentador XMRS, otimizado para a classe Telhados, e em (b), classificação da imagem em (a), com o classificador SVM, mostrando os erros de discrepância.

$2^{\circ}$ Objetos de imagem mal formados não classificados (vide Figura 42).

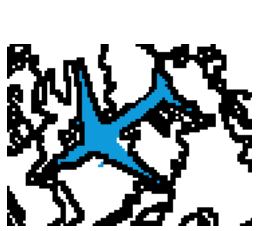

(a)

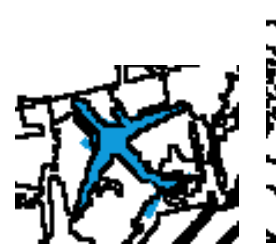

(b)

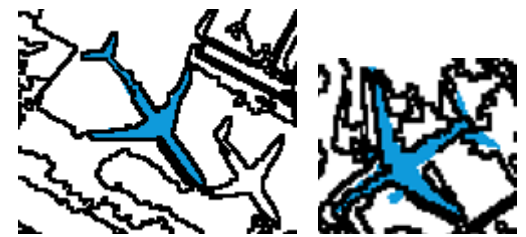

(c)

(d)

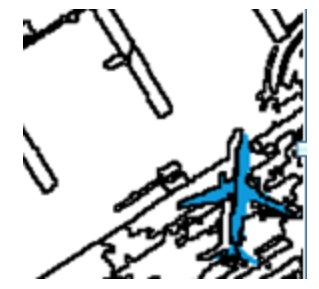

Segmentação (RBSB = 3,01)

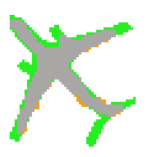

(g)

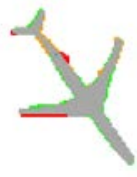

(h)

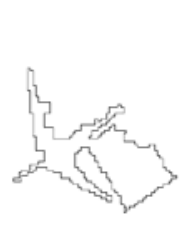

(i)

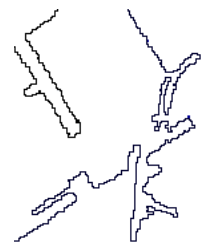

(j)

Classificação $($ RBSB $=0,65)$

Não classificados

Figura 42 - Exemplo de desempenho superior, em termos de exatidão espacial, após a etapa de classificação. Para a base de dados de Congonhas, tem-se: em (a), (b), (c), (d) e (e), uso do segmentador SCR, otimizado para a classe Aviões; em (f), (g) e (h), os objetos de imagem foram devidamente identificados com o classificador SVM, e em (i) e (j), tem-se objetos não classificados, que não foram contabilizados no cômputo da métrica RBSB. 


\section{Conclusões}

Este trabalho avalia uma metodologia para classificação baseada em objeto para a interpretação de imagens de sensoriamento remoto, com base em segmentações e classificações específicas para cada classe de interesse.

Utilizou-se como referência a abordagem mais usada pela comunidade de GEOBIA, baseada em segmentações hierárquicas top-down e bottom-up.

A hipótese de trabalho é que os objetos de imagem gerados pela segmentação terão maior aderência às instâncias dos objetos de imagem significativos na imagem, se a segmentação for ajustada individualmente para cada classe de objetos. Dai resultam dois benefícios: uma melhor exatidão espacial decorrente do ajuste específico para cada classe de objetos; e uma melhor exatidão temática, esta última em consequência de que os atributos morfológicos dos segmentos serão mais representativos da forma das classes de objetos presentes na imagem.

Enquanto a abordagem de segmentação hierárquica produz em cada nível da hierarquia segmentos com intersecção vazia e ao mesmo tempo inteiramente contidos em algum segmento do nível de maior escala, a segmentação específica por classe gera segmentos que se superpõem, dando origem aos chamados “conflitos espaciais”. A solução de tais conflitos ocorre na etapa de classificação com base nas probabilidades ou pertinências de cada pixel às classes do problema.

O trabalho apresenta uma extensiva análise experimental que compara as abordagens via segmentações específicas e segmentação hierárquica. Os experimentos fazem uso de três diferentes bases de dados envolvendo imagens de altíssima resolução espacial, três segmentadores de uso corrente na comunidade de GEOBIA e três diferentes classificadores. A análise mostrou de forma consistente que a metodologia baseada em segmentações específicas por classes produziu melhores resultados tanto em termos de exatidão temática quanto espacial.

Um dos motivos que contribuíram para a qualidade inferior da abordagem por segmentação hierárquica é a necessidade de agrupamento dos objetos de 
mesma escala em uma única etapa de segmentação, não contemplando com isso uma segmentação ótima para todas as classes de objetos envolvidas.

Os experimentos revelaram também que a superioridade da segmentação específica se torna mais pronunciada nos casos em que se utilizaram segmentadores que levam em conta a forma dos segmentos.

A etapa de classificação corroborou a premissa de que a qualidade da segmentação dos objetos envolvidos é um fator decisivo para a exatidão de interpretação das classes temáticas. A análise dos resultados obtidos nesta etapa mostrou que a metodologia proposta apresentou desempenho superior, em termos de coeficiente Kappa e exatidão global, àquele obtido pela classificação da segmentação hierárquica.

Cabe aqui resaltar que, de acordo com os experimentos realizados, a utilização de atributos morfológicos quando a segmentação não está consistente com a forma dos objetos, não contribui de modo significativo para o aumento global da exatidão da classificação. Tal efeito ficou evidenciado na segmentação de classes temáticas como vegetação e solo. Os benefícios trazidos por essa metodologia pode ser mais significativa para as classes de objetos que não são facilmente identificadas pelo uso de atributos unicamente espectrais.

\section{Trabalhos futuros}

A partir do estudo desenvolvido nesta Tese, sugerem-se como trabalhos futuros:

- Avaliar o custo computacional associado à resolução dos conflitos espaciais, inerente ao método de segmentações específicas.

- Estender a análise de modo a considerar em um mesmo projeto de interpretação vários algoritmos de segmentação. Ao se ampliarmos assim a dimensão do espaço de busca pela segmentação que melhor se ajusta a cada classe de objetos, abre-se, pelo menos em tese, uma perspectiva de resultados ainda melhores.

- Avaliar o comportamento da metodologia utilizando outros algoritmos de classificação. De fato, o presente estudo baseou-se em métodos estatísticos e de aprendizado de máquina para a etapa da classificação, e pouco do potencial da classificação baseada em conhecimento preconizada em 
GEOBIA foi explorada nesta análise. Embora não seja possível afirmar categoricamente, com base no estudo realizado, o autor do presente trabalho considera que os benefícios da metodologia de segmentações específicas podem ser ainda maiores ao se utilizarem esquemas mais sofisticados de classificação. 


\section{Referências bibliográficas}

ALBRECHT, F. Uncertainty in image interpretation as reference for accuracy assessment in object-based image analysis. In: Accuracy 2010. Proceedings of the Ninth International Symposium on Spatial Accuracy Assessment in Natural Resources and Environmental Sciences, Tate, N.J., P.F. Fisher (Ed.) , pp. 13-16 (MPG Books Group), 2010.

ALBRECHT, F.; LANG, S.; HÖLBLING, D. Spatial Accuracy Assessment of Object Boundaries for Object-Based Image Analysis. The International Archives of the Photogrammetry, Remote Sensing and Spatial Information Sciences, Vol. XXXVIII-4/C7, 2010.

ALLWEIN, E.L.; SCHAPIRE, R.E.; SINGER, Y. Reducing Multiclass to Binary: A Unifying Approach for Margin Classifiers. Journal of Machine Learning Research, vol. 1, pp. 113-141, 2000.

ANTUNES, A.F.B. Classificação de ambiente ciliar baseada em orientação a objeto em imagens de alta resolução espacial. Curitiba: Editora da UFPR, 2003.

ANTUNES, A.F.B.; CORTESE, S.C. Determinação de áreas de ocupação irregulares por meio de análise orientada a objeto. Anais do XIII Simpósio Brasileiro de Sensoriamento Remoto, Florianópolis-SC, 21 a 26 de abril de 2007, INPE, p.481-487.

AUDET, C.; DENNIS Jr., J.E. Mesh adaptive direct search algorithms for constrained optimization. SIAM J. Optim. 17(1):188-217, 2006.

AYTEKIN; Ö.; ULUSOY, İ; HALICI, U. Segmentation of high resolution satellite imagery based on mean shift algorithm and morphological operations. Image and Signal Processing for Remote Sensing XV. Proceedings of the SPIE, Volume 7477, article id. 747704, 11 pp. (2009).

BAATZ, M., SCHÄPE, A. Multiresolution Segmentation - An Optimization Approach for High Quality Multi-scale Image Segmentation. In: Strobl/Blaschke/Griesebner (editors): Angewandte Geographische Informationsverarbeitung XII, Wichmann-Verlag, Heidelberg, pp. 12-23, 2000.

BANERJEE, B.; SURENDER V.G.; BUDDHIRAJU, K.M. Satellite image segmentation: A novel adaptive mean-shift clustering based approach. Geoscience and Remote Sensing Symposium (IGARSS), 2012 IEEE International, 22-27 July 2012, Page(s):4319 - 4322 , Munich

BEAUCHEMIN, M.; THOMSON, K.P.B. The evaluation of segmentation results and the overlapping area matrix. International Journal of Remote Sensing, v. 18, n. 18, p. 3895-3899, 1997. 
BENZ, U.C.; HOFFMANN, P.; WILLHAUCK, G.; LINGERFELDER, I.; HEYENN, M. Multiresolution, objetct-oriented fuzzy analysis of remote sensing data for GIS-ready information. ISPR Journal of Photogrammetry \& Remote Sensing, vol, 58, 239-259, 2004.

BINS, L.; FONSECA, L.; ERTHAL, G. Satellite Imagery Segmentation: a region growing approach. In: VIII Brazilian Symposium on Remote Sensing, 1996, São José dos Campos, BR. INPE, p. 677-680.

BLASCHKE, T. Object based image analysis for remote sensing. ISPRS Journal of Photogrammetry and Remote Sensing, 65 2-16, 2010.

BLASCHKE, T.; LANG, S.; HAY, G. Object-based Image Analysis - Spatial Concepts for Knowledge-Driven Remote Sensing Applications. Series: Lecture Notes in Geoinformation and Cartography, 2008, XVIII, 818 p. 304 illus.

BLASCHKE, T.; STROBL, J. What is wrong with pixels? Some recent developments interfacing remote sensing and GIS. GIS - Zeitschrift für Geoinformationssysteme, n. 6, pp. 12-17. 2001

BOSER, B.E.; GUYON, I.M.; VAPNIK, V.N. A training algorithm for optimal margin classifiers. In D. Haussler, editor, 5th Annual ACM Workshop on COLT, pages 144-152, Pittsburgh, PA, 1992. ACM Press.

BROWN, M.; LEWIS, H.G.; GUNN, S.R. Linear spectral mixture models and support vector machines for remote sensing. IEEE Transactions on geoscience and remote sensing, v. 38, n. 5, p. 2346-2360. 2000.

BRUNETT, C.; BLASCHKE, T. A Multi-Scale Segmentation/Object Relationship Modeling Methodology for Landscape Analysis. Ecological Modeling, 168, pp. 233 - 249, 2003.

BUNTINE, W.L. Operations for learning with graphical models. Journal of Artificial Intelligence Research, vol. 2, pp. 159-225, 1994.

BÜSCHENFELD, T.; OSTERMANN, J. Edge preserving land cover classification refinement using mean shift segmentation. Proceedings of the 4th GEOBIA, p.242, May 7-9, 2012 - Rio de Janeiro - Brazil.

CÂMARA, G.; SOUZA, R.; FREITAS, U.; GARRIDO, J. SPRING: Integrating Remote Sensing and GIS with Object-Oriented Data Modelling. Computers and Graphics, v. 15, n. 6, p. 13-22, 1996. Disponível em: $<$ www.dpi.inpe.br/gilberto>.

CARLEER, A.; DEBEIR, O.; WOLFF, E. Comparison of very high spatial resolution satellite image segmentation. In Proc. SPIE Conf. Image and Signal Processing Remote Sensing IX, vol. 5238, pp. 532-542, Feb, 2004.

CASTILLA, G.; HAY, G.J. Image objects and geographic objects. In: Blaschke, T., Lang, S., Hay, G.J. (eds) Object Based Image Analysis - Spatial concepts for knowledge-driven remote sensing applications., Chapter 1.5. pp. 97112 Springer, 2008. 
CHANG, C.C.; LIN, C.J. 2001. LIBSVM: a library for support vector machines. Disponível em: <http://www.csie.ntu.edu.tw/ cjlin/libsvm/>.

CHENG, Y. Mean shift, mode seeking, and clustering. IEEE Trans. Pattern Anal. Mach. Intell. 17 (8): 790-799, Aug.,1995.

COHEN, J. A coefficient of agreement of nominal scales. Educational and Psychological Measurement. v.20, p. 37-46, 1960.

COMANICIU, D.; MEER, P. Mean shift analysis and applications. In: Computer Vision. The Proceedings of the Seventh IEEE International Conference on. Vol. 2. pp. 1197-1203 vol.2, 1999.

CONGALTON, R.G. A review of assessing the accuracy of classification of remotely sensed data. Remote Sensing of Environment, 37 (1), pp. 35-46, 1991.

CONGALTON, R.G.; GREEN, K. Assessing the Accuracy of Remotely Sensed Data: Principles and Practices. second ed. CRC Press, Boca Raton, FL. 2008

CONN, A.R.; SCHEINBERG, K.; VICENTE, L.N. Introduction to DerivativeFree Optimization. MPS-SIAM Series on Optimization, SIAM, Philadelphia, 2009.

CORTES, C.; VAPNIK, V. Support vector networks. Machine Learning, 20: 273-297, 1995.

COSTA, G.A.O.P.; FEITOSA, R.Q.; CAZES, T.B.; FEIJÓ, B. Genetic Adaptation of Segmentation Parameters. In: Blaschke, T., Lang, S. and Hay, G. (Eds.). Object-Based Image Analysis: Spatial concepts for knowledge-driven remote sensing applications. Heidelberg: Springer, 2008. pp. 679-695, 2008.

DEB, S. Overview of image segmentation techniques and searching for future directions of research in content-based image retrieval. Ubi-Media Computing, 2008 First IEEE International Conference on, vol., no., pp.184-189. 2008.

Definiens. eCognition: User Guide 3. Germany, 2003, 480 p. Disponível em: $<$ http://www.definiens-imaging.com/down/ecognition>. Acesso em: 15 out. 2003.

DOMINGOS, P.; PAZZANI, M. Beyond independence: Conditions for the optimality of the simple Bayesian classifier. In: Machine Learning: Proceedings of the Thirteenth International Conference on Machine Learning. Morgan Kaufmann, 1996.

DONGPING, M.; TIANYU, C.; HONGYUE, C.; LONGXIANG, L.; CHENG, Q.; JINYANG, D. Semivariogram-Based Spatial Bandwidth Selection for Remote Sensing Image Segmentation With Mean-Shift Algorithm. Geoscience and Remote Sensing Letters, IEEE Volume: 9, Issue: 5, Page(s): 813 817. 2012.

DRĂGUT,, L.; TIEDE, D.; LEVICK, S.R. ESP: a tool to estimate scale parameter for multiresolution image segmentation of remotely sensed data. 
International Journal of Geographical Information Science, Volume 24, Issue 6, 2010.

ESPÍNDOLA, G.M.; CAMARA, G.; REIS, I.A.L.; BINS, L.S.; MONTEIRO, A.M. Parameter selection for region-growing image segmentation algorithms using spatial autocorrelation. In: International Journal of Remote Sensing 27(14), pp. 3035-3040. Junho, 2006.

FAYYAD, U.M.; IRANI, K.B. Multi-interval discretisation of continuousvalued attributes for classification learning. InProceedings of the Thirteenth International Join Conference on Artificial Intelligence. Morgan Kaufmann, 1993.

FEITOSA, R.Q.; COSTA, G.A.O.P.; FREDRICH, C.M.B.; CAMARGO, F.F.; ALMEIDA, C.M. Uma avaliação de métodos genéticos para ajuste de parâmetros de segmentação. Anais XIV Simpósio Brasileiro de Sensoriamento Remoto, Natal, Brasil, 25-30 abril 2009, INPE, p. 6875-6882.

FEITOSA, R.Q.; COSTA, G.A.; CAZES, T.B.; FEIJÓ, B. A Genetic Approach for the Automatic Adaptation of Segmentation Parameters. International Conference on Object-based Image Analysis - ISPRS Proceedings, v. 36, n. 4/C42, 2006.

FERREIRA, R. Uma abordagem multiescalar, multicritério para a segmentação de imagens. 2011. 113p. Dissertação (Mestrado em Engenharia Elétrica) - Pontifícia Universidade Católica do Rio de Janeiro - PUC-Rio, Rio de Janeiro. 2011.

FOODY, G.M. Classification accuracy comparison: hypothesis tests and the use of confidence intervals in evaluations of difference, equivalence and noninferiority. Remote Sensing of Environment, 113 (8), pp.1658-1663, 2009.

FOODY, G.M.; MATHUR, A. Multiclass and Binary SVM Classification: Implications for Training and Classification Users. IEEE Geoscience and Remote Sensing Letters, vol.5, no2, pp 241-245, April 2008.

FOURIE, C.E. A one-class object-based system for sparse geographic feature identification. MSc thesis, Department of Geography and Environmental Studies, Stellenbosch University, Stellenbosch, 2011.

FU, K.S.; MUI, J.K. A survey on image segmentation. Pattern Recognition, vol. 13, Issue 1, pp. 3-16. 1981.

FUKUNAGA, K.; HOSTETLER, L.D. The Estimation of the Gradient of a Density Function, with Applications in Pattern Recognition. IEEE Transactions on Information Theory (IEEE) 21 (1): 32-40, 1975.

HALCON 9.3. MVTec Hancon Documentation. Disponível em: $<$ www.mvtec.com/download/documentation/documentation-9.0.html $>$. Acessado em: 20 agosto 2011. 
HALL, M.A. Correlation-based Feature Subset Selection for Machine Learning. Doctor Thesis - The University of Waikato, Hamilton - New Zealand, 178p, 1999.

HALL, M.; FRANK, E.; HOLMES, G.; PFAHRINGER, B.; REUTEMANN, P.; WITTEN, I.H. The WEKA Data Mining Software: An Update; SIGKDD Explorations. Volume 11, Issue 1, 2009.

HAPP, P.N.; FEITOSA, R.Q.; STREET, A. Assessment of Optimization Methods for Automatic Tuning of Segmentation Parameters. Proceedings of the 4th GEOBIA, May 7-9, 2012 - Rio de Janeiro - Brazil. p.490.

HARALICK, R.M.; SHAPIRO, L.G. Image segmentation techniques. Comput. Vis. Graph. Image Process., vol. 29, no. 1, pp. 100-132, Jan. 1985.

HAY, G.J.; CASTILLA, G. Geographic Object-Based Image Analysis (GEOBIA): A new name for a new discipline. Geographic Object-Based Image Analysis - Lecture Notes in Geoinformation and Cartography, Section 1, 75-89, 2008.

HAY, G.; BLASCHKE, T.; MARCEAU, D.; BOUCHARD, A. A comparison of three image-object methods for the multiscale analysis of landscape structure. In: International Journal of Photogrammetry and Remote Sensing (57), pp 327-345, 2003.

HOFMANN, P. Detecting Informal Settlements from Ikonos Image Data using Methods of Object Oriented Image Analysis An Example from cape Town (South Africa). 2nd Remote Sensing of Urban Areas Internacional Symposium. Regensburg/Alemanha: Instiut für Geographie an der universität Regensburg, p107-118, 2001.

HUANG, C.; DAVIS, L.S.; TOWNSHEND, J.R.G. An Assessment of Support Vector Machines for Land Cover Classification. International Journal of Remote Sensing, vol.23, no 4, pp 725-749, 2002.

INGLADA, J.; CHRISTOPHE, E. The Orfeo Toolbox remote sensing image processing software. In: IEEE International Geoscience and Remote Sensing Symposium (IGARSS)], (2009).

InterIMAGE, 2013, InterIMAGE - Interpreting images freely. Disponível em: <www.lvc.ele.pucrio.br/projects/interimage/>. Acessado em: 25 março de 2013.

JOACHIMS, T. Text categorization with support vector machines: learning with many relevant features. In: Proceedings of ECML-98, 10th European Conference on Machine Learning, number 1398, pages137-142, Chemnitz, DE, 1998. Springer Verlag, Heidelberg, DE.

JOHN, G.; LANGLEY, P. Estimating continuous distributions in Bayesian classifiers. In: Proceedings of the eleventh conference on uncertainty in artificial intelligence, vol. 1. Citeseer, 1995, pp. 338-345. 
KORTING, T.S. GEODMA: a toolbox integrating data mining with object-based and multi-temporal analysis of satellite remotely sensed imagery. 2012. 97p. Tese (Doutorado em Sensoriamento Remoto) - Instituto Nacional de Pesquisas Espaciais - INPE, São José dos Campos.

KUANG, Y. A Comparative Study on Feature SelectionMethods and Their Applications in Causal Inference. Doctor Thesis in Computer Science - Lund University, Lund - Sweden, 61p, 2009.

KUX, H.; NOVACK, T.; FERREIRA, R.; OLIVEIRA, D.A. Urban land cover classification using optical vhr data and the knowledge-based system interimage. The International Archives of the Photogrammetry, Remote Sensing and Spatial Information Sciences, Vol. XXXVIII-4/C7, 2010.

LANG, S. Object-based image analysis for remote sensing applications: modeling reality - dealing with complexity. In: Blaschke, T., Lang, S., Hay, G.J. (eds) Object Based Image Analysis - Spatial concepts for knowledge-driven remote sensing applications., Chapter 1.1. pp. 3-27 Springer, 2008.

LANG, S.; ALBRECHT, F.; KIENBERGER, S.; TIEDE, D. Object validity for operational tasks in a policy context. Journal of Spatial Science, 55(1), pp. 922, 2010.

LANG, S.; BLASCHKE, T. Bridging remote sensing and GIS - what are the main supporting pillars? International Archives of Photogrammetry, Remote Sensing and Spatial Information Sciences, vol. XXXVI-4/C42, 2006.

LEE, J.; WARNER, T.A. Image classification with a region based approach in high spatial resolution imagery. In: Proc. Int. Archives Photogramm, Remote Sensing Spatial Inf. Sci., Istanbul, Turkey, Jul. 2004, pp. 181-187.

LIEDTKE, C.E.; BÜCKNER, J.; GRAU, O.; GROWE, S.; TÖNJES, R. AIDA: a system for the knowledge based interpretation of remote sensing data. In: International Airborne Remote Sensing Conference \& Exhibit, 3., 1997, Copenhagen, Denmark. Proccedings Copenhagen, Denmark. p. 313-320., 1997.

LU, D.; WENG, Q. Survey of image classification methods and techniques for improving classification performance. International Journal of Remote Sensing, 28(5), p. 823-870, 2007.

LÜBKER, T.; SCHAAB, G. Optimization of parameter settings for multilevel image segmentation in GEOBIA. In: Proceedings of ISPRS Hannover Workshop 2009 'High-Resolution Earth Imaging for Geospatial Information', 2-5 June 2009, Hannover (Germany), ed. by C. Heipke, K. Jacobsen, S. Müller, and U. Sörgel.

MARPU, P.R.; NEUBERT, M.; HEROLD, H.; NIEMEYER, I. Enhanced evaluation of image segmentation results. Journal of Spatial Science, v. 55, n. 1, p. 55-68, 2010. 
MATHWORKS - MATLAB and Simulink for Technical Computing. Disponível em: <http://www.mathworks.com/> Acessado em: 10 fevereiro de 2012.

MCKAY, M.D.; BECKMAN, R.J.; CONOVER, W.J. A Comparison of Three Methods for Selecting Values of Input Variables in the Analysis of Output from a Computer Code. Technometrics, Vol. 21, n.2, p. 239-245, May 1979.

MEINEL, G.; NEUBERT, M. A Comparision of segmentation programs for high resolution remote sensing data. Int Arch Photogram Rem Sens Spatial Inform Sci XXXV-B4, pp. 1097-1102, 2004.

MELGANI, F.; BRUZZONE, L. Classification of Hyperspectral Remote Sensing Images with Support Vector Machines. IEEE Transactions on Geoscience and Remote Sensing, vol. 42, no8, pp 1778- 1790, August 2004.

MOIGNE, J.L.; TILTON, J.C. Refining image segmentation by integration of edge and region data. IEEE Transactions on Geoscience and Remote Sensing, v. 33, n. 3, 1995.

NEUBERT, M.; HEROLD, H.; MEINEL, G. Assessing Image Segmentation Quality - Concepts, Methods and Application. In: Blaschke, T.; Hay, G. \& Lang, S. (Eds.): Object-Based Image Analysis - Spatial concepts for knowledgedriven remote sensing applications. Lecture Notes in Geoinformation \& Cartography (LNG\&C), Springer, Berlin: 769-784, 2008.

NOVACK, T.; ESCH, T.; KUX, H.; STILLA, U. Machine Learning Comparison between WorldView-2 and QuickBird-2-Simulated Imagery Regarding Object-Based Urban Land Cover Classification. Remote Sens. 2011, 3, 2263-2282;

NOVACK, T.; KUX, H. Classificação da cobertura do solo urbano inserindo árvores de decisão a rede hierárquica. In: Simpósio Brasileiro de Sensoriamento Remoto, 14., Natal. Anais SBSR. São José dos Campos: INPE, 2009, p. 7871-7876.

PAL, M.; FOODY, G.M. Feature selection for classification of hyperspectral data by SVM. IEEE Transactions on Geoscience and Remote Sensing, 48, 22972307, 2010.

PAL, N.R.; PAL, S.K. A review on image segmentation techniques. Pattern Recognition, v. 26, n. 9, p. 1277, 1993.

PEKKARINEN, A. Image segment-based spectral features in the estimation of timber volume. Remote Sensing of Environment, vol. 82, pp 349-359, 2002.

PENNA, D.D.J. Definição da Árvore de Cenários de Afluências para o Planejamento da Operação Energética de Médio Prazo. 2009. 177p. Tese (Doutorado em Engenharia Elétrica) - Pontifícia Universidade Católica do Rio de Janeiro - Puc-Rio, Rio de Janeiro. 2009. 
PIEDRA-FERNÁNDEZ, J.A.; CANTÓN-GARBÍN, M.; WANG, J.Z. Feature Selection in AVHRR Ocean Satellite Images by Means of Filter Methods. Geoscience and Remote Sensing, IEEE Transactions on, Volume: 48, Issue: 12, pp.4193 - 4203, 2010.

PINHO, C.M.D. Análise orientada a objetos de imagens de satélites de alta resolução espacial aplicada à classificação de cobertura do solo no espaço intra-urbano: o caso de São José dos Campos. Dissertação (Mestrado em Sensoriamento Remoto) - Instituto Nacional de Pesquisas Espaciais (INPE), São José dos Campos, 180 p. 2005.

PINHO, C.M.D.; FONSECA, L.M.G.; KORTING, T.S.; ALMEIDA, C.M.; KUX, H.J.H. Land-cover classification of an intra-urban environment using highresolution images and object-based image analysis. International Journal of Remote Sensing, v. 33, p. 5973-5995, 2012.

PLATT, J. Probabilistic outputs for support vector machines and comparison to regularized likelihood methods. In: A. Smola, P. Bartlett, B. Schölkopf, and D. Schuurmans (eds.): Advances in Large Margin Classifiers. Cambridge, MA. 2000.

PRESS, W.H.; TEUKOLSKY, S.A.; FLANNERY, B.P.; WETTERLING, W.T. Numerical recipes in C: The art of scientific computing. Cambridge University Press, 1988.

ROCHA, A.D. Estabelecimento de Metodologia de Classificação de Imagens de Alta Resolução para Identificar e Avaliar o Crescimento e Áreas de Ocupação Irregular. Dissertação (Mestrado em Ciências Geodésicas) Universidade Federal do Paraná-UFPR, Curitiba, agosto 2007.

RUSS, J.C. The Image Processing Handbook - 3rd ed. Materials Science and Engineering Department North Carolina State University Raleigh - North Carolina, 1998.

SCHÖPFER, E.; LANG, S.; ALBRECHT, F. Object-fate analysis: Spatial relationships for the assessment of object transition and correspondence. In: Blaschke, T., Lang, S., Hay, G. J. (eds.) Object-Based Image Analysis : Spatial Concepts for Knowledge-Driven Remote Sensing Applications. Berlin, Heidelberg: SpringerVerlag, 2008.

SCOFIELD, G.B.; SANT'ANNA, S.J.S.; FREITAS, C.C.; DUTRA, L.V. Avaliação quantitativa do SegSAR através de medidas de borda e regiões em imagens ópticas sintéticas. 6167 Anais XIII Simpósio Brasileiro de Sensoriamento Remoto, Florianópolis, Brasil, 21-26 abril 2007, INPE, p. 61676174.

SEMOLINI, R. Support Vector Machines, Inferência Transdutiva e o Problema de Classificação. Dissertação de Mestrado em Engenharia Elétrica, Universidade Estadual de Campinas, Campinas - SP - Brasil, 128p, Dezembro de 2002. 
SENARAS, C.; OZAY, M.; YARMAN VURAL, F.T. Building Detection with Decision Fusion. IEEE Journal of Selected Topics in Applied Earth Observations and Remote Sensing, vol. 6, no. 3, june 2013.

SILVA, C.V.J.; SILVA, R.D.; GALVÃO L.S. Seleção de atributos em imagens AVIRIS para mapeamento de uma área do Pantanal Brasileiro. Anais XVI Simpósio Brasileiro de Sensoriamento Remoto - SBSR, Foz do Iguaçu, PR, Brasil, 13 a 18 de abril de 2013.

SMITH, B.; MARK, D.M. Ontology and Geographic Kinds. Proc. 8th Int. Symp. on Spatial Data Handling (SDH'98), pp 308-320, 1998.

SOH, L.K.; TSATSOULIS, C. Segmentation of satellite imagery of natural scenes using datamining. IEEE Transactions on Geoscience and Remote Sensing, v. 37, n. 2, p. 1086. 1999.

TIAN, J.; CHEN. D.M. Optimization in multi-scale segmentation of highresolution satellite images for artificial feature recognition. International Journal of Remote Sensing. Vol. 28, No. 20, 20 October 2007, 4625-4644.

TIEDE, D.; LANG, S.; ALBRECHT, F.; HÖLBLING, D. Object-based Class Modeling for Cadastre-constrained Delineation of Geo-objects. Photogrammetric Engineering and Remote Sensing, 76,193-202, 2010.

TILTON, J.C.; LAWRENCE, W.T. Interactive analysis of hierarchical image segmentation. Geoscience and Remote Sensing Symposium, 2000. Proceedings. IGARSS 2000. IEEE 2000 International, vol.2, no., pp.733-735.

TORCZON, V. On the Convergence of Pattern Search Algorithms. SIAM Journal on Optimization, Vol. 7, Issue 1, pages 1-25, February 1997.

UBA, D.M. e DUTRA, L.V. Detecção de objetos regulares em imagens de alta resolução utilizando casamento de modelos. Anais do XIV Simpósio Brasileiro de Sensoriamento Remoto, Natal, Brasil 25 a 30 de abril de 2009, INPE, p.893900 .

WEIDNER, U. Contribution to the assessment of segmentation quality for remote sensing applications. In: International Society for Photogrammetry and Remote Sensing annual conference: Silk road for information from imagery held 3-11 July 2008. Beijing, China.

XMRS, 2012, eXtended MultiResolution Segmentation. Disponível em: < www.lvc.ele.puc-rio.br/>. Acessado em: 10 fevereiro de 2012.

YOTHI, B.N.; BABU, G.R.; KRISHNA, I.V.M. Object Oriented and MultiScale Image Analysis: Strengths, Weaknesses, Opportunities and Threats-A Review. Journal of Computer Science, 4 (9), p.706-712, 2008.

ZHANG, H.G.; FRITTS, J.E.; GOLDMAN, S. A. Image segmentation evaluation: A survey of unsupervised methods. Computer Vision and Image Understanding, 110: 260-280, 2008. 
ZHANG, Y.J. A survey on evaluation methods for image segmentation. Pattern Recognition. Kidlington, v.29, n.8, p. 1335-1346., 1996. 


\section{Apêndice $A$}

\section{Resultados dos Experimentos}

\section{A.1}

\section{Tabelas e gráficos}

\section{A.1.1}

\section{Exatidão espacial}

As tabelas apresentadas na sequência desta seção correspondem aos resultados parciais dos experimentos realizados na Seção 5.5.1 - Exatidão Espacial após a Segmentação, bem como os conjuntos de treinamento e teste utilizados pelo algoritmo GPS.

\section{A.1.1.1}

\section{Base de dados de Maragogipe}

Nas Figuras A.1, A.2 e A.3 são mostradas as imagens de referência para os conjuntos de treinamento e de teste, para cada classe de interesse.

\begin{tabular}{|c|c|c|c|c|}
\hline & \\
\hline
\end{tabular}

Figura A.1 - Conjuntos de treinamento e teste (classes Barcos e Telhados), para a base de dados de Maragogipe. 


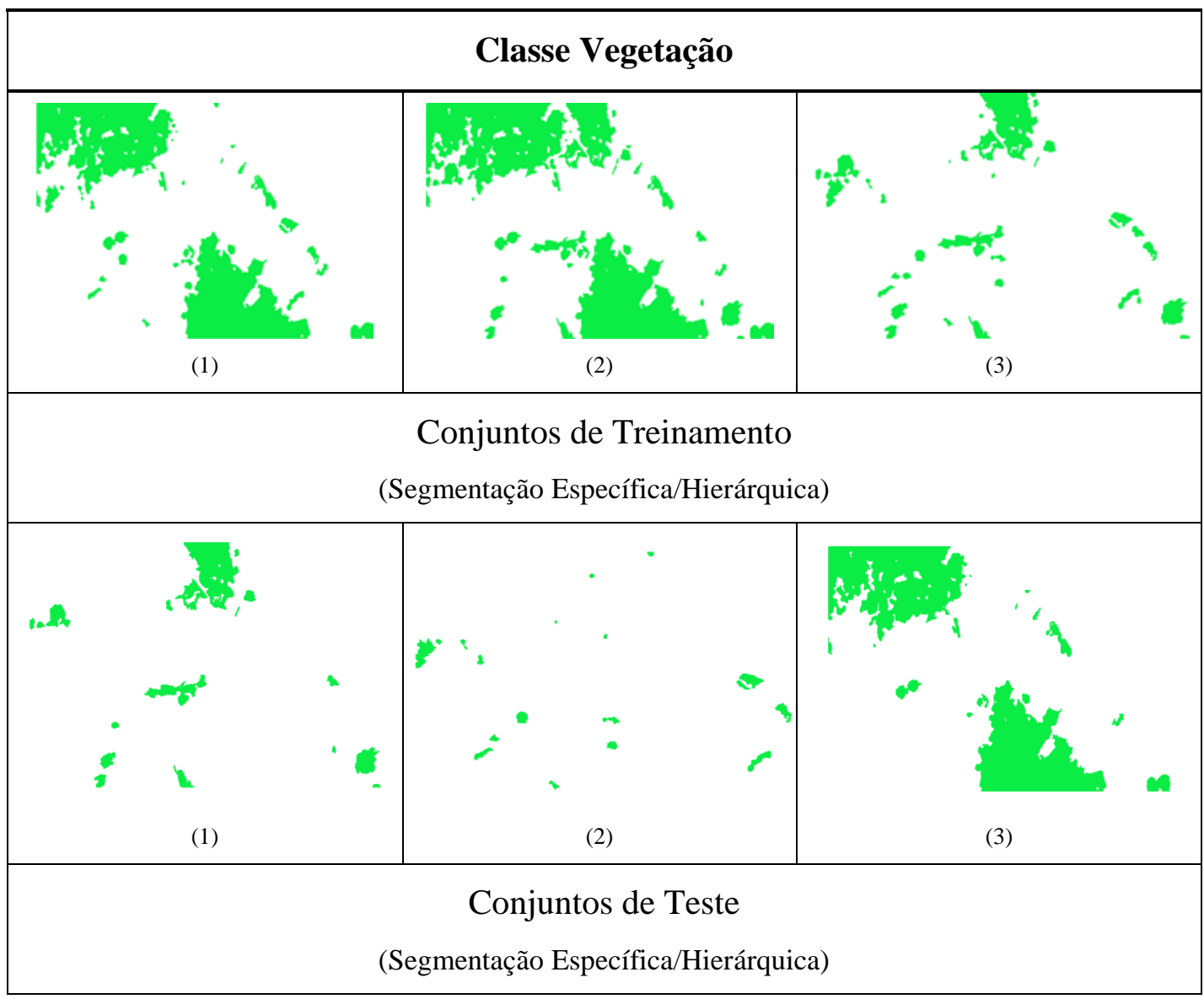

Figura A.2 - Conjuntos de treinamento e teste (classe Vegetação), para a base de dados de Maragogipe.

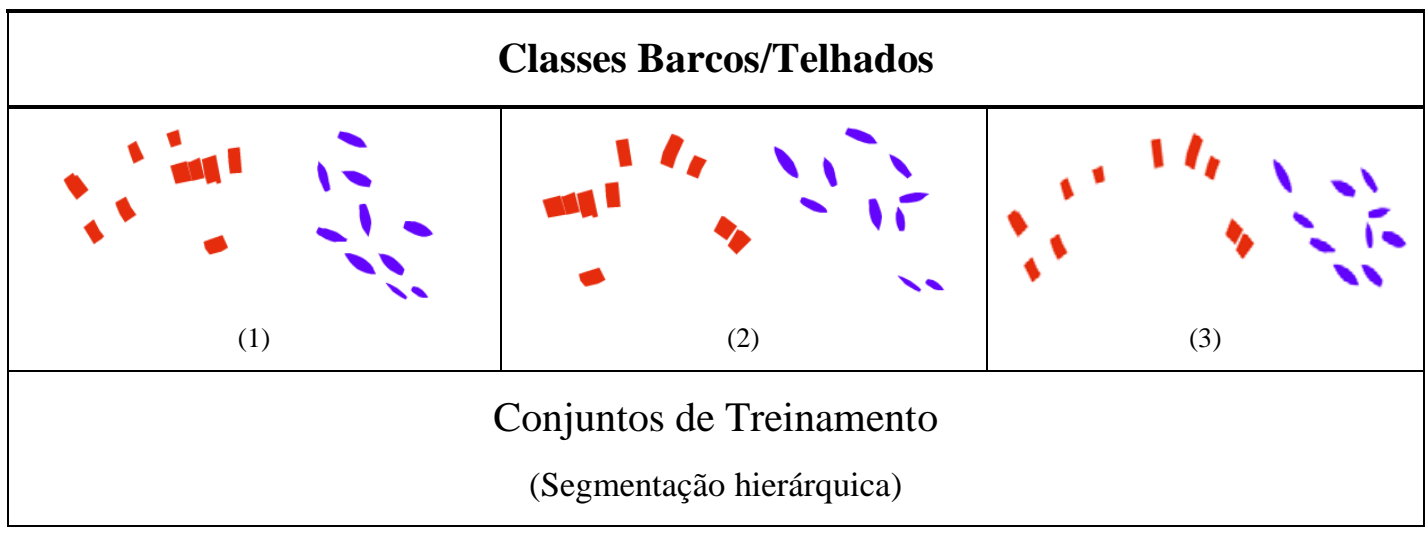

Figura A.3 - Conjuntos de treinamento, segmentação hierárquica (classes Barcos/Telhados), para a base de dados Maragogipe.

Os parâmetros dos segmentadores, encontrados pelo GPS, para cada classe e para cada conjunto de treinamento, são mostrados na Tabela A.1 para metodologia de segmentação específica e nas Tabelas A.2 e A.3 para as abordagens de segmentação hierárquica top-down e bottom-up respectivamente. 
Tabela A.1 - Parâmetros de segmentação obtidos pelo GPS, metodologia de segmentação específica, para a base de dados de Maragogipe.

\begin{tabular}{|c|c|c|c|c|c|}
\hline \multirow{2}{*}{ Segmentador } & \multirow{2}{*}{ Parâmetros } & \multicolumn{3}{|c|}{ Classes } & \multirow{2}{*}{ Conjunto } \\
\hline & & Barcos & Telhados & Vegetação & \\
\hline \multirow{10}{*}{ XMRS } & \multirow{3}{*}{$p_{e}$} & 60,08 & 46,56 & 21,80 & 1 \\
\hline & & 48,79 & 44,87 & 26,13 & 2 \\
\hline & & 53,03 & 42,95 & 23,30 & 3 \\
\hline & \multirow{3}{*}{$w_{\text {forma }}$} & 0,83 & 0,66 & 0,42 & 1 \\
\hline & & 0,85 & 0,67 & 0,36 & 2 \\
\hline & & 0,83 & 0,66 & 0,49 & 3 \\
\hline & \multirow{3}{*}{$w_{s}$} & 0,63 & 0,29 & 0,07 & 1 \\
\hline & & 0,42 & 0,35 & 0,07 & 2 \\
\hline & & 0,40 & 0,16 & 0,52 & 3 \\
\hline & Atributos de forma & Suav, Comp & Suav, Comp & Suav, Comp & $1,2,3$ \\
\hline \multirow{9}{*}{ MS } & \multirow{3}{*}{$h_{s}$} & 27,34 & 17,31 & 14,66 & 1 \\
\hline & & 15,50 & 18,09 & 10,68 & 2 \\
\hline & & 23,66 & 17,99 & 17,88 & 3 \\
\hline & \multirow{3}{*}{$h_{r}$} & 39,22 & 30,66 & 31,11 & 1 \\
\hline & & 30,30 & 29,58 & 17,13 & 2 \\
\hline & & 29,71 & 33,36 & 18,07 & 3 \\
\hline & \multirow{3}{*}{$A_{\min }$} & 153,78 & 179,21 & 103,28 & 1 \\
\hline & & 179,34 & 159,34 & 83,19 & 2 \\
\hline & & 143,21 & 178,62 & 80,13 & 3 \\
\hline \multirow{6}{*}{ SCR } & \multirow{3}{*}{$L_{s}$} & 20,38 & 20,33 & 20,96 & 1 \\
\hline & & 20,39 & 24,32 & 20,04 & 2 \\
\hline & & 22,15 & 24,92 & 20,98 & 3 \\
\hline & \multirow{3}{*}{$L_{a}$} & 478,37 & 491,71 & 201,99 & 1 \\
\hline & & 358,34 & 686,26 & 263,89 & 2 \\
\hline & & 794,39 & 232,35 & 201,58 & 3 \\
\hline
\end{tabular}


Tabela A.2 - Parâmetros de segmentação obtidos pelo GPS para a segmentação hierárquica com procedimento top-down para a base de dados de Maragogipe.

\begin{tabular}{|c|c|c|c|c|}
\hline \multirow[b]{2}{*}{ Segmentador } & \multirow[b]{2}{*}{ Parâmetros } & \multicolumn{2}{|c|}{ Classes } & \multirow[b]{2}{*}{ Conjunto } \\
\hline & & $\begin{array}{c}\text { Barcos } \\
\text { Telhados }\end{array}$ & Vegetação & \\
\hline \multirow{10}{*}{ XMRS } & \multirow{3}{*}{$p_{e}$} & 20,00 & 21,80 & 1 \\
\hline & & 20,43 & 26,13 & 2 \\
\hline & & 20,15 & 23,30 & 3 \\
\hline & \multirow{3}{*}{$w_{\text {forma }}$} & 0,50 & 0,42 & 1 \\
\hline & & 0,70 & 0,36 & 2 \\
\hline & & 0,51 & 0,49 & 3 \\
\hline & \multirow{3}{*}{$w_{s}$} & 0,30 & 0,07 & 1 \\
\hline & & 0,28 & 0,07 & 2 \\
\hline & & 0,26 & 0,52 & 3 \\
\hline & Atributos de forma & Suav, Comp & Suav, Comp & $1,2,3$ \\
\hline \multirow{9}{*}{ MS } & \multirow{3}{*}{$h_{s}$} & 18,28 & 14,66 & $\overline{1}$ \\
\hline & & 23,61 & 10,68 & 2 \\
\hline & & 16,44 & 17,88 & 3 \\
\hline & \multirow{3}{*}{$h_{r}$} & 29,38 & 31,11 & 1 \\
\hline & & 29,46 & 17,13 & 2 \\
\hline & & 47,72 & 18,07 & 3 \\
\hline & \multirow{3}{*}{$A_{\min }$} & 166,62 & 103,28 & 1 \\
\hline & & 176,50 & 83,19 & 2 \\
\hline & & 148,96 & 80,13 & 3 \\
\hline \multirow{6}{*}{ SCR } & \multirow{3}{*}{$L_{s}$} & 38,69 & 20,96 & 1 \\
\hline & & 25,40 & 20,04 & 2 \\
\hline & & 24,30 & 20,98 & 3 \\
\hline & \multirow{3}{*}{$L_{a}$} & 618,17 & 201,99 & 1 \\
\hline & & 551,52 & 263,89 & 2 \\
\hline & & 684,04 & 201,58 & 3 \\
\hline
\end{tabular}


Tabela A.3 - Parâmetros de segmentação obtidos pelo GPS para a segmentação hierárquica com procedimento bottom-up para a base de dados de Maragogipe.

\begin{tabular}{|c|c|c|c|c|}
\hline \multirow[b]{2}{*}{ Segmentador } & \multirow[b]{2}{*}{ Parâmetros } & \multicolumn{2}{|c|}{ Classes } & \multirow[b]{2}{*}{ Conjunto } \\
\hline & & $\begin{array}{c}\text { Barcos } \\
\text { Telhados }\end{array}$ & Vegetação & \\
\hline \multirow{10}{*}{ XMRS } & \multirow{3}{*}{$p_{e}$} & 62,44 & 21,80 & 1 \\
\hline & & 60,15 & 26,13 & 2 \\
\hline & & 41,69 & 23,30 & 3 \\
\hline & \multirow{3}{*}{$w_{\text {forma }}$} & 0,71 & 0,42 & 1 \\
\hline & & 0,75 & 0,36 & 2 \\
\hline & & 0,90 & 0,49 & 3 \\
\hline & \multirow{3}{*}{$w_{s}$} & 0,45 & 0,07 & 1 \\
\hline & & 0,48 & 0,07 & 2 \\
\hline & & 0,36 & 0,52 & 3 \\
\hline & Atributos de forma & Suav, Comp & Suav, Comp & $1,2,3$ \\
\hline \multirow{9}{*}{ MS } & \multirow{3}{*}{$h_{s}$} & 20,75 & 14,66 & $\overline{1}$ \\
\hline & & 21,84 & 10,68 & 2 \\
\hline & & 17,70 & 17,88 & 3 \\
\hline & \multirow{3}{*}{$h_{r}$} & 50,31 & 31,11 & 1 \\
\hline & & 52,14 & 17,13 & 2 \\
\hline & & 48,45 & 18,07 & 3 \\
\hline & \multirow{3}{*}{$A_{\min }$} & 178,03 & 103,28 & 1 \\
\hline & & 185,12 & 83,19 & 2 \\
\hline & & 192,01 & 80,13 & 3 \\
\hline \multirow{6}{*}{ SCR } & \multirow{3}{*}{$L_{s}$} & 20,51 & 20,96 & 1 \\
\hline & & 22,06 & 20,04 & 2 \\
\hline & & 21,05 & 20,98 & 3 \\
\hline & \multirow{3}{*}{$L_{a}$} & 201,98 & 201,99 & 1 \\
\hline & & 262,98 & 263,89 & 2 \\
\hline & & 200,48 & 201,58 & 3 \\
\hline
\end{tabular}

A exatidão espacial calculada pela métrica RBSB para as classes de interesse são mostradas nas Tabelas A.4 - A.6, para a metodologia de segmentação específica e nas Tabelas A.7 - A.9 para a segmentação hierárquica. 
Tabela A.4 - Métricas RBSB para a metodologia de segmentação específica da classe Barcos para a base de dados de Maragogipe.

\begin{tabular}{c|c|c|c|c|c}
\hline \multirow{4}{*}{ Segmentador } & \multicolumn{4}{c}{ Classes } & \multirow{2}{*}{ Conjunto } \\
\cline { 2 - 6 } & \multirow{2}{*}{ Treinamento } & \multicolumn{3}{c}{ Teste } & \\
\cline { 2 - 6 } & (Barcos) & Barcos & Telhados & Vegetação & \\
\hline \multirow{3}{*}{ XMRS } & 0,19 & 0,24 & 0,85 & 12,74 & 1 \\
\cline { 2 - 6 } & 0,15 & 0,16 & 0,64 & 18,34 & 2 \\
\cline { 2 - 6 } & 0,20 & 0,18 & 0,55 & 11,64 & 3 \\
\hline \multirow{3}{*}{ MS } & 0,41 & 0,45 & 0,91 & 13,64 & 1 \\
\cline { 2 - 6 } & 0,53 & 0,49 & 0,54 & 21,54 & 2 \\
\cline { 2 - 6 } & 0,46 & 0,48 & 0,59 & 9,66 & 3 \\
\cline { 2 - 6 } & 0,46 & 0,57 & 0,45 & 10,74 & 1 \\
\cline { 2 - 6 } & 0,52 & 0,54 & 0,47 & 40,02 & 2 \\
\hline
\end{tabular}

Tabela A.5 - Métricas RBSB para a metodologia de segmentação específica da classe Telhados para a base de dados de Maragogipe.

\begin{tabular}{c|c|c|c|c|c}
\hline \multirow{4}{*}{ Segmentador } & \multicolumn{4}{c}{ Classes } & \multirow{2}{*}{ Conjunto } \\
\cline { 2 - 6 } & \multirow{3}{*}{ Treinamento } & \multicolumn{3}{c}{ Teste } & \\
\cline { 2 - 6 } & (Telhados) & Barcos & Telhados & Vegetação & \\
\hline \multirow{3}{*}{ XMRS } & 0,22 & 0,51 & 0,31 & 6,25 & 1 \\
\cline { 2 - 6 } & 0,37 & 0,51 & 0,33 & 21,97 & 2 \\
\cline { 2 - 6 } & 0,24 & 0,57 & 0,33 & 11,67 & 3 \\
\hline \multirow{3}{*}{ MS } & 0,25 & 9,23 & 0,44 & 4,75 & 1 \\
\cline { 2 - 6 } & 0,49 & 0,56 & 0,49 & 33,23 & 2 \\
\cline { 2 - 6 } & 0,23 & 0,56 & 0,45 & 125,98 & 3 \\
\cline { 2 - 6 } & 0,38 & 25,01 & 0,39 & 3,58 & 1 \\
\cline { 2 - 6 } & 0,57 & 16,52 & 0,45 & 25,26 & 2 \\
\hline
\end{tabular}


Tabela A.6 - Métricas RBSB para a metodologia de segmentação específica e hierárquica bottom-up, da classe Vegetação para a base de dados de Maragogipe.

\begin{tabular}{|c|c|c|c|c|c|}
\hline \multirow{3}{*}{ Segmentador } & \multicolumn{4}{|c|}{ Classes } & \multirow{3}{*}{ Conjunto } \\
\hline & \multirow{2}{*}{$\begin{array}{c}\text { Treinamento } \\
\text { (Vegetação) }\end{array}$} & \multicolumn{3}{|c|}{ Teste } & \\
\hline & & Barcos & Telhados & Vegetação & \\
\hline \multirow{3}{*}{ XMRS } & 0,65 & 0,46 & 0,66 & 0,68 & 1 \\
\hline & 0,80 & 6,96 & 7,95 & 0,80 & 2 \\
\hline & 0,72 & 13,74 & 12,91 & 0,72 & 3 \\
\hline \multirow{3}{*}{ MS } & 0,74 & 0,40 & 0,61 & 0,78 & 1 \\
\hline & 0,76 & 2,93 & 0,51 & 0,78 & 2 \\
\hline & 0,60 & 19,31 & 18,0 & 1,22 & 3 \\
\hline \multirow{3}{*}{ SCR } & 2,02 & 0,58 & 0,50 & 3,12 & 1 \\
\hline & 3,53 & 0,58 & 0,51 & 3,71 & 2 \\
\hline & 2,19 & 0,58 & 0,51 & 2,70 & 3 \\
\hline
\end{tabular}

Tabela A.7 - Métricas RBSB para a segmentação hierárquica, procedimento top-down, específica para a classe Barcos/Telhados para a base de dados de Maragogipe.

\begin{tabular}{|c|c|c|c|c|c|}
\hline \multirow{3}{*}{ Segmentador } & \multicolumn{4}{|c|}{ Classes } & \multirow{3}{*}{ Conjunto } \\
\hline & \multirow{2}{*}{$\begin{array}{c}\text { Treinamento } \\
\left(\begin{array}{c}\text { Barcos } \\
\text { Telhados }\end{array}\right)\end{array}$} & \multicolumn{3}{|c|}{ Teste } & \\
\hline & & Barcos & Telhados & Vegetação & \\
\hline \multirow{3}{*}{ XMRS } & 0,28 & 0,32 & 0,45 & 9,33 & 1 \\
\hline & 0,32 & 0,49 & 0,36 & 7,44 & 2 \\
\hline & 0,30 & 0,22 & 0,69 & 12,08 & 3 \\
\hline \multirow{3}{*}{ MS } & 0,47 & 0,49 & 0,45 & 33,24 & 1 \\
\hline & 0,49 & 0,57 & 0,59 & 40,86 & 2 \\
\hline & 0,46 & 0,53 & 0,48 & 36,45 & 3 \\
\hline \multirow{3}{*}{ SCR } & 0,53 & 0,60 & 0,76 & 102 & 1 \\
\hline & 0,43 & 0,51 & 0,55 & 138 & 2 \\
\hline & 0,46 & 0,48 & 0,52 & 125 & 3 \\
\hline
\end{tabular}


Tabela A.8 - Métricas RBSB para a segmentação hierárquica, procedimento top-down, específica para a classe Vegetação para a base de dados de Maragogipe.

\begin{tabular}{|c|c|c|c|c|c|}
\hline \multirow{3}{*}{ Segmentador } & \multicolumn{4}{|c|}{ Classes } & \multirow{3}{*}{ Conjunto } \\
\hline & \multirow{2}{*}{$\begin{array}{c}\text { Treinamento } \\
\text { (Vegetação) }\end{array}$} & \multicolumn{3}{|c|}{ Teste } & \\
\hline & & Barcos & Telhados & Vegetação & \\
\hline \multirow{3}{*}{ XMRS } & 0,68 & 0,39 & 0,47 & 0,69 & 1 \\
\hline & 0,77 & 0,42 & 0,59 & 0,71 & 2 \\
\hline & 0,69 & 0,29 & 0,47 & 0,87 & 3 \\
\hline \multirow{3}{*}{ MS } & 0,97 & 0,55 & 0,86 & 1,08 & 1 \\
\hline & 1,01 & 5,23 & 0,88 & 1,17 & 2 \\
\hline & 1,45 & 0,67 & 4,56 & 1,52 & 3 \\
\hline \multirow{3}{*}{ SCR } & 0,69 & 15,35 & 6,15 & 0,70 & 1 \\
\hline & 0,68 & 16,52 & 0,74 & 0,80 & 2 \\
\hline & 0,69 & 16,52 & 0,63 & 0,87 & 3 \\
\hline
\end{tabular}

Tabela A.9 - Métricas RBSB para a segmentação hierárquica, procedimento bottom-up, específica para a classe Barcos/Telhados para a base de dados de Maragogipe.

\begin{tabular}{|c|c|c|c|c|c|}
\hline \multirow{3}{*}{ Segmentador } & \multicolumn{4}{|c|}{ Classes } & \multirow{3}{*}{ Conjunto } \\
\hline & \multirow{2}{*}{$\begin{array}{c}\text { Treinamento } \\
\left(\begin{array}{c}\text { Barcos } \\
\text { Telhados }\end{array}\right)\end{array}$} & \multicolumn{3}{|c|}{ Teste } & \\
\hline & & Barcos & Telhados & Vegetação & \\
\hline \multirow{3}{*}{ XMRS } & 0,20 & 0,30 & 0,41 & 8,76 & 1 \\
\hline & 0,17 & 0,26 & 0,47 & 5,93 & 2 \\
\hline & 0,25 & 0,30 & 0,49 & 12,14 & 3 \\
\hline \multirow{3}{*}{ MS } & 0,48 & 0,55 & 0,54 & 13,30 & 1 \\
\hline & 0,46 & 0,50 & 0,54 & 9,53 & 2 \\
\hline & 0,51 & 0,54 & 0,78 & 1,80 & 3 \\
\hline \multirow{3}{*}{ SCR } & 80,42 & 72,25 & 139,74 & 103,73 & 1 \\
\hline & 74,51 & 78,40 & 141,64 & 105 & 2 \\
\hline & 91,04 & 85,45 & 139,74 & 104,58 & 3 \\
\hline
\end{tabular}


A.1.1.2

\section{Base de dados REDUC}

As imagens de referência para os conjuntos de treinamento e de teste, para cada classe de interesse, são mostradas nas Figuras A.4 - A.5.

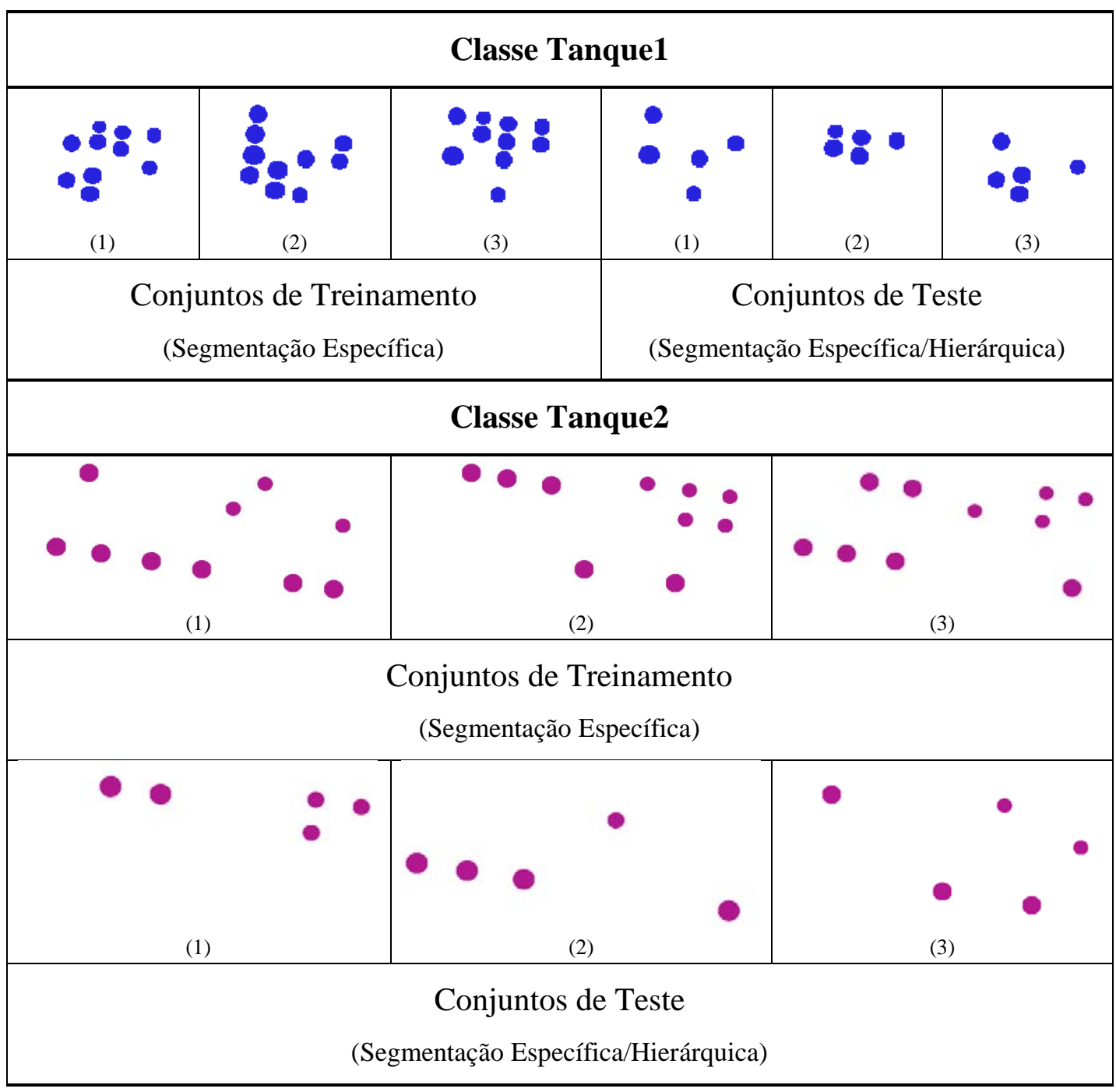

Figura A.4 - Conjuntos de treinamento e teste (classes Tanque1 e Tanque2), para a base de dados REDUC. 


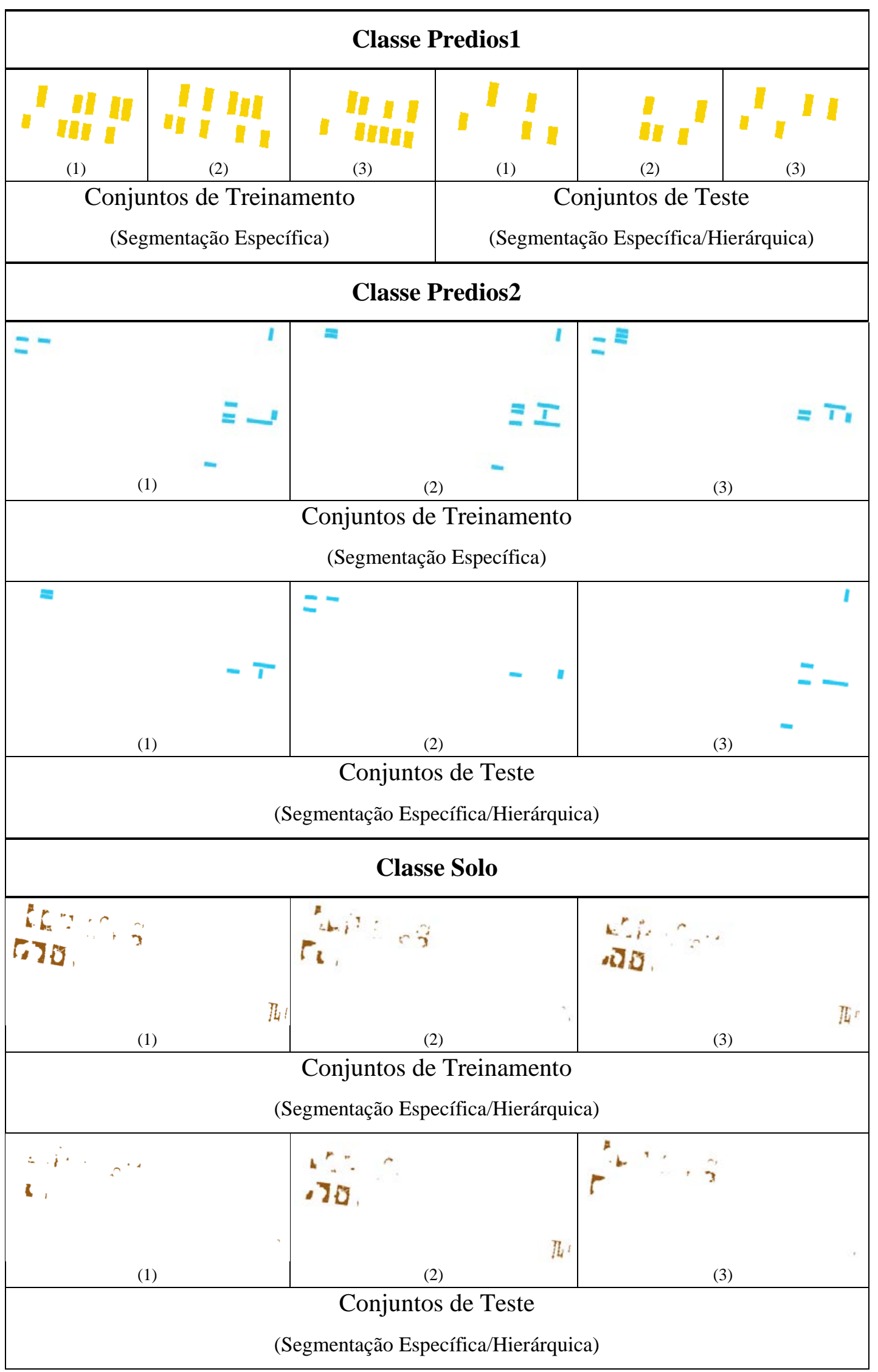

Figura A.5 - Conjuntos de treinamento e teste (classes Predios1, Predios2 e Solo), para a base de dados REDUC. 


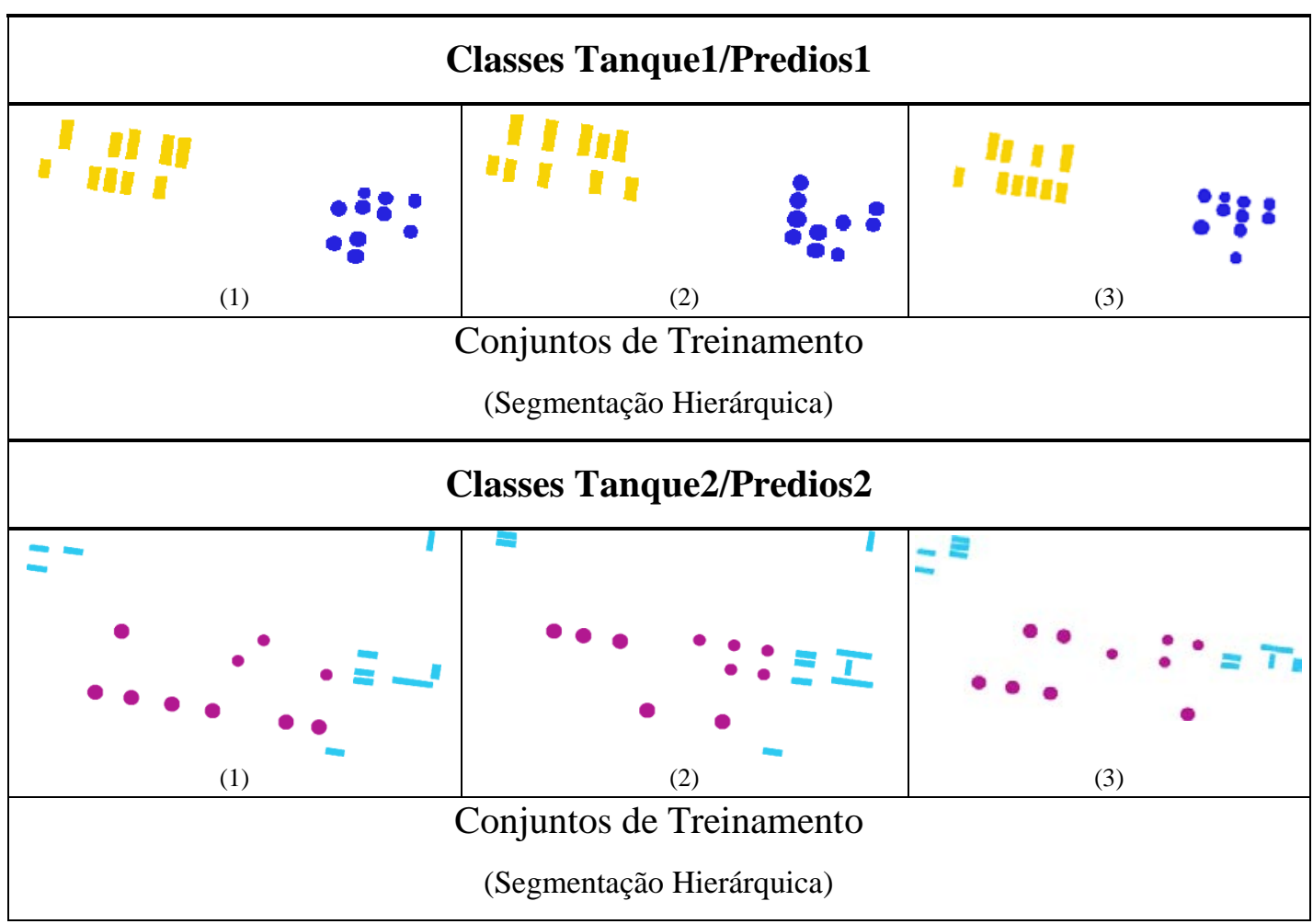

Figura A.6 - Conjuntos de treinamento (classes Tanque1/Predios1 e Tanque2/Predios2), segmentação hierárquica, para a base de dados REDUC.

Os parâmetros dos segmentadores, encontrados pelo GPS, para cada classe e para cada conjunto de treinamento, são mostrados na Tabela A.10 para metodologia de segmentação específica e nas Tabelas A.11 e A.12 para as abordagens de segmentação hierárquica top-down e bottom-up respectivamente. 
Tabela A10 - Parâmetros de segmentação obtidos pelo GPS, metodologia de segmentação específica, para a base de dados REDUC.

\begin{tabular}{|c|c|c|c|c|c|c|c|}
\hline \multirow{2}{*}{ Segmentador } & \multirow{2}{*}{ Parâmetros } & \multicolumn{5}{|c|}{ Classes } & \multirow{2}{*}{ Conjunto } \\
\hline & & Tanque1 & Tanque2 & Predios1 & Predios2 & Solo & \\
\hline \multirow{10}{*}{ XMRS } & \multirow{3}{*}{$p_{e}$} & 13,88 & 68,63 & 24,02 & 37,79 & 11,71 & 1 \\
\hline & & 18,27 & 78,84 & 19,04 & 36,60 & 15,78 & 2 \\
\hline & & 23,82 & 61,26 & 17,42 & 33,51 & 14,29 & 3 \\
\hline & \multirow{3}{*}{$w_{\text {forma }}$} & 0,83 & 0,67 & 0,54 & 0,75 & 0,59 & 1 \\
\hline & & 0,82 & 0,70 & 0,75 & 0,83 & 0,50 & 2 \\
\hline & & 0,79 & 0,66 & 0,79 & 0,86 & 0,64 & 3 \\
\hline & \multirow{3}{*}{$w_{s}$} & 0,26 & 0,63 & 0,04 & 0,60 & 0,10 & 1 \\
\hline & & 0,41 & 0,65 & 0,74 & 0,75 & 0,02 & 2 \\
\hline & & 0,34 & 0,75 & 0,18 & 0,56 & 0,23 & 3 \\
\hline & $\begin{array}{l}\text { Atributos de } \\
\text { forma }\end{array}$ & $\begin{array}{l}\text { Suav } \\
\text { Comp }\end{array}$ & $\begin{array}{l}\text { Suav } \\
\text { FFC }\end{array}$ & $\begin{array}{l}\text { Suav } \\
\text { Comp }\end{array}$ & $\begin{array}{l}\text { Suav } \\
\text { Comp }\end{array}$ & $\begin{array}{l}\text { Suav } \\
\text { Comp }\end{array}$ & $1,2,3$ \\
\hline \multirow{9}{*}{ MS } & \multirow{3}{*}{$h_{s}$} & 23,24 & 38,04 & 38,61 & 15,90 & 1,97 & 1 \\
\hline & & 14,90 & 39,45 & 41,47 & 18,45 & 1,51 & 2 \\
\hline & & 31,91 & 40,00 & 37,22 & 18,97 & 9,14 & 3 \\
\hline & \multirow{3}{*}{$h_{r}$} & 6,19 & 39,53 & 4,24 & 2,81 & 23,05 & 1 \\
\hline & & 43,66 & 37,84 & 8,47 & 4,24 & 42,70 & 2 \\
\hline & & 20,95 & 40,56 & 8,60 & 6,62 & 41,91 & 3 \\
\hline & \multirow{3}{*}{$A_{\min }$} & 146,45 & 169,40 & 91,94 & 163,17 & 102,45 & 1 \\
\hline & & 144,93 & 157,12 & 153,38 & 179,98 & 97,56 & 2 \\
\hline & & 160,86 & 120,45 & 169,14 & 168,15 & 82,87 & 3 \\
\hline \multirow{6}{*}{ SCR } & \multirow{3}{*}{$L_{s}$} & 22,28 & 35,02 & 20,00 & 22,95 & 25,32 & 1 \\
\hline & & 24,68 & 61,73 & 21,01 & 22,19 & 20,45 & 2 \\
\hline & & 27,02 & 75,62 & 20,86 & 25,71 & 20,47 & 3 \\
\hline & \multirow{3}{*}{$L_{a}$} & 200,14 & 566,40 & 457,00 & 202,65 & 200,08 & 1 \\
\hline & & 212,47 & 329,14 & 511,52 & 202,68 & 200,38 & 2 \\
\hline & & 283,10 & 629,43 & 280,12 & 212,28 & 222,10 & 3 \\
\hline
\end{tabular}


Tabela A.11 - Parâmetros de segmentação obtidos pelo GPS para a segmentação hierárquica com procedimento top-down para a base de dados REDUC.

\begin{tabular}{|c|c|c|c|c|c|}
\hline Segmentador & Parâmetros & $\begin{array}{l}\text { Tanque2 } \\
\text { Predios2 }\end{array}$ & $\begin{array}{c}\text { Classes } \\
\text { Tanque1 } \\
\text { Predios1 }\end{array}$ & Solo & Conjunto \\
\hline \multirow{10}{*}{ XMRS } & \multirow{3}{*}{$p_{e}$} & 32,92 & 22,74 & 11,71 & 1 \\
\hline & & 21,89 & 20,37 & 15,78 & 2 \\
\hline & & 34,84 & 26,94 & 14,29 & 3 \\
\hline & \multirow{3}{*}{$w_{\text {forma }}$} & 0,94 & 0,73 & 0,59 & 1 \\
\hline & & 0,95 & 0,86 & 0,50 & 2 \\
\hline & & 0,89 & 0,54 & 0,64 & 3 \\
\hline & \multirow{3}{*}{$w_{s}$} & 0,54 & 0,40 & 0,10 & 1 \\
\hline & & 0,60 & 0,56 & 0,02 & 2 \\
\hline & & 0,57 & 0,40 & 0,23 & 3 \\
\hline & Atributos de forma & Suav, Comp & Suav, Comp & Suav, Comp & $1,2,3$ \\
\hline \multirow{9}{*}{ MS } & \multirow{3}{*}{$h_{s}$} & 17,68 & 28,23 & 1,97 & 1 \\
\hline & & 16,71 & 14,77 & 1,51 & 2 \\
\hline & & 18,69 & 21,71 & 9,14 & 3 \\
\hline & \multirow{3}{*}{$h_{r}$} & 2,79 & 6,20 & 23,05 & 1 \\
\hline & & 2,97 & 7,11 & 42,70 & 2 \\
\hline & & 4,27 & 10,66 & 41,91 & 3 \\
\hline & \multirow{3}{*}{$A_{\text {min }}$} & 172,84 & 172,81 & 102,45 & 1 \\
\hline & & 178,61 & 147,63 & 97,56 & 2 \\
\hline & & 169,31 & 177,41 & 82,87 & 3 \\
\hline \multirow{6}{*}{ SCR } & \multirow{3}{*}{$L_{s}$} & 23,35 & 22,04 & 25,32 & 1 \\
\hline & & 22,73 & 24,27 & 20,45 & 2 \\
\hline & & 23,97 & 21,96 & 20,47 & 3 \\
\hline & \multirow{3}{*}{$L_{a}$} & 282,02 & 202,27 & 200,08 & 1 \\
\hline & & 280,89 & 202,27 & 200,38 & 2 \\
\hline & & 251,79 & 204,88 & 222,10 & 3 \\
\hline
\end{tabular}


Tabela A.12 - Parâmetros de segmentação obtidos pelo GPS para a segmentação hierárquica com procedimento bottom-up para a base de dados REDUC.

\begin{tabular}{|c|c|c|c|c|c|}
\hline Segmentador & Parâmetros & $\begin{array}{l}\text { Tanque2 } \\
\text { Predios2 }\end{array}$ & $\begin{array}{l}\text { Classes } \\
\text { Tanque1 } \\
\text { Predios1 }\end{array}$ & Solo & Conjunto \\
\hline \multirow{10}{*}{ XMRS } & \multirow{3}{*}{$p_{e}$} & 37,21 & 23,04 & 11,71 & 1 \\
\hline & & 47,41 & 24,73 & 15,78 & 2 \\
\hline & & 24,57 & 29,70 & 14,29 & 3 \\
\hline & \multirow{3}{*}{$w_{\text {forma }}$} & 0,91 & 0,88 & 0,59 & 1 \\
\hline & & 0,84 & 0,85 & 0,50 & 2 \\
\hline & & 0,97 & 0,81 & 0,64 & 3 \\
\hline & \multirow{3}{*}{$w_{s}$} & 0,50 & 0,36 & 0,10 & 1 \\
\hline & & 0,51 & 0,37 & 0,02 & 2 \\
\hline & & 0,92 & 0,24 & 0,23 & 3 \\
\hline & Atributos de forma & Suav, Comp & Suav, Comp & Suav, Comp & $1,2,3$ \\
\hline \multirow{9}{*}{ MS } & \multirow{3}{*}{$h_{s}$} & 13,55 & 28,23 & 1,97 & 1 \\
\hline & & 12,14 & 14,77 & 1,51 & 2 \\
\hline & & 23,11 & 21,71 & 9,14 & 3 \\
\hline & \multirow{3}{*}{$h_{r}$} & 25,27 & 6,20 & 23,05 & 1 \\
\hline & & 12,90 & 7,11 & 42,70 & 2 \\
\hline & & 11,46 & 12,66 & 41,91 & 3 \\
\hline & \multirow{3}{*}{$A_{\min }$} & 88,81 & 172,81 & 102,45 & 1 \\
\hline & & 107,13 & 147,63 & 97,56 & 2 \\
\hline & & 100,61 & 177,41 & 82,87 & 3 \\
\hline \multirow{6}{*}{ SCR } & \multirow{3}{*}{$L_{s}$} & 23,33 & 22,04 & 25,32 & 1 \\
\hline & & 20,36 & 24,27 & 20,45 & 2 \\
\hline & & 34,08 & 21,95 & 20,47 & 3 \\
\hline & \multirow{3}{*}{$L_{a}$} & 249,60 & 202,27 & 200,08 & 1 \\
\hline & & 210,92 & 202,27 & 200,38 & 2 \\
\hline & & 200,00 & 204,88 & 222,10 & 3 \\
\hline
\end{tabular}

A exatidão espacial calculada pela métrica RBSB para as classes de interesse são mostradas nas Tabelas A.13 - A.17, para a metodologia de segmentação específica e nas Tabelas A.18 - A.22 para a segmentação hierárquica. 
Tabela A.13 - Métricas RBSB para a metodologia de segmentação específica da classe Tanque1 para a base de dados REDUC.

\begin{tabular}{|c|c|c|c|c|c|c|c|}
\hline \multirow{3}{*}{ Segmentador } & \multicolumn{6}{|c|}{ Classes } & \multirow{3}{*}{ Conjunto } \\
\hline & \multirow{2}{*}{$\begin{array}{c}\text { Treinamento } \\
\text { (Tanque1) }\end{array}$} & \multicolumn{5}{|c|}{ Teste } & \\
\hline & & Tanque1 & Tanque2 & Predios1 & Predios2 & Solo & \\
\hline \multirow{3}{*}{ XMRS } & 0,23 & 0,23 & 0,47 & 0,31 & 0,65 & 5,60 & 1 \\
\hline & 0,17 & 0,24 & 0,33 & 0,29 & 0,40 & 6,05 & 2 \\
\hline & 0,20 & 0,23 & 0,24 & 0,29 & 0,37 & 11,23 & 3 \\
\hline \multirow{3}{*}{ MS } & 0,31 & 0,40 & 0,35 & 0,38 & 0,68 & 7,96 & 1 \\
\hline & 0,29 & 0,38 & 0,44 & 0,32 & 2,01 & 14,45 & 2 \\
\hline & 0,24 & 0,30 & 0,31 & 0,31 & 1,93 & 102,86 & 3 \\
\hline \multirow{3}{*}{ SCR } & 0,28 & 0,35 & 0,34 & 0,58 & 0,97 & 8,10 & 1 \\
\hline & 0,33 & 0,44 & 0,28 & 0,32 & 8,76 & 16,56 & 2 \\
\hline & 0,29 & 0,47 & 0,27 & 0,34 & 2,54 & 84,40 & 3 \\
\hline
\end{tabular}

Tabela A.14 - Métricas RBSB para a metodologia de segmentação específica da classe Tanque2 para a base de dados REDUC.

\begin{tabular}{|c|c|c|c|c|c|c|c|}
\hline \multirow{3}{*}{ Segmentador } & \multicolumn{6}{|c|}{ Classes } & \multirow{3}{*}{ Conjunto } \\
\hline & \multirow{2}{*}{$\begin{array}{c}\text { Treinamento } \\
\text { (Tanque2) }\end{array}$} & \multicolumn{5}{|c|}{ Teste } & \\
\hline & & Tanque1 & Tanque2 & Predios1 & Predios2 & Solo & \\
\hline \multirow{3}{*}{ XMRS } & 0,14 & 1,12 & 0,23 & 0,89 & 0,40 & 29,28 & 1 \\
\hline & 0,11 & 11,84 & 0,14 & 11,22 & 2,25 & 61,11 & 2 \\
\hline & 0,12 & 6,59 & 0,17 & 2,69 & 1,21 & 43,93 & 3 \\
\hline \multirow{3}{*}{ MS } & 0,11 & 0,82 & 0,34 & 1,63 & 4,83 & 128,10 & 1 \\
\hline & 0,10 & 0,88 & 0,22 & 1,57 & 4,81 & 131,25 & 2 \\
\hline & 0,12 & 5,28 & 0,14 & 1,36 & 9,75 & 95,70 & 3 \\
\hline \multirow{3}{*}{ SCR } & 0,15 & 6,69 & 0,24 & 37,55 & 45,55 & 111,56 & 1 \\
\hline & 0,09 & 43,12 & 0,15 & 8,26 & 30,89 & 231,87 & 2 \\
\hline & 0,11 & 70,09 & 0,26 & 97,54 & 39,11 & 323,80 & 3 \\
\hline
\end{tabular}


Tabela A.15 - Métricas RBSB para a metodologia de segmentação específica da classe Predios1 para a base de dados REDUC.

\begin{tabular}{|c|c|c|c|c|c|c|c|}
\hline \multirow{3}{*}{ Segmentador } & \multicolumn{6}{|c|}{ Classes } & \multirow{3}{*}{ Conjunto } \\
\hline & \multirow{2}{*}{$\begin{array}{c}\text { Treinamento } \\
\text { (Predios1) }\end{array}$} & \multicolumn{5}{|c|}{ Teste } & \\
\hline & & Tanque1 & Tanque2 & Predios1 & Predios2 & Solo & \\
\hline \multirow{3}{*}{ XMRS } & 0,23 & 0,30 & 0,44 & 0,24 & 0,51 & 7,55 & 1 \\
\hline & 0,23 & 0,26 & 0,44 & 0,26 & 0,51 & 5,55 & 2 \\
\hline & 0,24 & 0,26 & 0,40 & 0,26 & 0,55 & 7,78 & 3 \\
\hline \multirow{3}{*}{ MS } & 0,26 & 0,44 & 0,17 & 0,28 & 3,99 & 97,28 & 1 \\
\hline & 0,28 & 0,38 & 0,56 & 0,30 & 0,65 & 6,20 & 2 \\
\hline & 0,27 & 0,98 & 0,35 & 0,27 & 1,75 & 87,12 & 3 \\
\hline \multirow{3}{*}{ SCR } & 0,24 & 2,27 & 0,24 & 0,29 & 1,95 & 23,81 & 1 \\
\hline & 0,28 & 2,60 & 0,25 & 0,32 & 0,98 & 23,87 & 2 \\
\hline & 0,32 & 0,52 & 0,33 & 0,27 & 1,24 & 12,15 & 3 \\
\hline
\end{tabular}

Tabela A.16 - Métricas RBSB para a metodologia de segmentação específica da classe Predios2, para a base de dados REDUC.

\begin{tabular}{|c|c|c|c|c|c|c|c|}
\hline \multirow{3}{*}{ Segmentador } & \multicolumn{6}{|c|}{ Classes } & \multirow{3}{*}{ Conjunto } \\
\hline & \multirow{2}{*}{$\begin{array}{c}\text { Treinamento } \\
\text { (Predios2) }\end{array}$} & \multicolumn{5}{|c|}{ Teste } & \\
\hline & & Tanque1 & Tanque2 & Predios1 & Predios2 & Solo & \\
\hline \multirow{3}{*}{ XMRS } & 0,21 & 0,78 & 0,23 & 0,39 & 0,39 & 14,05 & 1 \\
\hline & 0,26 & 2,10 & 0,19 & 0,86 & 0,32 & 25,20 & 2 \\
\hline & 0,28 & 0,83 & 0,20 & 0,41 & 0,30 & 22,21 & 3 \\
\hline \multirow{3}{*}{ MS } & 0,34 & 0,36 & 0,36 & 0,39 & 0,41 & 7,79 & 1 \\
\hline & 0,42 & 0,29 & 0,39 & 0,39 & 0,43 & 7,21 & 2 \\
\hline & 0,35 & 0,36 & 0,50 & 0,30 & 0,42 & 6,58 & 3 \\
\hline \multirow{3}{*}{ SCR } & 0,95 & 0,35 & 0,32 & 0,58 & 1,13 & 8,60 & 1 \\
\hline & 0,99 & 0,34 & 0,33 & 0,58 & 0,92 & 8,10 & 2 \\
\hline & 2,63 & 0,56 & 0,30 & 0,30 & 3,18 & 17,61 & 3 \\
\hline
\end{tabular}


Tabela A.17 - Métricas RBSB para a metodologia de segmentação específica e hierárquica bottom-up, da classe Solo, para a base de dados REDUC.

\begin{tabular}{|c|c|c|c|c|c|c|c|}
\hline \multirow{3}{*}{ Segmentador } & \multicolumn{6}{|c|}{ Classes } & \multirow{3}{*}{ Conjunto } \\
\hline & \multirow{2}{*}{$\begin{array}{c}\text { Treinamento } \\
\text { (Solo) }\end{array}$} & \multicolumn{5}{|c|}{ Teste } & \\
\hline & & Tanque1 & Tanque2 & Predios1 & Predios2 & Solo & \\
\hline \multirow{3}{*}{ XMRS } & 0,53 & 0,54 & 0,71 & 0,61 & 0,76 & 0,78 & 1 \\
\hline & 0,72 & 0,46 & 0,69 & 0,45 & 0,67 & 0,94 & 2 \\
\hline & 0,73 & 0,47 & 0,71 & 0,41 & 0,69 & 0,83 & 3 \\
\hline \multirow{3}{*}{ MS } & 1,26 & 0,53 & 0,68 & 0,58 & 0,77 & 1,52 & 1 \\
\hline & 1,09 & 0,53 & 0,68 & 0,60 & 0,78 & 1,47 & 2 \\
\hline & 1,46 & 0,49 & 0,59 & 0,32 & 1,03 & 1,74 & 3 \\
\hline \multirow{3}{*}{ SCR } & 7,43 & 0,59 & 0,30 & 0,30 & 4,12 & 8,98 & 1 \\
\hline & 3,44 & 0,38 & 0,33 & 0,58 & 1,75 & 6,50 & 2 \\
\hline & 4,21 & 0,46 & 0,33 & 0,58 & 1,76 & 9,81 & 3 \\
\hline
\end{tabular}

Tabela A.18 - Métricas RBSB para a segmentação hierárquica procedimento top-down, específica para a classe Tanque2/Predios2, para a base de dados REDUC.

\begin{tabular}{|c|c|c|c|c|c|c|c|}
\hline \multirow{3}{*}{ Segmentador } & \multicolumn{6}{|c|}{ Classes } & \multirow{3}{*}{ Conjunto } \\
\hline & \multirow{2}{*}{$\begin{array}{c}\text { Treinamento } \\
\left(\begin{array}{c}\text { Tanque2 } \\
\text { Predios2 }\end{array}\right)\end{array}$} & \multicolumn{5}{|c|}{ Teste } & \\
\hline & & Tanque1 & Tanque2 & Predios1 & Predios2 & Solo & \\
\hline \multirow{3}{*}{ XMRS } & 0,26 & 1,92 & 0,27 & 0,73 & 0,47 & 8,30 & 1 \\
\hline & 0,18 & 0,46 & 0,25 & 0,32 & 0,40 & 8,21 & 2 \\
\hline & 0,16 & 2,85 & 0,17 & 1,74 & 0,42 & 15,60 & 3 \\
\hline \multirow{3}{*}{ MS } & 0,31 & 0,42 & 0,40 & 0,42 & 0,47 & 3,41 & 1 \\
\hline & 0,33 & 0,43 & 0,42 & 0,40 & 0,43 & 4,73 & 2 \\
\hline & 0,39 & 0,29 & 0,40 & 0,40 & 0,46 & 3,12 & 3 \\
\hline \multirow{3}{*}{ SCR } & 0,82 & 0,55 & 0,28 & 0,29 & 1,00 & 13,66 & 1 \\
\hline & 1,03 & 0,59 & 0,29 & 0,60 & 1,33 & 14,96 & 2 \\
\hline & 1,28 & 0,46 & 0,35 & 0,29 & 3,28 & 5,64 & 3 \\
\hline
\end{tabular}


Tabela A.19 - Métricas RBSB para a segmentação hierárquica procedimento top-down, específica para a classe Tanque1/Predios1, para a base de dados REDUC.

\begin{tabular}{|c|c|c|c|c|c|c|c|}
\hline \multirow{3}{*}{ Segmentador } & \multicolumn{6}{|c|}{ Classes } & \multirow{3}{*}{ Conjunto } \\
\hline & \multirow{2}{*}{$\begin{array}{c}\text { Treinamento } \\
\left(\begin{array}{c}\text { Tanque1 } \\
\text { Predios1 }\end{array}\right)\end{array}$} & \multicolumn{5}{|c|}{ Teste } & \\
\hline & & Tanque1 & Tanque2 & Predios1 & Predios2 & Solo & \\
\hline \multirow{3}{*}{ XMRS } & 0,28 & 0,41 & 0,37 & 0,24 & 0,43 & 3,32 & 1 \\
\hline & 0,25 & 0,27 & 0,23 & 0,27 & 0,38 & 5,59 & 2 \\
\hline & 0,25 & 0,33 & 0,43 & 0,27 & 0,47 & 3,31 & 3 \\
\hline \multirow{3}{*}{ MS } & 0,36 & 1,94 & 0,49 & 0,62 & 0,47 & 3,78 & 1 \\
\hline & 0,33 & 0,94 & 0,57 & 0,56 & 0,54 & 3,90 & 2 \\
\hline & 0,27 & 1,53 & 0,56 & 0,74 & 0,50 & 4,00 & 3 \\
\hline \multirow{3}{*}{ SCR } & 0,34 & 0,38 & 0,40 & 0,32 & 0,96 & 10,66 & 1 \\
\hline & 0,37 & 0,44 & 0,34 & 0,57 & 0,94 & 9,15 & 2 \\
\hline & 0,39 & 0,48 & 0,48 & 0,39 & 1,78 & 4,40 & 3 \\
\hline
\end{tabular}

Tabela A.20 - Métricas RBSB para a segmentação hierárquica procedimento top-down, específica para a classe Vegetação, para a base de dados REDUC.

\begin{tabular}{|c|c|c|c|c|c|c|c|}
\hline \multirow{3}{*}{ Segmentador } & \multicolumn{6}{|c|}{ Classes } & \multirow{3}{*}{ Conjunto } \\
\hline & \multirow{2}{*}{$\begin{array}{c}\text { Treinamento } \\
\text { (Solo) }\end{array}$} & \multicolumn{5}{|c|}{ Teste } & \\
\hline & & Tanque1 & Tanque2 & Predios1 & Predios2 & Solo & \\
\hline \multirow{3}{*}{ XMRS } & 0,65 & 0,54 & 0,78 & 0,57 & 0,74 & 0,69 & 1 \\
\hline & 0,65 & 0,47 & 0,72 & 0,46 & 0,67 & 0,78 & 2 \\
\hline & 0,62 & 0,43 & 0,73 & 0,41 & 0,69 & 0,84 & 3 \\
\hline \multirow{3}{*}{ MS } & 0,92 & 0,51 & 0,67 & 0,58 & 0,74 & 1,51 & 1 \\
\hline & 0,85 & 0,47 & 0,65 & 0,65 & 0,80 & 1,12 & 2 \\
\hline & 0,89 & 0,56 & 0,66 & 0,60 & 0,81 & 1,35 & 3 \\
\hline \multirow{3}{*}{ SCR } & 1,25 & 0,38 & 0,40 & 0,28 & 0,96 & 7,28 & 1 \\
\hline & 0,95 & 0,35 & 0,45 & 0,32 & 1,25 & 5,26 & 2 \\
\hline & 0,89 & 0,42 & 0,39 & 0,35 & 1,40 & 5,15 & 3 \\
\hline
\end{tabular}


Tabela A.21 - Métricas RBSB para a segmentação hierárquica procedimento bottom-up, específica para a classe Tanque2/Predios2, para a base de dados REDUC.

\begin{tabular}{|c|c|c|c|c|c|c|c|}
\hline \multirow{3}{*}{ Segmentador } & \multicolumn{6}{|c|}{ Classes } & \multirow{3}{*}{ Conjunto } \\
\hline & \multirow{2}{*}{$\begin{array}{c}\text { Treinamento } \\
\left(\begin{array}{c}\text { Tanque2 } \\
\text { Predios2 }\end{array}\right)\end{array}$} & \multicolumn{5}{|c|}{ Teste } & \\
\hline & & Tanque1 & Tanque2 & Predios1 & Predios2 & Solo & \\
\hline \multirow{3}{*}{ XMRS } & 0,18 & 1,54 & 0,24 & 0,41 & 0,45 & 12,67 & 1 \\
\hline & 0,22 & 0,72 & 0,28 & 1,14 & 0,38 & 9,19 & 2 \\
\hline & 0,17 & 1,59 & 0,25 & 0,36 & 0,34 & 12,47 & 3 \\
\hline \multirow{3}{*}{ MS } & 0,75 & 0,41 & 0,35 & 0,29 & 1,63 & 5,62 & 1 \\
\hline & 0,76 & 0,42 & 0,36 & 0,32 & 1,51 & 4,44 & 2 \\
\hline & 0,55 & 0,46 & 0,39 & 0,51 & 1,24 & 6,47 & 3 \\
\hline \multirow{3}{*}{ SCR } & 1,57 & 0,71 & 0,29 & 0,78 & 8,03 & 13,99 & 1 \\
\hline & 1,73 & 0,51 & 0,33 & 1,32 & 6,55 & 10,43 & 2 \\
\hline & 1,58 & 0,57 & 0,29 & 4,85 & 7,85 & 65,63 & 3 \\
\hline
\end{tabular}

Tabela A.22 - Métricas RBSB para a segmentação hierárquica procedimento bottom-up, específica para a classe Tanque1/Predios1 para a base de dados REDUC.

\begin{tabular}{|c|c|c|c|c|c|c|c|}
\hline \multirow{3}{*}{ Segmentador } & \multicolumn{6}{|c|}{ Classes } & \multirow{3}{*}{ Conjunto } \\
\hline & \multirow{2}{*}{$\begin{array}{c}\text { Treinamento } \\
\left(\begin{array}{c}\text { Tanque1 } \\
\text { Predios1 }\end{array}\right)\end{array}$} & \multicolumn{5}{|c|}{ Teste } & \\
\hline & & Tanque1 & Tanque2 & Predios1 & Predios2 & Solo & \\
\hline \multirow{3}{*}{ XMRS } & 0,26 & 0,49 & 0,26 & 0,28 & 0,42 & 5,12 & 1 \\
\hline & 0,23 & 0,36 & 0,28 & 0,26 & 0,36 & 4,60 & 2 \\
\hline & 0,24 & 0,40 & 0,27 & 0,27 & 0,36 & 6,31 & 3 \\
\hline \multirow{3}{*}{ MS } & 0,34 & 0,40 & 0,34 & 0,37 & 1,65 & 5,48 & 1 \\
\hline & 0,36 & 0,44 & 0,36 & 0,32 & 1,51 & 2,09 & 2 \\
\hline & 0,29 & 0,53 & 0,29 & 0,31 & 1,04 & 4,13 & 3 \\
\hline \multirow{3}{*}{ SCR } & 0,58 & 0,41 & 0,29 & 0,96 & 8,03 & 13,99 & 1 \\
\hline & 0,47 & 0,51 & 0,33 & 1,32 & 6,48 & 10,42 & 2 \\
\hline & 0,57 & 0,47 & 0,30 & 1,36 & 26,83 & 54,92 & 3 \\
\hline
\end{tabular}


A.1.1.3

\section{Base de dados Congonhas}

As imagens de referência para os conjuntos de treinamento e de teste, para cada classe de interesse, são mostradas nas Figuras A.7 - A.9.

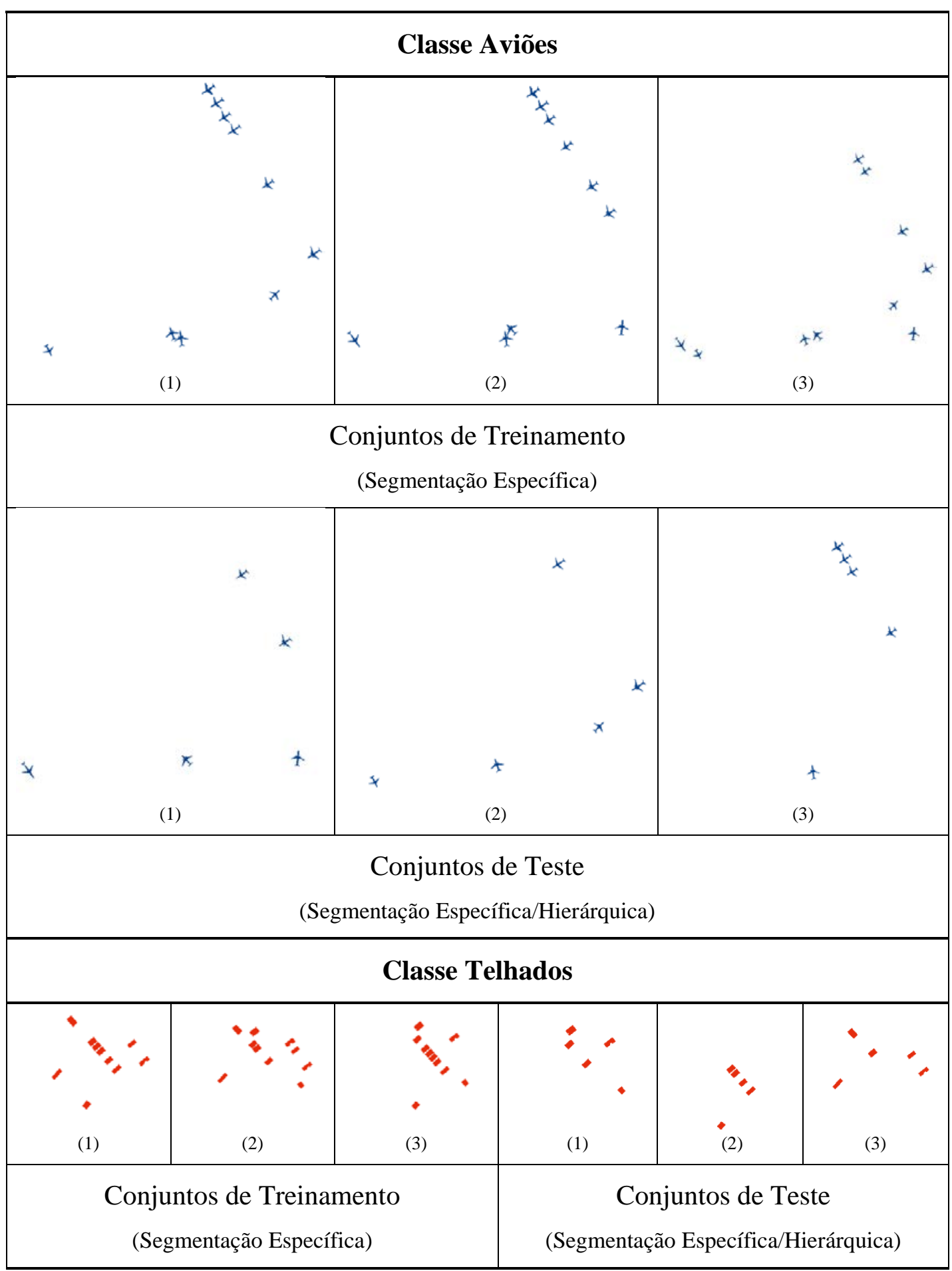

Figura A.7 - Conjuntos de treinamento e teste (classes Aviões e Telhados), para a base de dados Congonhas. 


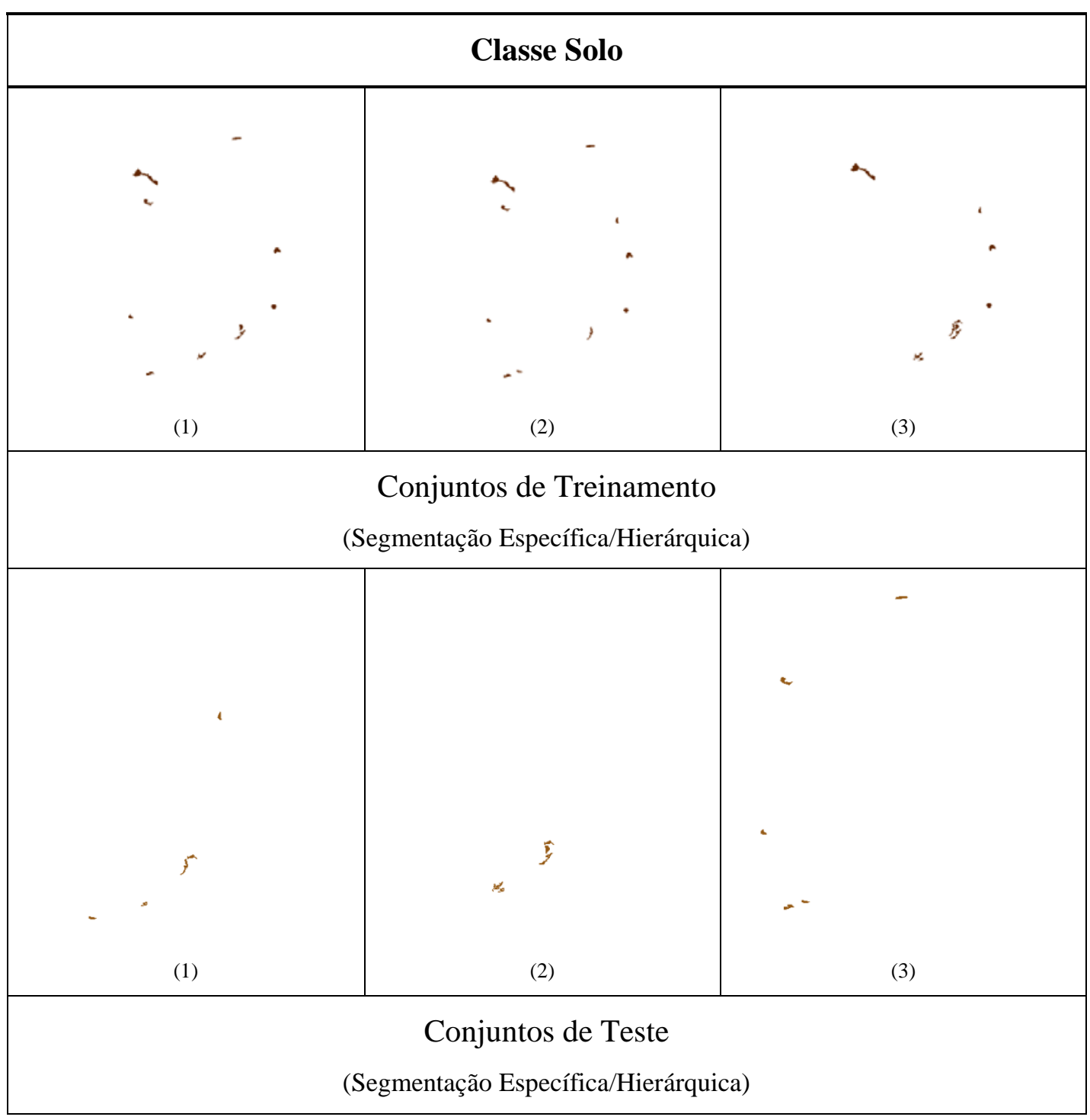

Figura A.8 - Conjuntos de treinamento e teste (classe Solo), para a base de dados Congonhas. 


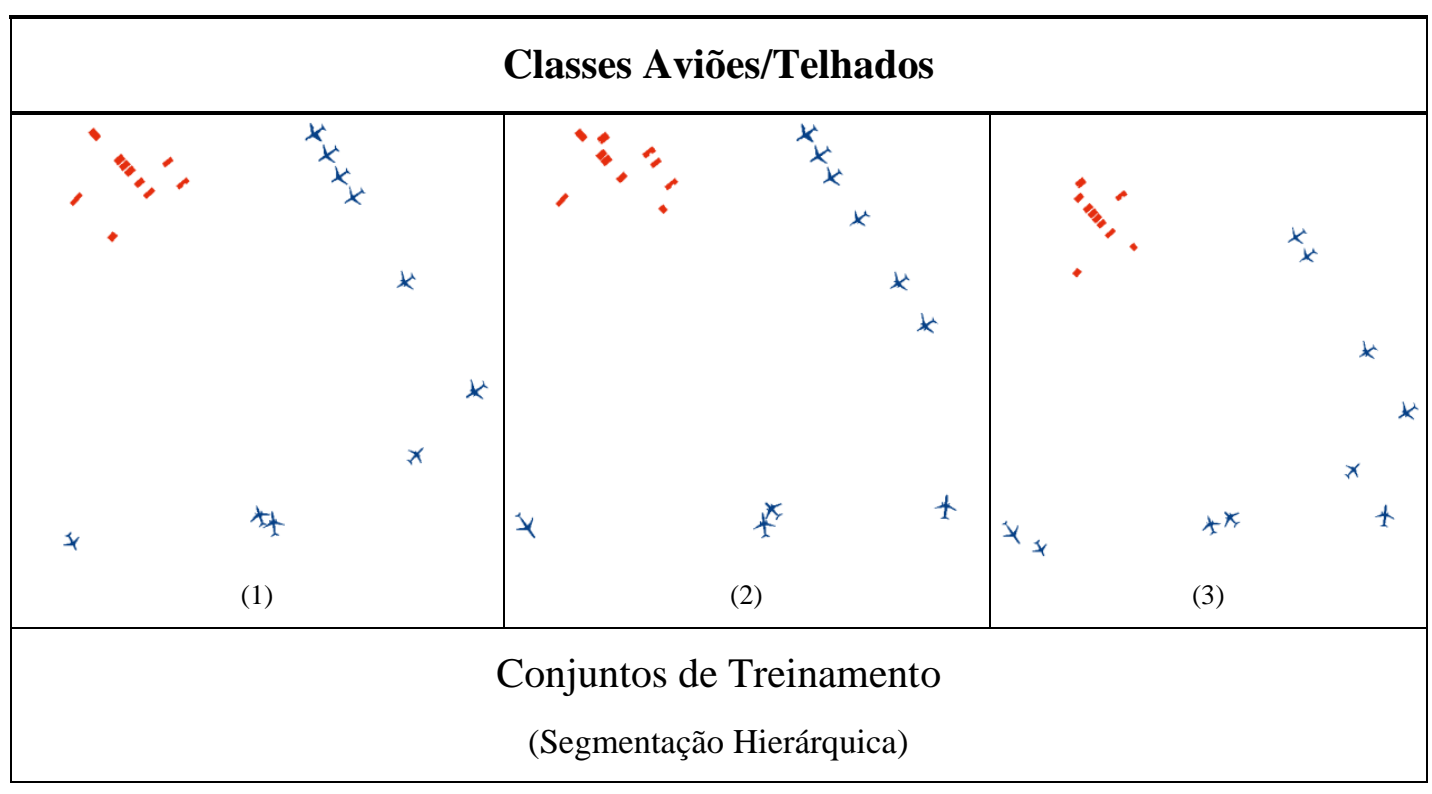

Figura A.9 - Conjuntos de treinamento (classe Aviões/Telhados), segmentação hierárquica, para a base de dados Congonhas.

Os parâmetros dos segmentadores, encontrados pelo GPS, para cada classe e para cada conjunto de treinamento, são mostrados na Tabela A.23 para metodologia de segmentação específica e nas Tabelas A.24 e A.25 para as abordagens de segmentação hierárquica top-down e bottom-up respectivamente. 
Tabela A.23 - Parâmetros de segmentação obtidos pelo GPS para a base de dados Congonhas.

\begin{tabular}{|c|c|c|c|c|c|}
\hline \multirow{2}{*}{ Segmentador } & \multirow{2}{*}{ Parâmetros } & \multicolumn{3}{|c|}{ Classes } & \multirow{2}{*}{ Conjunto } \\
\hline & & Aviões & Telhados & Solo & \\
\hline \multirow{10}{*}{ XMRS } & \multirow{3}{*}{$p_{e}$} & 45,58 & 35,42 & 14,24 & 1 \\
\hline & & 48,58 & 32,17 & 18,61 & 2 \\
\hline & & 42,38 & 37,02 & 17,04 & 3 \\
\hline & \multirow{3}{*}{$w_{\text {forma }}$} & 0,67 & 0,76 & 0,60 & 1 \\
\hline & & 0,63 & 0,78 & 0,58 & 2 \\
\hline & & 0,63 & 0,82 & 0,62 & 3 \\
\hline & \multirow{3}{*}{$w_{s}$} & 0,62 & 0,60 & 0,52 & 1 \\
\hline & & 0,77 & 0,68 & 0,56 & 2 \\
\hline & & 0,69 & 0,65 & 0,48 & 3 \\
\hline & Atributos de forma & Suav, Comp & Suav, Comp & Suav, Comp & $1,2,3$ \\
\hline \multirow{9}{*}{ MS } & \multirow{3}{*}{$h_{s}$} & 5,77 & 39,79 & 31,88 & 1 \\
\hline & & 6,33 & 39,67 & 34,20 & 2 \\
\hline & & 4,04 & 39,22 & 28,63 & 3 \\
\hline & \multirow{3}{*}{$h_{r}$} & 14,60 & 40,25 & 11,05 & 1 \\
\hline & & 12,67 & 56,57 & 9,42 & 2 \\
\hline & & 12,67 & 56,88 & 15,91 & 3 \\
\hline & \multirow{3}{*}{$A_{\min }$} & 84,73 & 132,12 & 81,67 & 1 \\
\hline & & 81,85 & 96,24 & 88,95 & 2 \\
\hline & & 82,34 & 138,46 & 91,09 & 3 \\
\hline \multirow{6}{*}{ SCR } & \multirow{3}{*}{$L_{s}$} & 22,99 & 36,45 & 24,90 & 1 \\
\hline & & 20,57 & 38,31 & 22,88 & 2 \\
\hline & & 26,83 & 38,64 & 24,90 & 3 \\
\hline & \multirow{3}{*}{$L_{a}$} & 206,91 & 298,33 & 218,67 & 1 \\
\hline & & 204,59 & 301,04 & 205,43 & 2 \\
\hline & & 207,69 & 291,72 & 218,67 & 3 \\
\hline
\end{tabular}


Tabela A.24 - Parâmetros de segmentação obtidos pelo GPS para a segmentação hierárquica com procedimento top-down para a base de dados Congonhas.

\begin{tabular}{|c|c|c|c|c|}
\hline \multirow[b]{2}{*}{ Segmentador } & \multirow[b]{2}{*}{ Parâmetros } & \multicolumn{2}{|c|}{ Classes } & \multirow[b]{2}{*}{ Conjunto } \\
\hline & & $\begin{array}{c}\text { Aviões } \\
\text { Telhados }\end{array}$ & Solo & \\
\hline \multirow{10}{*}{ XMRS } & \multirow{3}{*}{$p_{e}$} & 35,74 & 14,24 & 1 \\
\hline & & 35,85 & 18,61 & 2 \\
\hline & & 37,15 & 17,04 & 3 \\
\hline & \multirow{3}{*}{$w_{\text {forma }}$} & 0,69 & 0,60 & 1 \\
\hline & & 0,51 & 0,58 & 2 \\
\hline & & 0,81 & 0,62 & 3 \\
\hline & \multirow{3}{*}{$w_{s}$} & 0,64 & 0,52 & 1 \\
\hline & & 0,35 & 0,56 & 2 \\
\hline & & 0,49 & 0,48 & 3 \\
\hline & Atributos de forma & Suav, Comp & Suav, Comp & $1,2,3$ \\
\hline \multirow{9}{*}{ MS } & \multirow{3}{*}{$h_{s}$} & 33,56 & 31,88 & 1 \\
\hline & & 39,59 & 34,20 & 2 \\
\hline & & 33,12 & 28,63 & 3 \\
\hline & \multirow{3}{*}{$h_{r}$} & 3,02 & 11,05 & 1 \\
\hline & & 2,14 & 9,42 & 2 \\
\hline & & 2,61 & 15,91 & 3 \\
\hline & \multirow{3}{*}{$A_{\min }$} & 104,11 & 81,67 & 1 \\
\hline & & 93,02 & 88,95 & 2 \\
\hline & & 84,40 & 91,09 & 3 \\
\hline \multirow{6}{*}{ SCR } & \multirow{3}{*}{$L_{s}$} & 20,23 & 24,90 & 1 \\
\hline & & 22,09 & 22,88 & 2 \\
\hline & & 27,30 & 24,90 & 3 \\
\hline & \multirow{3}{*}{$L_{a}$} & 341,00 & 218,67 & 1 \\
\hline & & 307,10 & 205,43 & 2 \\
\hline & & 330,10 & 218,67 & 3 \\
\hline
\end{tabular}


Tabela A.25 - Parâmetros de segmentação obtidos pelo GPS para a segmentação hierárquica com procedimento bottom-up para a base de dados Congonhas.

\begin{tabular}{|c|c|c|c|c|}
\hline \multirow[b]{2}{*}{ Segmentador } & \multirow[b]{2}{*}{ Parâmetros } & \multicolumn{2}{|c|}{ Classes } & \multirow[b]{2}{*}{ Conjunto } \\
\hline & & $\begin{array}{c}\text { Aviões } \\
\text { Telhados }\end{array}$ & Solo & \\
\hline \multirow{10}{*}{ XMRS } & \multirow{3}{*}{$p_{e}$} & 50,68 & 14,24 & 1 \\
\hline & & 48,14 & 18,61 & 2 \\
\hline & & 47,28 & 17,04 & 3 \\
\hline & \multirow{3}{*}{$w_{\text {forma }}$} & 0,78 & 0,60 & 1 \\
\hline & & 0,82 & 0,58 & 2 \\
\hline & & 0,85 & 0,62 & 3 \\
\hline & \multirow{3}{*}{$w_{s}$} & 0,75 & 0,52 & 1 \\
\hline & & 0,85 & 0,56 & 2 \\
\hline & & 0,83 & 0,48 & 3 \\
\hline & Atributos de forma & Suav, Comp & Suav, Comp & $1,2,3$ \\
\hline \multirow{9}{*}{ MS } & \multirow{3}{*}{$h_{s}$} & 5,38 & 31,88 & 1 \\
\hline & & 8,70 & 34,20 & 2 \\
\hline & & 4,53 & 28,63 & 3 \\
\hline & \multirow{3}{*}{$h_{r}$} & 14,75 & 11,05 & 1 \\
\hline & & 10,22 & 9,42 & 2 \\
\hline & & 9,57 & 15,91 & 3 \\
\hline & \multirow{3}{*}{$A_{\min }$} & 112,27 & 81,67 & 1 \\
\hline & & 83,92 & 88,95 & 2 \\
\hline & & 114,21 & 91,09 & 3 \\
\hline \multirow{6}{*}{ SCR } & \multirow{3}{*}{$L_{s}$} & 20,20 & 24,90 & 1 \\
\hline & & 20,38 & 22,88 & 2 \\
\hline & & 28,53 & 24,90 & 3 \\
\hline & \multirow{3}{*}{$L_{a}$} & 280,63 & 218,67 & 1 \\
\hline & & 207,24 & 205,43 & 2 \\
\hline & & 259,21 & 218,67 & 3 \\
\hline
\end{tabular}

A exatidão espacial calculada pela métrica RBSB para as classes de interesse são mostradas nas Tabelas A.26 - A.28, para a metodologia de segmentação específica e nas Tabelas A.29 - A.31 para a segmentação hierárquica. 
Tabela A.26 - Métricas RBSB para a segmentação específica da classe Aviões para a base de dados Congonhas.

\begin{tabular}{c|c|c|c|c|c}
\hline \multirow{4}{*}{ Segmentador } & \multicolumn{4}{|c|}{ Classes } & \multirow{2}{*}{ Conjunto } \\
\cline { 2 - 6 } & \multirow{3}{*}{ Treinamento } & \multicolumn{3}{c}{ Teste } & \\
\cline { 2 - 6 } & (Aviões) & Aviões & Telhados & Solo & \\
\hline \multirow{3}{*}{ XMRS } & 0,34 & 0,55 & 2,65 & 9,53 & 1 \\
\cline { 2 - 6 } & 0,23 & 0,43 & 0,19 & 3,35 & 2 \\
\cline { 2 - 6 } & 0,28 & 0,53 & 0,20 & 4,47 & 3 \\
\hline \multirow{3}{*}{ MSR } & 0,35 & 0,42 & 0,58 & 0,82 & 1 \\
\cline { 2 - 6 } & 0,33 & 0,43 & 0,61 & 0,78 & 2 \\
\cline { 2 - 6 } & 0,30 & 0,38 & 0,63 & 0,88 & 3 \\
\cline { 2 - 6 } & 0,86 & 0,96 & 1,86 & 24,75 & 1 \\
\cline { 2 - 6 } & 1,04 & 3,01 & 4,04 & 22,79 & 2 \\
\hline
\end{tabular}

Tabela A.27 - Métricas RBSB para a segmentação específica da classe Telhados para a base de dados Congonhas.

\begin{tabular}{|c|c|c|c|c|c|}
\hline \multirow{3}{*}{ Segmentador } & \multicolumn{4}{|c|}{ Classes } & \multirow{3}{*}{ Conjunto } \\
\hline & \multirow{2}{*}{$\begin{array}{c}\text { Treinamento } \\
\text { (Telhados) }\end{array}$} & \multicolumn{3}{|c|}{ Teste } & \\
\hline & & Aviões & Telhados & Solo & \\
\hline \multirow{3}{*}{ XMRS } & 0,11 & 0,64 & 0,11 & 4,49 & 1 \\
\hline & 0,11 & 0,49 & 0,11 & 2,24 & 2 \\
\hline & 0,14 & 0,64 & 0,17 & 5,64 & 3 \\
\hline \multirow{3}{*}{ MS } & 0,16 & 4,08 & 0,24 & 404,89 & 1 \\
\hline & 0,18 & 5,98 & 0,20 & 293,65 & 2 \\
\hline & 0,20 & 6,00 & 0,26 & 594,51 & 3 \\
\hline \multirow{3}{*}{ SCR } & 0,33 & 3,70 & 0,36 & 35,40 & 1 \\
\hline & 0,33 & 5,74 & 0,36 & 210,50 & 2 \\
\hline & 0,29 & 5,81 & 0,34 & 208,55 & 3 \\
\hline
\end{tabular}


Tabela A.28 - Métricas RBSB para a segmentação específica da classe Solo para a base de dados Congonhas.

\begin{tabular}{c|c|c|c|c|c}
\hline \multirow{4}{*}{ Segmentador } & \multicolumn{4}{|c|}{ Classes } & \multirow{2}{*}{ Conjunto } \\
\cline { 2 - 6 } & \multirow{3}{*}{ Treinamento } & \multicolumn{3}{c}{ Teste } & \\
\cline { 2 - 6 } & $($ Solo) & Aviões & Telhados & Solo & \\
\hline \multirow{3}{*}{ XMRS } & 0,47 & 0,73 & 0,45 & 0,50 & 1 \\
\cline { 2 - 6 } & 0,59 & 0,62 & 0,46 & 1,03 & 2 \\
\cline { 2 - 6 } & 0,46 & 0,67 & 0,46 & 0,54 & 3 \\
\hline \multirow{3}{*}{ MS } & 0,52 & 3,20 & 0,52 & 0,56 & 1 \\
\cline { 2 - 6 } & 0,38 & 3,14 & 0,50 & 0,43 & 2 \\
\cline { 2 - 6 } & 0,65 & 3,29 & 0,54 & 0,67 & 3 \\
\cline { 2 - 6 } & 2,11 & 2,98 & 0,62 & 2,41 & 1 \\
\cline { 2 - 6 } & 2,21 & 3,01 & 0,62 & 3,26 & 2 \\
\hline
\end{tabular}

Tabela A.29 - Métricas RBSB para a segmentação hierárquica, procedimento top-down, específica para a classe Aviões/Telhados para a base de dados Congonhas.

\begin{tabular}{|c|c|c|c|c|c|}
\hline \multirow{3}{*}{ Segmentador } & \multicolumn{4}{|c|}{ Classes } & \multirow{3}{*}{ Conjunto } \\
\hline & \multirow{2}{*}{$\begin{array}{c}\text { Treinamento } \\
\left(\begin{array}{c}\text { Aviões } \\
\text { Telhados }\end{array}\right)\end{array}$} & \multicolumn{3}{|c|}{ Teste } & \\
\hline & & Aviões & Telhados & Solo & \\
\hline \multirow{3}{*}{ XMRS } & 0,55 & 0,55 & 0,41 & 2,77 & 1 \\
\hline & 0,57 & 0,57 & 0,23 & 1,49 & 2 \\
\hline & 0,41 & 0,67 & 0,43 & 4,31 & 3 \\
\hline \multirow{3}{*}{ MS } & 0,43 & 3,24 & 0,41 & 0,82 & 1 \\
\hline & 0,28 & 4,32 & 0,27 & 0,84 & 2 \\
\hline & 0,40 & 3,25 & 0,33 & 0,70 & 3 \\
\hline \multirow{3}{*}{ SCR } & 0,68 & 3,02 & 0,68 & 4,07 & 1 \\
\hline & 0,68 & 3,12 & 0,61 & 29,07 & 2 \\
\hline & 1,18 & 3,91 & 0,76 & 22,85 & 3 \\
\hline
\end{tabular}


Tabela A.30 - Métricas RBSB para a segmentação hierárquica, procedimento top-down, específica para a classe Solo para a base de dados Congonhas.

\begin{tabular}{|c|c|c|c|c|c|}
\hline \multirow{3}{*}{ Segmentador } & \multicolumn{4}{|c|}{ Classes } & \multirow{3}{*}{ Conjunto } \\
\hline & \multirow{2}{*}{$\begin{array}{c}\text { Treinamento } \\
\text { (Solo) }\end{array}$} & \multicolumn{3}{|c|}{ Teste } & \\
\hline & & Aviões & Telhados & Solo & \\
\hline \multirow{3}{*}{ XMRS } & 0,44 & 0,73 & 0,49 & 0,53 & 1 \\
\hline & 0,40 & 0,58 & 0,49 & 0,61 & 2 \\
\hline & 0,46 & 0,65 & 0,48 & 0,56 & 3 \\
\hline \multirow{3}{*}{ MS } & 0,38 & 0,43 & 0,67 & 0,80 & 1 \\
\hline & 0,39 & 0,45 & 0,62 & 1,11 & 2 \\
\hline & 0,36 & 0,51 & 0,64 & 1,01 & 3 \\
\hline \multirow{3}{*}{ SCR } & 2,11 & 2,83 & 0,63 & 2,82 & 1 \\
\hline & 3,23 & 2,84 & 0,58 & 3,23 & 2 \\
\hline & 2,56 & 2,10 & 0,55 & 3,12 & 3 \\
\hline
\end{tabular}

Tabela A.31 - Métricas RBSB para a segmentação hierárquica, procedimento bottom-up, específica para a classe Aviões/Telhados para a base de dados Congonhas.

\begin{tabular}{|c|c|c|c|c|c|}
\hline \multirow{3}{*}{ Segmentador } & \multirow{3}{*}{$\begin{array}{c}\text { Treinamento } \\
\left(\begin{array}{c}\text { Aviões } \\
\text { Telhados }\end{array}\right)\end{array}$} & \multicolumn{3}{|c|}{ Classes } & \multirow{3}{*}{ Conjunto } \\
\hline & & \multicolumn{3}{|c|}{ Teste } & \\
\hline & & Aviões & Telhados & Solo & \\
\hline \multirow{3}{*}{ XMRS } & 0,52 & 0,57 & 0,49 & 4,89 & 1 \\
\hline & 0,27 & 0,47 & 0,24 & 1,56 & 2 \\
\hline & 0,38 & 0,53 & 0,22 & 2,68 & 3 \\
\hline \multirow{3}{*}{ MS } & 0,49 & 3,25 & 0,56 & 0,66 & 1 \\
\hline & 0,51 & 3,19 & 0,49 & 0,87 & 2 \\
\hline & 0,57 & 3,37 & 0,53 & 1,04 & 3 \\
\hline \multirow{3}{*}{ SCR } & 1,21 & 3,03 & 0,65 & 31,38 & 1 \\
\hline & 1,08 & 3,28 & 0,67 & 24,14 & 2 \\
\hline & 1,55 & 6,50 & 0,73 & 146 & 3 \\
\hline
\end{tabular}




\section{A.1.2}

\section{Exatidão temática e espacial}

Os gráficos apresentados nesta seção ilustram os resultados comparativos entre as abordagens de segmentação específica e hierárquica relativos aos experimentos realizados na Seção 5.5.2 - Exatidão Temática e Espacial após a Classificação.

\section{A.1.2.1}

\section{Base de dados de Maragogipe}

Os gráficos mostrados na Figura A.10 apresentam os valores de exatidão temática (Kappa e exatidão global) e os gráficos da Figura 33A.11 a exatidão espacial (métricas RBSB) das classes de objetos após a etapa de classificação de ambas as abordagens de segmentação.

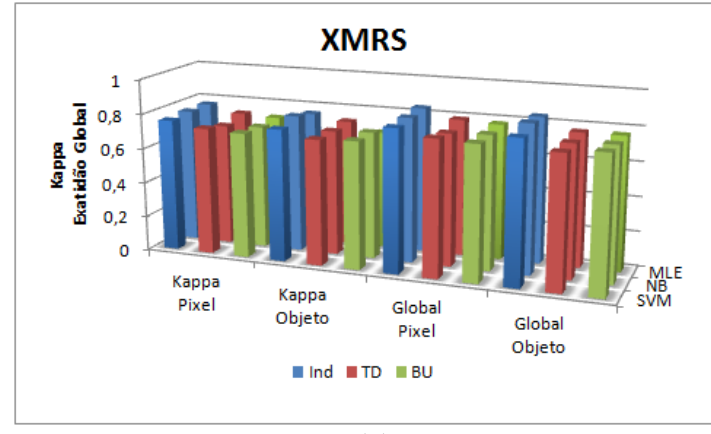

(a)

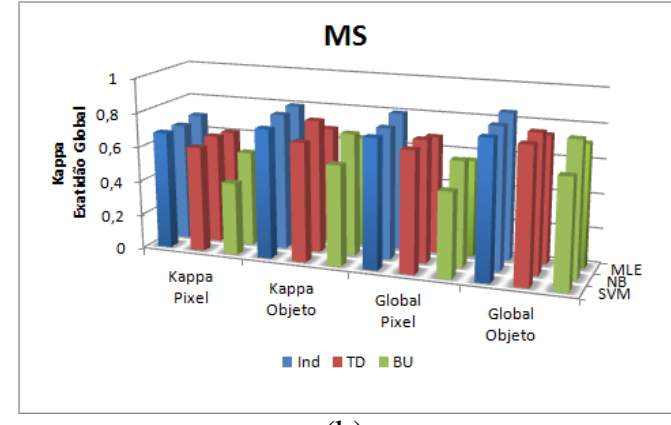

(b)

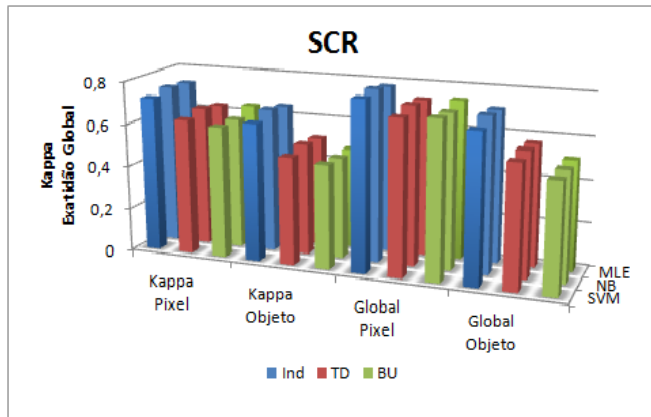

(c)

Figura A.10 - Valores de Kappa e Exatidão Global, dos classificadores SVM, NB e MLE, para as segmentações baseadas nos algoritmos XMRS (a), MS(b) e SCR (c), para a base de dados de Maragogipe. 


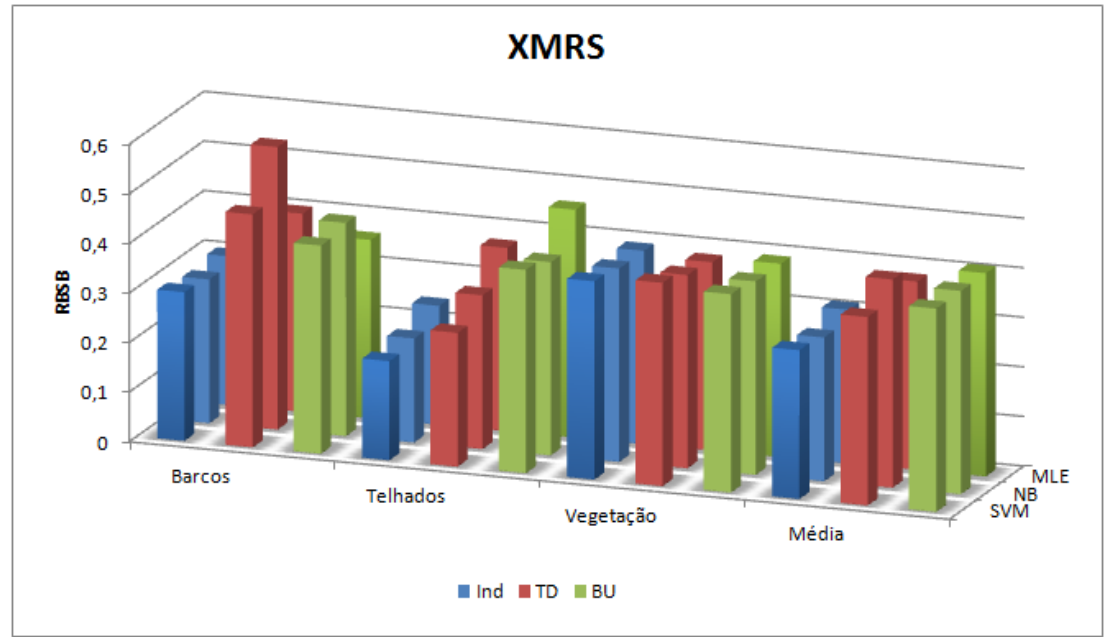

(a)

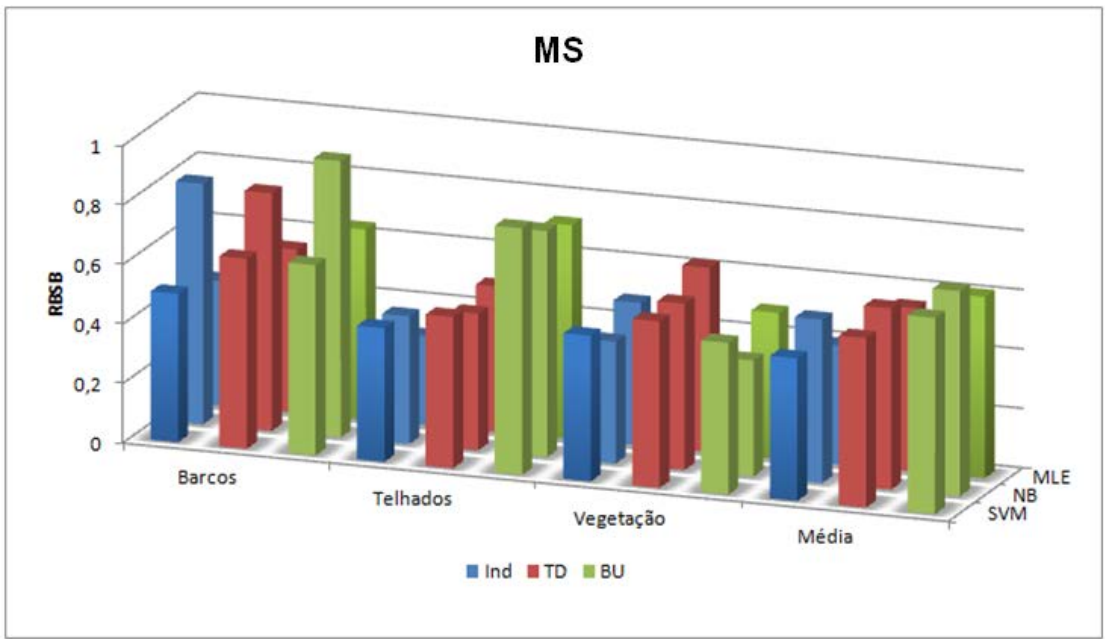

(b)

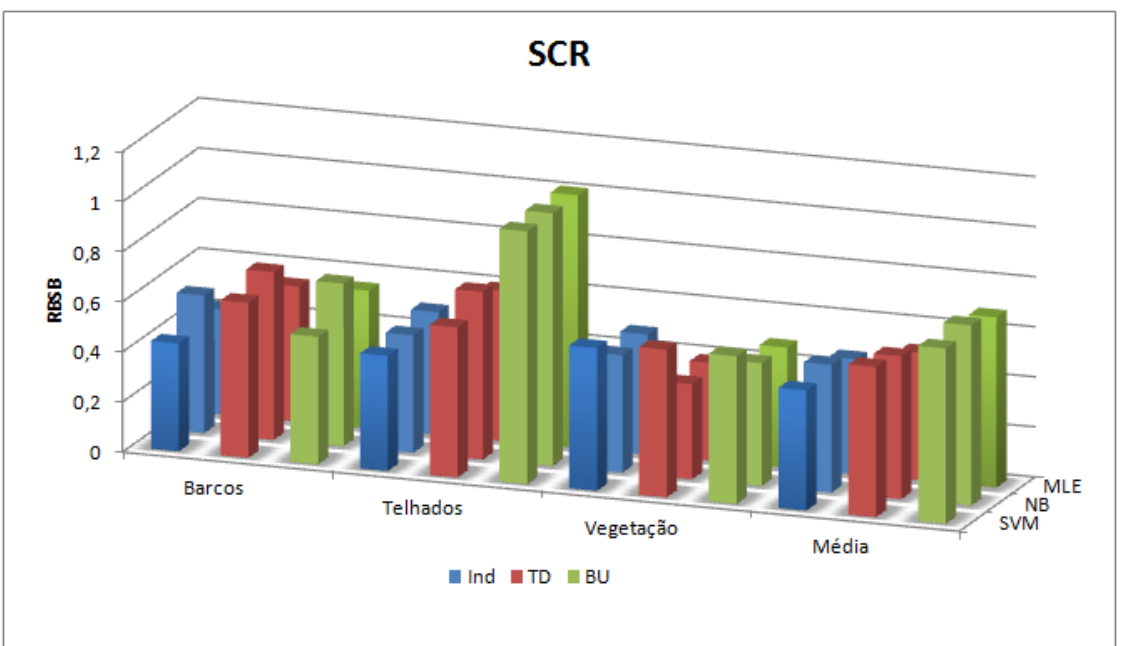

(c)

Figura A.11 - Exatidão espacial (métricas RBSB) das classes de objetos após a etapa de classificação (classificadores SVM, NB e MLE), com as segmentações baseadas nos algoritmos XMRS (a), MS(b) e SCR (c), para a base de dados de Maragogipe. 


\section{A.1.2.2}

\section{Base de dados REDUC}

Os gráficos mostrados na Figura A.12 apresentam os valores de exatidão temática (Kappa e exatidão global) e os gráficos da Figura 33A.13 a exatidão espacial (métricas RBSB) das classes de objetos após a etapa de classificação de ambas as abordagens de segmentação.

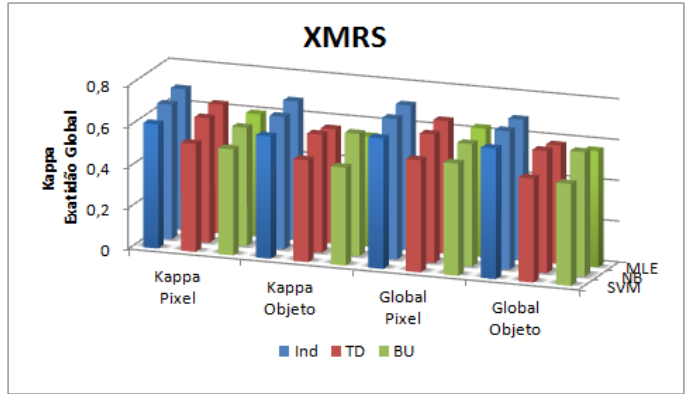

(a)

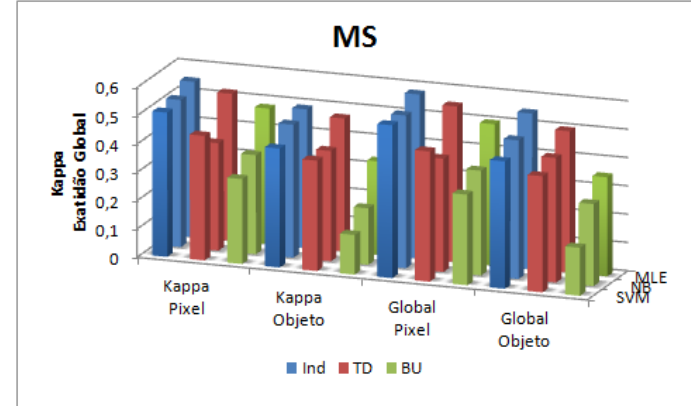

(b)

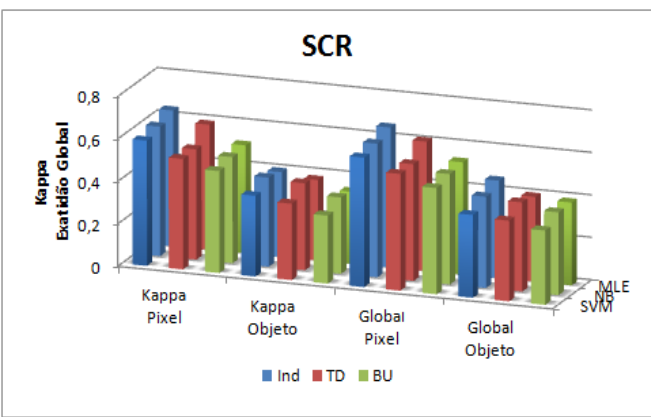

(c)

Figura A.12 - Valores de Kappa e Exatidão Global, dos classificadores SVM, NB e MLE, para as segmentações baseadas nos algoritmos XMRS (a), MS(b) e SCR (c), para a base de dados REDUC. 


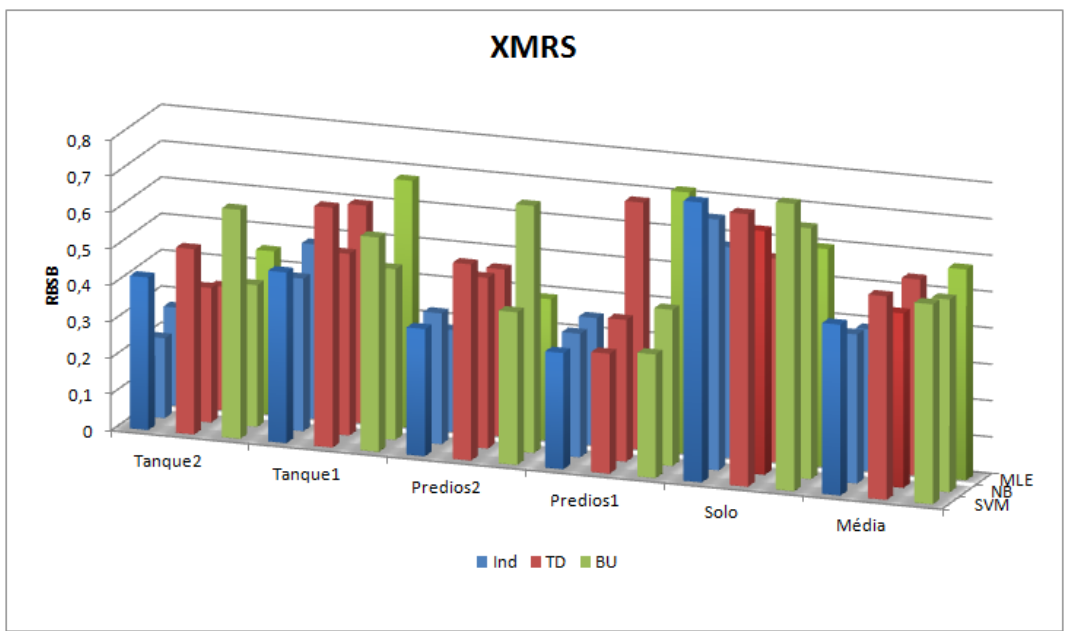

(a)

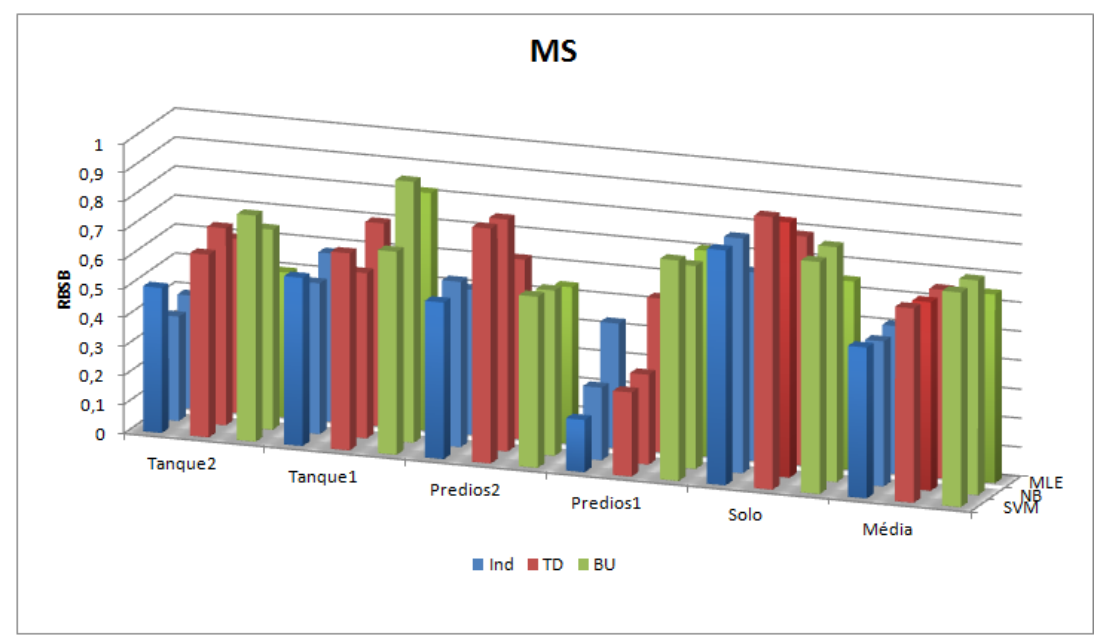

(b)

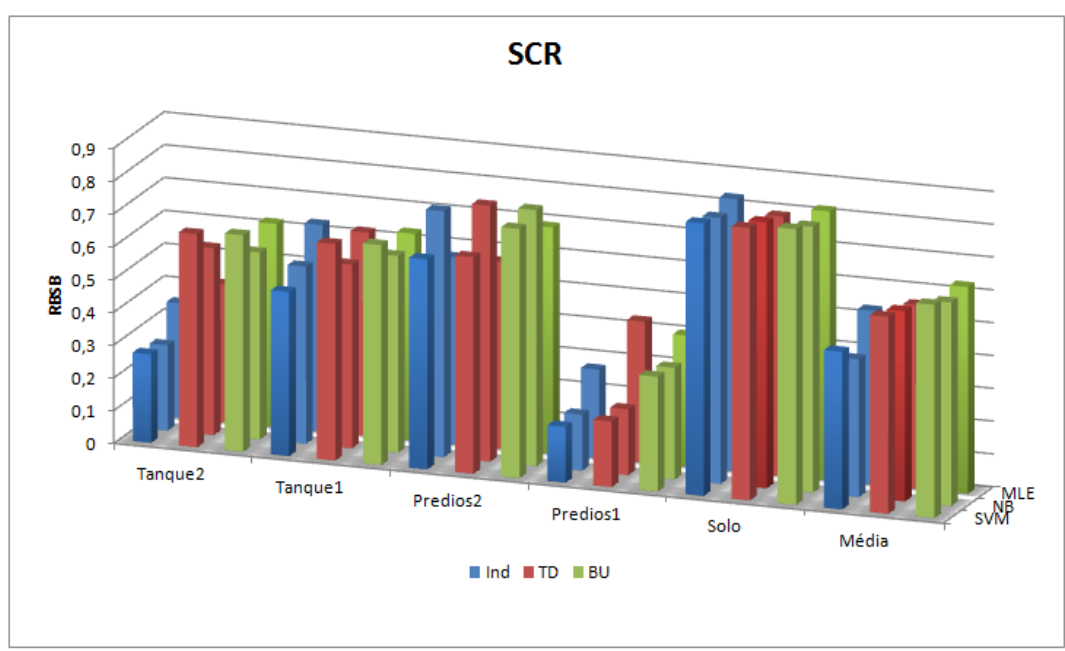

(c)

Figura A.13 - Exatidão espacial (métricas RBSB) das classes de objetos após a etapa de classificação (classificadores SVM, NB e MLE), com as segmentações baseadas nos algoritmos XMRS (a), MS(b) e SCR (c), para a base de dados REDUC. 


\section{A.1.2.3}

\section{Base de dados Congonhas}

Os gráficos mostrados na Figura A.14 apresentam os valores de exatidão temática (Kappa e exatidão global) e os gráficos da Figura A.15 a exatidão espacial (métricas RBSB) das classes de objetos após a etapa de classificação de ambas as abordagens de segmentação.

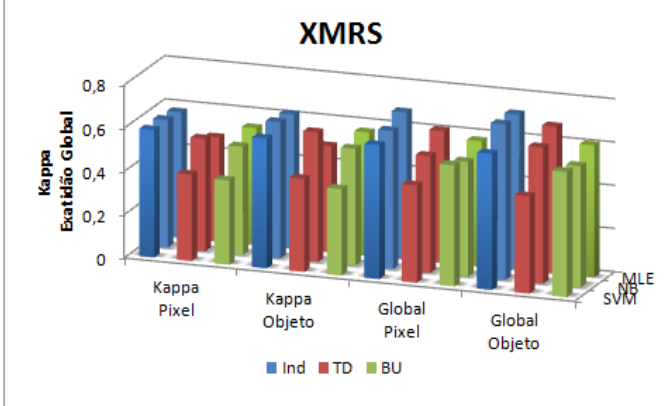

(a)

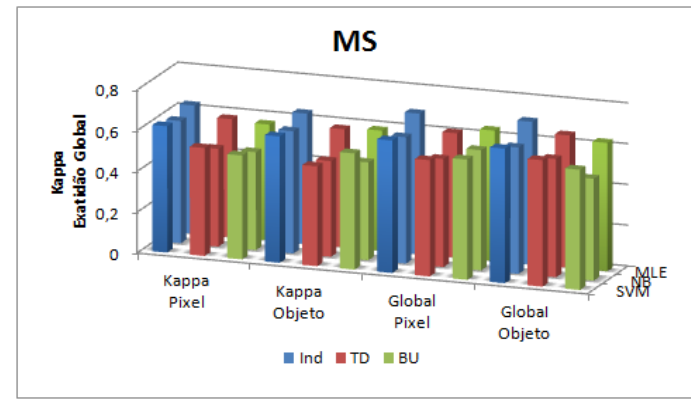

(b)

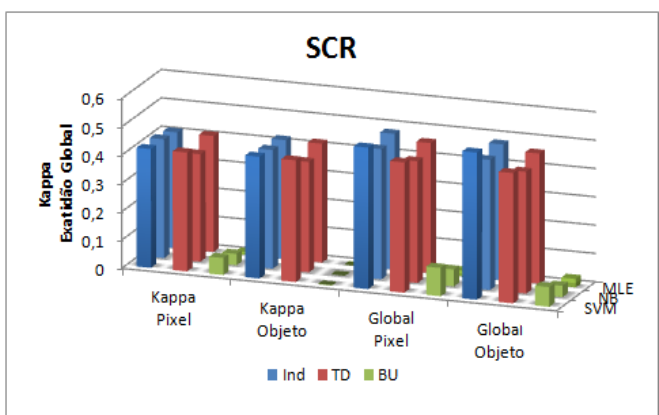

(c)

Figura A.14 - Valores de Kappa e Exatidão Global, dos classificadores SVM, NB e MLE, para as segmentações baseadas nos algoritmos XMRS (a), MS(b) e SCR (c), para a base de dados Congonhas. 


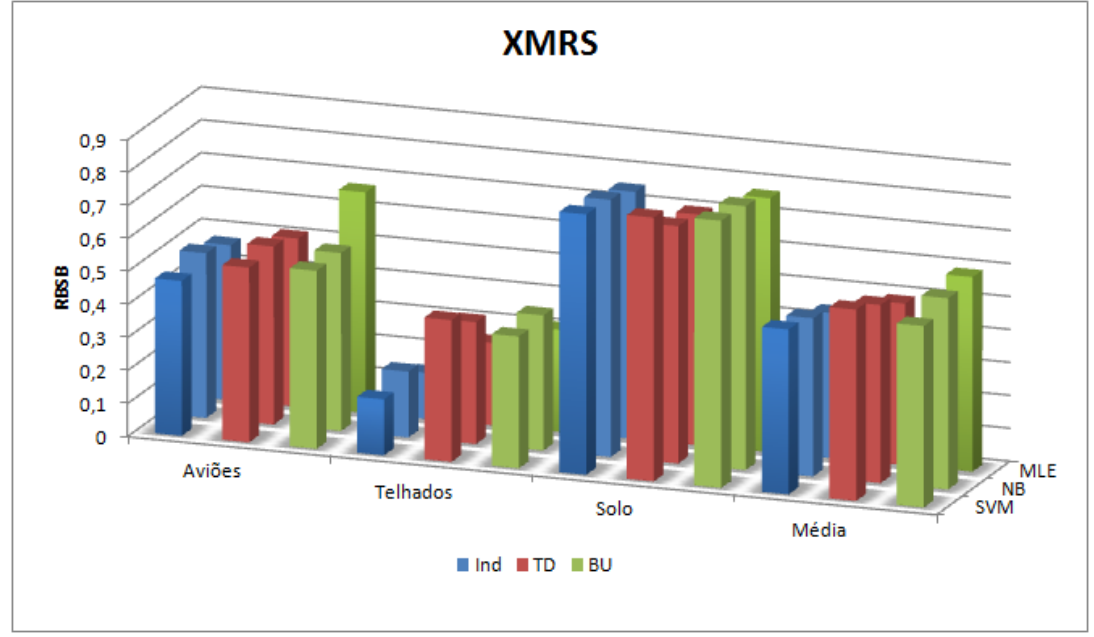

(a)

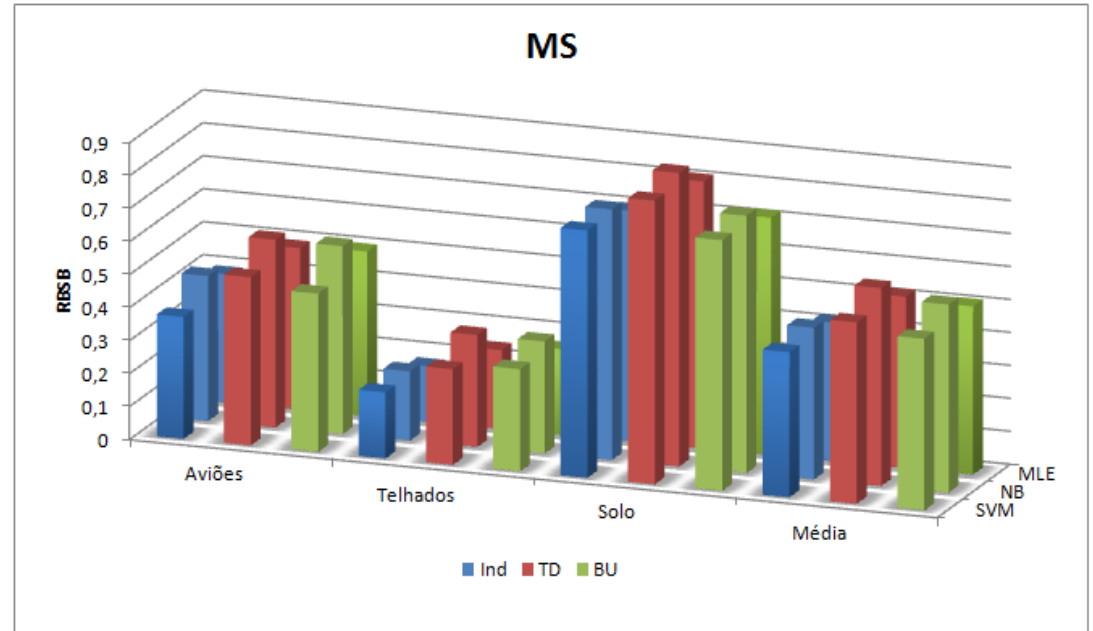

(b)

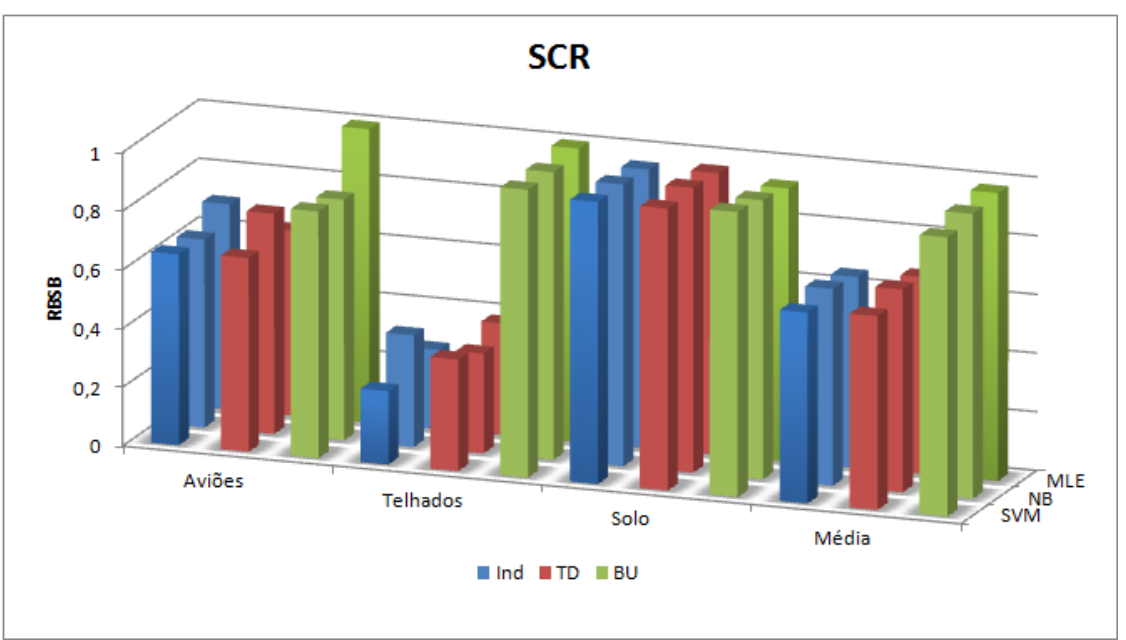

(c)

Figura A.15 - Exatidão espacial (métricas RBSB) das classes de objetos após a etapa de classificação (classificadores SVM, NB e MLE), com as segmentações baseadas nos algoritmos XMRS (a), MS(b) e SCR (c), para a base de dados Congonhas. 


\section{Apêndice $B$}

\section{Elementos de Imagens Digitais}

\section{B.1 \\ Modelo de cores}

Um sistema de cores é um modelo que explica as propriedades ou comportamento das cores num contexto particular. Não existe um modelo que explique todos os aspectos relacionados à cor. Por isso, são utilizados modelos diferentes para ajudar a descrever as diferentes características da cor que são percebidas pelo ser humano. Existem vários modelos de cores sendo que neste trabalho foram usados os modelos: RGB, HSV e YCbCr.

\section{B.1.1}

\section{Modelo RGB}

O modelo RGB é baseado em um sistema de coordenadas cartesianas, que pode ser visto como um cubo onde três de seus vértices são as cores primárias, outros três as cores secundárias, o vértice junto à origem é o preto e o mais afastado da origem corresponde à cor branca, conforme ilustra a Figura B.1. Neste modelo, a escala de cinza se estende através de uma linha (a diagonal do cubo) que sai da origem (preto) até o vértice mais distante dela (branco). Por conveniência, geralmente assume-se que os valores máximos de R, G e B estão normalizados na faixa de 0 a 1. 


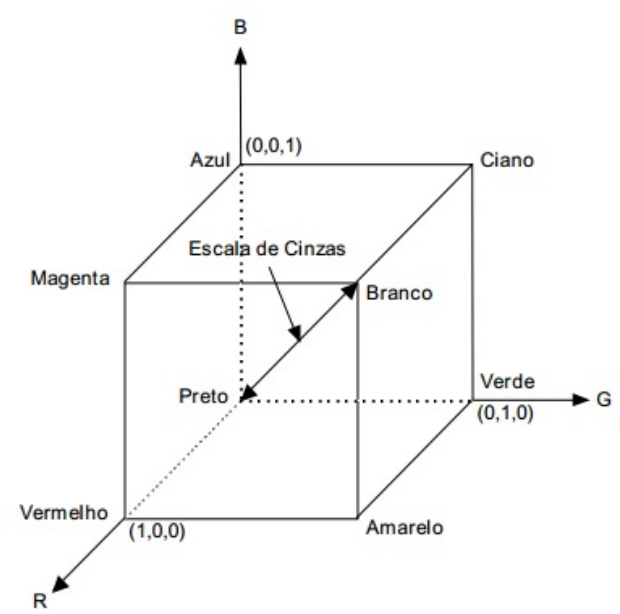

Figura B.1 - Modelo de cor RGB.

\section{B.1.2}

\section{Modelo HSV}

HSV é a abreviatura para o sistema de cores formadas pelas componentes Hue (tonalidade), Saturation (Saturação) e Value (Valor). Esse sistema também é conhecido como HSB (Hue, Saturation e Brightness - Tonalidade, Saturação e Brilho, respectivamente). Esse sistema de cores define o espaço de cor conforme seus três parâmetros: tonalidade ou matiz (define a cor do objeto ), saturação (define a quantidade de cinza na imagem) e valor (define o brilho da cor).

Esse sistema é caracterizado por ser uma transformação não linear do sistema de cores RGB. Geometricamente, o espaço HSV é representado pelo hexágono da Figura B.2.

O modelo HSV permite separar as componentes de matiz, saturação e brilho da informação de cor em uma imagem. 


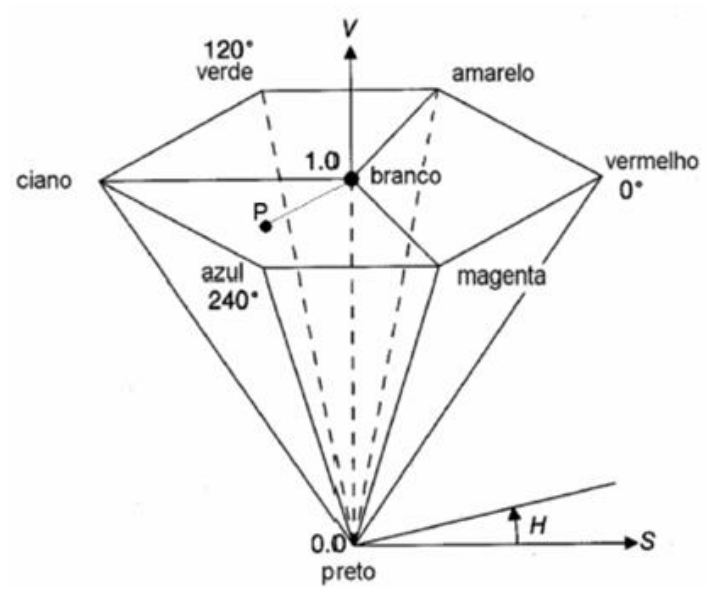

Figura B.2 - Hexágono representando o modelo de cores HSV.

\section{Transformação RGB para HSV}

Seja uma cor definida no espaço RGB, onde as componentes R, G e B estão no intervalo entre 0 e 1. A transformação para os parâmetros $(\mathrm{H}, \mathrm{S}, \mathrm{V})$ dessa cor pode ser determinada pelas fórmulas abaixo. Onde MAX e MIN são os valores máximo e mínimo, respectivamente, das componentes (R, G, B).

Os resultados dão a tonalidade variando de $0^{\circ}$ a $360^{\circ}$, indicando o ângulo no círculo onde a tonalidade $(\mathrm{H})$ está definida, e a saturação e brilho variando de 0 a 1 , representando o menor e o maior valor possível.

$$
\mathrm{H}=\left\{\begin{array}{c}
60 \frac{\mathrm{G}-\mathrm{B}}{\mathrm{MAX}-\mathrm{MIN}} \rightarrow \mathrm{se}(\mathrm{MAX}=\mathrm{R}) \text { e }(\mathrm{G} \geq \mathrm{B}) \\
60 \frac{\mathrm{G}-\mathrm{B}}{\mathrm{MAX}-\mathrm{MIN}}+360 \rightarrow \text { se }(\mathrm{MAX}=\mathrm{R}) \text { e }(\mathrm{G}<\mathrm{B}) \\
60 \frac{\mathrm{B}-\mathrm{R}}{\mathrm{MAX}-\mathrm{MIN}}+120 \rightarrow \text { se }(\mathrm{MAX}=\mathrm{G}) \\
60 \frac{\mathrm{G}-\mathrm{B}}{\mathrm{MAX}-\mathrm{MIN}}+240 \rightarrow \text { se }(\mathrm{MAX}=\mathrm{B}) \\
\mathrm{S}=\frac{\text { MAX-MIN }}{\text { MAX }} \\
\mathrm{V}=\mathrm{MAX}
\end{array}\right.
$$

\section{B.1.3}

\section{Modelo $\mathrm{YCbCr}$}

O modelo de cor YCbCr é amplamente utilizado em vídeo, processamento digital da imagem, etc. Neste formato, a informação de luminância é representada 
por um único componente, Y e a informação de cor é armazenado como dois componentes de diferença de cor, $\mathrm{Cr}$ e $\mathrm{Cb}$. A componentes $\mathrm{Cb}$ representa a diferença entre a componente azul e um valor de referência, e a componente Cr é a diferença entre a componente vermelho e um valor de referência.

A transformação utilizada para converter o espaço de cor RGB para YCbCr é mostrado abaixo:

$$
\left[\begin{array}{c}
\mathrm{Y} \\
\mathrm{Cb} \\
\mathrm{Cr}
\end{array}\right]=\left[\begin{array}{c}
16 \\
128 \\
128
\end{array}\right]+\left[\begin{array}{ccc}
65,481 & 128,533 & 24,966 \\
-37,797 & -74,203 & 112 \\
112 & -93,786 & -18,214
\end{array}\right]\left[\begin{array}{l}
\mathrm{R} \\
\mathrm{G} \\
\mathrm{B}
\end{array}\right]
$$

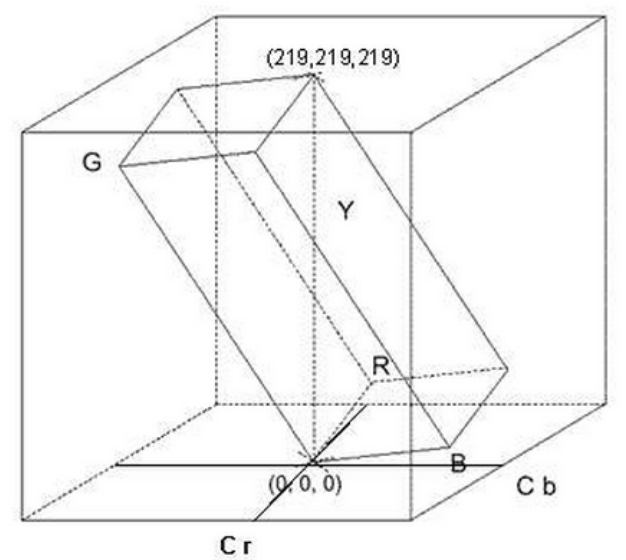

Figura B.3 - O cubo mostra a relação entre os modelos de cores RGB e YCbCr.

\section{B.2}

\section{Índice NDVI}

O Índice de Vegetação de Diferença Normalizada (Normalized Difference Vegetation Index - NDVI) é uma técnica bastante importante utilizada para melhor visualizar os alvos no que diz respeito à variação da vegetação. O índice NDVI é baseado no comportamento espectral da clorofila, que absorve a luz vermelha e reflete a radiação infravermelha. O NDVI consiste em uma equação que tem como variáveis as bandas do vermelho e infravermelho próximo, como se segue:

$$
\mathrm{NDVI}=(\mathrm{NIR}-\mathrm{R}) /(\mathrm{NIR}+\mathrm{R})
$$


onde,

NIR: valor da recfletância da banda no Infravermelho próximo;

R: valor de reflectância da banda no vermelho.

Apesar de levar esse nome, o NDVI é um índice de razão, sendo assim, seus resultados não dependem das condições de iluminação. 


\section{Apêndice C}

\section{Medidas Estatísticas}

\section{C.1}

\section{Coeficiente Kappa e exatidão global}

A literatura existente sobre a estimação do erro da classificação é extensa e muitos procedimentos são propostos. Frequentemente, na prática, os resultados sobre as amostras usadas para treinamento e teste são expressos em uma forma tabular denominada matriz de classificação (ou matriz de confusão) que oferece a percentagem das amostras que foram correta e incorretamente classificadas.

A matriz de confusão de uma hipótese oferece uma medida efetiva do modelo de classificação, ao mostrar o número de classificações corretas versus as classificações preditas para cada classe, sobre um conjunto de exemplos. A matriz de confusão pode ser vista na Tabela C.1.

Tabela C.1 - Matriz de confusão.

\begin{tabular}{ccccc}
\hline \multirow{2}{*}{ Classificação } & \multicolumn{2}{c}{ Dados de referência } & Total nas linhas $n_{i+}$ \\
\cline { 2 - 5 } & 1 & 2 & $c$ & \\
\hline 1 & $x_{1,1}$ & $x_{1,2}$ & $x_{1, c}$ & $x_{1+}$ \\
\hline 2 & $x_{2,1}$ & $x_{2,2}$ & $x^{2, c}$ & $x_{2+}$ \\
\hline$c$ & $x_{3,1}$ & $x_{3,2}$ & $x_{3, c}$ & $x_{c+}$ \\
\hline Total nas colunas $n_{+i}$ & $x_{+1}$ & $x_{+2}$ & $x_{+c}$ & $n$ \\
\hline
\end{tabular}

O número de acertos, para cada classe, se localiza na diagonal principal $x_{i, i}$ da matriz e os demais elementos $x_{i, j}$, para $i \neq j$, representam erros na classificação. A matriz de confusão de um classificador ideal possui todos esses elementos iguais à zero uma vez que ele não comete erros.

O método padrão para avaliação da precisão temática atualmente tem sido índices derivados da matriz de confusão. De uma matriz de confusão podem ser 
derivadas várias medidas de precisão da classificação, sendo a exatidão global uma das mais conhecidas.

A exatidão global é calculada dividindo a soma da diagonal principal da matriz de erros $x_{i, i}$, pelo número total de amostras coletadas $n$, ou seja:

$$
\mathrm{G}=\frac{\sum_{i=1}^{n} x_{i, i}}{n}
$$

O coeficiente Kappa é uma técnica multivariada discreta usada na avaliação da precisão temática e utiliza todos os elementos da matriz de confusão no seu cálculo. O coeficiente Kappa pode ser calculado através da seguinte equação:

$$
K=\frac{n \sum_{i=1}^{c} x_{i, i}-\sum_{i=1}^{c} x_{i+} x_{+i}}{n^{2}-\sum_{i=1}^{c} x_{i+1} x_{+i}}
$$

Onde $K$ é uma estimativa do coeficiente Kappa; $x_{i, i}$ é o valor na linha $i$ e coluna $i ; x_{i+}$ é a soma da linha $i$ e $x_{+i}$ é a soma da coluna $i$ da matriz de confusão; $n$ é o número total de amostras e $c$ o número total de classes.

Quando todos os elementos da matriz de classificação fora da diagonal principal possuírem valores nulos, o coeficiente assumirá o valor 1 , indicando um desempenho excelente. Também poderá assumir valores negativos indicando que o desempenho da classificação foi péssimo. Embora o coeficiente Kappa seja muito utilizado na avaliação da exatidão de mapeamento, não existe uma fundamentação teórica para recomendar quais os níveis mínimos aceitáveis deste coeficiente numa classificação. Entretanto, a Tabela C.2 apresenta níveis de desempenho da classificação para o valor de Kappa obtido, normalmente aceitos pela comunidade científica. 
Tabela C.2 - Desempenho da classificação em função do coeficiente Kappa.

\begin{tabular}{c|c}
\hline Coeficiente Kappa & Desempenho da Classificação \\
\hline$K \leq 0$ & Péssimo \\
\hline $0<K \leq 0,2$ & Ruim \\
\hline $0.2<K \leq 0,4$ & Razoável \\
\hline $0.4<K \leq 0,6$ & Bom \\
\hline $0.6<K \leq 0,8$ & Muito Bom \\
\hline $0.8<K \leq 1,0$ & Excelente \\
\hline
\end{tabular}

\section{C.2}

\section{Hipercubo latino}

O método de Hipercubo Latino (Latin Hypercube Sampling - LHS) é um método de simulação que tem como base a geração de uma quantidade de números pseudoaleatórios previamente estabelecidos, com seus valores distribuídos proporcionalmente pelos estratos quantificados.

O método LHS, foi desenvolvido por Mckay et al. (1979). Nela, o domínio de cada variável aleatória $X_{k}(k=1, \ldots, \mathrm{M})$ é dividido em $\mathrm{N}$ intervalos, $\Delta X_{k}^{i}$ ( $i=1$, 2,..., N), de igual probabilidade 1/N, como mostrado na Figura C.1(a) e (b).
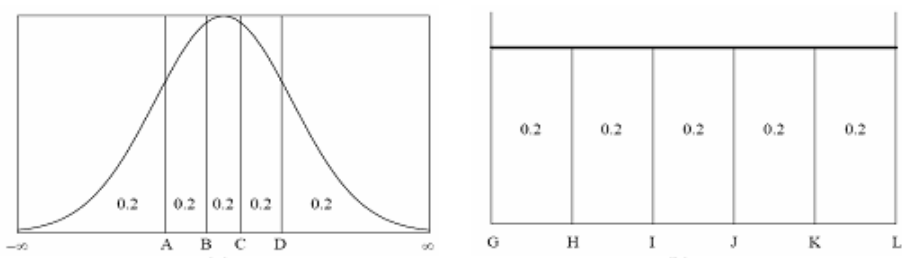

Figura C.1 - Divisão em 5 intervalos do domínio de duas variáveis aleatórias; (a) distribuição normal (b) distribuição uniforme.

O exemplo a seguir refere-se à geração de uma amostra do hipercubo latino de tamanho $\mathrm{N}=5$ com duas variáveis de entrada. Na Figura C.1 foram apresentadas duas variáveis aleatórias, uma tendo distribuição normal e outra, distribuição uniforme. Neste exemplo, o domínio de cada variável foi dividido em cinco intervalos.

$\mathrm{O}$ número de intervalos $\mathrm{N}$ na amostragem por hipercubo latino deve ser igual ao tamanho da amostra desejada, ou seja, igual ao número total de 
simulações. Para cada intervalo é amostrado apenas um valor $X_{k}^{i}$, isto é, este valor será usado em uma e apenas uma simulação.

Os valores amostrados $\Delta X_{k}^{i}$, para um valor $i$ qualquer, são obtidos pela resolução da equação C.3:

$$
F_{k}\left(X_{k}^{i}\right)=\frac{i-1+R_{i}}{\mathrm{~N}} \quad i=1,2, \ldots, \mathrm{N}
$$

onde: $R_{i}$ representa uma distribuição aleatória uniforme no intervalo [0,1].

A amostragem é realizada utilizando a transformada inversa da função de distribuição de probabilidade em questão, como em (C.4):

$$
x_{k}^{i}=F_{k}^{-1}\left(\frac{i-1+R_{i}}{\mathrm{~N}}\right)
$$

Na Figura C.2 são apresentados os cinco valores sorteados para cada uma das duas variáveis. Esses valores estão marcados nos respectivos eixos. Note que foi sorteado apenas um valor para cada intervalo.

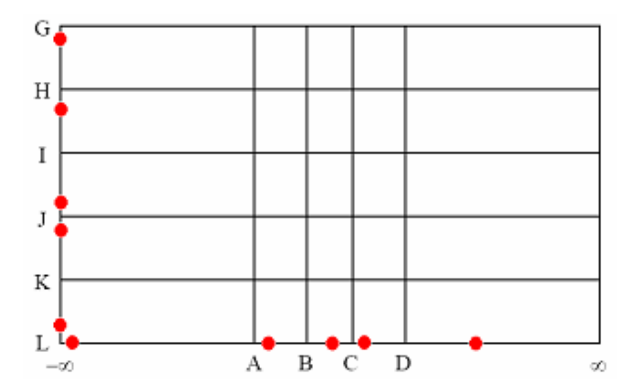

Figura C.2 - Valores sorteados para cada variável.

Depois de obtidos os $\mathrm{N}$ valores para cada variável $X_{k}$, esses devem ser emparelhados de forma aleatória com os valores das demais variáveis. Dessa forma, são formados $\mathrm{N}$ vetores de dimensão $\mathrm{M}$. A seleção aleatória do i-ésimo valor para cada variável é realizada mediante a permutação aleatória dos inteiros 1, 2,..., N. Na Figura C.3 é apresentada uma possível amostra de cinco pontos gerados utilizando a amostragem por hipercubo latino do exemplo anterior (Penna, 2009). 


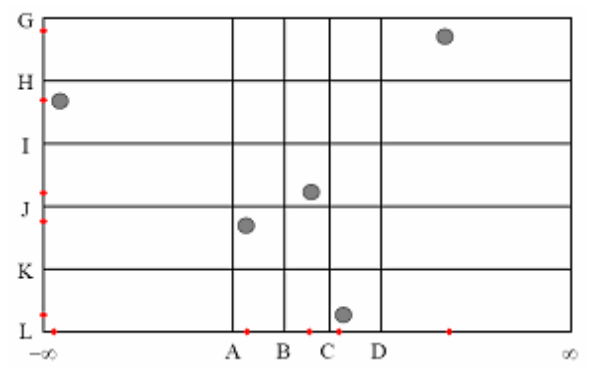

Figura C.3 - Representação bidimensional de uma possível amostragem por hipercubo latino. 